
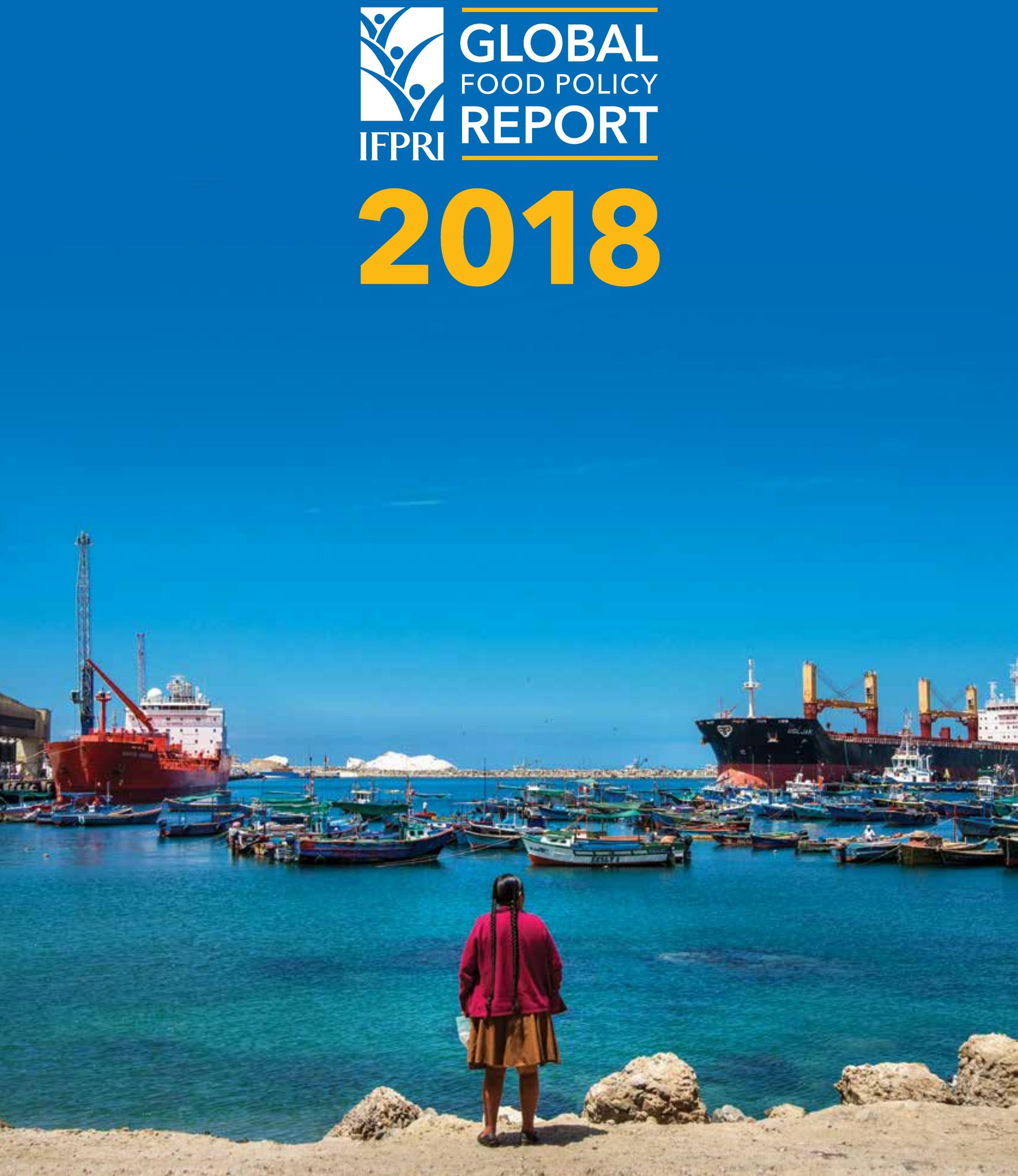


\section{About IFPRI}

The International Food Policy Research Institute (IFPRI), established in 1975, provides research-based policy solutions to sustainably reduce poverty and end hunger and malnutrition. IFPRI's strategic research aims to foster a climate-resilient and sustainable food supply; promote healthy diets and nutrition for all; build inclusive and efficient markets, trade systems, and food industries; transform agricultural and rural economies; and strengthen institutions and governance. Gender is integrated in all the Institute's work. Partnerships, communications, capacity strengthening, and data and knowledge management are essential components to translate IFPRI's research from action to impact. The Institute's regional and country programs play a critical role in responding to demand for food policy research and in delivering holistic support for country-led development. IFPRI collaborates with partners around the world. 



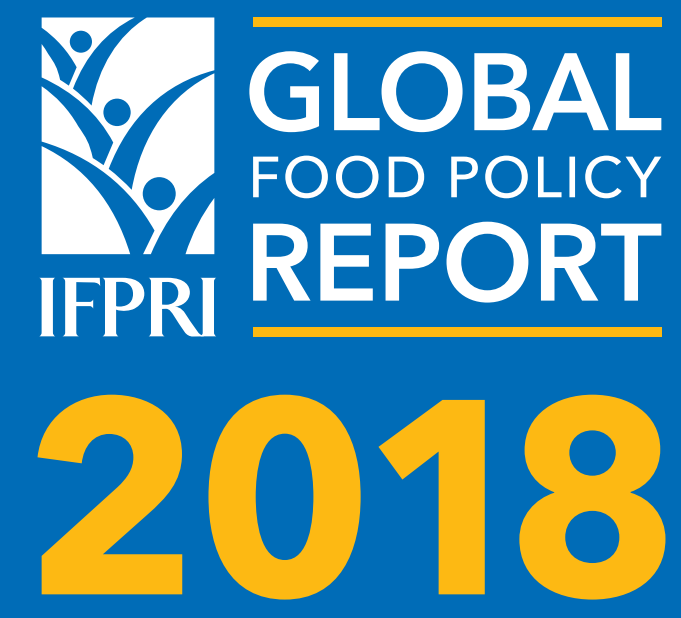

A Peer-Reviewed Publication 
Copyright @ 2018 International Food Policy Research Institute (IFPRI).

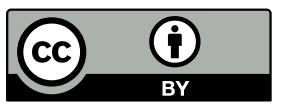

This publication is licensed for use under a Creative Commons Attribution 4.0 International License (CC BY 4.0). Subject to attribution, you are free to share (copy and redistribute the material in any medium or format), adapt (remix, transform, and build upon the material) for any purpose, even commercially.

THIRD-PARTY CONTENT: The International Food Policy Research Institute does not necessarily own each component of the content contained within the work. The International Food Policy Research Institute therefore does not warrant that the use of any third-party-owned individual component or part contained in the work will not infringe on the rights of those third parties. The risk of claims resulting from such infringement rests solely with you. If you wish to re-use a component of the work, it is your responsibility to determine whether permission is needed for that re-use and to obtain permission from the copyright owner. Examples of components can include, but are not limited to, tables, figures, or images.

ReCommended Citation: International Food Policy Research Institute. 2018. 2018 Global Food Policy Report. Washington, DC: International Food Policy Research Institute. https://doi.org/10.2499/9780896292970

This is a peer-reviewed publication. Any opinions expressed herein are those of the authors and are not necessarily representative of or endorsed by the International Food Policy Research Institute (IFPRI). The boundaries and names shown and the designations used on the maps do not imply official endorsement or acceptance by IFPRI.

International Food Policy Research Institute

1201 Eye Street NW, 12th floor

Washington, DC 20005 USA

Telephone: +1-202-862-5600

www.ifpri.org

ISBN: 978-0-89629-297-0

DOI: https://doi.org/10.2499/9780896292970

Cataloging-in-Publication Data is available from the Library of Congress.

\section{Photo credits}

Cover: Sebastian Liste/NOOR.

Chapter images: p. 7 Tommy Trenchard/Panos; p. 8 (top) Abbie Trayler-Smith/Panos, (bottom-left) Antoine Tardy/UNECE, (bottom-right) Vlad Sokhin/Panos; p. 9 Adam Dean/Panos;

p. 15 Mark Henley/Panos; p. 21 Chris Stowers/Panos; p. 31 Alfredo Caliz/Panos; p. 39 Patrick Brown/Panos; p. 47 G.M.B. Akash/Panos; p. 55 Fredrik Naumann/Panos; p. 63 Mark Henley/Panos; p. 72 Georg Gerster/Panos; p. 98 G.M.B. Akash/Panos.

Book layout: Jason Chow

Editorial manager: Pamela Stedman-Edwards 


\section{Contents}

PREFACE

ACKNOWLEDGMENTS . . . . . . . . . . . . . .

CHAPTER 1 Food Policy in 2017-2018: Progress, Uncertainty, and Rising Antiglobalism . . . . . . . . . . . . . 6 Shenggen Fan

CHAPTER 2 Food Security: The Global Food System under Radical Change . . . . . . . . . . . . . . . . . . . . . . . . . . 14 Gunhild Stordalen and Shenggen Fan

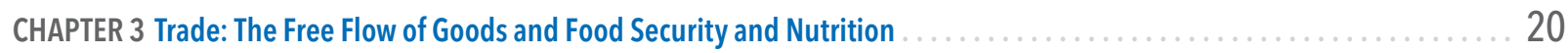
Will Martin and David Laborde

CHAPTER 4 Investment: International Investment and Local Food Security James Zhan, Hafiz Mirza, and William Speller

CHAPTER 5 Migration: Tightening Borders and Threats to Food Security Alan de Brauw and Kate Ambler

CHAPTER 6 Knowledge and Data: Achieving Food and Nutrition Security through Open Access Data Indira Yerramareddy and Suresh Chandra Babu

CHAPTER 7 Developed Country Policies: Domestic Farm Policy Reform and Global Food Security Joseph Glauber

CHAPTER 8 Global Institutions: Governance Reform for Food, Nutrition, and Agriculture Joachim von Braun

REGIONAL DEVELOPMENTS

Africa: Call for Sustaining Growth and Building Resilience

Tsitsi Makombe, Julia Collins, John Ulimwengu, and Ousmane Badiane

Middle East and North Africa: A Tale of Two MENAs

Clemens Breisinger, Fatma Abdelaziz, and Nadim Khouri

Central Asia: Steps toward Cooperation

Kamiljon Akramov, Jarilkasin Ilyasov, and Allen Park

South Asia: Food Systems at a Crossroads

Anjani Kumar, Akhter Ahmed, Stephen Davies, and P. K. Joshi

East and Southeast Asia: Progress Continues, Challenges Grow

Kevin Chen, Peter Timmer, David Dawe, and Zimeiyi Wang

Latin America and the Caribbean: Integration and Growth Advance

Eugenio Díaz-Bonilla and Valeria Piñeiro

FOOD POLICY INDICATORS: TRACKING CHANGE

Agricultural Science and Technology Indicators (ASTI) . . . . . . . . . . . . . . . . . . . . . . 100

Statistics on Public Expenditures for Economic Development (SPEED) . . . . . . . . . . . . . . . . . . . . 106

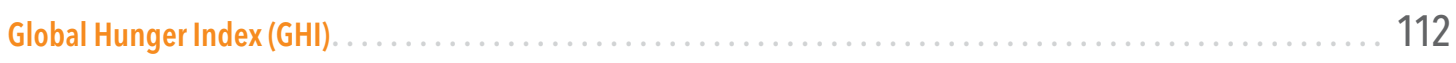

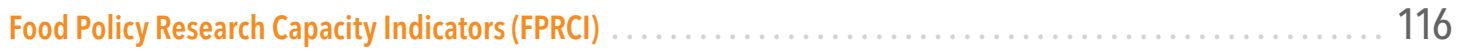

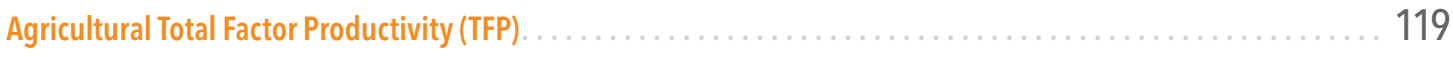

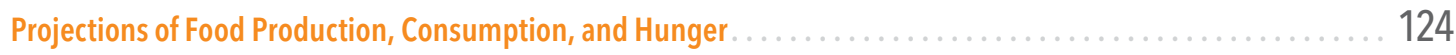





\section{Preface}

The 2018 Global Food Policy Report reviews major food policy developments and events from the past year. Leading researchers, policy makers, and practitioners examine what happened in food policy in 2017, and why, and look ahead to 2018. This seventh annual report explores the overarching theme of globalization and growing antiglobalization trends, looking at how current changes in the flow of goods, investments, people, and information impact global food systems.

In 2017, rising antiglobalization sentiments materialized in the growing protectionism of the United States and its withdrawal from the Paris Agreement on climate change as well as the continued "Brexit" process in the United Kingdom. At the Eleventh World Trade Organization Ministerial Conference, member states failed to reach agreement on a joint declaration, leaving issues such as agricultural subsidies and public food stocks unresolved. Nevertheless, some major policy developments maintained global momentum toward a sustainable future. Governments and donors came together at the Global Nutrition Summit to pledge US $\$ 640$ million in new funding to address global malnutrition, while countries such as Bangladesh, China, and India released their own national plans to improve nutrition. G20 leaders committed to the sustainable use of water in food and agricultural production, and the G7 Agriculture Ministerial Meeting focused on protecting farmers' incomes from market crises, natural disasters, and climate change.

Global economic growth and increased trade and investment in 2017 reflected the continued momentum of economic recovery, though rising inequality at the global, regional, and country levels may dampen the prospects for poverty reduction. After nearly a decade of decline, global hunger rose from 777 million undernourished people in 2015 to 815 million people in 2016, as conflicts and drought combined to create severe food crises. Global food prices, which were relatively high at the start of 2017, declined steadily at the end of the year and are expected to remain low into 2018, benefiting poor consumers who spend a large portion of their incomes on food. Throughout the year, extreme weather events, including hurricanes in the United States and Caribbean, persistent drought in Africa, and floods in South Asia, caused devastating damage and displaced vulnerable populations.

Political and economic uncertainties and conflicts are expected to persist in 2018, while climate change will continue to pose immediate and long-term threats. The international community must work together to address these challenges. Global cooperation to enact policies that leverage the benefits of globalization while minimizing its risks will be key to achieving food security and nutrition sustainably.

Topics covered in the 2018 Global Food Policy Report were the result of consultations with experts in the field. For inclusion in this report, a topic must represent a new development in food policy or a new way of looking at an important food issue; the topic has to be international in scope; and assessments and recommendations must be backed by evidence based on high-quality research results or expert judgment. Regional sections review events and trends in 2017 and provide a look forward to 2018. Supplemented by data tables and visualizations illustrating trends in key food policy indicators at the country and regional levels, the report provides a comprehensive overview of food policy.

I hope this report is met with interest by policy makers as well as academia, business, civil society, and media, all of whom have a stake in food policies that benefit the world's poorest and most vulnerable people.

\section{Shenggen Fan}

Director General 



\section{Acknowledgments}

The 2018 Global Food Policy Report was prepared under the overall leadership of Shenggen Fan and a core team comprising Jamed Falik, Rajul Pandya-Lorch, Pamela Stedman-Edwards, Klaus von Grebmer, Sivan Yosef, and Laura Zseleczky.

Text and data contributions were made by Fatma Abdelaziz, Akhter Ahmed, Kamiljon Akramov, Kate Ambler, Suresh Babu, Ousmane Badiane, Nienke Beintema, Jill Bernstein, Clemens Breisinger, Kevin Chen, Emily Cho, Julia Collins, Stephen Davies, David Dawe, Alan de Brauw, Eugenio Díaz-Bonilla, Paul Dorosh, Joseph Glauber, Jarilkasin llyasov, P. K. Joshi, Nadim Khouri, Anjani Kumar, David Laborde, Tsitsi Makombe, Will Martin, Marcia McNeil, Hafiz Mirza, Alejandro Nin-Pratt, Allen Park, Namita Paul, Valeria Piñeiro, Nilam Prasai, Christopher Rue, William Speller, Gunhild Stordalen, Timothy Sulser, Timothy Thomas, Peter Timmer, John Ulimwengu, Joachim von Braun, Zimeiyi Wang, Keith Wiebe, Indira Yerramareddy, Sivan Yosef, James Zhan, and Laura Zseleczky.

Production of the report was led by Pamela Stedman-Edwards and Jamed Falik, with support from Jason Chow and Michael Go. Editorial assistance was provided by Tracy Brown, Pat Fowlkes, Amy Gautam, and John Whitehead.

The report underwent a peer review by IFPRI's Publications Review Committee, under the chairmanship of Gershon Feder. 


\section{CHAPTER 1 \\ FOOD POLICY IN 2017-2018}

\section{Progress, Uncertainty, and Rising Antiglobalism}

\section{SHENGGEN FAN}

Shenggen Fan is the director general, International Food Policy Research Institute, Washington, DC, USA.

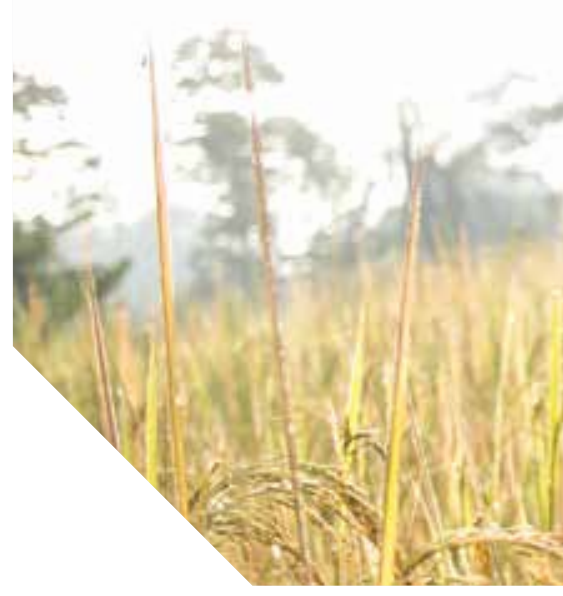

The year 2017 was marked by increasing uncertainty amid mixed signs of progress. The world enjoyed a strong economic recovery following a period of stagnation, but global hunger increased as conflicts, famine, and refugee crises persisted. The global landscape continued to change, as antiglobalization sentiment threatened international trade and investment as well as the flow of people and knowledge. Major global events evidenced a shift away from the decades-long trend toward greater global integration. These events included the failure to reach agreement at the World Trade Organization (WTO) Ministerial Conference as well as bilateral actions of the United States and the United Kingdom, all signaling the potential rise of isolationism and protectionism. These changes create uncertainties for global food security and nutrition.

\section{LOOKING BACK AT 2017}

\section{ECONOMIC RECOVERY, YET RISING INEQUALITY}

Following weak global economic growth in 2016, the weakest since the 2008 global financial crisis, 2017 saw an economic turnaround. Strong economic growth and recovery were supported by a positive global financial environment and the momentum of recovery in advanced economies and several emerging economies.'
While it is too early to measure changes in poverty in 2017, the global recovery bodes well for the world's poorest. However, rising inequality within countries may dampen the prospects for poverty reduction. Over recent decades, income inequality within almost all countries increased, although at different speeds, with the lowest levels of inequality in Europe and the highest levels in the Middle East. Global inequality has risen sharply since 1980, as the income of the richest individuals in the world-the top 1 percent-has grown twice as much as that of the bottom 50 percent. Despite promising growth in emerging economies, global inequality is expected to continue increasing if countries hold to "business as usual" policies. $^{2}$

\section{UPWARD TREND IN HUNGER AND FOOD INSECURITY}

Global hunger increased after nearly a decade of prolonged decline. The number of undernourished people globally rose from 777 million in 2015 to 815 million in 2016. Much of the worsening trend in global hunger can be linked to persistent conflicts, which have been exacerbated by climate shocks. ${ }^{3}$ The global community dealt with famine as an estimated 38 million people in Nigeria, Somalia, South Sudan, and Yemen faced severe food insecurity, and Ethiopia and Kenya suffered significant droughts. ${ }^{4}$ While the global prevalence of stunting 


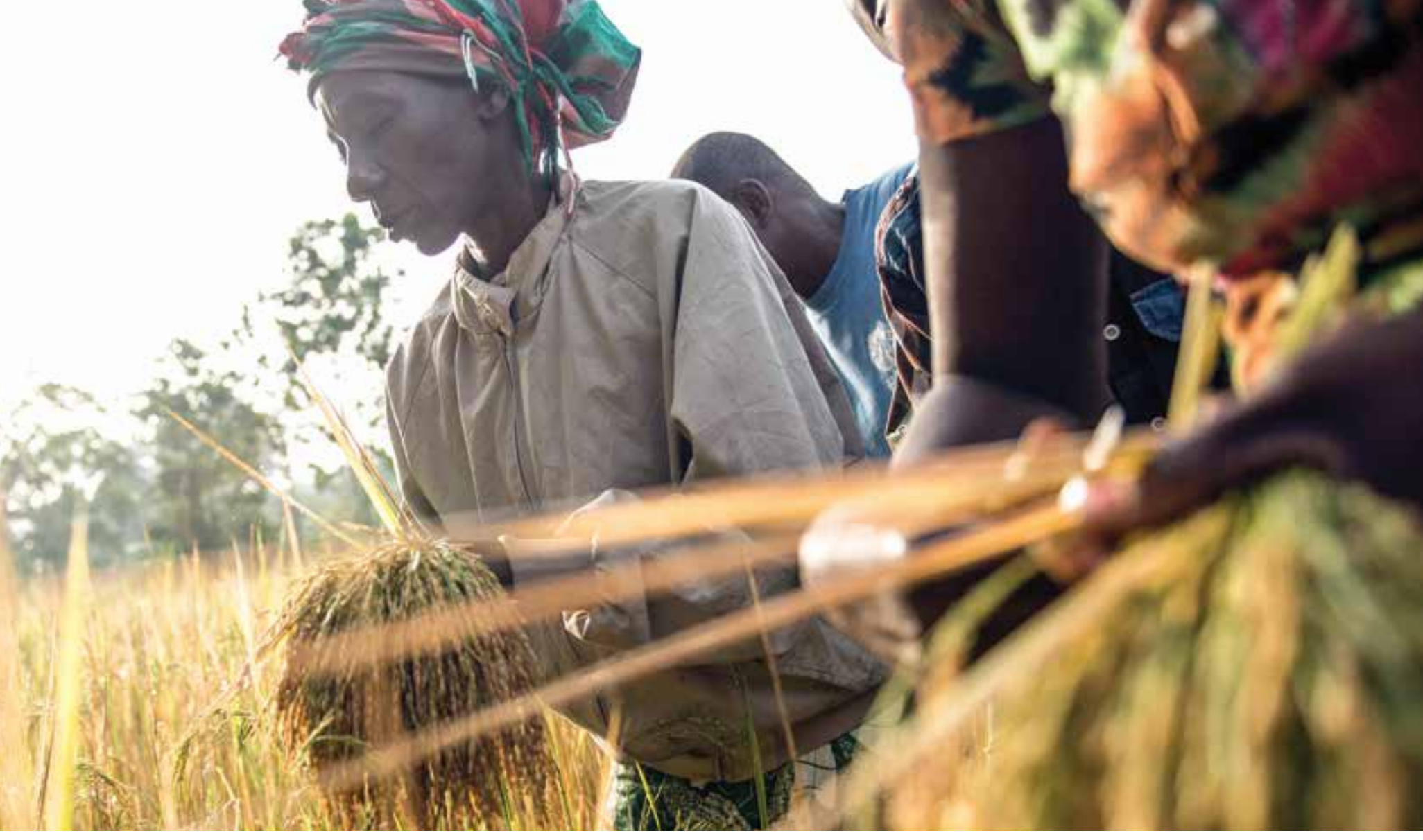

among children under age five fell from almost 30 percent in 2005 to 23 percent in 2016, stunting remained a significant issue, with 155 million children affected. If the current trend continues, 130 million children will be stunted in 2025, 30 million above the World Health Assembly target. $^{5}$ To significantly reduce stunting and hunger by 2030 if not sooner, many countries will need to accelerate progress. At the same time, overnutrition continues to be a growing concern, for example, in Central Asia, where all countries saw increases in overweight and obesity. ${ }^{6}$

\section{STRONG FOOD PRODUCTION AND DECLINING FOOD PRICES}

Global food prices remained relatively high for most of 2017, largely driven by higher prices of meat, dairy, and sugar, following low prices in 2015 and 2016. After three months of consecutive increases around midyear, prices declined steadily in the last months of 2017, with a steep decline in December from falling dairy, vegetable oil, and sugar prices. ${ }^{7}$ Global cereal production for 2017 is projected at 2,627 million metric tons, a 0.6 percent increase over 2016. Much of the increase is from higher production of coarse grains, forecast at
1,371 million metric tons, a 24-million-ton increase for the year. Contributing to this growth were record-high production in Indonesia and increases in US maize production. Global wheat and rice production are forecast to be marginally lower than 2016 levels. ${ }^{8}$ With global food commodity prices expected to remain low as a result of strong production and slowing demand growth in emerging economies, much of the world's poor population, who spend a large portion of their income on food, may experience improvements in food security and reductions in poverty. ${ }^{9}$

\section{ANTIGLOBALISM ON THE RISE}

Major events in 2017 pointed to a rise in antiglobalization sentiment in the international community. The United States announced its withdrawal from the Trans-Pacific Partnership trade agreement early in the year and later from the Paris Agreement on climate change, marking a shift away from multilateral and international agreements. In Europe, the United Kingdom continued its "Brexit" process, introducing the "Great Repeal Bill" and beginning negotiations for withdrawal from the European Union in 2019. Further, the failure to reach an agreement on a joint Ministerial Declaration at the 


\section{: G20 COMMITS TO SUSTAINABLE}

\section{WATER USE}

At their conference in Berlin, G20 agriculture

ministers commit to protecting water resources by

: ensuring sustainable and efficient water use in food

: and agricultural production.

\section{NORWAY CREATES FUND TO REDUCE}

DEFORESTATION

During the World Economic Forum, Norway

launches a US\$400 million fund to protect land

and promote deforestation-free agriculture.

\section{CHILD MALNUTRITION} REMAINS ALARMING

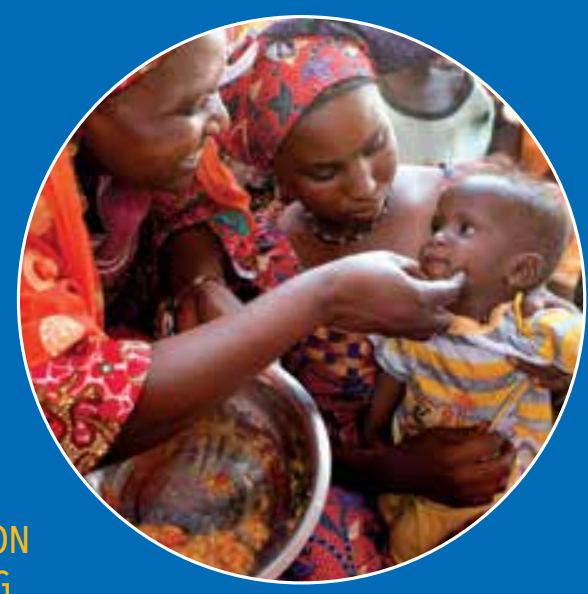

2017 estimates for child malnutrition show that stunting is declining too slowly and overweight is : rising, especially in Africa and Asia.

\section{FEB}

OVER 20 MILLION AT RISK OF FAMINE The United Nations appeals to the international community to help avert devastating levels of food insecurity in parts of Nigeria, Somalia, South Sudan, and Yemen.

UN ADOPTS INDICATOR FRAMEWORK FOR SUSTAINABLE DEVELOPMENT GOALS The United Nations Statistical Commission formally adopts an indicator framework to track progress toward the 2030 Agenda for Sustainable Development.

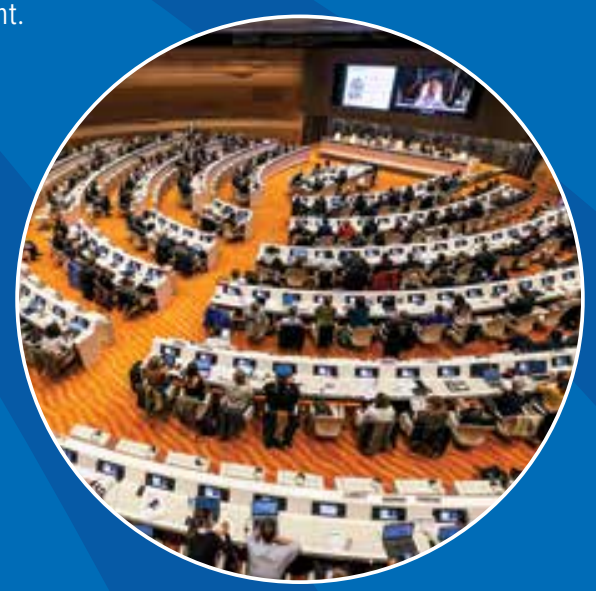

US ANNOUNCES WITHDRAWAL FROM CLIMATE AGREEMENT

The US president announces plans to withdraw from the 2016 Paris Agreement committing countries to act to limit the global temperature rise

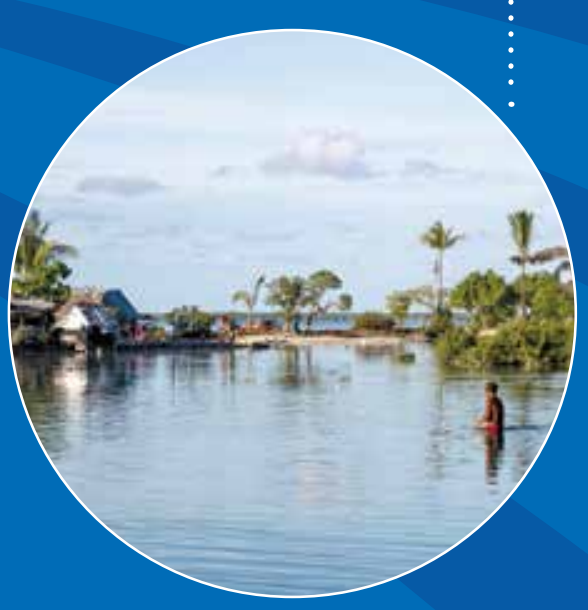


: CHINA ISSUES NATIONAL NUTRITION PLAN

China launches new plan for achieving health

and nutrition goals between 2017 and 2030 that

includes regulations, research, and monitoring.

\section{: BANGLADESH ROLLS OUT NEW ACTION}

\section{PLAN FOR NUTRITION}

The 2016-2025 plan aims to improve the

population's nutritional status and reduce all forms

of malnutrition, with a focus on children, adolescent

girls, pregnant women, and new mothers.

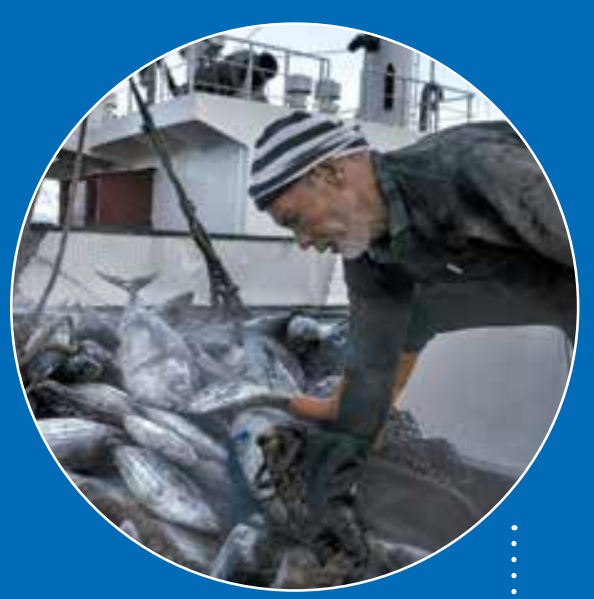

\section{WTO FAILS TO REACH AGREEMENT}

The 11th Ministerial Conference of the World Trade Organization ends in discord after members fail to reach agreement on farm and fisheries subsidies and other issues.

\section{ECONOMIC INEQUALITY IS WIDESPREAD AND GROWING}

G7 COMMITS TO PROTECT FARMERS The G7 Agricultural Ministerial Meeting focuses on protecting farmers' incomes amid market The first World Inequality Report finds that income inequality has increased nearly everywhere in recent decades but varies from region to region, suggesting that policies have an impact. crises, natural disasters, and climate change.

WORLD HUNGER IS RISING

The State of Food Security and Nutrition in the World 2017 estimates that the number of undernourished people rose from 777 million in 2015 to 815 million in 2016.

\section{INDIA LAUNCHES NATIONAL NUTRITION STRATEGY}

The strategy commits to ensuring that every child, adolescent girl, and woman attains optimal : nutritional status by 2022 .

\section{HURRICANES DEVASTATE CARIBBEAN}

Two back-to-back category 5 hurricanes and other storms displace hundreds of thousands of people destroy infrastructure, and cut off access to food and water supplies for weeks.

\section{DONORS PLEDGE MILLIONS TO} FIGHT GLOBAL MALNUTRITION

The Global Nutrition Summit draws

$\$ 640$ million in new funding commitments from governments and donors to battle the world's nutrition-related challenges.

\section{UN CLIMATE CHANGE CONFERENCE}

Amid political shifts and extreme weather events, the 2017 UN Climate Change Conference brings together signatory governments of the Paris Agreement and UN Climate Change Convention.

\section{THE GLOBAL ECONOMY IS RISING}

The latest ifo Institute survey finds that the current economic situation in all regions except for the Middle East and North Africa is better than at any time since 2011. 


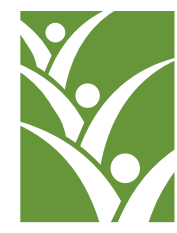
IFPRI

\section{GLOBAL FOOD POLICY REPORT}
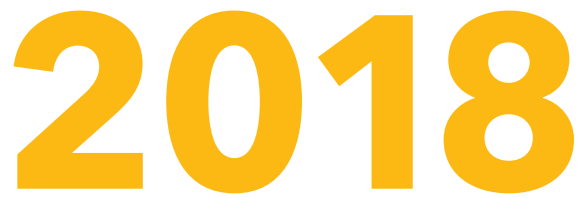

$\begin{array}{llllll}S & U & R & V & E & Y\end{array}$

\section{FOOD POLICIES}

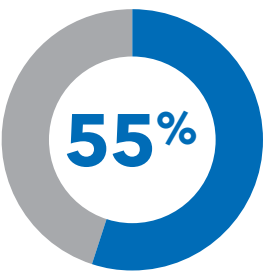

are dissatisfied with global

food policies.

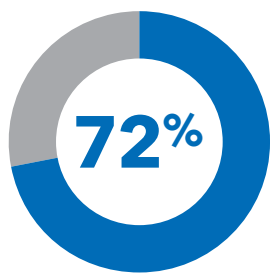

are dissatisfied with food policies in their own regions.

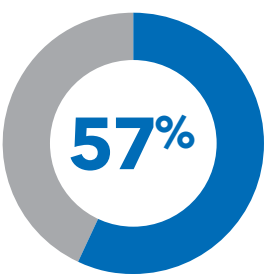

are dissatisfied with progress in global food and nutrition security.

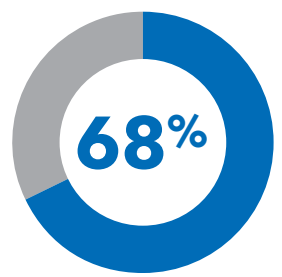

are dissatisfied with progress in food and nutrition security in their own regions.
Over 1,000 individuals from 105 countries responded to the 2018 Global Food Policy Report survey on perceptions about food policy and food security now and for the future, and on the impacts of globalization.

\section{HUNGER \& UNDERNUTRITION}

\section{$41 \%$}

of respondents think global hunger and undernutrition can be eliminated

\section{$8 \%$}

think global hunger and undernutrition will be eliminated by 2025 .

\section{$13 \%$}

of youth think global hunger and undernutrition will be eliminated by 2025 . by 2025 .

\section{$44 \%$}

of respondents think hunger and undernutrition can be eliminated by 2025 in their own regions.

\section{$18 \%$}

think hunger and undernutrition will be eliminated by 2025 in their own regions.

\section{$24 \%$}

of youth think hunger and undernutrition will be eliminated by 2025 in their regions.

\section{PERSPECTIVES ON GLOBALIZATION}

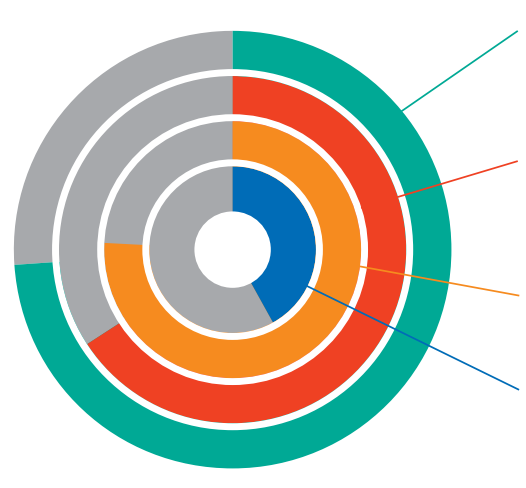

$74 \%$ think policies supporting the free flow of goods and investment contribute to global food security and nutrition.

$66 \%$ think recent antiglobalization policies and rhetoric will harm the hungry and impoverished.

$76 \%$ think tighter borders and migration restrictions will impact food security.

42\% think global governance mechanisms and institutions adequately support food security and nutrition in a globalized world.

\section{STAKEHOLDER PERSPECTIVES}

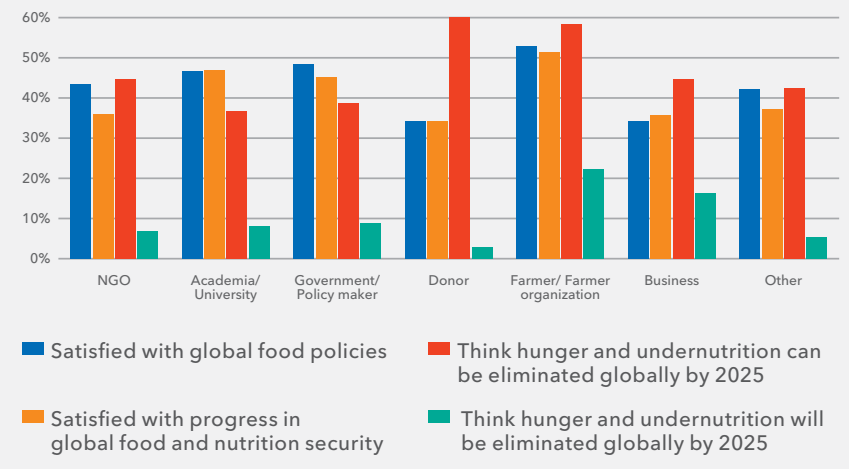

\section{REGIONAL PERSPECTIVES}

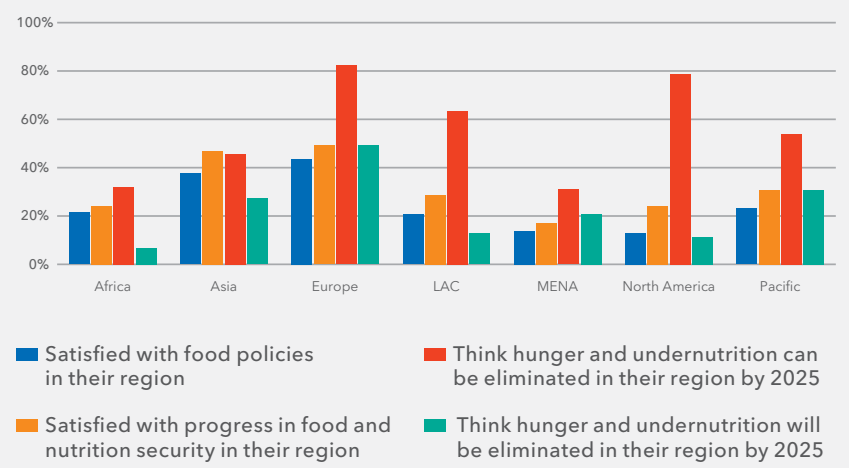

Source: The survey was conducted online, from January 4-18, 2018. 
Eleventh WTO Ministerial Conference in Buenos Aires highlighted critical setbacks, including for agriculture in terms of addressing domestic subsidies, public food stocks, and special safeguard mechanisms, which may presage a new era of isolationism and protectionist policies. ${ }^{10}$

Nevertheless, growth in international trade and investment indicated a continued overall trend toward global integration. World trade grew by 3.6 percent in 2017, a substantial increase from the 1.3 percent growth of 2016. Trade growth was largely driven by recovering import demand in Asia and North America. ${ }^{11}$ Global investment flows saw a modest recovery and were forecast to increase to US\$1.8 trillion in 2017. While foreign direct investment to developing economies fell by 14 percent, flows to developed economies increased by 5 percent, and flows to transition economies nearly doubled. ${ }^{12}$

\section{CONTINUED MOMENTUM FOR SUSTAINABLE DEVELOPMENT}

Several major global policy developments in 2017 helped to maintain momentum toward creating a sustainable future, and were marked by an increased focus on using a food systems approach to tackle the multiple challenges of hunger, climate change, inequality, jobs, and growth.

G20 leaders committed to the sustainable use of water in food and agricultural production at the 2017 Agriculture Ministers' Conference in Berlin, with an emphasis on governance and coherence of water-related policies; water-use efficiency and resilience; water quality; and information, innovation, and collaboration. ${ }^{13}$ The G7 Agriculture Ministerial Meeting focused on protecting farmers' incomes from market crises, natural disasters, and climate change, and noted the links between agriculture, migration, and rural development. The meeting in Milan called on governments not only to safeguard farmers' incomes but also to promote cooperation among farmers and diversification of production. The discussions highlighted the importance of providing concrete financial tools for farmers, such as risk management strategies, through investments in research, innovation, information, communication, and training. ${ }^{14}$
The Global Nutrition Summit galvanized governments and donors together to pledge US\$640 million in new funding to address the challenges in nutrition facing nearly every country. The summit brought together a wide range of stakeholders to accelerate the global response to malnutrition and launched the Global Nutrition Report 2017. ${ }^{15}$

Progress toward the 2030 Agenda for Sustainable Development continued, as the United Nations Statistical Commission formally adopted the indicator framework to track progress on meeting the Sustainable Development Goals (SDGs). This coincided with the adoption of the Cape Town Global Action Plan for Sustainable Development Data, which calls on governments, policy leaders, and the international community to work collectively toward improving data for the SDGs. Countries continued to work together to increase climate action under the Paris Agreement, with the 2017 United Nations Climate Change Conference held against a backdrop of extreme weather events, including hurricanes in the United States and Caribbean, drought in Africa, and floods in South Asia. ${ }^{16}$

\section{INCREASED NATIONAL COMMITMENTS}

At the national level, countries made progress on environmental sustainability as well as nutrition. Norway launched a US\$400 million fund to reduce deforestation through agriculture. China issued a new National Nutrition Plan for 2017-2030 that sets nutrition and health goals for anemia, stunting, and breastfeeding for 2020 and 2030. The plan also highlights the importance of regulations, research, and monitoring for nutrition and health outcomes. Bangladesh launched its Second National Plan of Action on Nutrition (2016-2025), outlining efforts to reduce all forms of malnutrition, especially for children, adolescent girls, pregnant women, and lactating mothers. India launched its National Nutrition Strategy, which commits to ensuring that every child, adolescent girl, and woman attains optimal nutritional status by 2022. Some countries undertook agricultural reforms, such as the expansion of irrigated areas and improved distribution of fertilizers and seeds in Algeria and enhanced water access in Djibouti. ${ }^{17}$ Many othersincluding Ghana, India, and Nigeria-reconfirmed their commitments to Zero Hunger and SDG2 on ending hunger and malnutrition by 2030 . 


\section{LOOKING FORWARD TO 2018}

Antiglobalism and the changing global landscape may create further political and economic uncertainties, and continue to impact trade, investment, and migration. In particular, the threatened retreat of the United States from international agreements and institutions, including the United Nations, may add to global uncertainties. As many emerging challenges faced by the international community transcend national borders, global governance will be evermore crucial to guide global norms and galvanize collective commitment and action. Whether European countries and emerging economies will step up to lead global governance efforts is an important question for the years ahead.

Global growth is projected to strengthen to 3.1 percent in 2018, which could translate to improvements in livelihoods, poverty status, and food security. Strong global manufacturing and trade, a benign financial environment, and largely stabilized commodity prices support these positive projections. Growth in emerging and developing economies is expected to be strong, with projected growth of 4.5 percent in 2018. East Asian growth is projected to slow slightly in 2018 to 6.2 percent, as China gradually slows but the rest of the region picks up modestly. The Europe and Central Asia region is forecast to accelerate to 2.9 percent in 2018, and Latin America and the Caribbean to 2.0 percent. After a slight decline in the Middle East and North Africa, growth is expected to rebound to 3.0 percent, assuming a moderation in geopolitical tensions and a rise in oil prices. South Asian growth is projected to accelerate to 6.9 percent in 2018 , driven by expansion of domestic demand and exports. Projections for Africa south of the Sahara are a modest 3.2 percent for $2018 .^{18}$

Despite this relatively positive economic outlook, adjustments in the global economy are expected to continue as national economies deal with shrinking workforces and diminished productivity gains while still recovering from the 2008 financial crisis. Growing tendencies toward protectionism, evidenced by changes in US and UK trade policies, also create further economic uncertainties.
However, technological advances will continue to accelerate rapidly, especially in automation and artificial intelligence. ${ }^{19}$ While this has the potential to threaten economies and industries that are not able to adjust to the rapid change, technological innovations, coupled with the global flow of knowledge, can be game changers for agriculture and food systems. For example, innovations in information and communication technologies, especially through mobile phones, together with open access data can put vital information in the hands of farmers.

In 2018, the international community is expected to face persistent threats to food security, especially hunger fueled by conflict and compounded by drought. International support will continue to be important for African countries that suffered famine and drought, as much of their populations will remain vulnerable to food insecurity, including 6 million people in South Sudan. In Africa, growth will also remain vulnerable to debt-related fiscal risks, especially in natural resource-exporting countries. ${ }^{20}$ Specific challenges will also require international attention, particularly the troubling outlook in Venezuela, where gross domestic product per capita declined for the fourth consecutive year and conditions worsened with acute shortages in food, medicine, and other basic products.

Climate change will continue to pose immediate and long-term threats, particularly extreme weather events, water and soil stress, and food insecurity. Global cooperation will be essential as tensions over climate change grow. ${ }^{21}$ Building resilience to climate shocks and strengthening climate-smart agriculture will be increasingly critical.

A renewed commitment to working together will be the key to achieving food security and better nutrition in a sustainable way. At the global, regional, and national levels, data and evidence must remain at the heart of more open, transparent, and inclusive food systems. Current discussions on food systems and commitments to ending hunger must be moved forward to action. Enacting policies to garner the benefits of globalization while minimizing the risks that fuel antiglobalism will be a critical priority in 2018 and beyond. 
"Global integration of national food systemsthrough the flow of goods, investments, people, and knowledgewill be key to progress, but will require good governance and strong commitment from the international community." 


\section{CHAPTER 2}

FOOD SECURITY

\section{The Global Food System under Radical Change}

\section{GUNHILD STORDALEN AND SHENGGEN FAN}

Gunhild Stordalen is the founder and president of the EAT Foundation, Oslo, Norway. Shenggen Fan is the director general, International Food Policy Research Institute, Washington, DC, USA.

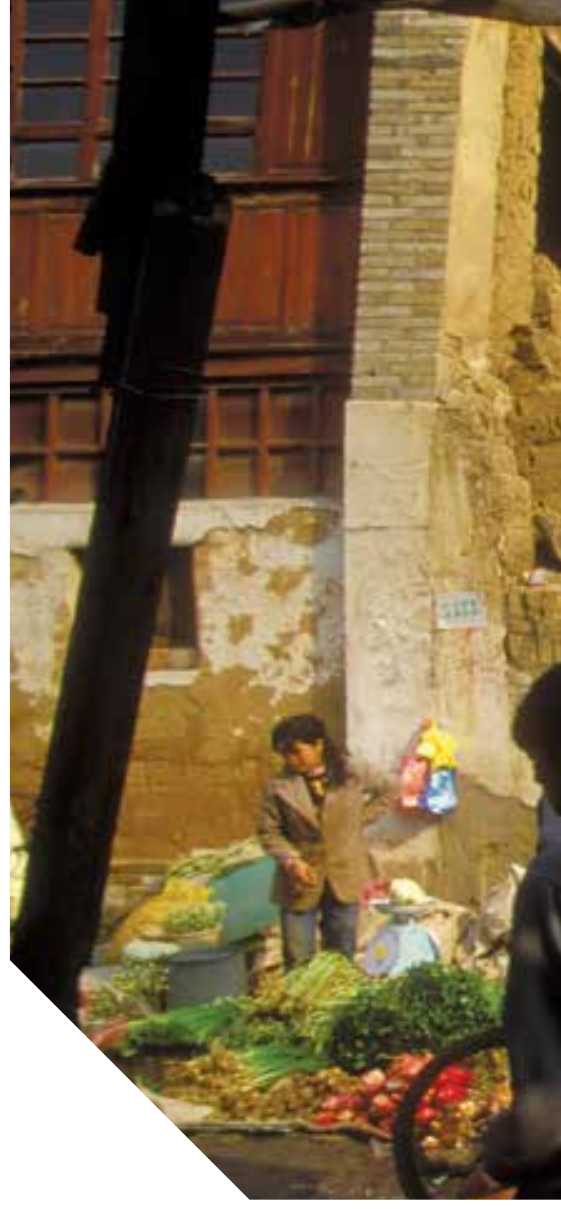

\section{KEY FINDINGS}

- Food is at the heart of reductions in global poverty and improvements in nutrition. Yet dysfunctional food systems also contribute to rising obesity and hunger and to environmental degradation.

- Radical global changes, including rising antiglobalism and emerging technologies, are creating new challenges and opportunities for progress.

- Addressing these global trends will be critical to ensure food systems can end hunger and malnutrition for all within environmental boundaries (climate, water, biodiversity, pollutants).

- Global integration of national food systems-through the flow of goods, investments, people, and knowledge-will be key to progress, but will require good governance and strong commitment from the international community.

\section{KEY RECOMMENDATIONS}

- Encourage an open, efficient, and fair trading system, especially for agricultural goods, through reform of trade, domestic support, and investment policies to promote nutrition, health, inclusiveness, and environmental sustainability.

- Support rural development to break the vicious cycle of conflict, food insecurity, and migration and to improve the livelihoods and food security of refugees.

- Invest more in research and innovation for food systems to increase sustainability of production and processing, make healthy foods available, and improve employment opportunities.

- Promote evidence-based policy making to support government investments that are coherent across the food system, recognize trade-offs, and harness agriculture's contribution to environmental sustainability.

- Promote cooperation and mutual learning among stakeholders and across sectors to accelerate progress toward ending hunger and malnutrition.

- Promote leadership and commitment for the SDGs at global, regional, and local levels to ensure follow-through on international commitments.

- Leverage new opportunities in emerging technologies and knowledge-sharing to maximize the benefits of sustainable food systems for all. 


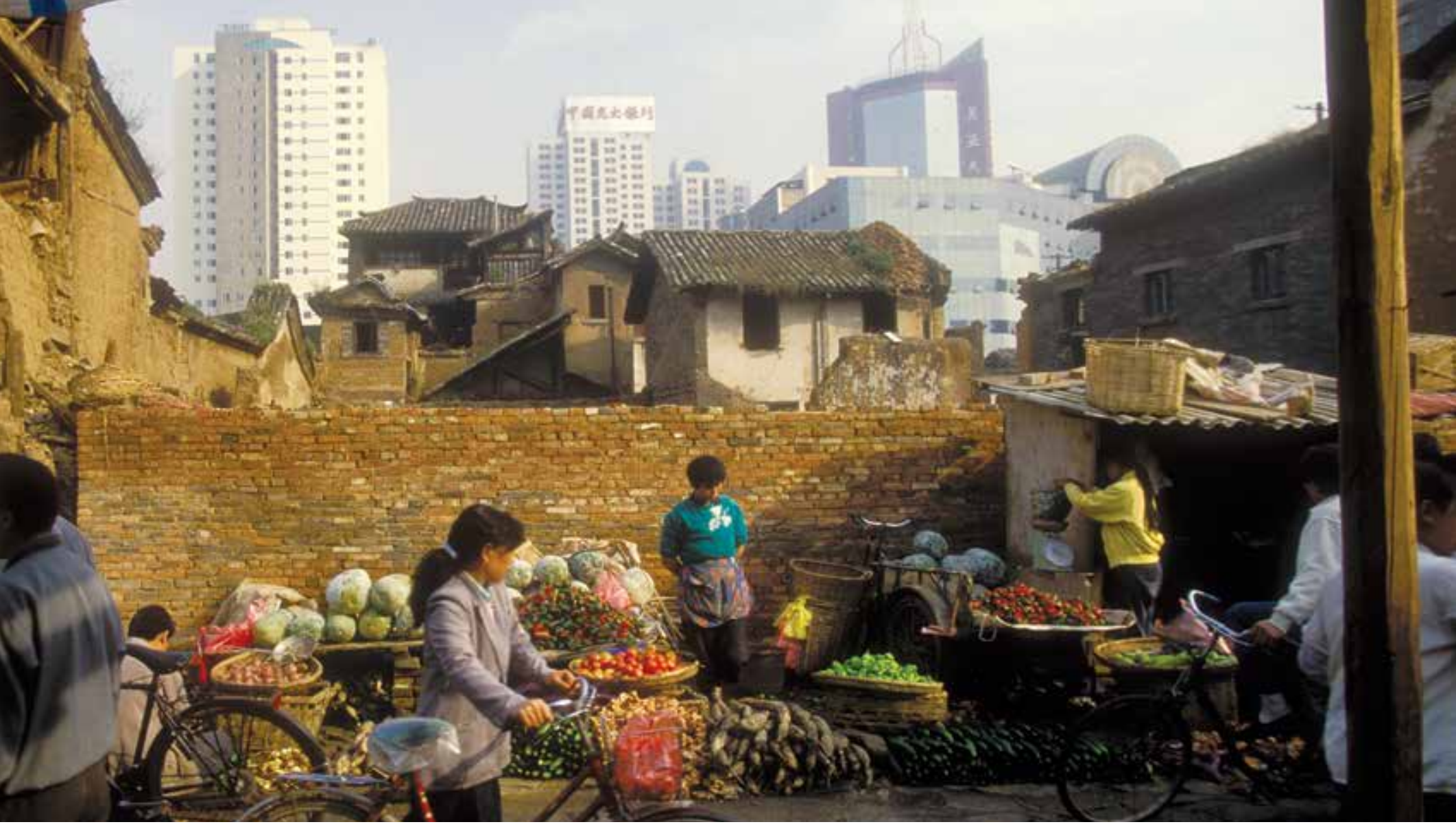

Food systems have been central to recent unprecedented reductions in global poverty, hunger, and undernutrition, and will be the foundation of future progress. There is no more important and valuable human endeavor than growing, making, and preparing the foods that nourish and sustain us. Yet food is among the leading causes of our global health and sustainability crises. ${ }^{1}$ Efforts to sustainably end hunger and malnutrition will depend on reshaping our food systems. Radical global changes, including rising antiglobalization sentiment and emerging technologies both inside and outside the agriculture sector, are creating new challenges and opportunities. How these global trends are managed will be crucial for ensuring that food systems can deliver sufficient nutritious, affordable, delicious, and healthy food for all within planetary boundaries.

\section{FOOD SYSTEMS CALLED ON TO DO BETTER}

Addressing radical global changes is critical to improving the contribution of food systems. After a period of prolonged decline, world hunger is again on the rise, millions of children remain stunted, and nearly 2 billion adults are overweight or obese., ${ }^{2,3}$ In part due to globalization, many national food systems are rapidly ushering in a transition toward animal-based and processed foods that are too salty, too sugary, or too high in fat-a transition strongly linked with the increase of diet-related noncommunicable diseases such as heart disease and diabetes. ${ }^{4}$ Moreover, the global food system-which includes all actors and sectors involved in producing, distributing, retailing, and consuming food-and national food systems are at the center of many environmental challenges facing the planet. Nearly 85 percent of global water use goes to agricultural irrigation, of which 15-35 percent is unsustainable. ${ }^{5}$ Close to a quarter of all global land is degraded. ${ }^{6}$ Food systems contribute about one-fifth of all greenhouse gas emissions, and agriculture is a primary cause of biodiversity loss. ${ }^{7}$ Overall, agrifood systems have been largely successful in feeding a growing number of people, but are pushing planetary boundaries in terms of greenhouse gas emissions, biodiversity loss, freshwater use, and both nitrogen and phosphorous cycles, risking expensive, potentially irreversible environmental change. ${ }^{8}$

As acute as these challenges are, food systems are uniquely positioned to reverse course to become the primary driver of improved human 
and environmental health. To do so, they must be transformed into restorative food systems to support healthy diets for all. Global models forecast that the combination of shifting toward healthy diets, increasing production efficiency, and reducing food waste and loss has potential to provide healthy diets for 9.5 billion people in 2050, while reducing food's land and climate footprints. Food systems must be more lucrative for smallholders, women, and youth, as such groups are critical in meeting emerging demand for a diversity of safe and nutritious foods, and smallholder farming must transition toward providing quality jobs. For food systems to support sustainable development, the global integration of national food systemsthrough the flow of goods, investments, people, and knowledge-will be key, provided their integration is governed appropriately.

\section{MEGATRENDS AFFECTING GLOBAL AND NATIONAL FOOD SYSTEMS}

Recent antiglobalization sentiment, especially the potential resurgence of trade protectionism, risks slowing progress toward achieving the Sustainable Development Goals (SDGs), greater economic growth, and improved food security and nutrition. ${ }^{9}$ Trade is not only necessary to feed growing populations, it also has the potential to raise incomes and provide access to more diverse foods at lower, more stable prices (Chapter 3). Trade also has an important, though little explored role in shifting food production from regions of high environmental risk (carbon-rich forests, water-scarce lands) to areas of lower environmental risk. For these benefits to be experienced by all, trade must be inclusive.

International investments must be a component of investment strategies for creating employment, boosting incomes, developing rural infrastructure, and introducing new technologies, among other benefits that improve livelihoods. Yet at times, such private investments result in exclusion of people from the food system, environmental unsustainability, and even conflict, as well as the introduction of new challenges such as obesity-thus fueling antiglobalization arguments. Carefully designed policies can maximize the contribution of investments to sustainable food security and nutrition and minimize the associated risks (Chapter 4).
Global governance failures and weakening commitments in the international community to a sustainable future are likely to have negative impacts on agriculture, food security, and nutrition. For example, declining commitment of countries to the Paris Agreement on climate change may increase exposure of agriculture and food production to climate shocks and natural resource depletion, and also increase agriculture's pressure on planetary boundaries. Local governance and coordination have the potential to help cities, districts, and provinces play key roles in promoting improved livelihoods, sustainability, and nutrition. Without appropriate global and local governance and coordination mechanisms that work based on evidence and trust, decision makers will face challenges in reacting to short-term and emerging crises, rather than successfully preventing those crises (Chapter 8).

Forced migration and protracted conflicts were major drivers of the rise in global hunger and the persistence of undernutrition in recent years. Currently, out of the 155 million stunted children globally, 122 million live in conflict areas, and conflicts continue to displace people-the number of forcibly displaced people doubled between 2007 and 2016, to about 64 million people. ${ }^{10}$ Conflicts, migration, and food insecurity can form a vicious cycle. ${ }^{11}$ And when borders are tightened or closed, the flow of migrants is restricted, and threats to food security and nutrition increase for those who would have migrated and their families (Chapter 5). Moreover, conflict is often compounded by the impacts of ongoing climate change, further affecting food security and livelihoods. ${ }^{12}$ Innovative solutions are needed to break the cycle of conflict and hunger in migrant source countries, while providing support to migrants and host countries.

At the same time, the global flow of knowledge and emerging technologies are on the rise. Open access to knowledge and data and effective information networks, particularly for farmers, businesses, and governments, can contribute to improving food security and nutrition (Chapter 6). Many innovative technologies inside and outside of the agriculture sector could be game changers for the future of food systems-gene sequencing, gene editing, vertical farming, precision agriculture, lab-grown meat, big data, and innovations in information and communication technologies show great promise for making food systems more interconnected, climate-resilient, and efficient, although the benefits and risks of these technologies are not fully understood. 


\section{ADDRESSING THE CHANGES}

Addressing these radical global changes can provide avenues to transform the global food system, moving toward a system that is driven by better nutrition, health, sustainability, and greater inclusiveness. Major food system levers to tackle health and sustainability and contribute to the SDGs center around increasing sustainable production efficiencies (more food with less impact), reducing food waste and loss, and shifting diets-notably shifting toward plant-based diets in developed countries with high meat consumption. The following key actions are required in support of these central priorities for food system transformation.

\section{ENCOURAGE AN OPEN, EFFICIENT, AND FAIR TRADING SYSTEM}

Considering the important role of trade in reducing hunger and malnutrition and in avoiding environmental harm, trade and related domestic policies must support and enhance an open, transparent, and inclusive trading system, especially for agricultural goods. Indeed, appropriate tools and policies that consider the trade-offs and potential unintended consequences of open trade must be employed to directly address global and local challenges instead of hindering trade. Countries should reduce trade distortions by reducing high import tariffs and eliminating export bans and restrictions in order to expand secure and equal access to markets for food and agricultural products, particularly for nutritious and sustainably sourced foods (Chapter 7). ${ }^{13}$ To encourage fair competition in the presence of large multinational players along the value chain, developing countries will have to strengthen domestic policy and legislation, such as antitrust laws, to prevent or govern monopolistic structures and market behavior. Responsible investments can be encouraged with strong international principles and by giving priority to investments that provide inclusive benefits for food security and nutrition, for example through productive, well-targeted, nutrition-driven social protection measures. Countries must also eliminate inefficient domestic support policies and redirect public resources to food system investments with greater impact. Rural infrastructure and agricultural research and development (R\&D), for example, can substantially increase agricultural productivity growth and reductions in poverty. ${ }^{14}$ Indeed, investments in these public goods, as well as in sustainable agriculture and farm extension, can support domestic producers and improve local diets without violating international trade rules.

Trade policies must strongly factor into strategies for nutrition, health, inclusiveness, and sustainability for trade to help fuel food system transformation. To ensure state-of-the-art food safety and protect human health from foodborne diseases, developing countries should strive to build capacity to implement tested and proven international standards and guidelines and receive assistance in doing so. In addition to enhancing awareness, stakeholder engagement, and collaboration among governance structures for food safety, greater investments in R\&D and information and communication technologies will be needed to improve food-safety testing and surveillance. The potential negative impacts of global free trade on nutrition and health, including greater access to unhealthy foods, need to be addressed. ${ }^{15}$ Trade policies must also support inclusiveness for developing countries to foster opportunities for value addition and create rural jobs for small producers. ${ }^{16}$ For trade policies to help advance environmental sustainability, governments should consider phasing out fossil fuel subsidies in favor of investment in renewable energy.

Strengthening regional and local trade can increase market opportunities and access to more healthy and nutritious foods, provided regulations and incentives exist to mitigate increased access to unhealthy foods. Africa lags behind other regions in intraregional trade; regional issues of productive capacity, trade-related infrastructure and services, private sector engagement, and diversification of traded products must be addressed to increase trade both regionally and more broadly. Facilitating local trade to improve nutrition and livelihoods while reducing food loss is likewise important. Improvements in urban-rural linkages through strengthened value chains, better coordination, and investments in rural infrastructure and intermediate towns will be essential for reaping the benefits of regional and local trade. ${ }^{17}$

\section{SUPPORT RURAL DEVELOPMENT TO ADDRESS CONFLICTS AND FORCED MIGRATION}

Investing in agriculture and rural development can help to slow or even halt the vicious cycle of conflict, food insecurity, and forced migration. Early warning systems and social protection programs 
must be strengthened to help policy makers and populations respond to and mitigate the impact of shocks, including rising food prices, loss of agricultural livelihoods, and negative weather events such as drought. Local agriculture must be supported through measures such as diversification, training, extension, and investments in postharvest infrastructure to increase resilience and help rural populations prevent and recover from conflict. Ensuring that marginalized populations-including women, smallholder farmers, and minority groups-are equitably included in such investments, as well as in access to natural resources, can reduce the tensions that often lead to conflict and forced migration.

Investments are also needed in strengthening livelihoods and food security in countries hosting refugees. Such support tends to be a cost-effective means for refugees to improve their integration in the labor market and society at large and helps them restore their livelihoods. ${ }^{18}$ Integration can generate social benefits in the long run for recipient countries, and potentially for countries of origin if migrants return when the conflict ends. Fostering economic opportunities and providing access to jobs for migrants will help to relieve fiscal pressure and other burdens on host countries. Moreover, these actions can stimulate the local economy which, especially in cases of protracted displacement, can contribute to social inclusion and cohesion and help integrate migrants into the economy.

\section{INVEST MORE IN RESEARCH AND INNOVATION}

Research and innovation are essential to promote an agrifood system that is nutritious and healthy, environmentally restorative, climate smart, and lucrative-particularly for smallholders, women, and youth. Expanding investments in agricultural R\&D will yield high returns in terms of reductions in poverty and regional inequality as well as improved rural incomes. ${ }^{19}$ It is encouraging that developing countries are increasing investments in agricultural R\&Dfor example, China tripled its investment between 2000 and 2013-but developed countries should not lag in these investments. ${ }^{20}$

Frontiers for sustainable intensification and nutrition-driven technologies must be advanced. For example, breeding high-yielding, climate-ready, high-nutrition crop varieties through biofortification has shown promise. ${ }^{21}$ Increasing the yield potential of the vast diversity of currently underutilized species also has potential to improve food availability and nutrition, as do low-cost technological and financial innovations geared to smallholders. Policy innovations have immense potential to improve nutrition, health, and sustainability. For example, behavior change communication can help stimulate nutrition knowledge and steer consumer demand toward healthier and more sustainable foods. ${ }^{22}$ Innovations in carbon tax policies addressing unsustainable food production have the potential to reduce greenhouse gas emissions and improve human health. ${ }^{23}$ Institutional innovations, such as public-private partnerships for sustainability and nutrition, should be explored.

Further investigation to assess the impact of different investments in nutrition-driven technologies and innovations for hunger and malnutrition reduction are needed to fill a knowledge gap in this area. Promoting the use of evidence-based research to set priorities and fine-tune strategies, as well as investing in data collection systems and capacity building for research, continue to be imperative. Collaborative research efforts such as the EAT-Lancet Commission report (forthcoming) can provide an essential evidence base for establishing universal dietary and health guidelines, within which food systems should operate.

\section{BREAK THE SILOS}

Countries' experiences of success-and failure-can help to inform and shorten the learning curve for others. Speeding progress will depend on assembling and sharing the relevant knowledge across sectors and local, national, and international levels. Stakeholders can support mutual learning by providing opportunities for sharing key experiences on what has and has not worked in improving food security and nutrition; promoting technology transfers; building capacity; and improving infrastructure in developing countries. Networks such as the C40 Food Systems Network in partnership with the EAT Foundation provide opportunities for cities in the global North and South to learn from each other. Interdisciplinary collaborations can play an important role in coordinating and synthesizing the evidence on healthy diets from sustainable food systems. Understanding the complexities of and linkages among food system components is key to enabling an integrated food systems approach in policy making. 
In addition, in this period of growing antiglobalization sentiment, avenues for cooperation among stakeholders and across sectors and subnational jurisdictions must be reinforced. Investments via channels of South-South cooperation can help accelerate progress toward the end of hunger and malnutrition. Joint ventures, cooperation contracts, and public-private partnerships offer possible means of working together toward this end. Global initiatives will facilitate knowledge exchange and multisectoral cooperation: Compact2025-an initiative of the International Food Policy Research Institute-brings stakeholders together to share knowledge and spur innovation for accelerating progress to end hunger and undernutrition by 2025. The EAT Foundation facilitates collaboration across sectors-science, business, policy, and civil society-and across the food-health-sustainability nexus to advance healthy diets from sustainable food systems.

\section{PROMOTE LEADERSHIP AND COMMITMENT TO THE SDGS}

Strong political will and leadership are key ingredients for accelerating progress toward achieving food security and improved nutrition. To build momentum toward these goals, leaders from all relevant sectors and fields will have to champion the SDGs-the anchor of the global development agenda. At the global level, leaders must follow through on international commitments, including the UN Decade of Action on Nutrition-a unified effort to implement the Second International Conference on Nutrition (ICN2) Framework for Action-and the Paris Agreement on climate change. Global initiatives can help champion food security and nutrition, among other SDGs. In addition, global institutions can serve as coordinators to enhance the effectiveness, efficiency, and productivity across sectors and countries of global efforts on food security and nutrition.

Regional commitments are critical. For example, African countries should continue to monitor progress toward the Malabo Declaration on Accelerated Agricultural Growth and Transformation for Shared Prosperity and Improved Livelihoods, while engaging with regional commitments on environmental health. Country-level leadership and champions who work to end hunger and malnutrition are among the most important drivers of change. Some encouraging campaigns include China's commitment to achieving Healthy China 2030 and Ethiopia's Seqota Declaration on ending undernutrition by 2030 .

Local governance will be increasingly important. For instance, cities have a growing role to play as urban populations expand across the world and poverty, food insecurity, and malnutrition become increasingly urban problems. ${ }^{24}$ Cities may be better poised to address these challenges nimbly than national governments. Local policies must be context specific; for example, in Africa, where many urban poor people get their food from informal food markets, governance for food safety must be improved while institutionalizing regular engagement between local governments and informal workers. ${ }^{25}$ Cities can also act as leaders in creating stronger climate policies. For example, 12 cities in the United States that have joined the C40 Cities Network are leading the way on climate action through investment and collaboration. ${ }^{26}$

\section{FOOD CAN FIX IT}

Food can fix many problems, but to do so food systems must be reshaped for nutrition, health, inclusion, and environmental sustainability. Growing antiglobalization pressures create additional challenges for food to help achieve these goals. New opportunities-especially in emerging technologies in and outside of the agriculture sector and new global forums for fostering multisectoral collaboration, sharing knowledge, best practices, and research-must be leveraged through appropriate actions to maximize benefits for all. Indeed, how these actions are implemented will be crucial to ensuring that no one is left behind and to minimize negative trade-offs in achieving economic, social, and environmental goals. Similar to the science-based goals set for climate change, a strong evidence base is needed for healthy and sustainable diets, and would contribute to agreement on targets. Evidence encourages stakeholders to act with confidence and greater speed, and facilitates the assessment of progress. Evidence-based policies will enhance competence, and global cooperation will foster trust; both are key to ensuring that food system changes are broadly accepted and contribute positively to global development in a rapidly changing world. 


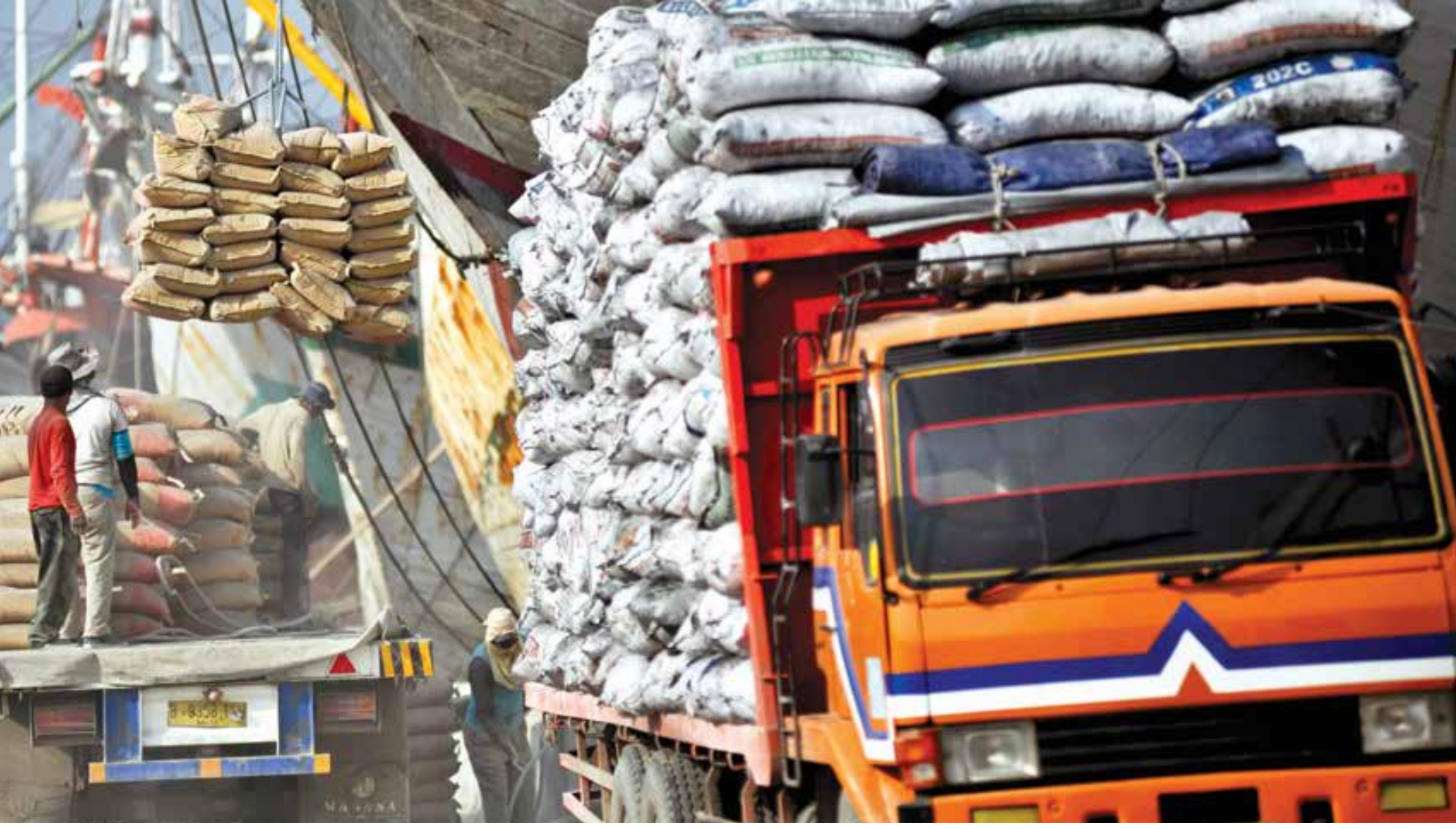

The benefits of international trade are embedded in our everyday lives, our meals have been shaped by globalization, and many farmers profit from export markets for their products. Global improvements in food and nutrition security under an open and inclusive trade regime have contributed to falling levels of undernourishment, better nutrition and greater dietary diversity, and overall economic development. Trade contributes to the four key requirements of food security-food availability, access, utilization, and stability of supply. Over the last 40 years, the share of food, measured in calories, crossing an international border rose from 12.3 percent to over 19 percent. ${ }^{1}$ But in today's climate of skepticism about globalization, with longstanding trade agreements such as the North American Free Trade Agreement (NAFTA) under threat, the benefits of trade may be forgotten as negative impacts are emphasized by advocates of trade barriers and self-sufficiency. In this chapter, we examine the links between trade and food security, drawing on evidence from history and economics and from the available data.

For most of history, people depended on local food production from traditional producers. Quite typical were the regions of India, isolated by the high costs of traditional transport and dependent upon local supplies of staple foods. ${ }^{2}$ Farmers relied on long-established farming practices, but were at risk of famine when the rains failed. ${ }^{3}$ When the railways arrived in India, between 1870 and 1930, transport costs were reduced by a factor of about five, making trade in food feasible. Incomes rose as Indian regions with more or better agricultural land began exporting food and those with an advantage in other goods began to import food. Food supplies became more stable, sharply reducing the incidence of famine. ${ }^{4}$ This story has been repeated in many different places and periods. International trade provides similar benefits, so why are challenges to international trade agreements on the rise? Let's first summarize the benefits for food and nutrition security of liberalizing trade with a focus on agriculture before addressing some of the challenges linked to open trade.

\section{AGRICULTURAL TRADE, FOOD SECURITY, AND DEVELOPMENT}

International agricultural trade is necessary to allow for both population growth and economic development. A world reliant on traditional agriculture 
without trade in food is not just vulnerable in the short term. It also faces the Malthusian trap of population growth outpacing food growth in the longer term. If living conditions are initially favorable, the population grows geometrically, but agricultural output grows more slowly, hampered by the need for land.

A few years after Thomas Malthus posed the problem of population and food supplies at the end of the 18th century, David Ricardo introduced the key rationale for free trade in food products when he formulated the notion of comparative advantage, which explains why countries with relatively more efficient agriculture sectors should export food products in return for other goods. Interregional trade in the United States offers a good example: in a context of minimal trade barriers in the 20th century, regions with greater agricultural potential, such as the Midwest, replaced less suited regions, such as New England, in the production of field crops. Given enormous differences in productivity between regions, the gains from increased trade in agricultural products within the United States are estimated to have been similar in magnitude to the enormous gains in productivity recorded over that period. ${ }^{5}$
Modern economic development offers a way out of the Malthusian demographic trap, with most regions experiencing falls in the death rate, followed by declining birthrates and ultimately a transition to stable or declining populations. ${ }^{6}$ But because this transition is long and complex, and countries vary enormously in their size and share of potential agricultural land, they have ended up with very different ratios of agricultural land per person (Figure 1). A group of super-land-abundant countries, such as Argentina, have about 2 hectares (ha) or more of agricultural land per person. Other important agricultural exporters, such as the United States and Brazil, have close to 1 ha per person. Countries like China, France, and India are intermediate cases. At the other extreme, countries such as Egypt, Japan, and the Republic of Korea have only about 0.04 ha per person.

Given the vast differences in land endowments, only international trade or massively greater productivity in the land-scarce countries would allow food demand in those countries to be met at reasonable cost. Of these two alternatives, international trade is the easier to implement in the short run, and the only one directly in the hands of policy makers. Agricultural productivity growth is

FIGURE 1 Agricultural land per person, selected countries, 2009

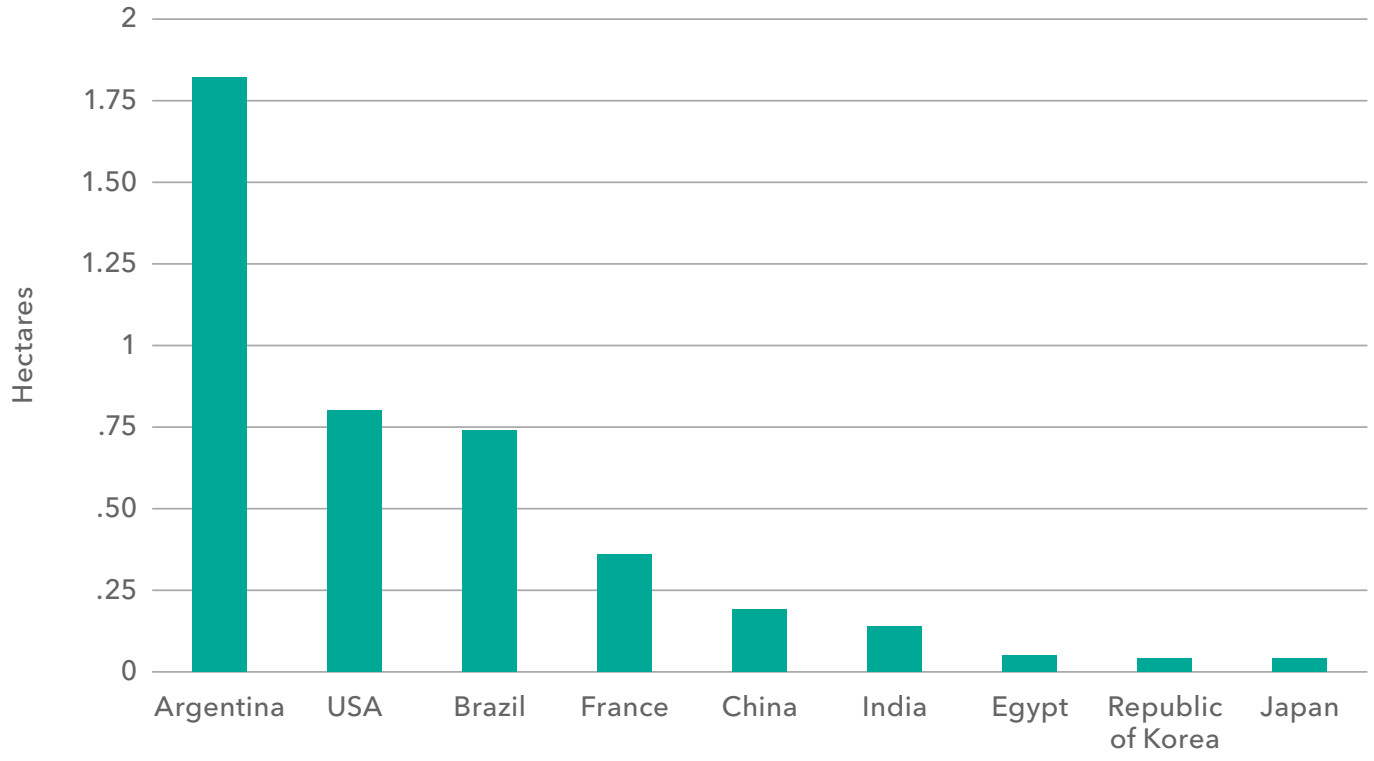

Source: Based on E. Fukase and W. Martin, "Who Will Feed China in the 21st Century? Income Growth and Food Demand and Supply in China," Journal of Agricultural Economics 67, no. 1 (2016): 3-23.

Note: Agricultural land is defined as arable land plus one-third of permanent pasture. 
enormously important in the development process because it allows countries-whether land-abundant or land-scarce-to raise farm incomes and potentially to lower food prices, both of which can contribute to lowering poverty. Trade in inputs and commodities and in ideas can promote this improvement and contribute to technological progress by facilitating the international diffusion of technology and creating incentives for innovation. $^{7}$

Since the 19th century, many countries have been able to take advantage of opportunities for international food trade because of lower transport costs, reductions in conflict, and the establishment of a workable institutional framework for international trade. ${ }^{8}$ Two major episodes of global trade liberalization have supported population growth and economic development. The first occurred during the 19 th century, when the European population doubled, benefiting from food imports from emerging countries of the time (Australia, Russia, and the United States) in the context of a safer international order and improved communication and transportation technologies. The second occurred more recently: since 1970, Asia has managed to combine a doubling of population with increases in quantity and quality of per capita food consumption, thanks to higher agricultural productivity at home and better integration with global markets and, in recent years, expansion of livestock-feed exports, especially from South America. Even countries with a conservative attitude toward agricultural trade-such as Japan-rely heavily on imports of nonsensitive agricultural products such as maize and soybeans.

The World Trade Organization (WTO) included agriculture in its Uruguay Round negotiations (19861994), which achieved some liberalization of agricultural trade and provided a framework for further reform (for more on international trade governance, see Chapter 8$).{ }^{9}$ The Uruguay Round also included rules on standards that reduced the risk of covert protectionism. Regional reforms such as the establishment of the European Union (EU) and NAFTA liberalized agricultural trade within these blocs. Perhaps partly in response to these reforms, agricultural trade liberalization became much more controversial in the 2000s, with the G33 coalition in the WTO resisting further reform of agricultural trade in developing countries, and the food sovereignty movement questioning the role of agricultural trade both within and between countries. ${ }^{10}$

\section{BENEFITS OF OPENING TO TRADE}

Opening to trade has important implications for incomes, food consumption, nutritional outcomes, and resource use. By encouraging production in areas with a comparative advantage in agriculture, trade raises countries' incomes and provides access to better prices on world markets. Widespread opening to trade, of the type observed since trade costs began to fall sharply in the 19th century, has lowered the average cost of food worldwide. In contrast, limiting trade-given the huge differences in land and resource endowments-would have resulted in extremely high prices in land-scarce countries, depressed food prices in land-abundant countries, and lower real incomes in both. ${ }^{11}$ This unbalanced pattern would have been good for neither group-with Argentine tables groaning under the weight of even more beef and Japanese farmers struggling to produce enough food on the country's scarce land.

Beyond improving food availability and access, international trade can improve nutrition by allowing better access to a diversified food basket. Relying on locally produced food greatly limits dietary choices. For those living in temperate climates, it restricts options in winter months and rules out products that require a more tropical climate. Trade allows year-round consumption of many healthy products, such as fruits and vegetables, and gives access to nontraditional food items that have improved nutrition-for example, allowing East Asian countries to rapidly integrate more milk into their diets; consumers in developed and emerging economies to adopt olive oil, a healthy source of unsaturated fat; and markets to expand for lesser-known nutritious crops such as quinoa. ${ }^{12}$

Similarly, international trade provides consumers with various sourcing options for any given product. Economic development has been accompanied by an increase in the variety of food imports and sources of food imports (Table 1). In 15 years, Ghana moved from importing 310 food products from world markets to 491, each product being sourced now from 7.1 countries on average compared to 3.0 in the past. China, which was already importing many products in the late 1990s, increased the diversity of its suppliers by 50 percent on average (from 9.4 to 14.5) to meet the expectations of consumers with growing purchasing power. The preference for diversity is well illustrated by advanced economies. Australia and 
TABLE 1 Diversity of internationally traded food products

\begin{tabular}{|c|c|c|c|c|}
\hline \multirow[b]{2}{*}{ Country } & \multicolumn{2}{|c|}{ Average number of food products } & \multicolumn{2}{|c|}{$\begin{array}{l}\text { Average number of origin } \\
\text { countries by product }\end{array}$} \\
\hline & $1998-2000$ & 2011-2013 & $1998-2000$ & 2011-2013 \\
\hline Afghanistan & 97 & 397 & 1.5 & 3.7 \\
\hline Argentina & 514 & 429 & 5.3 & 4.8 \\
\hline Australia & 548 & 546 & 10.4 & 15.7 \\
\hline Brazil & 540 & 502 & 6.4 & 7.4 \\
\hline China & 575 & 558 & 9.4 & 14.5 \\
\hline Ghana & 310 & 491 & 3.0 & 7.1 \\
\hline Guatemala & 491 & 495 & 3.9 & 4.7 \\
\hline Malawi & 221 & 359 & 1.7 & 2.2 \\
\hline Mali & 250 & 309 & 3.0 & 3.7 \\
\hline Paraguay & 379 & 369 & 3.0 & 3.7 \\
\hline United States & 601 & 585 & 20.9 & 24.9 \\
\hline Uzbekistan & 230 & 299 & 2.5 & 3.2 \\
\hline
\end{tabular}

Source: L. Deason and D. Laborde, "Trade and Nutritional Contents," unpublished, International Food Policy Research Institute, 2012.

Note: Food products are defined here as HS6 products (the Harmonized System 6-digits), the international classification for trade in goods.

the United States-major net agricultural exportersimport nearly all varieties of food products and from a rising number of countries. The growing number of exporters is an important feature of the ongoing globalization trend that, even for countries already largely open, continues to deliver gains in terms of food diversity, development of more efficient value chains for transferring and transforming agricultural products, and the emergence of new suppliers, including from developing countries.

Trade can also contribute to the sustainability of food systems and reduce both the risk of overexploitation of natural resources and negative environmental impacts linked to production, known as externalities. For example, by reducing the need to rely on domestic supply, trade in agricultural products can reduce local water and fertilizer use in countries where these inputs are relatively scarce. Analysis of the main crops of the world's two largest exporters, the United States and China, shows the magnitude of these impacts (Figure 2). While the United States is a net exporter of "virtual" water-the water used to produce agricultural goods that is embedded in the traded products-and "virtual" fertilizers, China, whose domestic resources are already strained, saves substantial resources through imports, partly because its partners use technology that is less fertilizer- and water-intensive than China would have to use to replace these imports.

\section{CHALLENGES OF OPENING TO TRADE}

Trade has driven great improvements in food security and nutrition, but real risks are associated with trade opening, including increases in inequality and negative impacts on health and the environment. Acknowledging and identifying problematic aspects of the globalized food system can lead to effective policy solutions that protect the benefits of trade.

REDISTRIBUTION, POVERTY, AND INEQUALITY. Trade improves food access and availability, allowing consumers in importing countries access to more food at lower prices and raising incomes for producers in exporting countries. However, free trade has redistributive implications that may affect food security. In exporting countries, the higher product prices resulting from international trade opportunities push local prices up, hurting local consumers. Indeed, even "success stories," where increased exports raise smallholder incomes, can be offset by the adverse economic and nutrition outcomes for consumers. This is the story of quinoa-as Andean exports of the grain exploded and many poor producers enjoyed rising incomes, traditional poor consumers faced reduced access to a nutritious staple food. ${ }^{13}$ To tackle inequalities related to trade and protect people from adjustment costs, tax and revenue transfer programs (including social safety 
FIGURE 2 Water and fertilizer content embedded in international trade

\section{Water content of primary crops}

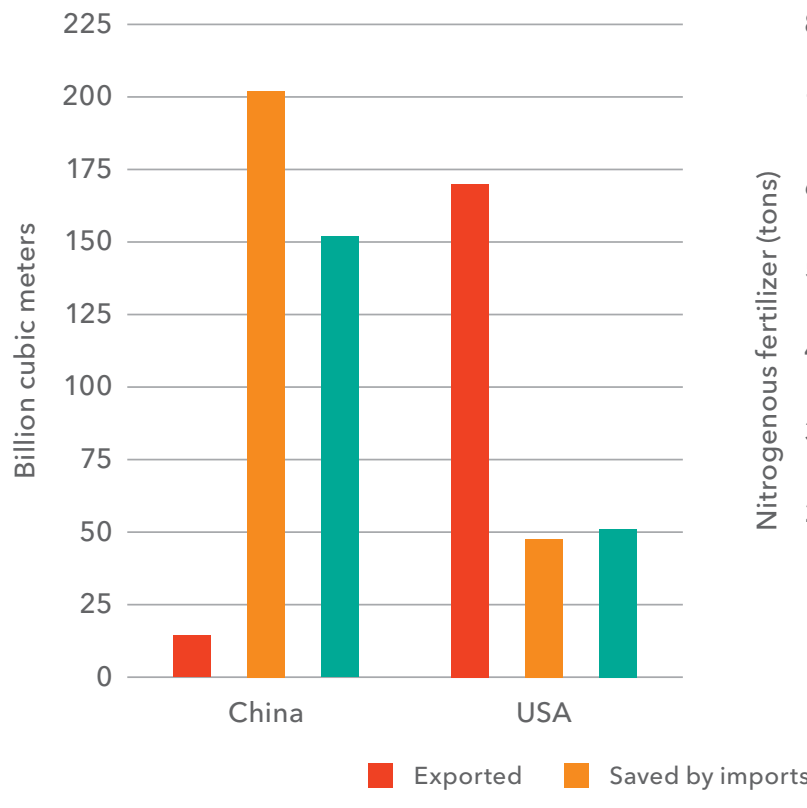

Fertilizer content of primary crops

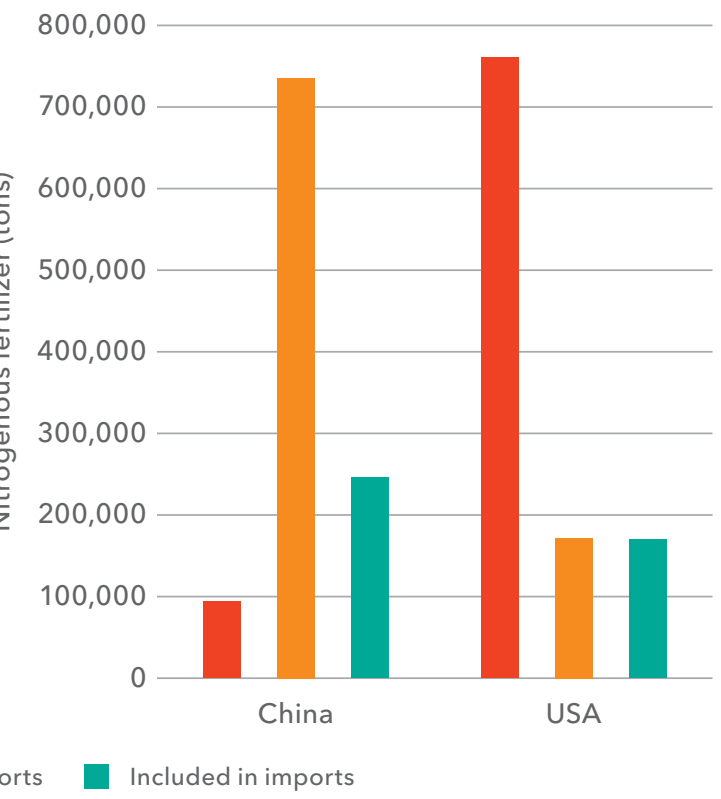

Source: D. Laborde, "International Trade and Natural Resources: A Sustainable Path toward Global Food Security," presentation at the US-China Oilseeds and Grains Annual Forum, Beijing, June 17, 2017.

Note: Water content includes all water used in the production and processing of primary crops.

nets) are better options than restricting trade. Provision of public goods (such as education and agricultural research and development) can also play a role both in increasing national incomes and improving the distribution of income and opportunities.

ENERGY USE AND EMISSIONS. Bringing food from farther afield clearly involves transport costs. Both producers and traders factor in these costs and only transfer goods from one region to another if doing so lowers costs or improves product quality. However, there are externalities-unaccounted for costs, including greenhouse gas emissions-associated with production and transport of food. Such externalities should be dealt with "symmetrically." For example, if energy use is a problem, it should be discouraged equally in transportation, in production, and in consumption. This approach recognizes that free trade is not the problem, but rather distortive policies, such as tax rebates on fossil fuel use in the agriculture sector, that can alter incentives and lead to overuse of fossil energy are the problem. Limiting these distortionary policiesincluding subsidies and tariffs-is a cornerstone of the modern global trading system managed by the WTO.
ENVIRONMENTAL DEgRAdATION. Agricultural trade is also frequently criticized for contributing to biodiversity loss and driving land use change that affects both biodiversity and greenhouse gas emissions. ${ }^{14}$ The risk to endangered species from agricultural productionwhether linked to trade or to domestic consumption-is a real and pressing problem. Investigation of this issue must consider not just the specific links between trade and species loss, but also the potential land use gains from trade: trade allows for sourcing products more efficiently, reducing the total demand for land in agriculture by encouraging production in the most efficient areas. However, by expanding markets, trade can influence the extent and pace of adverse environmental impacts.

Two well-studied examples illustrate the problem of biodiversity externalities. The slaughter of 30 million bison in the United States in the 1870s was driven by tanning innovations in Europe and a consequent booming demand for hide exports. ${ }^{15}$ With no conservation policy in place in the United States, foreign demand clearly contributed to the near-extinction of this iconic animal. However, suppressing international trade in hides would only have 
retarded the slaughter very slightly, as American tanners were rapidly learning the new techniques. Even a ban on hide exports would merely have resulted in exports of leather and other products, with the slaughter continuing in the absence of conservation policy. Only public and private conservation efforts, rather than trade restrictions, ultimately ensured the survival of the bison. ${ }^{16}$

Over a century later, a debate has arisen about a similar problem driven by the EU's demand for vegetable oil to feed its biodiesel policies. These policies have increased demand for palm oil and led to expansion of palm plantations in some parts of Southeast Asia, where land and environmental governance are weak. The resulting deforestation and peatland degradation has led to loss of biodiversity, including iconic species like the orangutan, and to massive greenhouse gas emissions. ${ }^{17}$ Even if the EU biofuel policies are not the main driver of the palm plantation expansion, policy debates have been fierce since the EU policy has aggravated the environmental damage. In addressing such issues, it is more important to address the root cause-weak land and biodiversity governance in Southeast Asiarather than restrict trade.

UNHEALTHY DIETS. Health impacts present a similar policy challenge. Human nutrition is complex, and people often make choices that are not in their long-term interests. New, tasty, energy-dense, or ultraprocessed foods, often heavily promoted, attract many consumers. The adverse health outcomes, such as obesity and diabetes, only become apparent with time. If the new food is foreign, a frequent response is to call for a ban on imports of the good, such as Fiji's ban on imports of high-fat mutton "flaps." ${ }^{18}$

Identifying the source of the nutritional problem is critical to selecting the right response. Such analysis has been done for related issues, including the health burden of some agricultural products, notably tobacco. ${ }^{19}$ Import bans may not significantly reduce consumption, even if the problematic commodity was originally introduced through international trade, because domestic substitutes emerge. If domestic substitutes become available at a similar cost, restricting trade will not solve the health or nutritional problem. By encouraging domestic production, trade restrictions may also create a powerful domestic lobby opposed to efforts to reduce consumption.
In complex situations like these, the "assignment principle" states that we should target each goal with the policy that most directly affects it. ${ }^{20}$ For example, to cut sugar consumption to reduce obesity-related diseases such as type-2 diabetes, we should focus on policies that directly address sugar consumption. If the problem is that consumers lack information about the effects of the good, then provision of information is likely the best policy. And if the good has addictive properties that make it difficult for people to give up, even when informed of its attributes? Perhaps consider taxes that will reduce the risk of people becoming addicted. We know that policies that raise the price of sugar-either consumption taxes or import duties-will reduce consumption. The assignment principle favors the tax rather than an import duty, because it affects consumption alone, without creating collateral damage by stimulating domestic production.

\section{UNDERSTANDING TRADE RESTRICTIONS}

Trade barriers create economic losses by encouraging costly production of goods that could be purchased on world markets for less and discouraging efficient production of goods that could be sold at a profit on world markets. A tax on imports, which stimulates production of import-competing goods, functions as an equivalent tax on exports, reducing exports in line with imports-it does not create the trade surplus frequently anticipated by proponents of protection. ${ }^{21}$ If trade policies are to be used to raise revenue, a strong argument exists for using relatively low and uniform rates of tariff protection. Trade regimes using high rates of protection, or variable rates of protection across commodities or across time, create much higher costs than low and uniform rates-a 10 percent tariff is 100 times as costly, in terms of welfare, as a 1 percent tariff. So why do countries restrict agricultural trade?

Several arguments for high levels of protection, or taxation, of agriculture have been offered, including the terms-of-trade argument; the infant industry argument; the income redistribution argument; and a number of arguments for "active" protection rates that change over time, usually to stabilize domestic prices. Political economy explanations of trade restrictions look at the role of organizational and political factors. 
TERMS OF TRADE. Larger countries may be able to improve the price of imports relative to exportstheir terms of trade-by lowering the prices of their imports or raising the prices of exports. However, these gains come at the expense of their trading partners, who will pay more or earn less; it will generally be possible to make both these countries and their trading partners better off by lowering these barriers. This builds an argument for trade negotiations to lower barriers, rather than for use of trade barriers, since retaliation and noncooperative outcomes lead to lose-lose situations, both at the multilateral and bilateral level and for both import and export restrictions. ${ }^{22}$

INFANT INDUSTRIES. Surprisingly, the infant industry argument is sometimes used to justify protection for agricultural products. Proponents argue that inferior technology prevents developing countries from competing against established producers in developed countries, and that protection is needed to foster the growth of new industries. Protection is provided through export taxes on raw products. This is the flip side of the argument made in developed countries that they cannot compete because of low wages in developing countries. The problem with both of these arguments is the failure to recognize that they are two sides of the same coin. Developed countries have higher wages because their productivity-in a range of sectors-is higher than in developing countries. Developing countries hold a comparative advantage-and will be successful exporters-in those sectors where their productivity is higher relative to other potential export sectors (the theory of comparative advantage, outlined above). Infant industry protection for agricultural processing activities does not create an incentive to increase productivity, but rather enables low-productivity firms to stay in business. ${ }^{23}$ This protection also frequently hurts poor agricultural producers such as cotton growers, who receive lower prices for their products.

REDISTRIBUTION. Another common argument for protection is that it can redistribute income. In rich countries, which tend to import labor-intensive goods, using trade protection to raise the price of these goods may raise wages relative to the returns to capital. Protectionist policies have occasionally been justified in this way. ${ }^{24}$ In developing countries, however, imports tend to be capital intensive and protection against imports will tend to raise the returns to capital relative to labor, meaning that incomes will fall, with implications for food and nutrition security.

volATILITY. Active or variable trade policies in agriculture are sometimes implemented to reduce domestic impacts of world price volatility. Yet developing country markets can be destabilized by domestic shocks, such as drought, and suffer high domestic price volatility even when international markets are calm. ${ }^{25}$ Global food markets have lower volatility in the long run than most country markets because the impact of supply and demand shocks is spread across multiple markets. In addition, trade connects the two hemispheres, which have different planting and harvesting periods, further reducing global volatility. Policy interventions through variable tariffs and export restrictions are attractive to individual countries, but increase volatility in world market prices by reducing export supplies and increasing import demand when world prices rise. Once this is considered, we see these tools are not effective in reducing the volatility of domestic prices or in sheltering the poor from the impacts of higher prices. ${ }^{26}$ Moreover, poorly calculated policy interventions in many low-income countries increase domestic price volatility. For example, use of export bans to ensure availability of food during the 20152016 El Niño event in southern Africa resulted in price volatility, as the supply outlook changed after the bans went into effect.

POLITICAL ECONOMY. The most widely accepted explanation for the high levels of intervention seen in many agricultural markets is related to the redistribution argument. Some sectors are able to organize at relatively low cost and to exert strong pressure on governments for interventions that raise the prices of their outputs and/or lower the cost of their inputs. ${ }^{27}$ This explains the tendency for agricultural production to be taxed in poor countries and subsidized in rich countries. ${ }^{28}$ In poor countries, farmers are numerous and widely dispersed, while urban consumers care deeply about the price of food and are few enough to be readily organized. As incomes grow, the number of farmers declines sharply, and urban consumers become both more numerous and less concerned 
about the price of food. The result is low (or negative) protection for agriculture in poor countries and high protection in rich countries. This political economy model explains the current high levels of farm support in the United States, the EU, and Japan. ${ }^{29}$ It also helps explain the rise of agricultural protectionism in the late 19th century. For instance, the German "iron and rye" tariff of 1879 was Chancellor Otto von Bismarck's response to political pressure from Prussian Junkers hurt by falling transportation costs and the resulting decline in European grain prices. ${ }^{30}$

\section{ENSURING SUSTAINABLE TRADE LIBERALIZATION}

As shown, the merits of trade for strengthening food and nutrition security are clear. Self-sufficiency is costly and likely to put food security at risk. But this is not a call for laissez-faire. Market and policy imperfections can be alleviated by appropriate interventions, and movement toward free trade needs to be backed by active policies and strong institutions to guarantee cooperative behavior and coordination. International trade can be an important catalyst: it can support and accelerate economic growth, diffusion of agricultural production technology, and reallocation in food consumption and production patterns. But opening to trade has both benefits and costs, and generates winners and losers. In the presence of incomplete markets (for example, no pricing for carbon or biodiversity), poor resource governance, and externalities, it can be tempting to limit trade, switching off the catalyst instead of addressing the root causes of economic, health, or environmental problems. When considering policy in this situation, the assignment principle suggests that policies should be targeted at production when that is the source of the problem (for example, biodiversity loss or emissions) or at consumption (overnutrition or poor access to food) when that is the root of the problem. Important recommendations include:
ADDRESS INEQUALITY AND VOLATILITY WITH SAFETY NETS. Investing in human capital and social safety nets is an important way to tackle the impacts of shocks, whether from trade reform or other events. With improvements in biometric identification, it has become much easier to target safety nets to beneficiaries with particular nutritional needs, such as low-income mothers of young children. Smart policy solutions will protect the population (consumers and producers) through direct support, rather than exporting problems to their neighbors.

\section{ADDRESS ENVIRONMENTAL IMPACTS WITH RESOURCE} MANAGEMENT POLICIES. When looking at environmental issues, policies targeting trade rather than production, such as log export bans, are frequently ineffective in dealing with the market failures that lead to environmental damage. ${ }^{31}$ Likewise, dealing with biodiversity problems requires an approach that mainstreams good management of resources and maintenance of diversity into production. ${ }^{32}$

ADDRESS OVERNUTRITION WITH EDUCATION. To tackle the nutrition challenges that arise with rapid income increases and growing consumption, and our human preference for rich, high-calorie foods, governments should focus on providing information and consumer education. Banning or limiting trade is likely to promote smuggling and other illegal or unmonitored activities leading to worse outcomes, such as higher prices and violation of sanitary and phytosanitary norms, creating serious health risks for national food systems on both the consumer and producer sides.

Today, the world is facing global challenges, including climate change and a growing population, that cannot be solved uniquely with local solutions, but will need strong global institutions and governance based on cooperation. These institutions must ensure that international trade continues to contribute to the peaceful redistribution of wealth and resources among nations, fostering development, and playing a key role in achieving food security. 
"Global improvements in food and nutrition security under an open and inclusive trade regime have contributed to falling levels of undernourishment, better nutrition and greater dietary diversity, and overall economic development." 


\section{CHAPTER 4}

INVESTMENT

\section{International Investment and Local Food Security}

\section{JAMES ZHAN, HAFIZ MIRZA, AND WILLIAM SPELLER}

James Zhan is the director of Investment and Enterprise at the United Nations Conference on Trade and Development (UNCTAD), Geneva, Switzerland. Hafiz Mirza is professor of international business and strategy at the Henley Business School, University of Reading, UK. William Speller is economist, Investment and Enterprise, UNCTAD, Geneva, Switzerland.

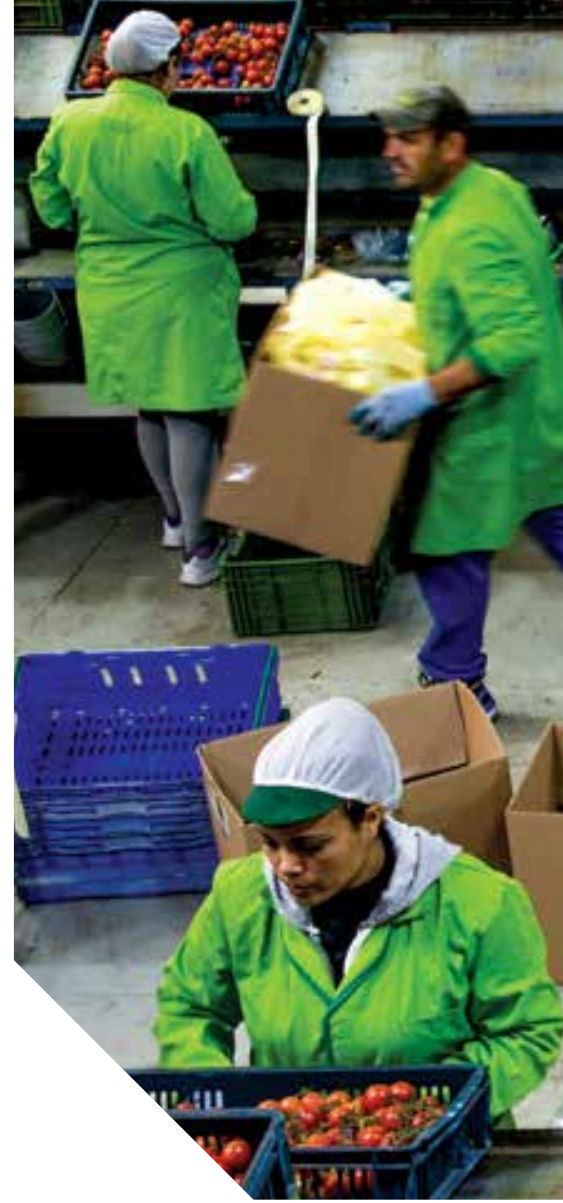

\section{KEY FINDINGS}

- International private investments in agriculture can help the world meet the Zero Hunger goal by boosting food security and nutrition and supporting development.

- International investments can: create jobs; develop rural infrastructure; connect smallholders to global markets; introduce new productivity-enhancing technologies; and improve access to finance for farmers.

- Benefits are felt through increases in production, improved value chains, rising rural incomes, infrastructure development, increased use of digital and other technology, and higher safety and quality standards for food.

- A study of 50 major private agribusiness investments in Africa and Asia found that the greatest benefit was improved ability of local people to buy more food and more nutritious food.

- Without proper governance and screening, international investments can have negative impacts, including violations of people's rights and access to land.

\section{KEY RECOMMENDATIONS}

- Align food security and nutrition targets with broader national development strategies, with attention to the role of private investment.

- Promote and facilitate investment in staple and cash crops in food insecure regions.

- Support public-private partnerships for agro-infrastructure to link farms to markets and attract investment.

- Improve access to digital technology from farmer to consumer to address information needs for productive investments.

- Ensure responsible investing by implementing agricultural investment principles and supporting government screening of investments through technical assistance to host governments.

- Give preference to business models that fairly integrate smallholders through contract farming or outgrower schemes.

- Prioritize investments that support women's empowerment, given women's key role in food and nutrition security, as well as improve the position of vulnerable groups such as youth and pastoralists.

- Develop a data collection consortium to improve data on international investment in agriculture. 


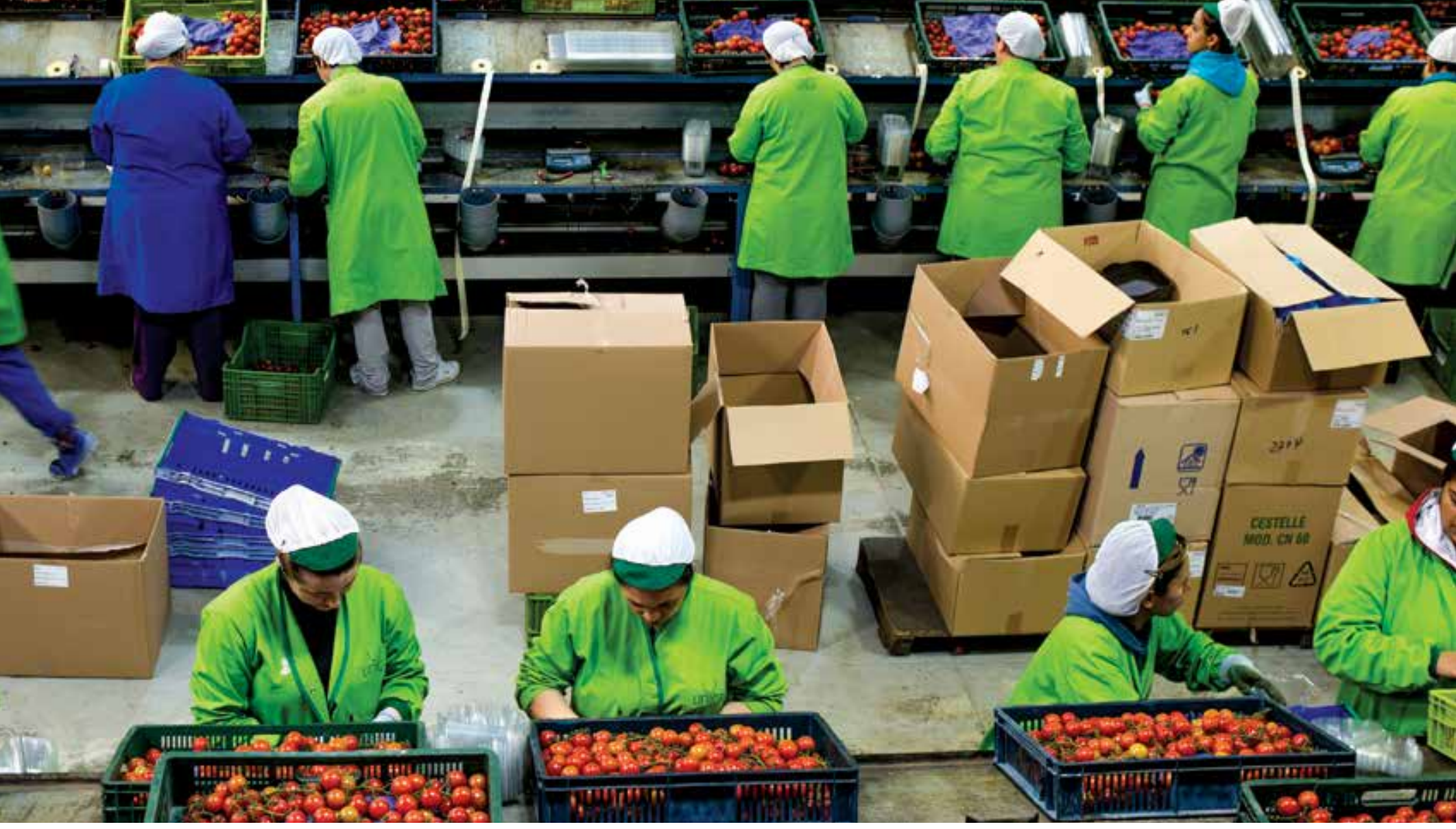

International investments in agriculture have a broad range of social, economic, and environmental impacts. At their best, they create decent jobs that upgrade local skills, provide local farmers with incomes, improve access to markets and finance, develop rural infrastructure and introduce new technologies to modernize domestic sectors, create new sources of food security, and generate lasting, mutually beneficial partnerships with surrounding communities. At worst, investments result in the displacement of people, are detrimental to existing sources of food security, lead to violent conflicts with local communities, damage the natural environment, fail to generate promised benefits for the host country, and themselves fail financially, with companies exiting the host country and leaving a void in their wake.

In an era when globalization-and associated flows of international investment-is increasingly under threat, the challenge for policy makers is how to maximize the benefits of international investments while minimizing the risks. Achieving Zero Hunger, the ambitious Sustainable Development Goal 2 (SDG2), will require significant increases in investment, including international investment. Agricultural production must grow by 70 percent by 2050 to keep 9 billion people fed and healthy. ${ }^{1}$
Ninety percent of this increase needs to come from sustainable intensification of existing production. To reach this goal, investment must be increased in rural development and agriculture in developing countries, including investment in production, processing, and storage infrastructure. Current annual investment (private and public) is about US $\$ 220$ billion, significantly less than the US $\$ 480$ billion required annually if SDG2 is to be realized. ${ }^{2}$ This figure includes investment in agriculture-specific infrastructure, natural resource development, research, and food safety nets.

Much of this investment will need to come from the public sector. Meeting the total cost of ending hunger worldwide by 2030 is estimated to require an additional US\$11 billion per year in public spending over and above current public investment levels, which would need to be contributed

The findings of this chapter derive from an ongoing program of field work conducted by the United Nations Conference on Trade and Development (UNCTAD) and the World Bank, generously funded by the Government of Japan. The findings, interpretations, and conclusions expressed herein are those of the authors and do not necessarily reflect the views of the United Nations or its officials or Member States. The authors would like to thank Richard Bolwijn for valuable comments on earlier versions. 
by developing country governments and international donors. ${ }^{3}$ A more significant share will come from the domestic private sector. The largest investors in agriculture are smallholders investing in their own farms-on-farm investment is estimated to be three times as much as all other sources of investment combined. ${ }^{4}$

International private investment, in comparison, represents a relatively small share of the total investment in developing country agriculture. Yet the international private sector is critical to achieving the SDGs. The role of international investment in delivering food security includes, but is certainly not restricted to, investment in the agriculture sector, either in primary production or other segments of the agricultural value chain. Foreign investment in a range of other sectors can have positive impacts that contribute indirectly to greater food security. In fact, investment in agriculture alone will never be enough. A food security strategy must be part of a broader economic development strategy that takes advantage of foreign investment flows across a range of sectors and in the various links of the value chain.

Turning to investment in agriculture and related food and beverage sectors, international investment can play a more important role than suggested by its current scale. International investments can create jobs, develop rural infrastructure, connect smallholders to global markets, introduce new technologies that improve productivity, and improve access to finance for local farmers. International investments can also "crowd in" further domestic investment through demonstration and spillover effects.

But international investments can also have negative impacts on host countries and local communities and have been criticized in recent years for violations of people's rights and access to land. It is important, however, not to conflate foreign investment in agriculture with foreign investment in land for primary production. A significant and, anecdotally at least, increasing share of international investment occurs through business models that require little land, such as contract farming and processing operations. Furthermore, investment is often through modes that require neither land acquisition nor equity investment in the host country, and instead focus on the economic power that multinational enterprises have over links in the value chain. $^{5}$

\section{INTERNATIONAL INVESTMENT AND FOOD SECURITY}

International investment affects food security across its four key dimensions: availability of food; access to food; stability of supply; and safe and healthy utilization, including access to nutritious diets. ${ }^{6}$ To design policies that ensure that international investments enhance food security, governments need to be aware of the potential positive and negative impacts and the various pathways through which investment affects food security (Figure 1).

DOMESTIC PRODUCTION. The most direct impacts on food security are felt when an international investor engages in the production of staple crops for domestic consumption, which improves their availability and stability of supply. International investors may also enter other segments of a country's domestic agricultural value chain, as suppliers of inputs, processors, or supermarkets and retailers, which can also enhance food availability and stability of supply. However, to the extent that international agricultural investments are either in production for export or in high-value-added cash crops, the direct impact on staple crops and local food security will be limited and potentially negative. For example, where large areas of land are converted from staple crop to cash crop production, poor urban consumers may be adversely affected by rising prices for staple crops.

RISING INCOMES. Multinational enterprise activity can enhance food security indirectly through rising rural incomes. International investments can increase formal employment levels and the number of people enjoying a living wage. Where a contract farming or outgrower business model is adopted, farmers receive revenue from their sales to the investor. When an investor sources other inputs (such as fertilizer or equipment) locally, suppliers also benefit. Higher and more stable incomes improve people's ability to access food. And higher incomes tend to be associated, at least initially, with a shift to more nutritious diets, thereby improving food utilization.

PRODUCTIVITY AND TECHNOLOGY. Multinational enterprise activity can also lead to improvements in domestic agricultural productivity, both in domestic and internationally run farms and operations. Where training and contract farming or outgrower schemes 
FIGURE 1 International investment in agriculture and impact on food security

\section{Investment}

dimensions
Food security dimensions

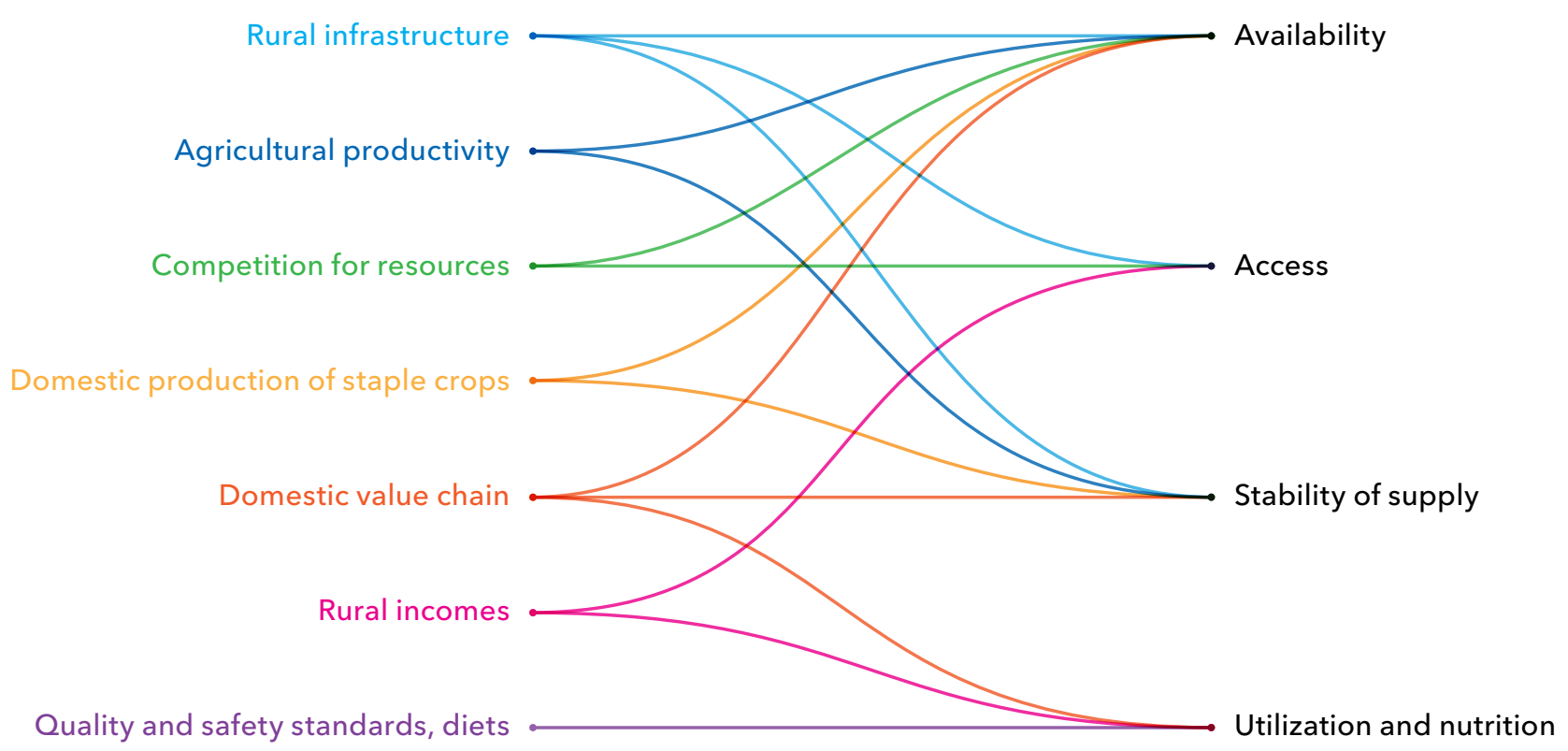

Source: Authors based on UNCTAD (United Nations Conference on Trade and Development), World Investment Report: Transnational Corporations, Agricultural Production and Development (Geneva: 2009) and UNCTAD-World Bank Survey of Responsible Agricultural Investment Database.

exist, the resultant spillover gains in production volume and efficiency can occur beyond the investment area. The transfer of agricultural technology, modern management techniques, use of enhanced inputs, and better supply chain management can all contribute to increases in the amount of food produced (improving availability) and better distribution (improving access). The digital economy in particular is making a growing contribution to productivity. The critical importance of increasing agricultural productivity is recognized by SDG2 target 2.3 to "double the agricultural productivity and incomes of small-scale food producers" by 2030 .

INFRASTRUCTURE. Multinational enterprises require infrastructure to store and transport output from their operations, especially for export products. International investment in infrastructure-by investors, host governments, or through public-private partnerships-that connects producing regions to urban centers and ports can promote other investments in rural development. Building these connections can help improve food access and stability of supply for food-insecure regions. Improved infrastructure can also play a critical role in reducing the postharvest losses that often result from inadequate transport, storage, and refrigeration facilities. ${ }^{8}$

NATURAL Resources. Depending on the business model adopted, international investment can alter access to natural resources, especially land and water. This is particularly true for large-scale, land-based investments that require relocation of people in order to provide secure tenure to investors. Such business models have real potential for socioeconomic harm, including jeopardizing existing food availability and access.

QUALITY AND SAFETY STANDARDS. Finally, international agribusinesses can introduce higher quality and safety standards for food. Their involvement in agricultural production has spillovers related to quality control, food standards, and consumption patterns that can lead to improved food utilization and nutrition in host developing countries. In some cases, however, undesirable food consumption patterns, such as frequent fast food meals that are less nutritious than traditional diets, may be emulated in developing countries. 
FIGURE 2 Product and market focus of foreign and domestic investors in agriculture

All investors

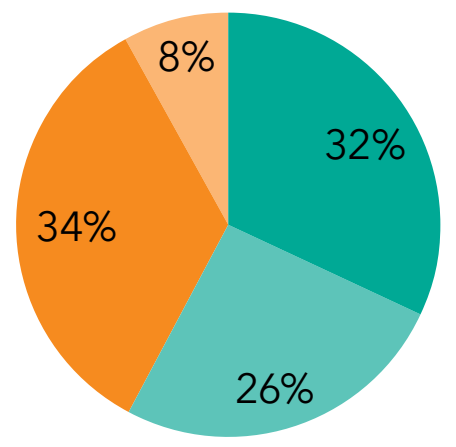

Foreign investors

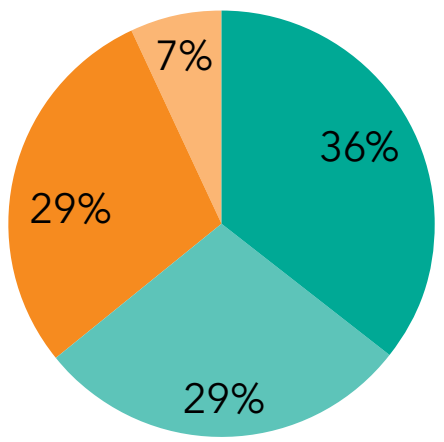

Production for domestic markets

Food crops

Nonfood crops
Production for foreign markets

Food crops

Nonfood crops
Domestic investors

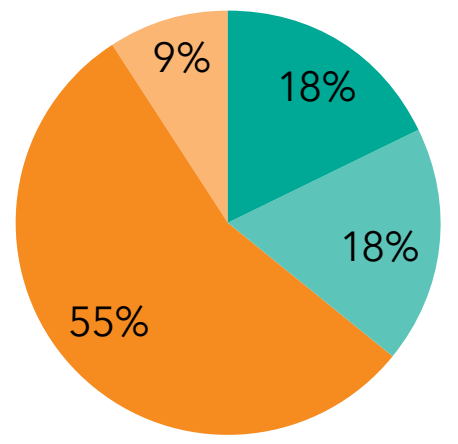

Source: UNCTAD-World Bank Survey of Responsible Agricultural Investment Database.

\section{EVIDENCE FROM FIELD WORK}

With these theoretical linkages between international investment and food security in mind, we now turn to evidence from the field. A

five-year program of field research-undertaken by the United Nations Conference on Trade and Development (UNCTAD) and the World Bank under the auspices of the interagency working group of UNCTAD, the World Bank, the International Fund for Agricultural Development, and the Food and Agriculture Organization of the United Nationsconducted extended field work in close concert with over 50 major private agribusiness investments in Africa and Asia. More than 500 external stakeholders (community members, employees, resettled persons, government officials, civil society organizations, suppliers, and local business owners) were interviewed to gather perceptions regarding the full range of impacts of these investments, including impacts on food security. ${ }^{9}$

Of the investors included in the field research, fewer than one-third were producing staple crops for sale in domestic markets, meaning their direct impact on food availability was low (Figure 2). Most investors were either selling to export markets or growing cash crops that were not part of the local staple diet. Local communities often switched from growing staple crops to growing the crops that investors committed to buy as part of contract farming arrangements. At one site, local farmers were encouraged to intercrop the cash crop introduced by the investor with their local food crops.

The main positive impact on food security and nutrition was the ability of local people to buy more food-and more nutritious food-due to a rise in rural incomes from direct employment, participation in outgrower schemes, and broader economic spillovers related to the agribusiness investment. These benefits were not automatic, however. Some investments in the study operated as "enclaves"-predominantly employing expatriates, adopting estate-style business models, importing inputs, exporting produce, and generating few linkages with the local economy-with limited benefits to local and national food security. For food security improvements to occur, jobs must be stable and pay a decent wage; outgrower schemes must be well designed and pay fair prices; and strategies must be in place to maximize forward and backward linkages between the investment and the local or national economy. Value-chain multipliers can also yield significant local impacts. For instance, an investor in Tanzania 
invested in a new processing facility, adding further value to the primary product. The resulting product was sold to local beverage industries, creating some 60 additional jobs. The new facility also acted as an incentive for local people from within and outside the area to establish logistics companies to support the investor's operations.

Training provided as part of some outgrower schemes helped local smallholders to improve productivity, thereby improving the availability and stability of food sources (where food crops are grown), and to increase the income received through such schemes. Training was not always provided, or in some cases was provided but not beneficial. This depended on the design of the outgrower scheme and the level of technical support provided to outgrowers by the agribusiness.

Some investors built roads or other rural infrastructure, including for provision of water and electricity, required for project implementation, but which was also made available for wider local public use. For smallholders, these investments contributed to improved productivity and market access, thereby improving food access, availability, and stability of supply. An investor in Cambodia constructed and improved road infrastructure in surrounding villages that resulted in better access for the residents and improved market access for local farm produce. The investor built a 4-kilometer road to connect a key junction with its farm and has maintained a 50-kilometer section of government road. The surrounding area was previously left uncultivated because of inaccessibility, but since the road construction, people have returned and it is now a market town. In another instance, an investor provided free electricity to support the operation of local businesses where public electricity could be unreliable. Despite some similar positive examples, a lack of rural infrastructure generally remained a major constraint to food security, and the lack of transportation and storage facilities contributed to food loss and waste along the supply chain in food-insecure areas.

In the worst cases, the arrival of an agribusiness investor was detrimental to food security. This occurred where allocation of large land areas to investors forced the displacement or resettlement of local communities. When displacement occurred, existing sources of food security were often jeopardized. Even when resettlement conformed with principles of free, prior, and informed consent, there was a risk that resettled persons, relying on alternative livelihoods and food sources, would suffer a decrease in food security. ${ }^{10}$ Reduced access to land and natural resources, including water, on which smallholders often depend for survival was the main negative impact identified. In addition, the fencing off of land may impede local access to particular resources if areas and routes become unusable. One woman explained that she and other women in her village used to collect wild spinach and a variety of other edible plants on land they no longer had access to, due to an electrified perimeter.

Food security also suffered when investments were failing or struggling. A significant proportion of agricultural investments failed to achieve anticipated outcomes, many for reasons that could and should have been foreseen and dealt with at the outset through a comprehensive screening of prospective investors and investments. Financial and operational success is essential for investments to make a positive contribution to sustainable development in the host country and to local communities. Moreover, when local communities become reliant on investors for income, either through direct investment or outgrower schemes, the failure and departure of an investor can leave local communities struggling to find alternative means to ensure food security. One investor in Mozambique had to reduce permanent employee numbers and was three years behind schedule due to the withdrawal of a key financier during the implementation phase. It also had to put a planned smallholder scheme on hold. On the other hand, an investor that successfully developed an outgrower scheme in Cambodia was able to move from semi-processing in the host country to establishment of full-scale processing and export operations, generating further employment, value added, and export revenue for the host country-with significant benefits for food security.

Overall, research indicated a wide range in the extent to which investors contributed to food security, depending on the business model, crop, target market, integration with the local economy, approaches to social and environmental responsibility, and the financial success of the investment. 


\section{POLICY APPROACHES}

How can policy help to maximize the food security contribution of international investments and minimize the associated risks?

NATIONAL DEVELOPMENT STRATEGY. Although international investment in agriculture and related value chains is not a panacea that can deliver food security and nutrition alone, international investment can play a key role in providing demonstration effects, enhancing productivity through technology, and catalyzing market access. But its role in boosting food security must be part of a broader nationally appropriate development strategy. The critical factor is to align food security and nutrition targets with the broader national development strategy and to be selective about the type of international investment desired.

\section{INVESTMENT PROMOTION AND FACILITATION.}

There is a case for targeted agricultural investments in remote and food-insecure areas that may not appear attractive to international investors. Boosting investor interest in these areas will require investment promotion and facilitation in food-insecure regions, coordinated by central governments and attentive to the needs of regions and local communities. This might include fiscal, financial, and technical support through "sustainability-based" incentives aimed at promoting investment conditional on its sustainable development impact. ${ }^{11}$ Some countries have sought to develop and market a pipeline of bankable projects in agricultural growth poles or corridors such as the Bagrépôle in Burkina Faso and the Southern Agricultural Growth Corridor of Tanzania. ${ }^{12}$

Investment in either staple or cash crops could generate employment or incomes for food insecure people, improving food access. Investment in staple crops would have the additional advantage of improving local and national food availability. With increasing urbanization in developing countries, potential exists for investors to consider production of domestically consumed crops. At the same time, it must be recognized that in some areas the underlying reason for food insecurity-such as conflict or extreme drought-cannot be addressed through investment and requires other strategies.
RURAL INFRASTRUCTURE. Investment in remote areas, and indeed all agricultural investments, must be supported by adequate rural infrastructure to enable investors to run their operations and transport produce to market. While examples exist of multinational enterprises' investing in infrastructure facilities that benefit farmers and promote rural development, rural infrastructure remains inadequate in many developing countries. Improving infrastructure will require promotion of public-private partnerships for agro-infrastructure, including power, irrigation, transport, and storage networks.

DIGITAL ECONOMY. A further critical component of the commercialization and modernization of agriculture sectors is access to digital technology for farmers and domestic agribusinesses. Agriculture in developing countries is becoming increasingly integrated with the digital economy. Farmers can use mobile phones and applications to access information on weather and climatic conditions, to find market prices, to hire equipment, and to link with customers and suppliers along the value chain. ${ }^{13}$ Digital adoption remains low in countries where food insecurity is most prevalent: in developing countries as a whole, 70 percent of the population has $3 \mathrm{G}$ broadband coverage, but only 40 percent uses the internet; in the least developed countries, 50 percent has coverage, but usage is only 13 percent. ${ }^{14}$ Developing countries should enact policies that speed up digital adoption in the wider economy, through investment in infrastructure and in skills development for farmers to increase adoption and use of digital technology and services.

RESPONSIBLE INVESTMENT PRINCIPLES. More broadly, the impact of investments on food security depends on investors' approach to social and environmental responsibility. For foreign investments to make a positive contribution to reducing food insecurity, both good governance by host country governments and responsible behavior by investors are necessary. Ensuring responsible behavior calls for practical implementation of responsible agricultural investment principles. Several sets of principles have been devised; the challenge for investors and host governments is how to apply these on the ground in day-to-day decision making. To this end, UNCTAD and the World Bank produced a series of guidance notes for use by private investors and governments that are relevant to specific issues, including food security and nutrition. ${ }^{15}$ 
INVESTOR SCREENING AND MONITORING. A critical element of ensuring responsible investment is improving host country governments' ability to screen and select among prospective investors. Government screening procedures were often underresourced and lacked capacity to assess the viability of business plans. Screening and selection of prospective investments is a critical component of countries' policy frameworks, intended to ensure that investments maximize social, economic, and environmental benefits while minimizing risks. Screening should verify that a proposed investment aligns with national food security strategies, that it has a viable business model to be run by competent management, and that the investor takes its social and environmental responsibilities seriously. Screening should consider the full range of potential food security impacts of an investment. The UNCTADWorld Bank guidance notes, mentioned above, provide detailed advice on how governments can improve screening and monitoring procedures.

INCLUSIVE BUSINESS MODELS. Preference should be given to business models that employ contract farming or outgrower schemes, as opposed to large-scale, estate-style models. Support from international investors to small-scale producers-through training, provision of inputs, and access to financeis a key mechanism for achieving the SDG target of doubling agricultural productivity among smallholders. These inclusive business models link small-scale producers with global value chains and increase rural incomes, provided the schemes are designed in a fair and transparent manner. Support for cooperative arrangements among outgrowers can improve economies of scale and collective bargaining power, redressing to some extent the power differential between investors and producers. Governments, in partnership with international development agencies, can help to develop model contracts between investors and outgrowers or cooperatives, with a view to safeguarding the interests of smallholders.

WOMEN'S EMPOWERMENT AND VULNERABLE GROUPS. Progress in women's empowerment and gender equality is strongly correlated with improved nutrition. ${ }^{16}$ Given these multiple benefits, priority should be given to investments that have a positive impact on women's empowerment, by providing training, integrating women into the workforce, facilitating their participation in outgrower schemes, and giving them a voice in decision-making and consultative forums. Attention should likewise be given to improving the position of other vulnerable groups, such as youth and pastoralists.

DATA AND RESEARCH. Finally, more detailed and comparable data are needed on the patterns and impact of international investment. Official data are not available on a sectoral level for many countries, and international investment deals are often conducted without public transparency. Data sources often rely on media reports that have proved inaccurate. The international community should develop a data collection consortium to improve data on investments in agriculture. Further research is also needed to analyze the impacts of international investments on food security and increase understanding of how best to design policies to maximize positive impacts and minimize negative ones. 


\section{CHAPTER 5}

\section{MIGRATION}

\section{Tightening Borders and Threats to Food Security}

\section{ALAN DE BRAUW AND KATE AMBLER}

Alan de Brauw is a senior research fellow and Kate Ambler is a research fellow, Markets, Trade, and Institutions Division, International Food Policy Research Institute, Washington, DC, USA.

\section{KEY FINDINGS}

- Politically motivated arguments for immigration restrictions are increasingly common but not supported by evidence on economic and employment impacts, crime, or fiscal costs associated with migrants.

- Voluntary migration can improve food security both for migrants and for the families left behind by raising incomes and reducing pressure on resources. Migration provides a critical option for poor rural and urban families.

- Conflict is driving increasing involuntary migration. Despite concerns, refugee camps can benefit local communities by stimulating incomes and entrepreneurial activity.

- Further research is needed on the links between migration and food security, but evidence suggests a net positive impact for migrants, their families, and the communities accepting migrants.

\section{KEY RECOMMENDATIONS}

- Improve mechanisms for seasonal migration. Helping farmers to migrate within countries to find alternative work during the lean season can boost food security.

- Reduce international migration costs at the source. In the face of increasing restrictions abroad, migrant source countries can lower domestic obstacles to migration and support participation of members of poor communities in legal migrant work programs.

- Develop innovative financial products to facilitate migration. Migration can be costly, but new technologies and related financial products may offer ways to lower costs for the poor.

- Intensify use of technology to improve services before and during crises. New information and communication technologies are improving early warning systems and management of crises and refugee camps. 


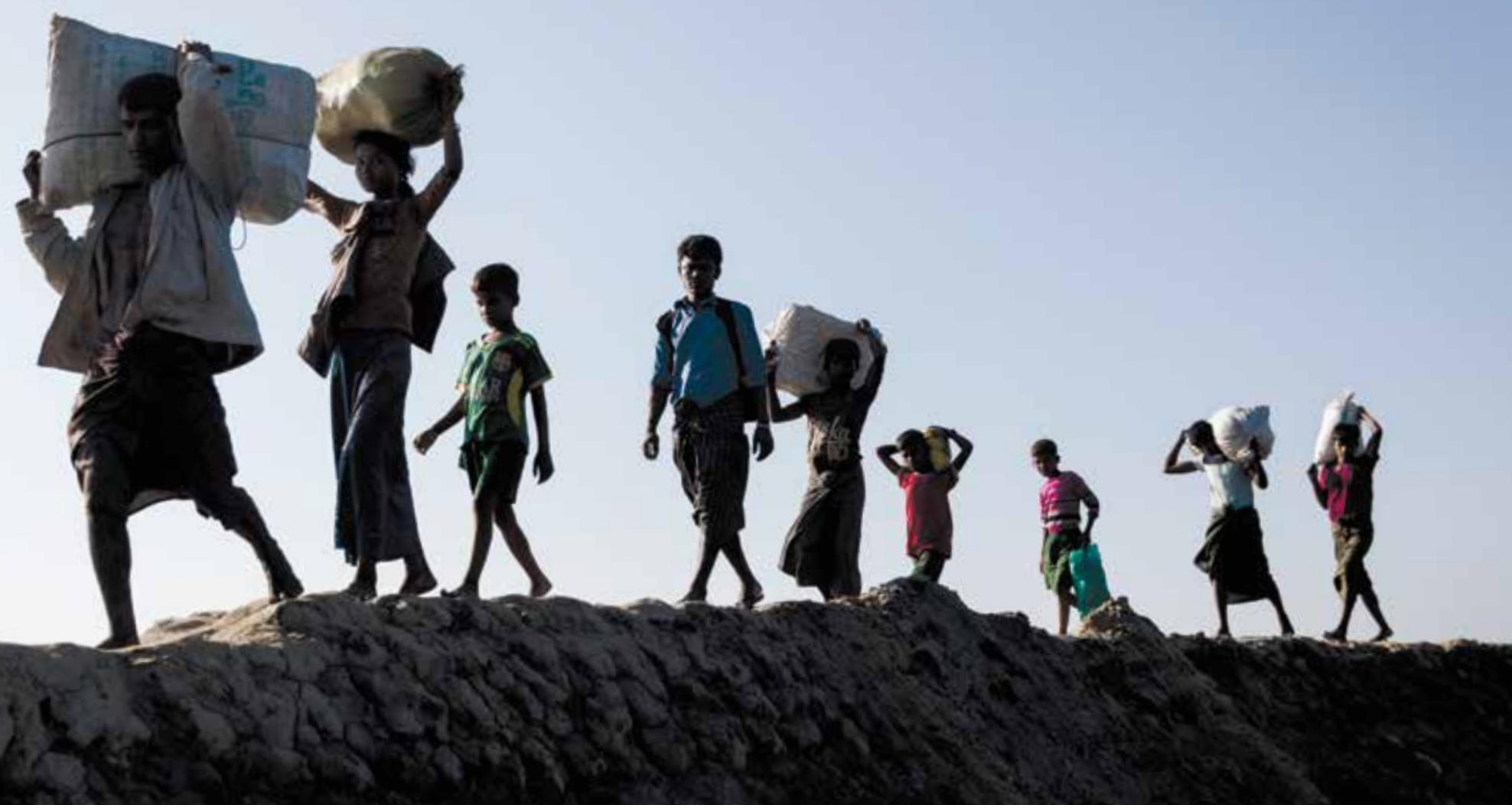

Recent changes in the political landscape in the United Kingdom and the United States have put tighter borders and migration restrictions on the agenda. ${ }^{1}$ Concerns about unchecked migration have also risen in mainland Europe, as migration by boat to Italy from Libya grew rapidly after civil war broke out in the country in 2014. Meanwhile, protracted violence in Central America, the Middle East, and the Lake Chad basin has led to increasing flows of people out of their homes and farms into internally displaced persons (IDP) camps and refugee camps in neighboring countries. Governments in receiving countries have responded to the increasing voluntary and involuntary movement of people out of developing countries and conflict zones either by raising the rhetoric on border enforcement or reducing the number of voluntary migrants and of refugees they are willing to absorb. Yet overall flows of refugees, or forced migrants, may increase in the future. Models of climate change suggest that environmental displacement will increase pressure for migration from environmentally threatened areas of developing countries. ${ }^{2}$ And while accurately predicting migratory responses to either environmental degradation or climate change is difficult, recent work definitively links temperature changes to changing migration patterns across countries. ${ }^{3}$

\section{MIGRATION AND TIGHTENING BORDERS}

When borders are tightened, food and nutrition security are potentially threatened in several ways. First, it is well established that migrants who leave voluntarily enjoy higher living standards after they migrate. ${ }^{4}$ Migrants who were food insecure prior to leaving therefore have a better chance of being food secure postmigration; restrictions on migration would leave them food insecure. Second, households that migrants leave-source households-also tend to become better off on a per capita basis as a consequence of migration. This improvement occurs either because of remittances sent home by migrants or because the gain in consumption on a per capita basis outweighs the loss in household production. If family members cannot migrate, such households are more likely to be food insecure. Third, in the context of forced migration, reduced opportunities for permanent resettlement can expose refugees to prolonged food or nutrition insecurity and strain donor resources used to support IDP and refugee camps in protracted crises.

Though in theory a clear connection should exist between migration and food and nutrition 
security, the literature does not explicitly link the two concepts. Research on migration tends to neglect food security outcomes, while the food security research tends to neglect migration. ${ }^{5}$ From the perspective of migration analysis, it is difficult to demonstrate how migration affects food security for those who leave or for those left behind, as unobservable factors affecting the migration decision may also affect food security. ${ }^{6}$ From the perspective of food security analysis, many of the surveys that collect information on food security at the national level neglect international migration because it is a "rare event" and not deemed sufficiently important to include in either censuses or labor force surveys. ${ }^{7}$

Here, we look at what we know about the links between migration and food security, evaluate the political rationale for immigration restrictions, and consider the implications for voluntary and involuntary migration and food and nutrition security.

\section{THE "RATIONALE" FOR TIGHTENING BORDERS}

Proponents of increased restrictions on immigration and refugee resettlement make three main arguments. First, they are concerned that increasing immigration and refugee populations will reduce the wages of native workers. Evidence suggests that the size of the migration flow mattersonly quite large refugee flows appear to negatively affect outcomes in labor markets among natives. For example, the Mariel boatlift in 1980, an influx of Cuban refugees into Miami that increased the labor market by about 7 percent, did not affect natives' wages, even among high school dropouts. ${ }^{8}$ Substantially larger refugee flows, however, can affect employment outcomes among natives. Preliminary research demonstrates that the influx of Syrian refugees into Turkey, numbering 1.7 million by mid-2015, displaced natives from the informal sector, while increasing formal-sector opportunities among less-educated native men. ${ }^{9}$ Similarly, in Colombia, the displacement of rural residents from conflict-affected areas to urban areas led to lower wages among unskilled workers in cities unaffected by violence, as the share of internally displaced workers in the urban labor force rose as high as 12 percent. ${ }^{10}$ However, immigration can have positive effects on wages among subgroups of the population; for example, the notable increase in women's participation in the US labor force over the past 50 years might not have been possible without immigrants available to provide labor for domestic tasks. ${ }^{11}$

A second argument relates to immigrants and crime. Proponents of restrictions suggest that immigrants and refugees commit more crimes, and public opinion is often swayed to this belief. ${ }^{12}$ The fear that refugees and other immigrants may be linked to terrorist organizations has exacerbated this concern. Studies in both the United States and the United Kingdom suggest small increases in property crime but no differences in other crime rates as a result of immigration. In the United States, perhaps the best available study uses a policy change in Arizona to examine the impact on crime of a reduction in the presence of Mexican immigrants. Immigrants were found to be associated with increased property crime, but this effect can be almost fully explained by the gender and age composition of Mexican immigrants in Arizona, who are predominantly young and male. ${ }^{13}$ Similarly, a study of two immigration waves into the United Kingdom from Eastern Europe found only a small increase in property crime after the first wave and a decline following the second wave. ${ }^{14}$ Moreover, there is no evidence to substantiate the notion that immigrants have a greater proclivity to engage in terrorist attacks than other citizens.

Third, proponents of restricting immigration and refugee resettlement point to the fiscal costs of immigration, often neglecting the tax contributions made by immigrants. Since 1995, immigrants as a group have made a positive fiscal contribution to the United Kingdom, while natives, on net, cost the government more than they pay in taxes. ${ }^{15}$ In the United States, a 2017 report prepared by the Department of Health and Human Services, but not released by the current administration, estimated the 10-year net benefit of refugees to the US economy at US\$63 billion; much of that benefit is attributable to long-term refugees who come from countries such as Viet Nam and Cambodia and earn on par with natives. ${ }^{16}$ Finally, a consensus report from the US National Academies of Sciences, Engineering, and Medicine concludes that immigrants not only add to fiscal revenues but also help to grow the overall economy. ${ }^{17}$ Clearly migrants and refugees can be positive contributors to their destination countries over time. 
FIGURE 1 Proportion of international migrants from rural areas, selected countries

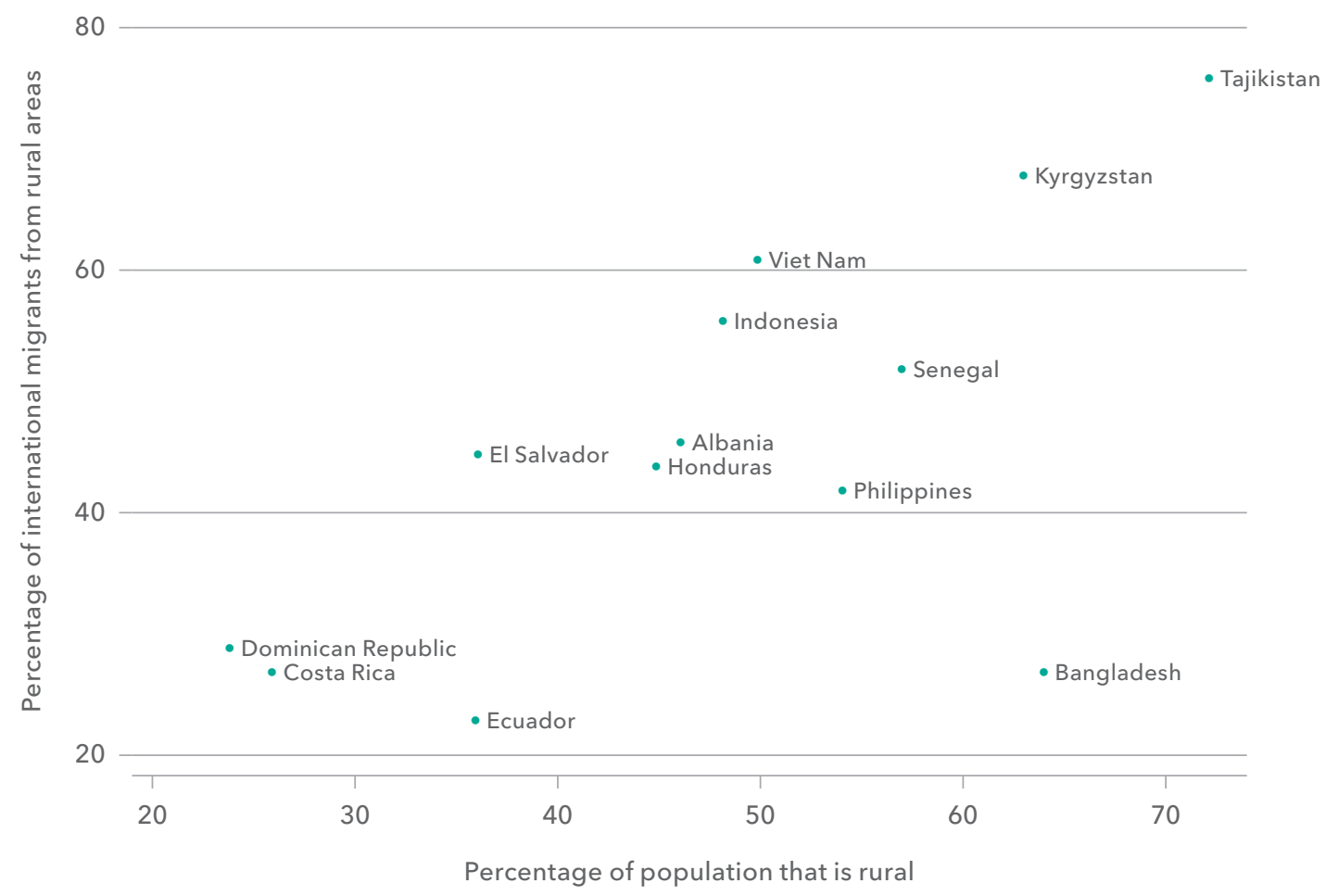

Source: A. de Brauw, "Migration and Development: Implications for Rural Areas," presentation prepared for the JRC-IFPRI Conference on Food and Nutrition Security Measurement, Brussels, November 2017.

\section{VOLUNTARY MIGRATION}

Linking voluntary international migration to food and nutrition insecurity is complex. Although both urban and rural areas are affected by voluntary migration, poverty and undernutrition, precursors of food insecurity, are concentrated globally in rural areas. ${ }^{18}$ However, the effect of emigration on food security in rural areas is often overlooked due to the preconception that international migrants tend to come from urban areas. To estimate the share of migrants from rural areas, we compiled 13 comprehensive data sources from developing countries that include information about family members living abroad. ${ }^{19}$ In general, with the exception of Bangladesh, the proportion of migrants who left rural areas for international destinations was roughly equivalent to the proportion of the population living in rural areas (Figure 1), meaning that international migration is clearly linked to rural poverty.

Decisions made by rural households to send out migrants are interrelated with other decisions that affect their food security. ${ }^{20}$ Households must weigh the expected benefits of migration against all the costs, including financial, psychic, and job-search costs. Among households at risk of food insecurity, those costs may be substantial and difficult to overcome, particularly for international migration. ${ }^{21}$ Once a rural household member leaves, his or her labor is no longer available for household agricultural production; however, remittances sent back by migrants may compensate for that loss and can be used for consumption or invested in agricultural or nonagricultural production. Remittances may arrive with a time lag as migrants establish themselves and pay off loans related to the journey. Thus the impacts on food security and nutrition are complex for source households, particularly as rural households receiving remittances may substitute food purchases for home production.

Establishing a causal link between migration and improved food and nutrition security requires several steps. ${ }^{22}$ The first is to show that migration affects household agricultural production or incomes among source households, depending on whether households rely primarily on their own production 
or on markets for food. Next, it must be shown that either increased production or income leads to increased food consumption on a per capita basis; households may choose to sell any production in excess of consumption needs, or to save any additional income generated through migration, rather than boosting consumption. If regular food shortfalls occur during the year, the increase in income may not be enough to increase food and nutrition security; additional income or product must be available during times when households normally fall short of food.

In fact, little direct evidence links migration and standard measures of food security. However, the available indirect evidence in countries with high levels of food insecurity suggests that, across several different contexts, migration leads to greater food security among those who are left behind when migrants voluntarily leave households. For example, in Guatemala and El Salvador, stunting prevalence among children under five appears to be lower among migrant source households than non-source households. ${ }^{23}$ A study from Tajikistan suggests that left-behind members of source households have higher per capita kilocalorie consumption than non-source households. ${ }^{24}$ International migration likewise tends to increase the incomes of source households, largely through remittances. ${ }^{25}$

Internal migration can also increase food security. A program that gave food-insecure households in northwest Bangladesh money for bus ticketsless than US\$9 per potential migrant-during the hungry season led to permanent increases in seasonal migration as well as in per capita consumption among migrant households. ${ }^{26}$ However, because migration entails large costs, the poorest of the poor are often unable to leave, limiting the scope of impact on food security despite increases in consumption among the better-off poor households.

Tightening restrictions on migration only serves to increase both monetary and nonmonetary migration costs, with monetary costs disproportionately affecting those potential migrants with the fewest resources. Increasing migration costs to specific destinations would either reduce the migration rate among relatively poor potential migrants, or change the set of potential destinations for these households. To illustrate, Figure 2 shows the propensity

FIGURE 2 Household income and probability of international migration, Bangladesh

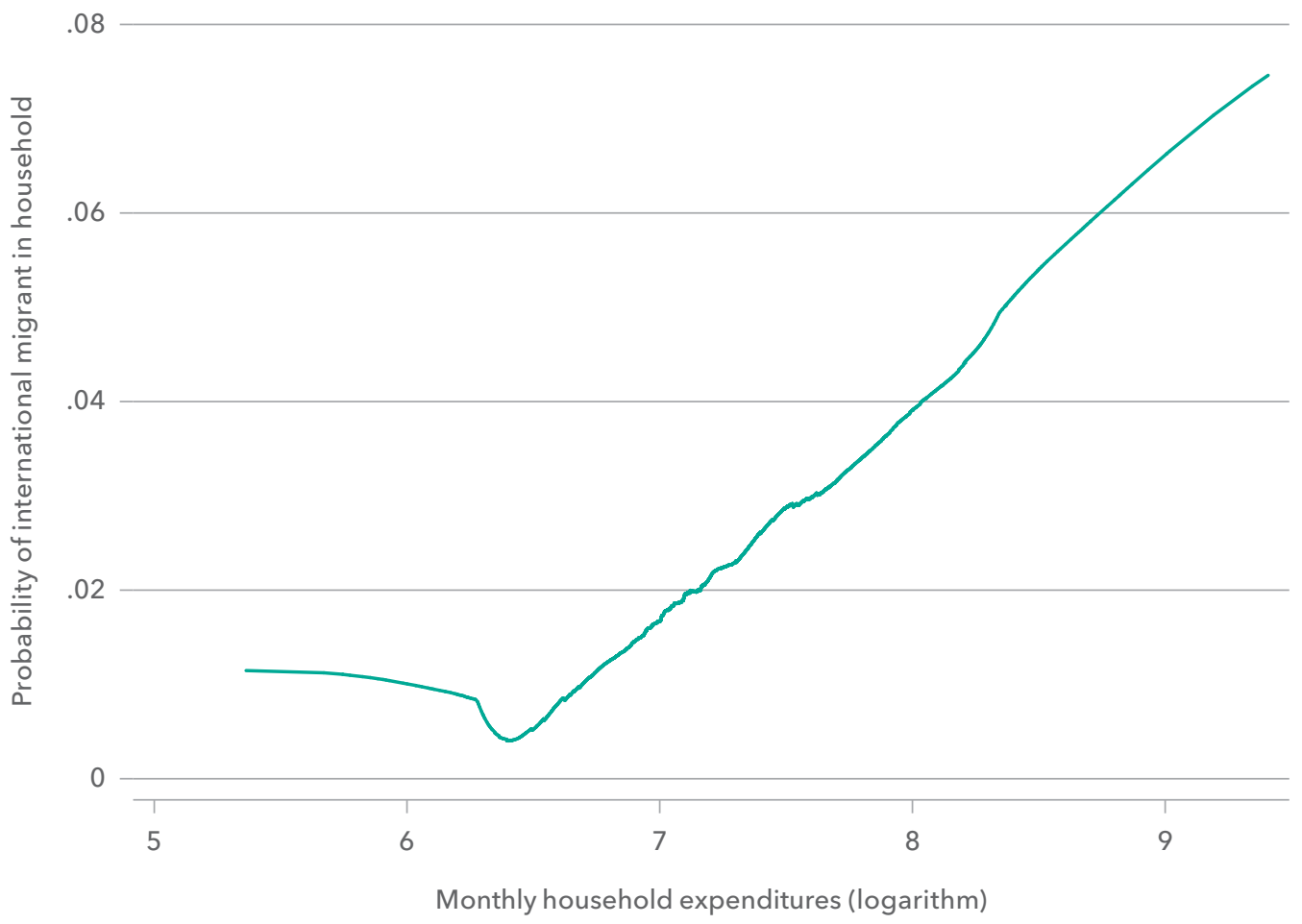

Source: Authors, based on data from the Bangladesh Integrated Household Survey 2015. 
to migrate from rural Bangladeshi households; the probability is low for the poorest households and then increases rapidly at higher income levels. If migration costs were to rise, the entire curve would shift to the right, reflecting greater difficulty for people from relatively poor households to migrate, and therefore potentially increasing the incidence of food insecurity.

Important migrant flows that affect food security in source countries are those from Central America to the United States and from South Asia to the Middle East. In migrant source countries with large remittance inflows, such as Bangladesh, El Salvador, and Guatemala, between 10 and 15 percent of the population is considered food insecure. Increased migration restrictions imposed by the primary host countries could exacerbate food insecurity. ${ }^{27}$ Proposed increases in the forced removal of migrants already abroad, particularly in the United States, would only exacerbate these negative impacts, as rural source communities would have to absorb returning migrants while no longer receiving remittances.

\section{INVOLUNTARY MIGRATION}

The number of refugees and IDPs doubled between 2007 and 2016, to around 64 million people. ${ }^{28}$ In the presence of conflict, people risk personal or familial safety if they choose to stay. But if they choose to leave, they might face dramatic uncertainty about their food and nutrition security, at least in the short term. Of course, food insecurity can also play an important role in sparking conflicts in the first place. ${ }^{29}$ When conflicts arise and people begin to flee, the United Nations is called upon to provide food and/or cash aid to refugees to mitigate food and nutrition security risks. As emergency food aid is planned and distributed, it can have both a direct effect, which is a transfer, and an indirect "insurance" effect, as the anticipated aid effectively ensures food security. ${ }^{30}$ As the world's displaced population has grown, more crises have become protracted, stretching the resources required to stave off food insecurity among refugees. Donor fatigue can set in, creating greater risk of food insecurity. One solution is to integrate more refugees into economies able to absorb them through resettlement programs; however, this requires countries willing to receive those refugees.
Given the proposed and existing restrictions on refugee resettlement programs, a primary policy question for developing country governments that host refugee or IDP camps is whether these camps increase or reduce food insecurity among local residents. Despite concerns that refugee camps may stretch local resources, studies suggest that the camps stimulate incomes and entrepreneurial activity among locals living nearby. Research on Kagera, Tanzania, which hosted refugees from Rwanda and Burundi, found that proximity to camps was welfare-increasing on average, though agricultural wage workers faced additional competition for jobs. ${ }^{31}$ Similarly, Kenyans within 10 kilometers of the Kakuma refugee camp in northwest Kenya have a consumption rate that is 25 percent higher than similar Kenyans who live farther from the camp. ${ }^{32}$ And models of two refugee camps in Uganda suggest that potentially substantial economic benefits arise among households within 15 kilometers of the camps. $^{33}$ In the Kenya and Uganda studies, food aid provided by the World Food Programme factors into the impact of the camps on nearby households; these benefits create employment and therefore increase economic activity among both refugees and locals. Without such aid, local economies could suffer.

\section{WHAT CAN BE DONE?}

The perception of migrants is increasingly negative in receiving areas, whether for economic reasons or not, and politicians in some migrant destinations are either reducing or threatening to reduce immigration and the acceptance of refugees. Migration restrictions will raise the cost of migrating to some destinations, so that, in the short term, poorer, less food-secure households will be less able to send out voluntary migrants. Restrictions on the resettlement of refugees could lead to prolonged stays in camps or returns to unsafe situations where food insecurity is high. In the current global political climate, what can be done to mitigate these effects and support the food security benefits of migration?

\section{IMPROVE MECHANISMS FOR SEASONAL MIGRATION}

Among farmers who are food insecure, the value of their labor on the farm fluctuates with the agricultural season. There are times during the year when agricultural laborers can leave the farm with little or no consequence for farm productivity. One policy 
option is to promote seasonal migration, as in the successful experiment in northwest Bangladesh. ${ }^{34}$ Evidence Action, an international nongovernmental organization, is currently testing a scaled-up version of this program in both Bangladesh and Indonesia, providing a US $\$ 20$ transportation subsidy to farmers to catalyze migration during the lean season. ${ }^{35}$ Seasonal internal migration is not subject to the same political challenges as international migration, but can offer many of the same benefits. In addition, nongovernmental actors could implement similar programs designed to make existing cross-border seasonal migration programs, such as New Zealand's Recognised Seasonal Employer program, more accessible to food-insecure households.

\section{REDUCE INTERNATIONAL MIGRATION COSTS AT} THE SOURCE

While developed countries may seek to restrict migration from developing countries in the near future, developing countries can act unilaterally to increase access to migration opportunities for their most vulnerable residents. Bureaucratic obstacles such as high passport costs can be removed. And in countries such as the Philippines that operate legal contract-work programs with countries with labor shortages, migrant recruiters could be required to also target relatively poor rural areas. ${ }^{36}$

\section{DEVELOP INNOVATIVE FINANCIAL PRODUCTS TO FACILITATE MIGRATION}

Costs related to directly financing migration and initial adaptation to the destination may limit the ability of food-insecure households to pursue migration as a coping strategy. Migrants must often turn to costly informal channels to finance these expenses, yet new migration restrictions will only serve to increase such expenses. Due to reduced costs both of managing accounts through mobile phones and of monitoring credit, it is now possible for financial service providers to develop new products. Mobile technology can also be harnessed to allow migrants to remain better connected to their home country, which would allow poorer potential migrants access to necessary capital at a lower cost.

\section{INTENSIFY USE OF ICT TO IMPROVE SERVICES BEFORE AND DURING CRISES}

Resources for forced migrants and refugees are not likely to increase in the near future, so it is essential to be as efficient as possible in providing aid to refugees in need. Newer information and communication technologies (ICTs), such as remote sensing, data collection on mobile phones, and improved connectivity, can be used both to help warn of crises before they occur and to manage them after they occur. The integration of early warning systems and social protection can help mitigate crises before they occur. ${ }^{37}$ Developing improved methods of tracking resource use and flows into or out of IDP or refugee camps can contribute to better standards of living and improved nutrition for long-term camp residents. These strategies can also increase the capacity of camps in terms of number of refugees and quality of services offered in situations where opportunities for permanent resettlement are limited. ICT use need not be limited to tracking flows of people and resources; technology can be used to improve management and monitoring of crises and responses more broadly. 
"Politically motivated arguments for immigration restrictions are increasingly common but are not supported by evidence on economic and employment impacts, crime, or fiscal costs associated with migrants." 


\title{
Achieving Food and Nutrition Security through Open Access Data
}

\author{
INDIRA YERRAMAREDDY AND SURESH CHANDRA BABU
}

Indira Yerramareddy is the manager for Knowledge Management and Web, Communications and Public Affairs Division, and Suresh Chandra Babu is a senior research fellow and head of the Capacity Strengthening Program, International Food Policy Research Institute, Washington, DC, USA.

\section{KEY FINDINGS}

- Open data can improve the performance of food systems and help achieve global food and nutrition security.

- Accessible data are critical for decision making, from the farm to the retail level of food systems.

- Open data increase both the visibility and utility of research, allowing researchers to create more knowledge products and support decision making.

- Open data allow governments to make evidence-based policy decisions and push governments toward increased accountability.

- Data quality and ease of use are essential for putting data to use, but datasets are often too large or complex to be easily handled.

- Inequality in access to knowledge is increasing. Data policies, commitments, and investments can improve access to and use of knowledge, but current commitment and action on open data are uneven.

\section{KEY RECOMMENDATIONS}

- Democratize data access and improve livelihoods by putting data tools, such as mobile-phone apps, into farmers' hands.

- Increase the efficiency of knowledge transfers to prevent loss of information and ensure uptake in the field.

- Make government "big data" public to drive high-quality analysis of food systems and better policy and decision making.

- Build open data initiatives, including to reduce inequality and address issues of data quality, use, storage, and dissemination.

- Increase data quality and ease of use through better data collection, new tools, working groups, capacity building, and improvements in big data platforms.

- Empower citizen stakeholders to demand open data through capacity building and access to data tools. 

can also address the information asymmetries within markets that can put farmers' operations, especially smallholder farmers, at a disadvantage. When price data are openly available, for example, farmers can obtain more affordable inputs and sell their produce for the best farmgate price.

Open data and knowledge have been shown to increase both the visibility and utility of research. ${ }^{4}$ Researchers can use data to create more knowledge products, conduct cross-sectoral studies, and support decision making. Government leaders benefit from having more evidence available to inform policy making and can avoid decision making based on assumptions or "gut feelings." During natural and manmade emergencies, data availability can significantly improve the timeliness and appropriateness of humanitarian responses.

In Malawi, for example, droughts resulted in a food security emergency in 2015-2016. A vulnerability assessment was conducted in May 2016 to understand the extent of the crisis and to collect information on the performance of food markets across the country. The assessment showed that 6.5 million people (later updated to 6.7 million) were affected by drought in Malawi. Food security and nutrition monitoring systems that collect, process, analyze, and openly share data can improve food and nutrition security in such situations. Currently, much of the data collected for emergency purposes are not shared through open data systems, delaying interventions and increasing the vulnerability of affected populations. ${ }^{5}$

Open access policies help push governments toward increased transparency and accountability. For example, India's Right to Information Act of 2005 requires that citizens have access to information regarding constitutional authorities, including the executive, legislature, and judiciary. Information obtained through this act is claimed to have revealed that shopkeepers and food grain officers had siphoned off 87 percent of wheat and 94 percent of rice from a food program meant for the poor-findings that prompted significant reforms. ${ }^{6}$

\section{CHALLENGES IN ACCESSING AND USING DATA}

Many governments and international organizations are working to make knowledge and data freely and easily available, but challenges remain to open access. Developing countries, in particular, are hampered by a lack of infrastructure and capacity to support data collection, processing, and management, all necessary to ensure data quality. They also face limited standardization of data collection formats needed to make data easier to compare and aggregate. ${ }^{7}$ A cornerstone of open access must be reducing the knowledge inequality within and among societies that arises from both lack of access and lack of capacity to make use of the world's growing store of knowledge and data.

\section{MAINTAINING DATA QUALITY}

Exchange of knowledge and data between the global, national, and local levels is essential to putting it to use. However, information and data quality can be lost as knowledge flows from one level to another. For example, inaccurate or incomplete transfer of knowledge to farmers can reduce its usefulness. Likewise, aggregation of data that are not standardized can be problematic. Preserving and enhancing data quality is critical for improving production and livelihoods and for credible policy making.

For example, the National Food Balance Sheets of the Food and Agriculture Organization of the United Nations (FAO) are compiled at the country level and aggregated to provide insight into global trends. The data sheets provide essential information on a country's food system, including trends in domestic food supply, use of commodities, and changes in the types of food consumed, and reveal whether a country's food supply is adequate to meet nutritional requirements. ${ }^{8}$ However, data collection for the Food Balance Sheets varies widely from country to country, and because there is no standardization, cross-national comparisons can be misleading. Thus, even when data are openly available, poor quality or other limitations can decrease their utility. ${ }^{9}$

\section{EASE OF USE}

Access to knowledge and data depends not only on availability but also ease of use. The national surveys conducted by many countries provide a clear example. Even when these extensive sets of primary socioeconomic data are open, access is severely limited by the difficulty of using the large datasets. Often datasets available to individuals and researchers are so large and complex that they cannot be handled efficiently using traditional data-processing tools. India's National Sample 
Survey Organization, which since 1950 has conducted large-scale surveys to provide data needed for national income estimation, is one example. In addition to making such individual datasets readily accessible, there is a growing need to make these datasets interoperable or machine readable so that they can be combined with other datasets to produce new insights on food and nutrition security and poverty reduction. Considering the large investments made in conducting national surveys, and the potential usefulness of the data for many stakeholders, the datasets should be made easier to use to ensure they are accessible to all.

\section{REDUCING KNOWLEDGE INEQUALITY}

Increasing ease of access and use is central to reducing the inequality of knowledge between developed and developing countries. In the past few decades, a vast amount of raw data has been made available for further exploration by stakeholders working on improving food and nutrition security. However, while open access to data has increased, limited infrastructure means that data are not available to users in developing countries at the same speed as in developed countries. As the world continues to digitize, knowledge inequality is actually increasing. According to Data.gov, a US government website that aims to make government more open and accountable through open data, 53 countries in the developed and developing world have set up national open data platforms. ${ }^{10}$ However, open data initiatives are still limited in developing countries as a result of technological, economic, political, and social barriers. In the words of the Open Data Charter, more timely access to data would help increase food security globally by "enabling better decision making, transparency and innovation." ${ }^{11}$

\section{PROGRESS TOWARD OPEN DATA}

Democratization of data access is the key to evidence-based decision making for stakeholders ranging from farmers to policy makers. Broad consensus exists among stakeholders-including among governments, development institutions, research organizations and universities, publishers, and nonprofit and civil society organizations-that opening data access is a critical step toward attaining the Sustainable Development Goals. Yet while open data have been widely identified as a priority, commitment and action remain uneven. Some organizations are making substantial investments in open data. The Bill \& Melinda Gates Foundation, for example, makes its data freely available immediately and without restrictions. Several international organizations, including the World Bank, CGIAR centers (including the International Food Policy Research Institute [IFPRI]), and United Nations' agencies such as $\mathrm{FAO}$, are moving quickly toward open data but are yet to be fully FAIR-compliant-that is, findable, accessible, interoperable, and re-usable. Other institutions have shown less commitment to open data. But even among those that have made open data a priority, efforts to translate that commitment into action have been limited (Table 1).

Some countries have been in the vanguard in making data more accessible, taking steps to connect individuals directly with the knowledge and data they require. The Katalyst program in Bangladesh aims to increase household incomes across sectors, including agriculture. As part of the program, the Soil Resource Development Institute of the Ministry of Agriculture analyzed soil-sample data in various locations and for different crops. This information was used to develop recommendations for farmers on fertilizers, in order to optimize their use of inputs and improve yields. In collaboration with Banglalink and Grameen Phone, the Katalyst program launched a mobile-based fertilizer information service in the local language, Bangla. Since the program's inception in 2009, it is claimed that farmers have experienced up to a 25 percent reduction in fertilizer costs and up to a 15 percent increase in crop yields. ${ }^{12}$ Based on this apparent success, Katalyst is launching a similar project to provide irrigation-related information.

In Peru, access to information about weather and climate patterns is expensive and limited. Data collected by the government cover only a small portion of the country. Capitalizing on Peru's large number of mobile-phone users, the Institute for University Cooperation (Istituto per la Cooperazione Universitaria Onlus), an Italian nongovernmental organization, developed a mobile platform that permits widespread sharing of information on climate and irrigation at a low cost. Farmers have access to relevant information on their crops based on climate, meteorological, and soil data. ${ }^{13}$ 


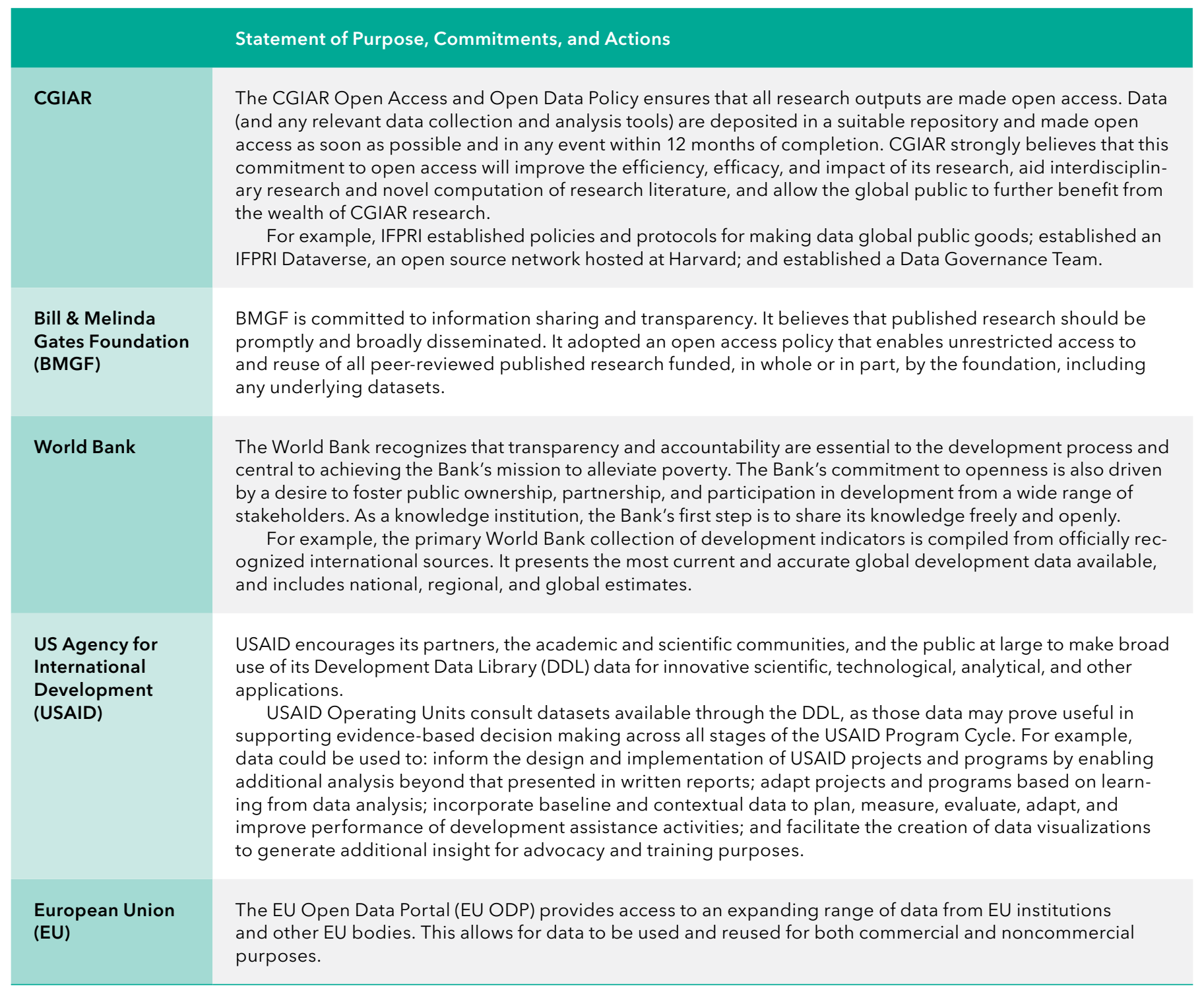

Source: Authors' compilation.

Colombia's Ministry of Agriculture and the International Center for Tropical Agriculture worked together from 2007 to 2013 to identify what was causing reductions in rice crop yields. Using both open and private data, they developed climate-smart tools that were made available to all farmers. Giving farmers access to these knowledge resources helped them avoid extreme damage from a subsequent drought and was estimated to have saved farmers about US $\$ 3.6$ million. $^{14}$

Other countries are working to scale up information and communication technologies and are promoting the use of open-source knowledge and information flows within their borders and with other countries. India's Public Distribution System has become more cost-effective and transparent with the adoption of a computerized system-consumers receive individual identification cards that they can use at any ration shop to purchase subsidized groceries. Data collected on these transactions are recorded and can be used to analyze the amount of stock a shop owner receives and disburses and who purchases the rations, as well as to identify duplicate cards. ${ }^{15}$ Computerized monitoring of the supply and distribution of food grains ensures a more cost-effective system and reduces the opportunities for corruption in this distribution system. ${ }^{16}$ 


\section{NEXT STEPS}

Data policies, commitments, and action to promote openness, capacity building, technologies, and other assets have the power to reduce knowledge inequality and improve access to and use of knowledge. Together these can contribute to better livelihoods and food security. A few investments can make a big difference.

PUT DATA TOOLS IN FARMERS' HANDS. Simple steps can enhance the use of data by making them available in easily downloadable formats. The number of cell phone and smartphone users has dramatically increased in developing counties; in Africa south of the Sahara, more than 60 percent of the population now has access to mobile phones. Because mobile phones are cheap, easy to use, and require only limited literacy, mobile applications can be powerful mechanisms for increasing data accessibility. Some initiatives have begun. For example, the government of India created several mobile apps-AgriMarket, Kisan Suvidha, and Crop Insurance-for the benefit of farmers. These user-friendly apps can help reduce the digital divide among and within countries.

EMPOWER STAKEHOLDERS. TO overcome knowledge and data access inequality, citizens must demand open data. Data curators can promote the use of open data and help get data into the hands of stakeholders, for example, by sharing data through well-targeted tweeting, press releases, website announcements, and email distributions; catering messages to target audiences; and choosing the right Open License for data. ${ }^{17}$ Data users can also be empowered through capacity building, including trainings and tools for analysis, such as open access software, and support for information and communications infrastructure to enhance easy access.

IMPROVE KNOWLEDGE TRANSFERS. Increasing the efficiency of knowledge transfers can prevent loss of information during the process. A study in Malawi looked at the knowledge transmission chain from researchers to agricultural extension agents to "lead" farmers to other farmers, and suggested that the greatest loss of information was in the transfer from extension agents to lead farmers, potentially due to agents' and farmers' lack of attention. ${ }^{18} \mathrm{New}$ options are available for knowledge transfer-Digital Green, for example, is a nonprofit organization that trains farmers through videos. ${ }^{19}$
MAKE GOVERNMENT DATA PUBLIC. National governments collect the bulk of data related to food systems. However, national systems are slow to make the information public and many countries place restrictions on the use of this kind of data. If made openly accessible to the public, this "big data" could drive high-quality analyses of food systems and better decision making. India's National Sample Survey, for example, has collected data for over 50 years, providing invaluable insights on the country's population and challenges related to food and nutrition security. Analysis of these data is regularly published in Agriculture Situation in India, a monthly journal available to the public. ${ }^{20}$

BUILD OPEN DATA INITIATIVES. Realizing the importance and benefits of data accessibility, several key organizations including the World Bank, FAO, the United Nations Development Programme, and CGIAR/IFPRI are promoting big data and open data movements for the benefit of food and nutrition security. ${ }^{21}$ Initiatives such as Global Open Data for Agriculture and Nutrition (GODAN) are working toward knowledge equalityhelping developing countries achieve open data parity with their developed-country counterparts-and addressing pertinent issues including data quality, interoperability, storage, and dissemination. ${ }^{22}$ IFPRI makes primary and secondary datasets freely available and encourages their use in research and policy analysis (Box 1). The World Bank's Open Data initiative is intended to provide all users with access to Bank data. ${ }^{23}$

INCREASE DATA QUALITY AND EASE OF USE. A number of steps can be taken to support use of knowledge and data from both national and international datasets.

These include:

- collecting more nationally representative and real-time data that enhance understanding of food systems

- introducing tools and technologies that facilitate access to data

- creating forums and working groups to discuss food system data challenges

- building capacity for data collection, processing and preparation, analysis, presentation, and showing impact results

- adapting big data platforms to better facilitate data collection, curation, storage, analysis, search, sharing, transfer, visualization, querying, and information privacy 


\section{REAPING THE BENEFITS OF OPEN DATA}

Open data and knowledge are essential to reap the benefits of globalization and to mitigate its costs. But increasing data access is not sufficient to achieve food security in developing countries. The gap between availability and usability of data must be bridged, and the quality and consistency of data must be improved. While there is broad commitment to open data and some notable advances have been made, greater investment is needed to build open channels for knowledge and data at the global, national, and local levels. More freely available and usable information can both reduce the digital divide and related inequality, and contribute to poverty reduction and food and nutrition security for all.

\section{BOX 1 AN OPEN DATA INITIATIVE AT IFPRI}

Open data require institutional support and strategic vision on the part of institutions collecting data from the public and using them for decision making, including the International Food Policy Research Institute (IFPRI). IFPRI's Open Data Initiative aims to amplify the potential impact of the Institute's research by disseminating it widely and in a timely fashion to researchers, policy makers, and the public. To help ensure that IFPRI's research data are easy to find, access, and use for decision making, the Institute has invested substantially in improving its data infrastructure, administration, and staff training over the past 20 years. To enhance the delivery and usability of data, IFPRI works with other CGIAR centers, government agencies, and international and academic communities in making its datasets "global public goods."

IFPRI began publishing and distributing data through CD-ROM in 1998, and two years later began requiring that its researchers publish all their datasets. These data have been shared on IFPRI's website since 2005 and, since 2008, through Harvard Dataverse, an open source network. IFPRI's data policy also establishes a timeline for making data public. In 2013, IFPRI along with other CGIAR centers endorsed CGIAR's Open Access and Open Data Policy, which requires that data be made public within one year.

To date, IFPRI has made some 370 datasets openly available, including household- and community-level surveys; country-level data; social accounting matrixes; and institution-level survey datasets. IFPRI datasets are downloaded thousands of times each year by a wide range of users working on food security and nutrition, including students, researchers, faculty, policy makers, and organizations worldwide.

\section{IFPRI dataset downloads by year, cumulative}

\section{0,000}

400,000

300,000

200,000

100,000

0
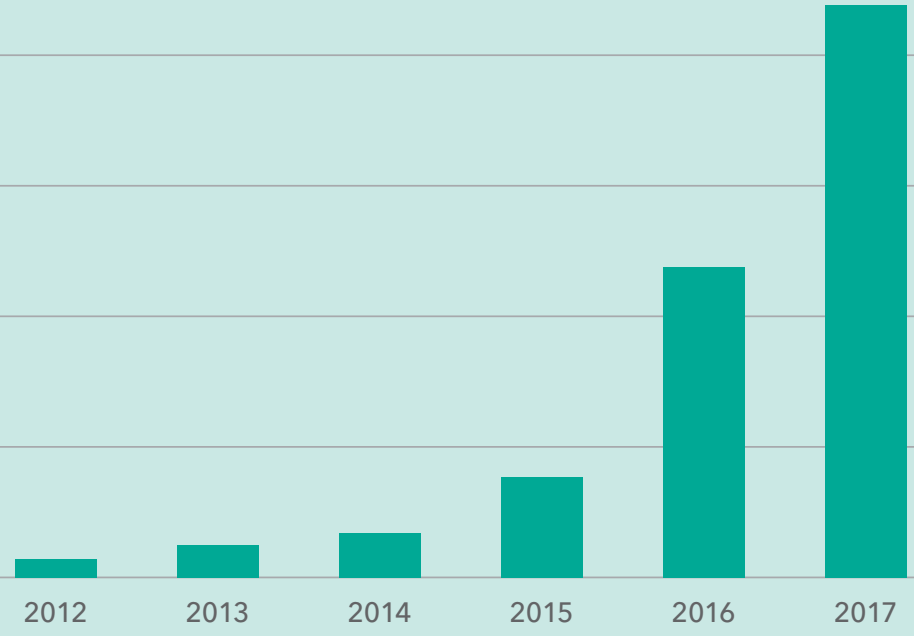

Source: Authors. 
"A cornerstone of open access must be reducing the knowledge inequality within and among societies

that arises from both lack of access and lack of capacity to make use of the world's growing store of knowledge and data." 


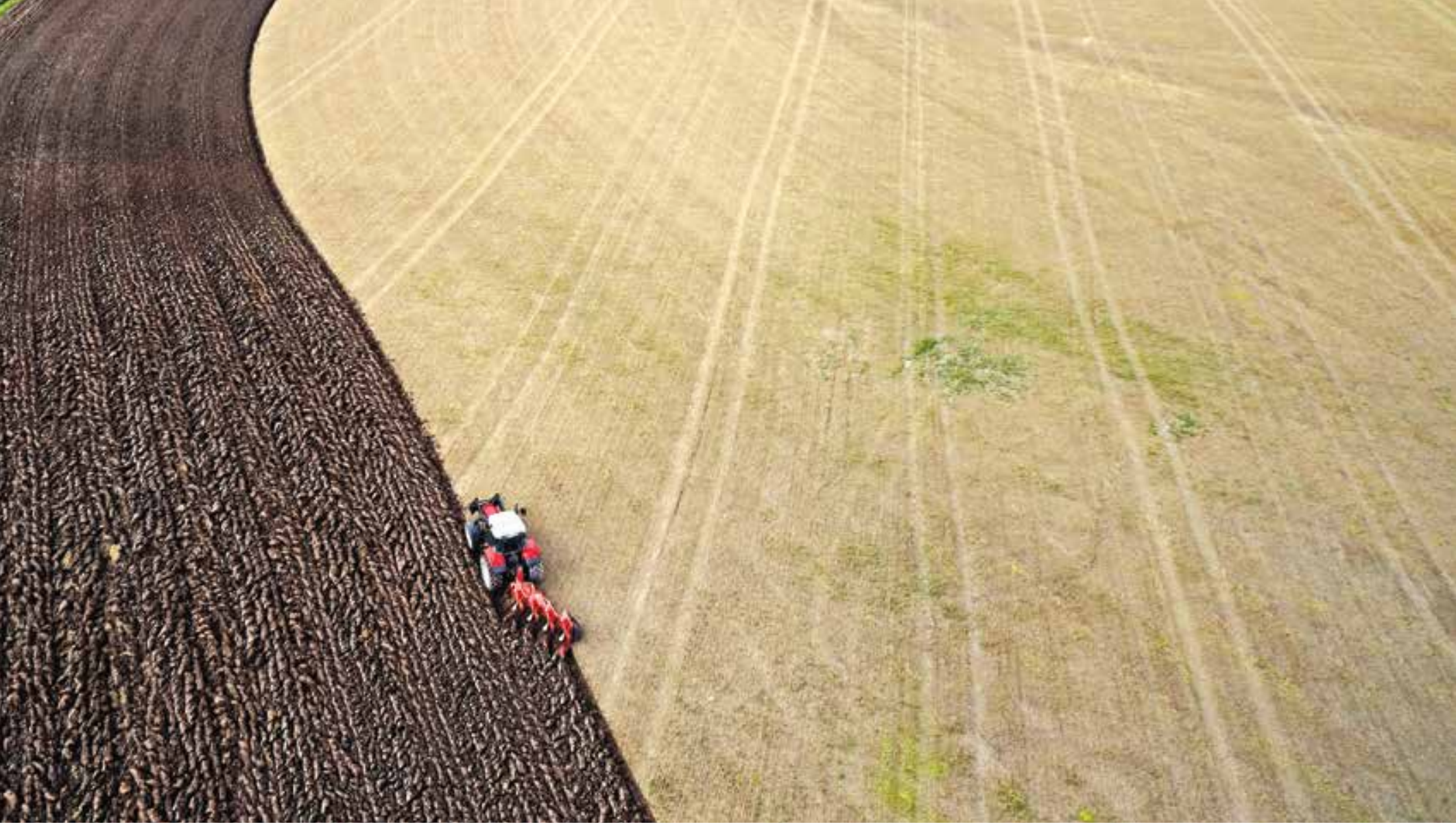

The failure of World Trade Organization (WTO) members to reach agreement on reforming domestic agricultural support at the 2017 Ministerial Conference in Buenos Aires is a reminder of how difficult it is to convince countries to give up harmful farm subsidies. Despite progress made over the past 25 years in reducing farm support among developed countries, support remains high, particularly for specific commodities. Total support in the countries of the Organisation for Economic Co-operation and Development (OECD) exceeded US $\$ 228$ billion in 2016 and, if support policies in major emerging markets such as China, Indonesia, and Russia are included, support levels topped US $\$ 508$ billion. ${ }^{1}$

Policy reforms put in place just prior to and following completion of the 1994 Uruguay Round of trade negotiations were instrumental in lowering the level of support in OECD countries from 33.4 percent of gross farm receipts in 1992 to 18.8 percent in $2016 .{ }^{2}$ Not only did the levels of support decline, but countries changed the type of support provided to producers, moving from policies linked to production and input use to less distorting forms mostly not tied to production. Yet over the last decade, reforms in OECD countries have largely stagnated, and as commodity prices have fallen, support levels have risen marginally.
More concerning is the fact that recent policy discussions in the United States and the European Union (EU) raise the possibility that some of the reforms of the past 25 years may be weakened in ways that could relink payments to production. In the United States, new policy instruments such as revenue insurance and margin-protection insurance blur the notion of providing a safety net in the event of yield loss with providing price and revenue support for producers. In the EU, concern over the effects of full decoupling on rural activity has resulted in policies that allow member states to partially recouple payments to production. And, in large emerging economies, support levels have risen significantly over the past 10 years. ${ }^{3}$

Domestic farm policies tend to be costly-in terms of costs either to consumers in the form of higher prices or to taxpayers, and often to both. Of greater concern is the potential impact of farm policy outside a country's borders. Policies that insulate producers from market prices often lead to overproduction that ends up on world markets and depresses prices. Low-income farmers in poor developing countries are the real losers, as they are forced to compete against subsidized production, often from countries with far higher average incomes. Lower prices mean lower incomes, which can substantially increase rural 
poverty. ${ }^{4}$ The long-term effects of farm subsidies on developing countries are particularly pernicious, as depressed farm income can reduce production incentives. Reductions in production in turn can increase malnutrition and food insecurity, with adverse consequences for rural development.

What follows is a review and analysis of the broad trends in agricultural policy reform over the past 25 years. While the focus is primarily on the large subsidizing OECD countries including those of the EU, the United States, and Japan, implications are drawn for emerging economies as well, many of which have recently begun to implement production-distorting policies to support their agriculture sectors.

\section{MUCH PROGRESS, MORE NEEDED}

For many OECD countries, agriculture-sector support was introduced in the mid-20th century or earlier and expanded following the Second World War. In the United States, support in the form of high tariffs was provided to producers of export commodities as early as the late 1700 s. However, most of the "modern" US price and income support programs have their roots in the New Deal programs of the 1930s that were initially established on a temporary basis to address the economic depression and perceived inequalities between the income of farm and nonfarm households. ${ }^{5}$ Some 85 years later, those "temporary" programs or their successors remain in place. While many European countries established agricultural policies (including tariffs) long before the formation of the EU, the EU Common Agricultural Policy dates to the 1960s. By the late 1980s, the average level of domestic farm support provided by OECD countries exceeded 36 percent of the value of gross farm receipts, and a number of countries (Iceland, Japan, Norway, Switzerland) provided support averaging 60 percent or higher. ${ }^{6}$

\section{TRENDS IN PRICE-SUPPORT PROGRAMS}

Support policies in the postwar period ranged from high tariffs that insulated producers from international competition (for example, rice producers in Japan and the Republic of Korea) to high support prices (grain producers in the United States and the EU). High tariffs protected domestic producers from foreign competition at the expense of consumers, particularly low-income consumers who spend a larger portion of their income on food. Tariffs were often supplemented with support prices that kept domestic prices high by removing surplus production from the market. Together these programs often resulted in a large buildup of public reserves. To manage the costs, governments either sold surplus stocks in world markets at below-cost prices or attempted to manage supply by restricting planting or marketing of specific crops through mandatory supply-control programs. Agriculture was truly "a world in disarray."

By the early 1980s, those problems came to a head. Inflationary pressures had caused both the EU and the United States to raise support prices in the late 1970s. With a strengthening dollar and large global supplies, world food prices slumped, resulting in the buildup of massive government stockpiles, as world market prices fell below high support prices. These surpluses often ended up on the world market with the support of export subsidies or in the form of concessional food aid. And while food aid recipients may have benefited from lower food prices and increased food availability, foreign producers were hurt by lower prices and, in many instances, commercial exports were displaced by subsidized sales.

Skyrocketing government outlays, massive butter and cereal mountains, and depressed world prices caused by surplus production led many countries to rethink their policies by the mid-1980s. Reform efforts were bolstered by the launch of the Uruguay Round negotiations (1986), which resulted in the creation of the WTO in 1995, and then by the new limits on domestic support and export subsidies established by the Uruguay Round Agreement on Agriculture (AoA).

In the United States, reforms introduced by the 1985 farm bill and further legislation in 1990 and 1996 reduced support prices for most commodities and gradually de-linked income support from production. As a result, planting decisions more closely reflected underlying market prices. Government stockpiles were drawn down and essentially eliminated by the early 1990s.

Over the same period, the EU substantially reformed its Common Agricultural Policy (CAP). The MacSharry reforms of 1992 lowered support prices and instituted direct income support tied to supply-limiting programs. Further reforms in 2003 decoupled income payments from production (through the single farm payment), and "cross-compliance" features were introduced, linking payments to respect of standards for food safety, environmental protection, and animal health and 
FIGURE 1 Producer support as a percentage of gross farm revenue

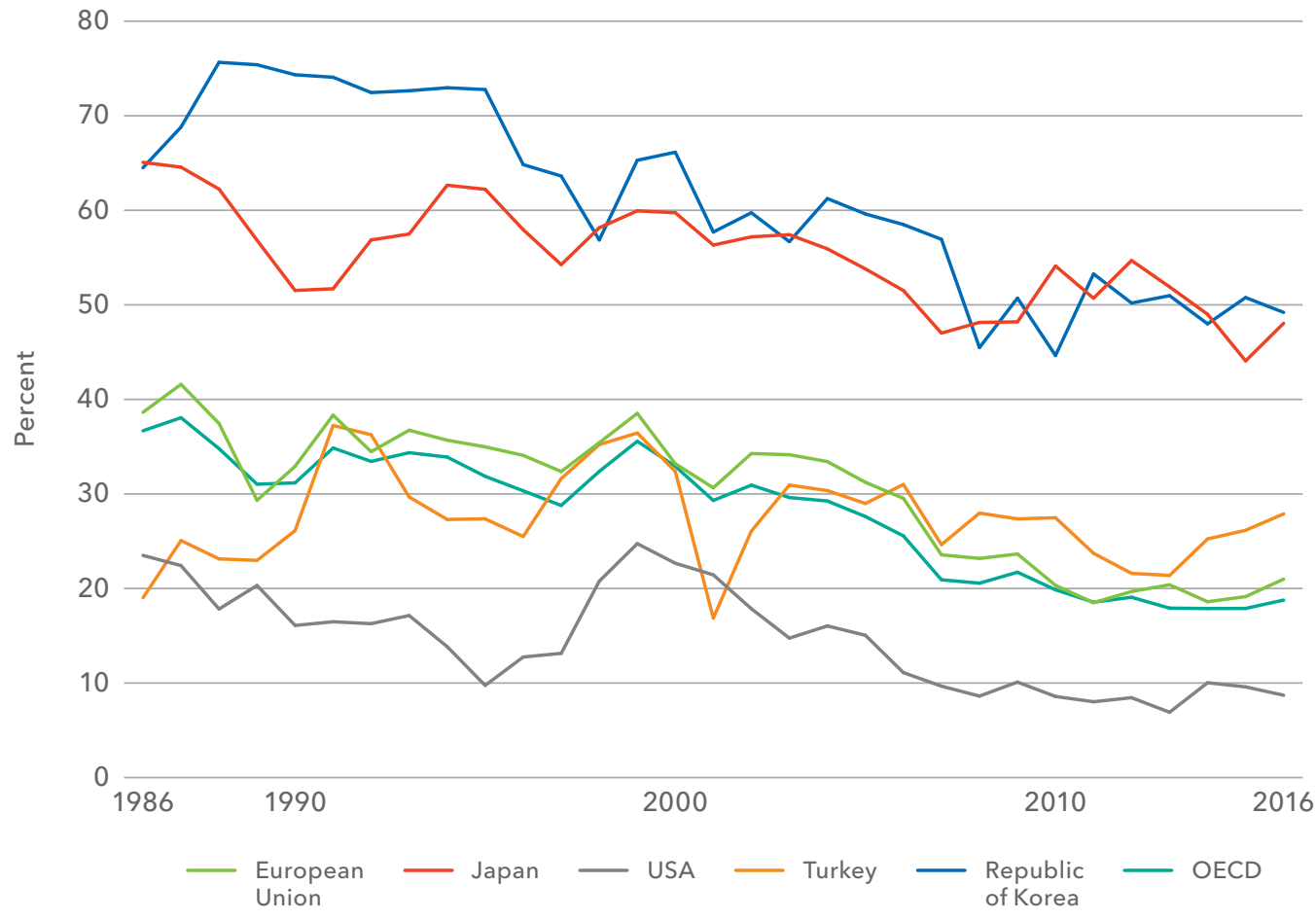

Source: OECD (Organisation for Economic Co-operation and Development), OECD Data, https://data.oecd.org, accessed December 2017.

welfare (the so-called greening of the CAP). In 2013, quotas for dairy, sugar, and wine were eliminated.

As in the United States, the EU reforms resulted in sharp reductions in government stockpiles. As support prices fell below world prices and tariffs were reduced under the AoA, EU grain became competitively priced in world markets. By 1995, when the AoA was implemented, the United States and, soon after, the EU had ended use of export subsidies for most commodities, with the notable exception of dairy exports.

In the 1990s, Japan, the Republic of Korea, and Canada also reformed many of their price-support programs, in some cases replacing them with direct payment schemes. Australia and New Zealand began phasing out supports for many commodities in the mid-1980s and largely liberalized their agricultural programs by the late 1990s, bringing support levels below 5 percent of the value of production.

Together these reforms reduced OECD support levels significantly between 1986 and 2005. Figure 1 shows producer support levels as a percentage of gross farm revenue for the EU, Japan, the United States, Turkey, and the Republic of Korea, which account for about 90 percent of total support in the OECD.

\section{DECOUPLING SUPPORT FROM PRODUCTION}

The composition of producer support also shifted in many OECD countries from support tied to production to less distorting forms that are decoupled from production (Figure 2). Among OECD members, currently less than half of the support provided to producers is linked to production, down from almost 80 percent in the early 1990s. That means both that less support has a direct impact on what is planted, and that producers are responding more to market signals.

Yet while support declined greatly between 1986 and 2005, the rate of decline has slowed over the past 10 years and, in some cases, support levels have even increased in response to falling market prices. The policy changes de-linking production from support were largely in place by the mid-2000s, and trends since then have been flat. Moreover, some countries reversed their reforms. For example, the United States reintroduced price-based countercyclical payments in its 2002 farm bill and, in the 2014 farm bill, replaced decoupled direct payments with price- and revenue-based support programs, raising concerns about recoupling planting decisions with support. ${ }^{8}$ 
FIGURE 2 Share of OECD producer support tied to production

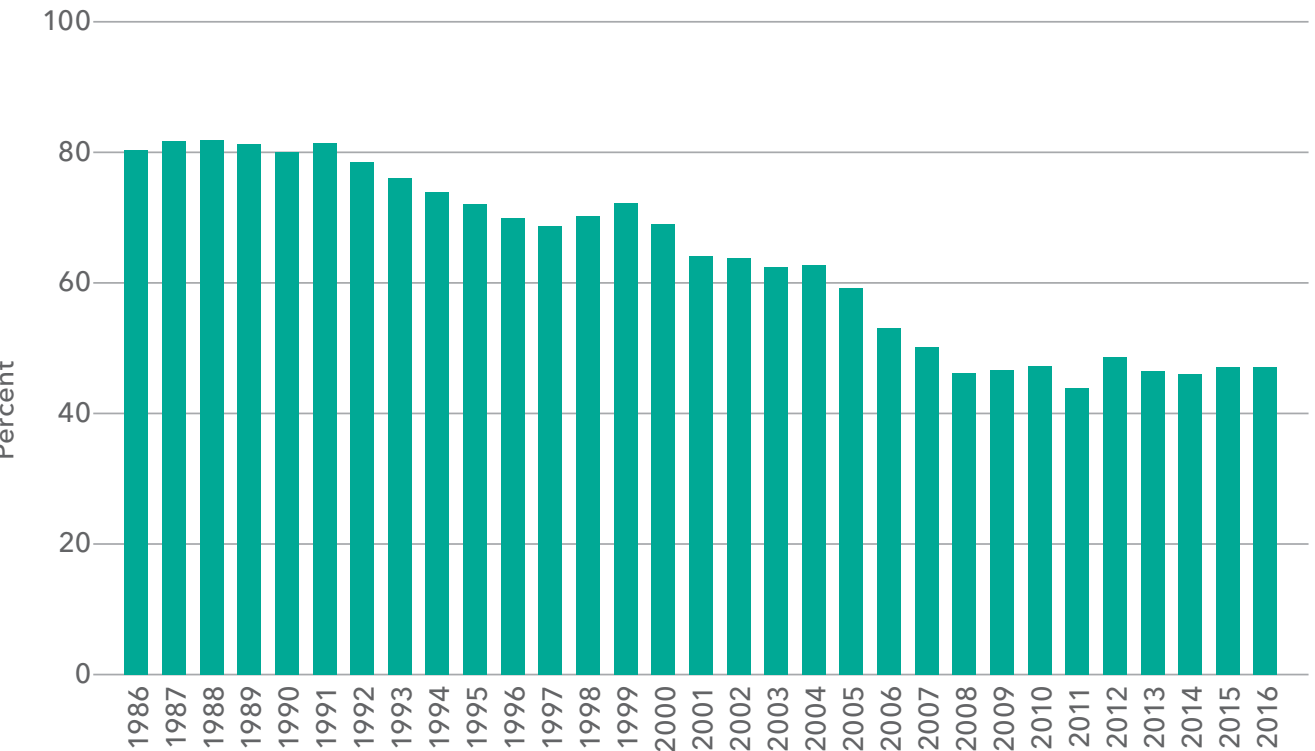

Source: OECD (Organisation for Economic Co-operation and Development), Agricultural Policy Monitoring and Evaluation 2017 (Paris: 2017).

Decoupling has raised concerns among EU member states, as planting flexibility has led farmers to switch out of less profitable crops. To address the shifts in planted area away from certain crops (or crop abandonment) and the resultant impacts on rural infrastructure (such as cotton mills), the EU currently allows member states to tie a portion of their support payments to planting requirements.

\section{GROWTH OF INSURANCE PROGRAMS}

Another significant trend in OECD support programs is the growth of risk management programs, particularly insurance programs. In the United States, Canada, and Japan, crop insurance programs date to the late 1930s. While initially those programs were operated on a pilot basis, participation grew as government subsidies increased. At the launch of the Uruguay Round in 1986, agricultural insurance premiums for these three countries totaled about US $\$ 1.6$ billion.

Although many other countries established insurance programs in the second half of the 20th century, these were relatively small. ${ }^{9}$

Agricultural insurance markets have grown rapidly since 2004 (Figure 3). This expansion is attributable to (1) the rise in global commodity prices; (2) increased US government subsidies, resulting in higher coverage levels in the US market where crop insurance is the largest single program in the US farm safety net; and (3) growth of agricultural insurance in emerging economies, particularly China, whose insurance program in 2014 recorded premium volumes and liability second only to the United States. ${ }^{10}$ Upcoming reforms in the EU may expand insurance programs there as well. ${ }^{11}$ Moreover, since the late 1990s, many pilot programs using weather-based and other index insurance measures have been introduced in developing countries. ${ }^{12}$

Growth of revenue insurance products, including products that insure crop or livestock net margins (output price minus input costs), is also notable. Subsidized revenue insurance was introduced in the United States in the late 1990s and now accounts for about 70 percent of the insured liability in its crop insurance program. ${ }^{13}$ Revenue products are offered in Canada, and Japan plans to offer revenue insurance as part of its policy reform agenda announced in November 2016.

Critics point out that agricultural insurance markets are typically heavily subsidized; in the absence of subsidies, private markets have generally failed. ${ }^{14}$ But subsidized insurance has also been criticized for distorting planting decisions by encouraging production in marginal areas and influencing crop mix. 
FIGURE 3 Growth of world agricultural insurance premium volume

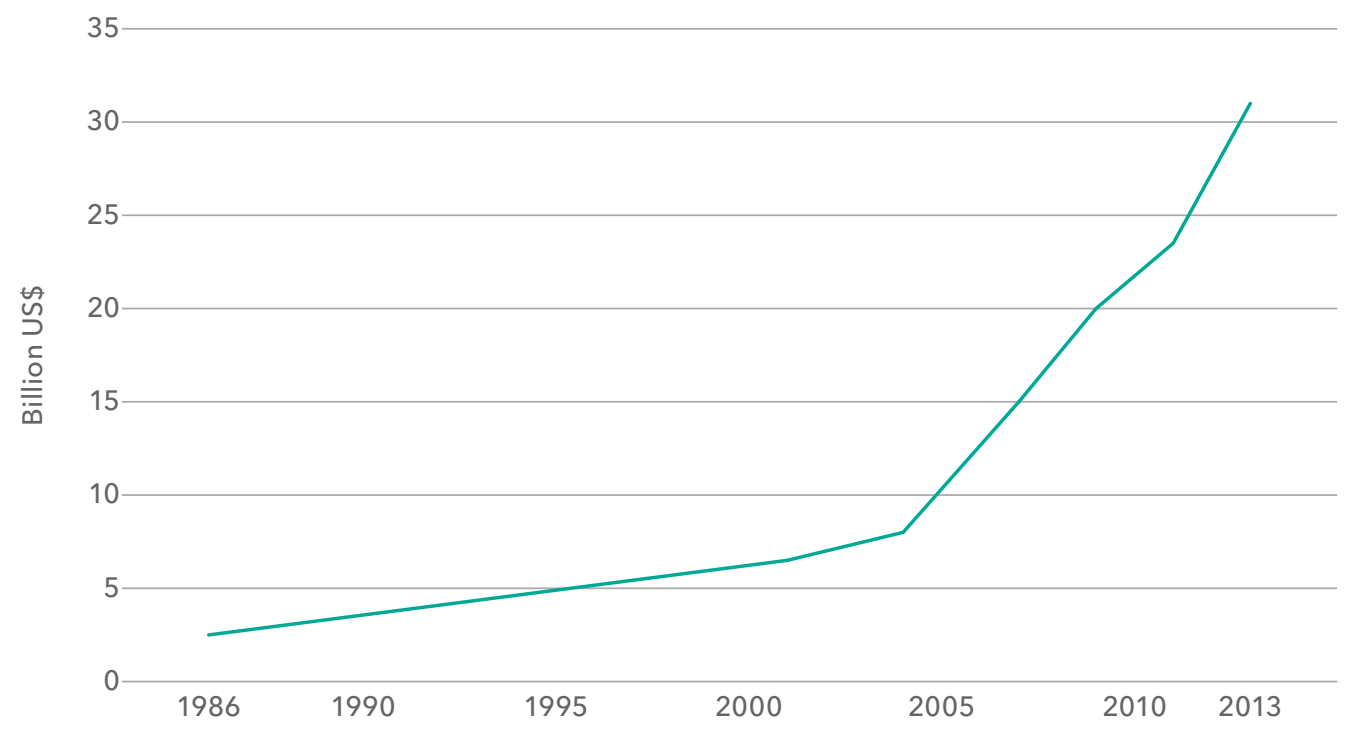

Source: J. Glauber, "Agricultural Insurance and the WTO," in Agriculture, Development, and the Global Trading System: 2000-2015, eds. A. Bouët and D. Laborde (Washington, DC: International Food Policy Research Institute, 2017).

\section{SENSITIVE COMMODITIES}

Despite progress in reducing overall support levels, support for a number of individual commodities remains far above the OECD average. These so-called sensitive commodities generally benefit from high tariff protection that insulates them from world markets. Overall support levels for the United States averaged 9.5 percent of gross farm receipts for 2014-2016, but US sugar support averaged 34.2 percent over the same period. Support for beef producers averaged over 20 percent of receipts in the EU, Japan, and the Republic of Korea, while dairy support was over 40 percent of gross farm receipts in Canada, Korea, and Japan. Rice support remains particularly high in Japan and Korea (over 50 percent of farm revenues) and in the EU (almost 25 percent of farm revenues).

\section{WTO DRIVES REFORMS}

The creation of the WTO and introduction of rules and commitments on agricultural support in the AoA were a major impetus for reform of OECD farm policies. ${ }^{15}$ Because of these reforms to domestic programs, support levels in most OECD countries are far below their WTO domestic support bindings, that is, the level they have committed not to exceed (Figure 4). The recent low support levels suggest that OECD members could reduce the level of their support bindings by up to 65 percent, though actual levels for countries such as the United States vary with market prices and thus could increase significantly during periods of low prices. ${ }^{16}$

Despite reductions in trade-distorting support, several concerns arise with the current WTO "disciplines" that govern agriculture-sector support. The current AoA caps on domestic support apply only to the aggregate level of support across all commodities and do not limit spending on individual commodities for members with bindings. Thus, despite the broad reductions seen in domestic support in OECD countries, support remains high for selected commodities.

The AoA also exempts some forms of trade-distorting support from reduction commitments. These include certain direct payments to farmers tied to production limits (so-called blue box measures); certain government assistance programs designed to encourage agricultural and rural development in developing countries; and other support that is on a small scale ("de minimis") when compared with the total value of the product or products supported (5 percent or less in the case of developed countries and 10 percent or less for developing countries).

The AoA encourages adoption of support policies that have minimal production- and trade-distorting effects, known as "green box" policies, and exempts them from reduction commitments. Critics, however, 
FIGURE 4 Support as percentage of bound support levels

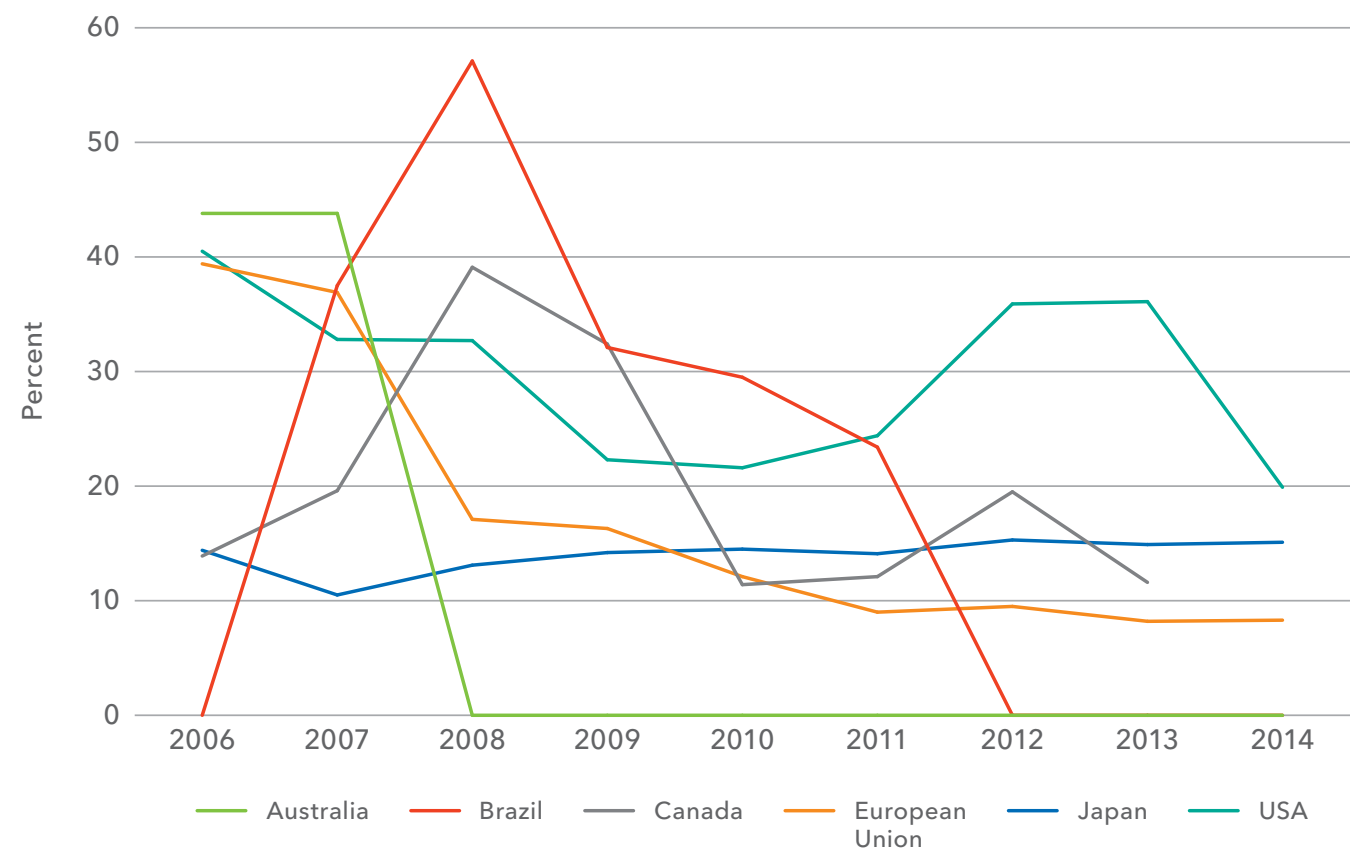

Source: WTO (World Trade Organization), Agriculture Information Management System, http://agims.wto.org, accessed December 2017.

Note: Support is the total aggregate measurement of support (AMS), measured as a percent of each country's bound AMS (the level each country has committed not to exceed).

have expressed concerns about the growth in green box spending, particularly in the areas of decoupled income support and agricultural insurance programs. Both the EU and the United States have notified the WTO of large amounts of decoupled support. In 2012/13, the EU provided notification of its Single Payment Scheme and other decoupled programs, totaling more than $€ 32.8$ billion. In 2013, the United States provided notification of direct payments totaling US $\$ 5$ billion; however, the direct payment program was eliminated in the 2014 US farm bill. Recent empirical research questions whether decoupled support is truly decoupled in that it provides producers with additional income that could keep them in farming (wealth effect) or help mitigate against fluctuations in income (risk effect). ${ }^{17}$

Insurance programs have also come under scrutiny for their impacts on production. These effects, while small, can be significant, particularly in terms of their impact on the crop mix when insurance is available for some crops but not others. ${ }^{18}$ Many of these programs are misreported as green box-compliant. ${ }^{19}$ Moreover, the newly developed gross revenue and net margin insurance products allow governments to protect producers against negative price and revenue movements. When premiums are heavily subsidized, the line blurs between insurance products and price and income supports, raising concerns about how such programs affect production decisions.

Lastly, in advanced developing countries such as Brazil, China, India, and Indonesia, non-green box support has increased since 1995, though from very low levels. ${ }^{20}$ This support is largely in the form of input subsidies (India and Indonesia) or investment subsidies (Brazil). China's price-support programs have grown considerably, particularly since the fall in global prices that began in 2013. Buildups in government-held grain stocks in emerging markets such as China raise questions about the long-term sustainability of such programs. China, for example, has already implemented reforms to its cotton and maize programs to reduce burdensome stockpiles.

\section{CHANGES ON THE HORIZON?}

Both the EU and the United States will soon address potential changes to their farm programs. The United States is expected to pass a new farm bill in 2018 that will guide farmers for at least the next five years. Early debate suggests that there will be little change to the 
current suite of price- and income-support programs, insurance programs, or conservation measures, with two notable exceptions. First, cotton producers have proposed changes to make cotton eligible for price-based countercyclical payments again. The 2014 farm bill replaced direct and countercyclical payments for cotton with a supplemental insurance product as part of a WTO dispute settlement with Brazil, but cotton producers are dissatisfied with the insurance product and would like to replace it with a new countercyclical payment program. ${ }^{21}$ While the proposed program is not expected to cost any more than current programs, it could trigger additional scrutiny on the part of Brazil and potential legal action at the WTO.

Second, US dairy producers have been dissatisfied with the milk margin protection program, a quasi-insurance scheme that pays producers when milk margins fall below an elected level. Few producers participate in the program, and some have argued for replacing it with a margin insurance program currently offered under the crop insurance program. Such changes could potentially increase outlays and distort production decisions.

In the EU, there have been discussions about granting more flexibility in implementing payments at the regional level, some of which could be used to augment insurance schemes. Many member states currently offer agricultural insurance, but proposed changes in the Common Agricultural Policy would encourage the development of insurance products offering coverage levels above 70 percent and insuring revenue as well as yields.

All these reforms can be characterized as modest at best and will do little to reduce support levels. However, looming fiscal challenges for both the EU and the United States may drive more substantive reforms in the future. For the EU, Brexit will pose financing difficulties, as the departure of the United Kingdom will likely mean a net loss for CAP revenues. Similarly, recently passed tax legislation in the United States could constrain future government outlays. Farm programs have thus far been largely protected, but fiscal pressures could increase scrutiny of farm entitlements.

\section{NEED FOR FURTHER REFORM}

Substantial reforms of OECD agricultural policies have been achieved, particularly since the creation of the WTO, but recent efforts to further multilateral reforms have stalled and support levels have generally been flat over the last decade. Yet the failure of the recent WTO Ministerial Conference to agree to further reforms in domestic support should not deter countries from pursuing new reforms.

While developed countries' agricultural policies have moved to less distorting forms of support, OECD expenditures on agriculture remain high, and many countries continue to support producers through market price-support measures at the expense of consumers, particularly low-income households. Support that insulates producers from global market prices can distort production decisions, with the burden of lower prices falling on foreign producers. And while insurance products may offer producers important ways to manage risks, highly subsidized programs providing price and revenue protection arguably act more as a price support than a safety net. That is not to say that public support for agriculture is not warranted, particularly for research and development, inspection services, or other public goods. On the contrary, such investments are critical for agricultural development. But support that distorts production and trade should be phased down and eliminated.

Perhaps the biggest lesson from the OECD experience is not to embark on the path of subsidizing agriculture in the first place. While many agricultural policies in OECD countries were put in place as temporary measures, they have been resistant to change. Although prominent examples exist of countries that have liberalized their farm policies (notably New Zealand and Australia), reforms in most OECD countries have been modest. Farm policies persist because the benefits tend to be concentrated among a limited number of producers, landowners, or other indirect beneficiaries (such as crop insurance companies and agricultural lenders) who are able to organize and lobby in favor of these policies. The costs are more widely dispersed across consumers and taxpayers, who accordingly are less motivated to organize for counterlobbying. As a result, lawmakers too often listen more to the program beneficiaries than to those who pay the price for the programs.

Ultimately, the real beneficiaries of reform are those most vulnerable-poor producers in developing countries-who are often the "mice who get trampled when elephants battle." Reducing agricultural distortions in global markets would allow producers in developing countries to capitalize on their comparative advantages, thus improving income and reducing rural poverty and malnutrition. 


\section{CHAPTER 8}

\section{GLOBAL INSTITUTIONS}

\section{Governance Reform for Food, Nutrition, and Agriculture}

\section{JOACHIM VON BRAUN}

Joachim von Braun is director of the Center for Development Research (ZEF) and professor, economics and technological change, at the University of Bonn, Germany.

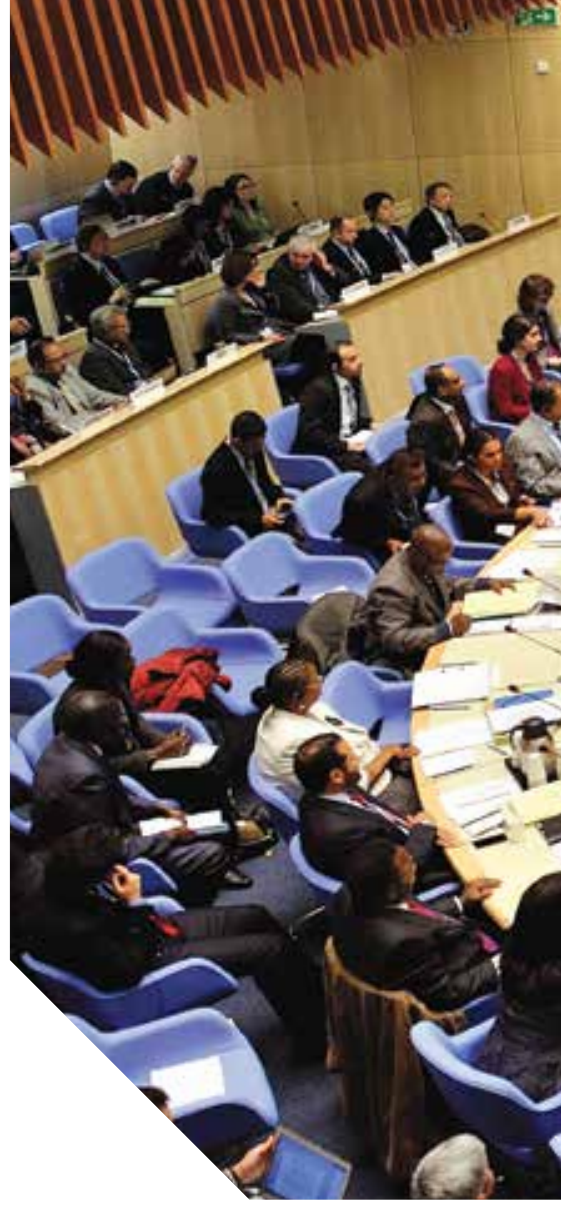

\section{KEY FINDINGS}

- Policy and governance issues related to food and nutrition security are becoming increasingly complexincluding conflict-related hunger, the triple burden of malnutrition, environmental risks, and the politics of global integration.

- Inadequate responses to food crises reveal the need for nations to strengthen global planning and coordination of policy on food, nutrition, and agriculture.

- Global governance can provide and protect "international public goods," such as standards for healthy and safe foods or international coordination of food aid in a disaster.

- Food and agricultural systems must be able to innovate and adapt to changing circumstances, given the rapid and uncertain pace of global change, but this will require better coordination and integration of science into policy.

- Formal institutions, less formal networks, and food and agriculture corporations all have roles to play in governance for food security and nutrition.

\section{KEY RECOMMENDATIONS}

- Conduct formal stakeholder consultations on what a well-functioning global institutional architecture and governance of agriculture, food, and nutrition should look like.

- Base redesign of governance on the principles of legitimacy, accountability, effectiveness, and inventiveness.

- Create institutional coordination capacity to match the increased scope of global action required to achieve the Sustainable Development Goals and address growing complexity.

- Design a "Governing Platform" for intergovernmental coordination, decision making, and funding that can facilitate global action and support consultative participation by stakeholders.

- Establish an "International Panel on Food, Nutrition, and Agriculture" comprising members of the global scientific community to meet the demand for research-based evidence to support sound policy making at the global level. 


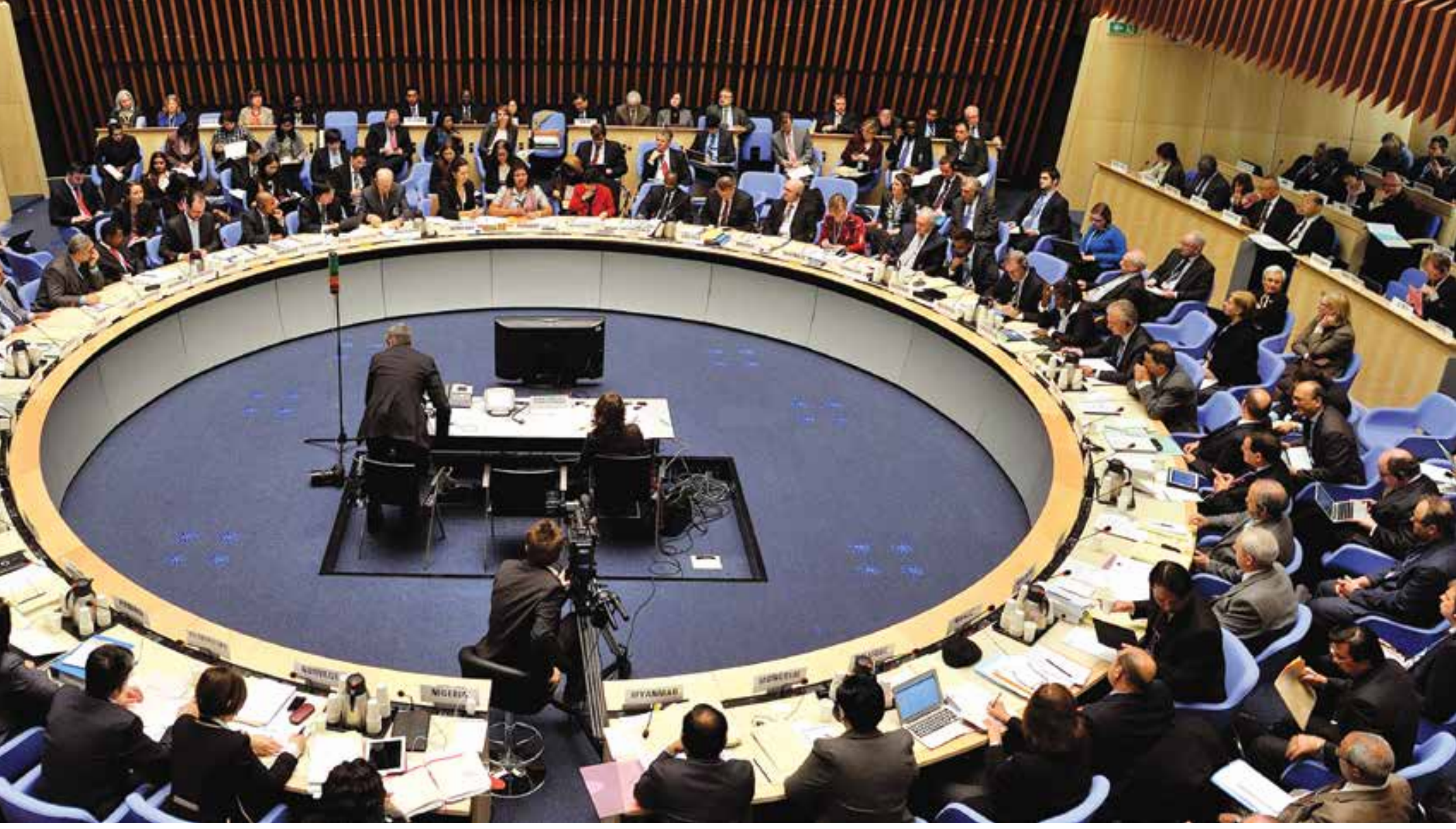

As food and agricultural systems become increasingly globalized, the policy and governance issues related to food and nutrition security are becoming more complex. New and growing complexities require more systematic, coordinated, and evidence-based responses. Among these complexities is the need for diplomacy and security interventions to prevent hunger in conflict- and war-affected zones. Another complexity is the triple burden of malnutritionundernutrition, micronutrient deficiencies and other diet quality problems, and obesity in an increasingly urban world-all three requiring simultaneous attention but different policy responses. A third is posed by the need to address production constraints and environmental risks, including low agricultural productivity growth, climate change, increased soil and land degradation, and loss of biodiversity. Finally, food and nutrition policy must account for the complexity related to global integration through trade and investment, most notably contested positions on fair and free trade, risks of market and price volatility, food industries' international roles, and the protection of food safety. These interwoven challenges call for global governance to improve food and nutrition security. ${ }^{1}$ This chapter argues that a redesign of the current global food and agricultural governance system is needed to facilitate actions for accelerated reduction of undernutrition and malnutrition.

The world food and agricultural system shows signs of serious malfunctioning. The number of chronically undernourished people increased by 38 million in 2016, after years of slow reduction in absolute numbers of undernourished. ${ }^{2}$ Governance failures-resulting in complex emergencies and violent conflicts-underlie this adverse turn. Following the inadequate response to the 2008 food crisis, the world remains ill-prepared to manage the major challenges facing the global food and agricultural system and the nutritional deficiencies of the 21st century. In the two regions most affected by hunger-South Asia and Africa south of the Sahara-different patterns of undernutrition and nutrition deficiencies prevail: In South Asia, child undernutrition, as measured by child stunting and child wasting (often related to

This chapter draws on J. von Braun and R. Birner, "Designing Global Governance for Agricultural Development and Food and Nutrition Security," Review of Development Economics 21, no. 2 (2017): 265-284, and on J. von Braun and M. Kalkuhl, International Science and Policy Interaction for Improved Food and Nutrition Security: Toward an International Panel on Food and Nutrition (IPFN), ZEF Working Paper 142 (Bonn: Center for Development Research [ZEF], University of Bonn, 2015). 
a poor hygiene and health environment), is higher than in Africa south of the Sahara, whereas in Africa south of the Sahara, child mortality rates (which are significantly driven by malnutrition) and undernourishment levels (reflecting overall calorie deficiency) are higher. ${ }^{3}$ Some African countries have significantly improved their food and nutrition situation; what these countries have in common are government commitment and reform of governance arrangements for food and nutrition security. ${ }^{4}$ Asian countries with noted progress, especially in East and Southeast Asia, implemented more social protection, hygiene, and child nutrition policies. More is needed to spread these benefits more widely. Countries could benefit especially from strengthening joint and coordinated policies on food, nutrition, and agriculture.

\section{WHY GLOBAL GOVERNANCE?}

Global governance is beneficial for addressing problems that nations cannot or will not optimally manage by themselves. Most policy action for food and nutrition security is best managed at a national and local level, but global policy also has a role to play. Globalization of agriculture and its dynamics and complexities, as well as the food system more broadly, have outpaced the capabilities of organizations that have evolved to deal with the global and local dimensions of agricultural and food systems. This chapter focuses on needs and opportunities for action at the global level.

Global governance refers to governing relationships that transcend national frontiers, including global rules, norms, and standards, that is, "the rules of the game" that guide organizations. ${ }^{5}$ Global governance of the agricultural, food, and nutrition system encompasses the formal and informal institutions and organizations at the global level that aim to influence this system. Both humanitarian and economic reasons drive action at the global level to improve food and nutrition security. The humanitarian rationale is rooted in welfare and ethical goals, including humanitarian principles such as the international human right to food, global equity, and fairness. The economic rationale calls for global action to address market and other institutional failures that either cannot be addressed at a national level due to their transnational nature or are more efficiently dealt with at the global level.
Central to this economic rationale is the need to provide and protect "international public goods" (IPGs). IPGs differ from private goods in two ways: they are accessible to all, and they do not compete in the market. Here we use the term IPG broadly to include all areas where public action at the global level is justified. Examples include global trade standards for healthy and safe foods, coordinated aid to prevent food crises during disasters and among refugees, and coordination for fair and free trade.

Seven clusters of IPGs particularly relevant for food and agriculture are presented in Table 1.

Providing for such IPGs requires governance arrangements. ${ }^{6}$ The key principles for sound international governance of public goods are legitimacy combined with accountability, effectiveness, and inventiveness. Given the fast-changing and uncertain nature of the drivers of global food, nutrition, and agricultural systems, the capacity to innovate and adapt to changing circumstances is crucial. While the current governance system, with its host of United Nations (UN) agencies, has a strong claim of legitimacy, it lacks both effectiveness and inventiveness in delivering public goods.' Inventiveness requires capacity and freedom to experiment and link to and among innovators working in research and innovation systems, possibilities not typically facilitated by the hierarchical structures of global organizations. Creating a governance system that meets these criteria calls for an independent research body to support policy making and the implementing organizations.

\section{GLOBAL GOVERNANCE MECHANISMS AND ORGANIZATIONS}

Working together, national governments can, in principle, use the following governance mechanisms to pursue the types of global action needed:

- Formulation of internationally agreed upon global goals and priorities (such as the Sustainable Development Goals [SDGs], and in particular SDG2 for ending hunger).

- Negotiated agreements among national governments (such as the Kyoto Protocol under the UN Framework Convention on Climate Change).

- Voluntary commitments of national governments (such as the "Voluntary guidelines to support the progressive realization of the right to adequate food $^{\prime 8}$ or the Paris climate agreement). 
TABLE 1 International public goods clusters for agriculture, food, and nutrition security

International Public Goods

(IPGs) to be addressed for

food and nutrition security

Action areas and examples of current deficiencies

1. EFFECTIVELY PREVENTING AND RESPONDING TO FOOD AND NUTRITION EMERGENCIES AND TO MIGRATION CRISES

\section{TRADE REGIMES, FOOD RESERVES, AND RELATED GLOBAL INFORMATION} 3. COMPETITION POLICY AND
STANDARDS FOR FOREIGN
DIRECT INVESTMENT (FDI)

\section{NATURAL RESOURCE MANAGEMENT RELATED TO BIODIVERSITY, WATER, AND SOILS}

\section{CLIMATE CHANGE ADAPTATION AND MITIGATION RELATED TO FOOD SECURITY AND AGRICULTURE}

\section{TRANSBOUNDARY FOOD SAFETY AND HEALTH- RELATED INVESTMENTS AND STANDARDS}

\section{INTERNATIONAL RESEARCH AND INNOVATION IN FOOD AND AGRICULTURE}

Nutrition as a global problem (including undernutrition, micronutrient deficiencies, and obesity) has no well-defined organizational home. Food assistance in failed states and war-affected regions remains a tremendous challenge. A more comprehensive emergency aid mechanism is called for in which the World Food Programme (WFP) is essential and where nongovernmental actors find improved ways to effectively engage in a coordinated manner. Global diplomacy and security action capability need to be strengthened and support this function. The UN Security Council rarely addresses hunger crises.

Rule-based and fair trade is an essential IPG for food security. Of importance at the global level are regimes that reduce food price volatility and extreme price spikes. There is an institutional vacuum in terms of addressing these matters. An essential basic element is reliable information on markets, production, and stocks at national levels, which is shared internationally. The Agricultural Market Information System (AMIS) was an important step in this direction, but needs strengthening.

Recent mega-mergers among agricultural industries need appropriate scrutiny from a perspective of competitive market functioning, including impacts on markets in low-income countries, which typically are not included in related assessments. An important IPG for FDI is appropriate and transparent rules for assuring efficiency as well as fairness for both investors and countries invested in, including prevention of corruption on both sides. For investments in land and other agricultural resources, voluntary guidelines exist but have limited reach.

A more comprehensive approach is needed to provide management guidelines and information bases for these resources as public goods, such as world soil degradation mapping, transboundary water systems monitoring, air pollution monitoring, and biodiversity tracking, including respective standards. ${ }^{a}$

Agriculture is both a contributor to greenhouse gas (GHG) emissions and part of the solution for reducing GHG emissions related to land use change and animal (ruminants) production. ${ }^{b}$ In view of the complex linkages of climate policy relevant to agriculture and food security, a more prominent and integral positioning of agriculture in global climate policies is called for; this is partly governed by the UN Framework Convention on Climate Change (UNFCCC), but other actors should be involved more, such as those related to health (World Health Organization [WHO]) and land use (Food and Agriculture Organization [FAO]).

Food safety cannot be left to national control and enforcement; international food trade and the demands by consumers for sound standards are an essential IPG. ${ }^{\mathrm{C}}$ Early detection of transboundary food and agriculture-related health risks, such as livestock-originated human diseases, seems to have improved, and $\mathrm{WHO}$ and FAO must play important roles in that. ${ }^{\mathrm{d}}$ Emergency measures to address the root causes of agriculture-linked infection risks remain too ad hoc.

The backbone of technological change is research, and for developing countries, international agricultural research in particular is a public good, vital for food security. Current investments in this IPG are too low, and research capacities of middle- and high-income countries are not drawn on enough for global food and nutrition security.

Source: Adapted from J. von Braun and R. Birner, "Designing Global Governance for Agricultural Development and Food and Nutrition Security," Review of Development Economics 21, no. 2 (2017): 265-284. Additional sources: 'TEEB (The Economics of Ecosystems and Biodiversity), Mainstreaming the Economics of Nature: A Synthesis of the Approach, Conclusions and Recommendations (Geneva: 2010); E. Nkonya, A. Mirzabaev, and J. von Braun, Economics of Land

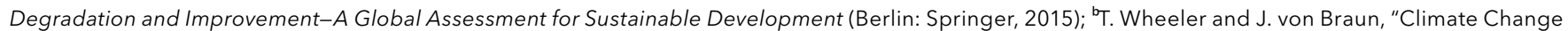
Impacts on Global Food Security," Science 341, no. 6145 (2013): 508-513; 'P. Oosterveer, Global Governance of Food Production and Consumption: Issues and Challenges (Cheltenham, UK: Edward Elgar, 2007); 'WHO (World Health Organization) and FAO (Food and Agriculture Organization), International Food Safety Authorities Network (INFOSAN): INFOSAN Activity Report 2013 (Geneva: WHO, 2013). 
- Creation of global organizations permanently funded by national governments to serve international and national food, nutrition, and agricultural goals (such as the Rome-based development organizations).

- Agreements and implementation of standards and labels by governmental or nongovernmental organizations (NGOs) and private businesses (such as food standards or monitoring of corporate performance in the food sector in terms of commitment to nutrition, for example, the Access to Nutrition Index). ${ }^{9}$

Global organizations play an important role in achieving coordination and can thus increase effectiveness, efficiency, or productivity across countries in specific sectors. Examples are coordination mechanisms within the UN system, such as the Economic and Social Council, which has the mandate to coordinate the specialized agencies of the UN, including the Food and Agriculture Organization (FAO). The UN Committee on World Food Security (CFS) is a particularly vital coordination mechanism for food security-related global action. Informal coordination mechanisms among governments, notably the G7 and G20, have also come to play a key role in global governance, and agriculture and food have featured on both the G7 and G20 agendas. Global coordination mechanisms among private organizations and NGOs have been set up, such as the critically assessed Roundtable on Sustainable Palm Oil and the Grow Africa Partnership founded by the African Union, the New Partnership for Africa's Development, and the World Economic Forum to enhance private sector investment in African agriculture. ${ }^{10}$

For most of the seven clusters of IPGs requiring global action, pertinent organizations, conventions, and declarations are already established (Table 2).

All these formal organizations serve important functions in the global arena and all have made valuable global contributions. However, formal global organizations account for only a partand not even the bulk-of global action in support of agricultural and food systems. Increasingly, a complex global web of less formal government networks, in which a collection of nation states communicates via heads of state, ministers, parliamentarians, and the UN and in which corporations and NGOs participate in various ways, is driving global action on food and nutrition. ${ }^{11}$

\section{CORPORATE SECTOR GOVERNANCE AND IPGS}

Sound competition policy is identified above as a global public good. Internationally operating food and agricultural corporations should be viewed as players in global food governance, and attention should be paid to two types of impacts. First, their own governance should be transparent, accountable, and fair to all stakeholders, not just shareholders. Second, corporations must not have excessive power in markets, which can impede market functioning either internationally or locally and contribute to food insecurity. For instance, large-scale mergers and acquisitions with potential to cause global impact by reducing competition-for example, the Syngenta/ Chem China and Monsanto/Bayer mergers or the Amazon/Whole Foods and Google/WalMart partnerships-should be scrutinized not only in the countries of their headquarters. Global attention is also needed, including voices from developing countries. However, institutional mechanisms to facilitate this global stakeholder input are lacking.

Policies on trade and foreign direct investment, like policies on competition, are increasingly integral to providing IPGs. For example, voluntary guidelines have been established for investments in land and other agricultural resources. For foreign direct investment, appropriate rules for assuring efficiency as well as fairness for both investors and countries receiving investment are an important IPG. Policies for constraining corruption and illicit financial flows, including from developing countries, provide an IPG that is important for rural infrastructure investments and agricultural investment and trade. These issues must be addressed at the international corporate level, as well as through strengthening of countries' legal systems. ${ }^{12}$

\section{RESPONDING TO SHORT-TERM AND EMERGING CRISES}

Food crises occurring in the context of armed conflicts are an important cause of the recent increase in the number of undernourished people. Global response to these conflict-driven crises lacks a functioning formal coordination mechanism and is largely reactive rather than preventive. The food and nutrition crises in 2016/17 in the Horn of Africa, South Sudan, northeast Nigeria, Yemen, Iraq, and in and around Syria must not be seen in isolation. They are not just local policy and governance failures; international powers are involved directly or indirectly in the conflicts that have led to 
TABLE 2 Global organizations and mechanisms with relevance for agriculture, food, and nutrition

\begin{tabular}{|c|c|c|}
\hline Sector/Specialization & $\begin{array}{l}\text { Intergovernmental organizations and } \\
\text { mechanisms }\end{array}$ & Other organizations by type \\
\hline $\begin{array}{l}\text { SPECIALIZED } \\
\text { ORGANIZATIONS IN } \\
\text { THE AGRICULTURE, } \\
\text { FOOD, AND NUTRITION } \\
\text { SECTOR }\end{array}$ & $\begin{array}{l}\text { Food and Agriculture Organization (FAO) } \\
\text { Committee on World Food Security (CFS) } \\
\text { International Fund for Agricultural } \\
\text { Development (IFAD) } \\
\text { World Food Programme (WFP) }\end{array}$ & $\begin{array}{l}\text { Global networks of farmers' organizations } \\
\text { (such as World Farmers Organization, La Via Campesina) } \\
\text { Global Alliance for Improved Nutrition (GAIN) } \\
\text { CGIAR } \\
\text { Organizations of multinational agribusiness enterprises } \\
\text { (such as New Vision for Agriculture, Global Harvest Initiative) } \\
\text { Scaling Up Nutrition (SUN) }\end{array}$ \\
\hline $\begin{array}{l}\text { DEVELOPMENT } \\
\text { ORGANIZATIONS } \\
\text { AND INTERNATIONAL } \\
\text { FINANCIAL } \\
\text { ORGANIZATIONS } \\
\text { WITH AGRICULTURAL } \\
\text { PROGRAMS }\end{array}$ & $\begin{array}{l}\text { World Bank Group } \\
\text { United Nations Development } \\
\text { Programme (UNDP) } \\
\text { Organisation for Economic } \\
\text { Co-operation and Development (OECD) } \\
\text { Regional development banks }\end{array}$ & $\begin{array}{l}\text { NGOs with some focus on food and agriculture } \\
\text { (such as Oxfam, CARE, Welthungerhilfe, Concern) } \\
\text { Private foundations (such as Rockefeller Foundation, } \\
\text { Bill \& Melinda Gates Foundation) }\end{array}$ \\
\hline $\begin{array}{l}\text { SPECIALIZED } \\
\text { ORGANIZATIONS } \\
\text { FOCUSED ON OTHER } \\
\text { SECTORS RELEVANT TO } \\
\text { AGRICULTURE, FOOD, } \\
\text { AND NUTRITION }\end{array}$ & $\begin{array}{l}\text { United Nations Environment } \\
\text { Programme (UNEP) } \\
\text { Intergovernmental Panel on Climate } \\
\text { Change (IPCC) } \\
\text { International Labour Organization (ILO) } \\
\text { Global Environment Facility (GEF) } \\
\text { World Health Organization (WHO) } \\
\text { UNICEF } \\
\text { World Trade Organization (WTO) } \\
\text { United Nations Development Fund for } \\
\text { Women (UNIFEM) }\end{array}$ & $\begin{array}{l}\text { Environmental NGOs } \\
\text { (such as World Wide Fund for Nature [WWF], Greenpeace) } \\
\text { NGOs with watchdog function over global organizations } \\
\text { (such as Global Policy Forum) } \\
\text { International Union for Conservation of Nature (IUCN) }\end{array}$ \\
\hline $\begin{array}{l}\text { GOVERNANCE BODIES } \\
\text { IN CHARGE OF UN } \\
\text { CONVENTIONS } \\
\text { RELEVANT TO FOOD } \\
\text { AND AGRICULTURE }\end{array}$ & $\begin{array}{l}\text { United Nations Framework Convention } \\
\text { on Climate Change (UNFCCC) } \\
\text { Green Climate Fund } \\
\text { Convention on Biological Diversity (CBD) } \\
\text { United Nations Convention to Combat } \\
\text { Desertification (UNCCD) } \\
\text { International Treaty on Plant Genetic } \\
\text { Resources for Food and Agriculture }\end{array}$ & $\begin{array}{l}\text { NGOs and their networks, } \\
\text { some having observer status } \\
\text { Business organizations and their networks, } \\
\text { some having observer status }\end{array}$ \\
\hline $\begin{array}{l}\text { GENERAL GLOBAL } \\
\text { GOVERNANCE BODIES } \\
\text { WITH COORDINATION } \\
\text { FUNCTIONS }\end{array}$ & $\begin{array}{l}\text { United Nations Secretariat, Assembly, } \\
\text { and Security Council, UN Economic and } \\
\text { Social Council (ECOSOC) } \\
\text { G7, G20 }\end{array}$ & $\begin{array}{l}\text { NGOs and their networks, } \\
\text { some having observer status } \\
\text { Business organizations and their networks, } \\
\text { some having observer status }\end{array}$ \\
\hline
\end{tabular}

\section{KEY}

- Global NGOs and nonprofit networks

Foundations primarily focused on funding

Global organizations receiving public funds

Global private sector organizations and networks of for-profit organizations

Global networks of different types of organizations

Source: Adapted from J. von Braun and R. Birner, "Designing Global Governance for Agricultural Development and Food and Nutrition Security," Review of Development Economics 21, no. 2 (2017): 265-284. 
these food crises. Hunger is a common outcome, and sometimes even a weapon, in such conflicts, but global action to prevent and resolve these humanitarian emergencies has been limited.

That was different in the food crisis of 2008. Unlike the current set of crises, the 2008 event shocked global players into action. However, in that global food stress situation, the lack of a functioning coordination mechanism became obvious. Without an established mechanism, parallel coordination efforts, supported by numerous consultations, led to slow responses on the ground. The then G8 and the G20 discussed food security extensively at the heads of state meetings in 2008 and 2009, committing to coordinated action, and in 2015, the G7 committed to lifting 500 million people out of hunger by 2030 . The issue of food security remained on the G20 agenda in 2017 and 2018, but these initiatives have failed to address the growing number and scale of conflict-related hunger crises.

High-level conferences in 2008 and 2009, including summits, were held under the auspices of the FAO, and a reform agenda was established for the UN's Committee on World Food Security (CFS). The reform of the CFS in 2009 constituted a significant step toward global cooperation, but the organization warrants further strengthening. ${ }^{13}$ Unlike other UN committees, the CFS has an advisory committee as part of its governance structure that includes UN bodies, civil society organizations, international agricultural research organizations, private sector associations, and philanthropic foundations as equal members. The CFS also established a High Level Panel of Experts as a mechanism to provide evidence for decision making.

A burgeoning number of conferences on agriculture and food security since 2008 has created an unprecedented marketplace of ideas and proposals for action that-with considerable overlap-shapes international agenda-setting today. Conferencing, however, has made little difference for people increasingly caught in emergency food situations.

Not only acute but also emerging slow-onset crises require global attention. The increased burden of obesity is one such crisis. Advancing effective nutrition policy is constrained by the complex web of interest groups that complicate the political economy of nutrition policy. ${ }^{14}$ In view of industry opposition and government reluctance to regulate for healthier food environments, quasi-regulatory approaches might be considered to address such problems, including strengthened accountability systems and engagement of civil society in creating demand for healthy foods. ${ }^{15}$ Examples include strengthening consumer information, nutrition education, evidence-based and understandable labeling systems, and support for formation of consumer interest groups and for giving them a seat at international food-related policy negotiations.

\section{TOWARD REDESIGN OF INTERNATIONAL GOVERNANCE}

The common response to the world's unresolved food, nutrition, and agriculture challenges has been to seek solutions in meetings at the global level, often with large-scale conference events, that leave the governance structures untouched. Consultations are overdue on what a well-functioning global institutional architecture and governance of agriculture, food, and nutrition should look like, and how it could be achieved. Redesign of the governance of the essential IPGs related to food, nutrition, and agriculture systems must be based on the principles mentioned above: legitimacy, accountability, effectiveness, and inventiveness. Global governance of food and nutrition security needs to be lifted from the current technical levels to a much higher political level of decision making. Ending hunger is a goal that all major nations already agreed on in setting SDG2. Ideally, a legitimate and innovative set of well-informed strategic bodies should help coordinate global policies, including the work of existing international organizations, to overcome the current governance challenges.

Following these four principles and with the goal of strengthening support for the currently underdelivered IPGs, institutional coordination capacity must be created to match the increased scope of global action required to achieve SDG2, an end to hunger and malnutrition, as well as the SDGs aiming for related health and sustainable agriculture and environmental outcomes. The current system offers complementarities and a fair amount of competition among food-, nutrition-, and agriculture-related international organizations. While such competition and complementarities address global problems to some extent, without stringent oversight this institutional arrangement leaves critical gaps (as depicted in Table 1), including for nutrition, and creates inefficient overlaps among organizations due to "mission creep" in organizations' programs. 


\section{GOVERNING PLATFORM}

A governance body providing policy oversight could help address these coordination issues. Ideally, this oversight body should have legalized intergovernmental authority and could take the form of a Governing Platform for International Food, Nutrition, and Agriculture. It should be designed as a mechanism for intergovernmental coordination, decision making, and funding that can facilitate global action, as well as providing a platform for associated consultative participation by government-to-government networks, the private sector, and civil society organizations. This Platform should be nimble and able to respond quickly to new risks and opportunities. To facilitate rapid response, power over budget allocations should be at the level of the Platform, above the relevant technical agencies. And to ensure legitimacy, governance of the Platform should be built on the governance bodies of related technical agencies, thus aggregating, not duplicating, governance.

The Governing Platform would be tasked with providing clarity, currently lacking, regarding who has the authority to do what, and who is accountable and responsible. Providing this clarity will reduce the likelihood of organizations' being held responsible and accountable for situations in which they have not been granted authority to act. This would require strengthening the existing agencies, such as FAO, the World Food Programme, and the International Fund for Agricultural Development, with a view to delivering the IPGs that facilitate sustainable agricultural transformation, food security information, and global food safety services. Global nutrition policy, for example, currently split among many agencies, needs an organizational home; and the World Food Programme needs to be supported to better mitigate and respond to emergency food crises, including through a reliable global food store and funding mechanisms that would permit flexible responses to crises.

In today's political context and multipolar world, there should be no illusion that such a sweeping change in international governance arrangements can be easily achieved. However, it is equally hard to imagine that under the current arrangements the international challenges posed by food, nutrition, and agriculture could be suitably addressed in the coming decades.

A promising structure for the Governing Platform would comprise three clusters of organizational setups (Figure 1)-each having coordination capacity and authority-to serve the seven IPGs for which global action is required:

- Cluster 1 on food and nutrition security and food safety: trade regime and food reserves, and related global information; responding to and preventing food and nutrition emergencies; and investments and standards related to transboundary food safety and health.

- Cluster 2 on protection of natural resources: natural resource management related to biodiversity, water, and soils; and climate change adaptation and mitigation.

- Cluster 3 on enhanced sustainable agricultural productivity and food systems: sound competition policy and standards for FDI; sharing international knowledge on transformation of smallholder farming and related services such as insurance; food waste and loss reduction; and international research and innovation in food and agriculture.

AN INTERNATIONAL PANEL IN SUPPORT OF THE PLATFORM Agriculture, food security, and nutrition are increasingly knowledge-intensive sectors, and the provision of a sound evidence base for policy making is crucial. While the demand for research-based evidence should emerge from the proposed policy clusters, the research support for policy making should be organized independently. The challenges of food and nutrition security justify a permanent institutional arrangement to drive appropriate research. An International Panel on Food, Nutrition, and Agriculture-modeled on the Intergovernmental Panel on Climate Change (IPCC) but established with lower transaction costs as an international rather than intergovernmental entity-could take on this task. ${ }^{16}$ While initially the Panel should focus on research related to the SDGs, it must also have a long-term perspective beyond 2030. Importantly, the Panel should include only the global scientific community in an organized fashion; the experience of the International Assessment of Agricultural Knowledge, Science and Technology for Development (IAASTD) has shown that inclusion of stakeholders and interest groups, such as NGOs and industry representatives, can impede assessments based on the best scientific evidence. ${ }^{17}$ The Panel should adopt the IPCC design, which separates the provision of science-based assessments from political decision making. Political 
GOVERNING PLATFORM FOR INTERNATIONAL FOOD, NUTRITION, AND AGRICULTURE

A governing coordination and funding mechanism that facilitates global action as well as

government-to-government networks, with inclusion of private and civil society actors

\section{CLUSTER 1: FOOD AND NUTRITION SECURITY AND FOOD SAFETY}

- Trade regime, food reserves, and related global information

- Responding to and preventing food and nutrition emergencies

- Investments and standards related to transboundary food safety and health

\section{CLUSTER 2: PROTECTION OF NATURAL RESOURCES}

- Natural resource management related to biodiversity, transboundary water, and land and soils

- Climate change adaptation and mitigation

- Rural energy

- Oceans
CLUSTER 3: ENHANCED SUSTAINABLE AGRICULTURAL PRODUCTIVITY AND FOOD SYSTEMS

- Sound competition policy and standards for FDI

- Sharing international knowledge on transformation of smallholder farming and related services

- Food waste and loss reduction

- International research and innovation in food and agriculture

INTERNATIONAL PANEL ON FOOD, NUTRITION, AND AGRICULTURAL RESEARCH

Source: Author

decision making should be based on facts, but must also take value judgments and political objectives into account.

This function of the proposed Panel goes far beyond the mandate of any existing science advisory body for food, nutrition, and agricultural policy at the international level. Engaging the entire international science system related to food and nutrition security and agriculture would be an institutional innovation with important advantages, as it would better reflect the diversity as well as the lack of consensus in international science insights from different disciplines. Improved exchange between science and policy domains would be possible. Transparency in the assessment processes and rigorous peer review on key issues for food, nutrition, and agriculture would increase the legitimacy of the assessments and recommendations to governments and society. The Governing Platform and the International Panel would need to interact in productive and constructive ways. The Panel would have a global reach, extending to both developing and developed countries. For example, the InterAcademy Partnership, CGIAR, and the CFS High Level Panel of Experts and their networks, together with many others in university and public research systems, could partner in establishing the Panel mechanism.

\section{NEXT STEPS}

While outlining the details of implementation of the governance reform goes beyond the scope of this chapter, clearly a redesign process for global food governance would require consideration of structures, actors, and interests. For practical purposes, it would be useful to establish a high-level, broad-based, legitimized, and time-bound international forum to discuss the organizational implications of redesign proposals. Ensuring that the redesign goes beyond marginal adjustments to the current weak system would suggest mapping that dialogue along the lines of the identified IPGs, rather than along the lines of existing agencies. Any far-reaching and fundamental redesign of the global food, nutrition, and agricultural governance system would be difficult to achieve step by step. Coming to a meaningful implementation of redesign will require leadership. Such leadership for change could come from the UN, from the G20, or from a committed group of nations, in particular emerging economies that are confronting the greatest challenges in food, nutrition, and agriculture. 


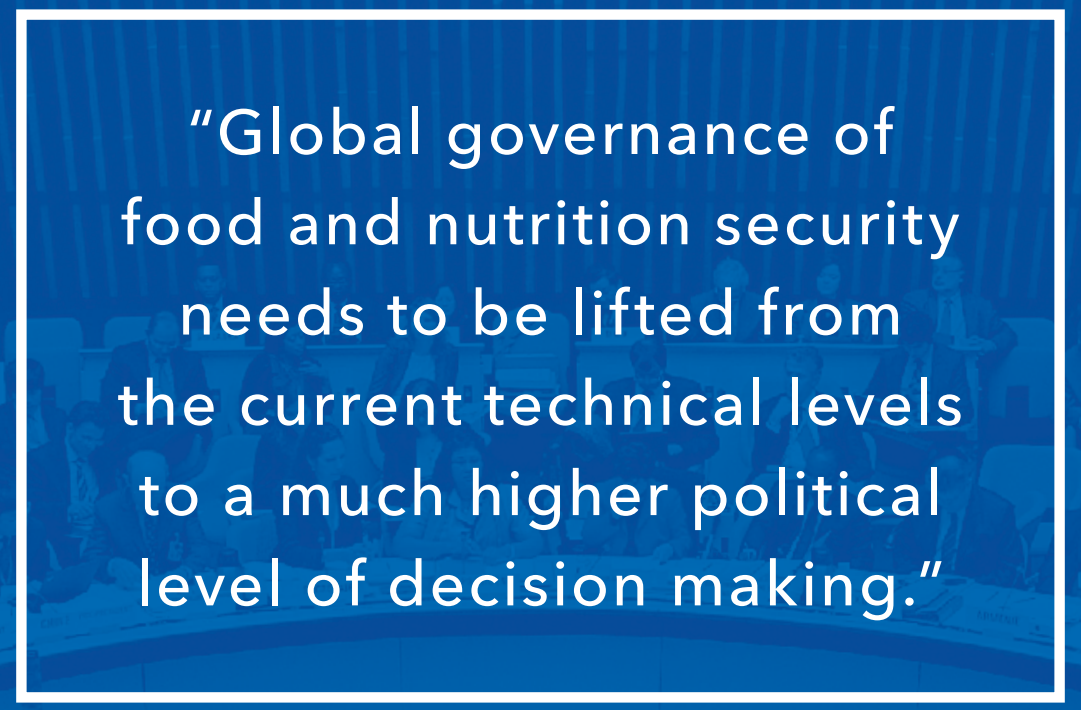




\section{REGIONAL DEVELOPMENTS}

At the regional and country level, developments in 2017 had important repercussions for food security and nutrition. This section offers perspectives on food policy developments across the major regions: Africa, the Middle East and North Africa, Central Asia, South Asia, East and Southeast Asia, and Latin America and the Caribbean. Globalization and the impact of growing antiglobalization pressures on food security are examined for each region, along with many other current topics:

- Africa's need to raise investment in agriculture and build resilience, especially given continued threats from climate variability and conflict

- Substantial reforms undertaken in the Middle East and North Africa, marked by stark differences between those countries directly affected by conflict and those not affected

- Notable steps taken toward regional integration in Central Asia, opening new doors for cooperation

- Global food value chains creating new opportunities in South Asia

- Investments in agricultural transformation, regional connectivity, and e-commerce in East and Southeast Asia

- Benefits of economic recovery in Latin America and the Caribbean threatened by lingering impacts of economic slowdown and changing US policies 
AFRICA

MIDDLE EAST AND NORTH AFRICA

CENTRAL ASIA

SOUTH ASIA

EAST AND SOUTHEAST ASIA

LATIN AMERICA AND THE CARIBBEAN
74

78 |

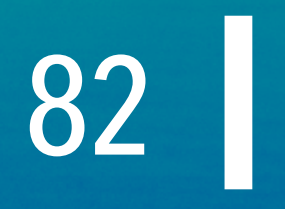

86

901

94 


\section{Africa}

\section{Call for Sustaining Growth and Building Resilience}

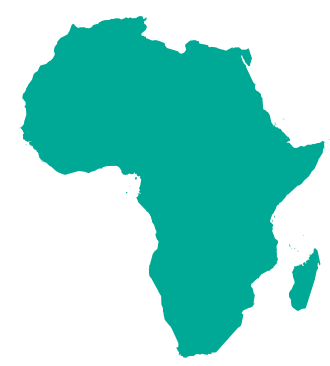

\section{TSITSI MAKOMBE, JULIA COLLINS, JOHN ULIMWENGU, AND OUSMANE BADIANE}

Tsitsi Makombe is a senior program manager, Julia Collins is a research analyst, and John Ulimwengu is a senior research fellow, West and Central Africa Office, and Ousmane Badiane is director for Africa, International Food Policy Research Institute, Washington, DC, USA.

Africa's sustained economic growth since the early 2000 s has been underpinned, in part, by globalization through increased investments, including capital inflows, and by favorable commodity prices that enabled strong export growth. The improved growth performance resulted in declines in poverty, hunger, and malnutrition and enabled a middle class to flourish. However, Africa south of the Sahara still has a higher poverty rate and number of poor compared to the other regions of the world. Furthermore, the continent's dependence on exports of primary commodities leaves it vulnerable to volatile global markets, as witnessed in 2016 when the sharp decline in commodity prices slowed economic growth. Meanwhile, conflicts and increased climate variability continue to threaten food security and nutrition in Africa. In addition, high poverty levels and conflict have forced many Africans to migrate abroad illegally, especially to Europe, under treacherous conditions.

In the face of the headwinds of antiglobalism, African countries should focus on implementing broad-based policy reforms that will allow their economies to thrive in a competitive global environment, generate employment, and build resilient food systems and livelihoods. Policy reforms should also promote trade openness, export diversification, and foreign direct investment (FDI) to keep these countries on a path of sustained and inclusive growth and food security.

\section{MAJOR POLICY DEVELOPMENTS IN 2017}

Gross domestic product (GDP) growth in Africa south of the Sahara was expected to have reached 2.6 percent in 2017, up from a sluggish 1.4 percent in
2016. Modestly stronger growth can be attributed to the rebound in oil and agricultural production; the easing of drought, which stressed southern Africa in 2016 and early 2017; and an improved global economic environment. ${ }^{1}$

Africa's agriculture sector continues to grow steadily. For Africa as a whole, agricultural value-added grew at 4.7 percent annually in 2008-2016, up from 4.2 percent in 2003-2008 but below the Comprehensive Africa Agriculture Development Programme (CAADP) target of 6 percent. Nonetheless, 13 countries surpassed the 6 percent target in 2008-2016.

Prior to the 2008-2009 global financial crisis, public agricultural expenditure for Africa as a whole had also increased steadily. Following the crisis, however, the rate of growth in expenditures decelerated, even turning negative (Table 1). For the region as a whole, the share of agricultural expenditures in total public expenditures continues to fall short of the CAADP target of 10 percent; only five countries managed to meet the target on average during the 2008-2016 period. Although the amount of annual agricultural expenditure has grown significantly during the CAADP period, the recent decreases in absolute expenditures represent a serious new development that requires prompt attention.

Rates of poverty, hunger, and child malnutrition declined over the last 20 years in Africa but remain relatively high. The proportion of Africa's population living in poverty and the prevalence of child underweight and stunting declined slightly between 20032008 and 2008-2016, but high levels persist (Figure 1). Some countries achieved more rapid improvement, with reductions in poverty of 50 percent or more 
between 2003 and 2016 in Chad, Mali, Morocco, Namibia, the Republic of the Congo, and Swaziland. Five countries (Algeria, Angola, Equatorial Guinea, Morocco, and Tunisia) saw reductions of 50 percent or more in the prevalence of underweight children between 2003 and 2016, while Angola and Tunisia saw similarly large reductions in child stunting. Hunger levels, as measured by the Global Hunger Index (GHI), are still considered "serious" or "alarming" in most African countries; the regional GHI score for Africa south of the Sahara is considered "serious." Several African countries saw significant gains, with Senegal showing the largest improvement (51 percent) in its $\mathrm{GHI}$ score between 2000 and 2017.

\section{INTERNATIONAL LINKAGES}

In the face of economic slowdown and a decline in export revenues, attracting FDI becomes critical to sustaining economic recovery. Overall, FDI flows to Africa decreased by 3 percent in 2016 to US $\$ 59$ billion. ${ }^{3}$ However, FDI levels vary greatly across the continent, with over half of total FDI directed to five countries (Angola, Egypt, Ethiopia, Ghana, and Nigeria). Egypt's increase of 17 percent in FDI reflects the discovery of gas reserves, while the 28 percent decline in the Democratic Republic of the Congo followed the sharp fall of global metals prices. In East Africa, FDI to Ethiopia increased by 46 percent, with rising investment in manufacturing and infrastructure. In West Africa, FDI grew by 12 percent, boosted by increased investment in oil and other natural resources in Nigeria and Ghana. FDI in southern Africa decreased by 18 percent, driven by oil-related declines in Angola.
Africa's FDI inflows are expected to reach about US $\$ 65$ billion in 2017, driven by moderately higher oil prices as well as non-oil investment. For 2017, investment promotion agencies rank agriculture, food and beverages, and utilities as the most promising industries for attracting FDI to Africa. ${ }^{4}$ Multinational enterprises from the United States, the United Kingdom, and France are still the leading investors in Africa; however, the biggest surge in FDI from 2010 to 2015 came from China, with an increase of 169 percent.

In terms of trade, African countries have yet to reverse the declines in exports and imports that started in 2012 and 2014, respectively. The declines are driven mostly by low commodity prices, more modest growth in China and other trading partners, and drought affecting parts of Africa. Overall, exports fell by 12 percent in 2016, with most of the decline concentrated in oil-producing countries that were affected by low oil prices. ${ }^{5}$

Conflict, drought and other natural disasters, and stubbornly high poverty have led to high rates of internal displacement and emigration. In response to the unprecedented wave of migration from Africa, the $\mathrm{G} 20$ finance ministers and central bank governors adopted the Compact with Africa in March 2017 to promote private investment as a means to address the underlying causes of migration. The initiative will establish investment compacts between individual African countries and partners, including development banks, international organizations, and donors. The compacts will outline government policy actions and technical and financial support from partners to improve the enabling environment for investors.

TABLE 1 Public agricultural expenditures (PAE) and nutrition outcomes in Africa

\begin{tabular}{|l|c|c|} 
& $2003-2008$ & $2008-2016$ \\
\hline PAE annual average growth & $11.0 \%$ & $-4.8 \%$ \\
\hline PAE as share of total public expenditures & $3.5 \%$ & $3.0 \%$ \\
\hline Poverty headcount ratio, \$1.90/day poverty line & $45.6 \%$ & $42.2 \%$ \\
\hline Prevalence of underweight in children under five & $22.4 \%$ & $19.8 \%$ \\
\hline Prevalence of stunting in children under five & $39.2 \%$ & $35.3 \%$ \\
\hline Global Hunger Index (GHI) score & 43.5 (value for 2000) & 29.4 (value for 2017) \\
\hline
\end{tabular}

Source: T. Makombe et al., "Tracking Key CAADP Indicators and Implementation Processes," in A Thriving Agricultural Sector in a Changing Climate: Meeting Malabo Declaration Goals through Climate-Smart Agriculture-ReSAKSS Annual Trends and Outlook Report 2016, ed. A. De Pinto and J. M. Ulimwengu (Washington, DC: IFPRI, 2017); K. von Grebmer et al., 2017 Global Hunger Index: The Inequalities of Hunger (Bonn, Washington, DC, and Dublin: Welthungerhilfe, IFPRI, and Concern Worldwide, 2017).

Note: $\mathrm{PAE}=$ public agricultural expenditures. Data refer to Africa as a whole. 
FIGURE 1 Annual average percentage change in selected indicators, 2003-2008 and 2008-2016

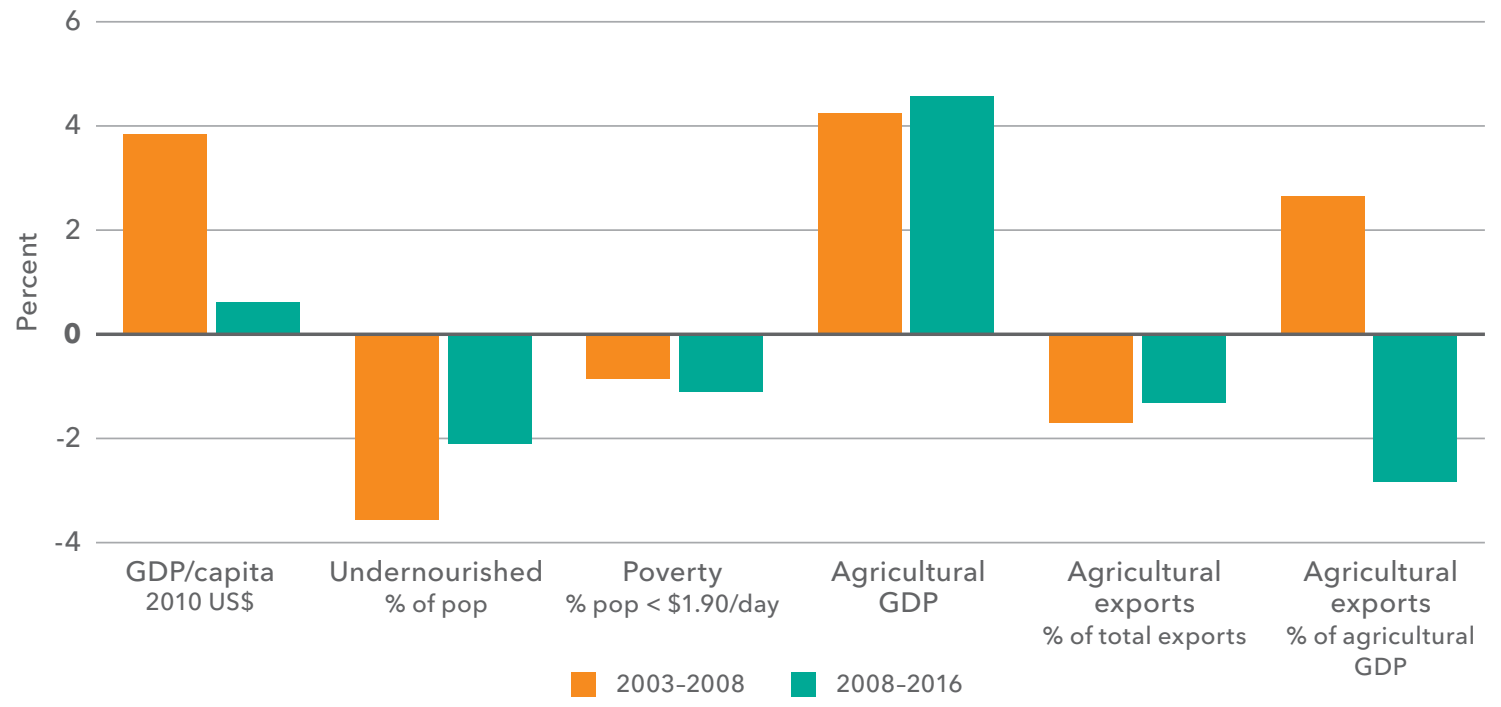

Source: A. De Pinto and J. Ulimwengu, ed., A Thriving Agricultural Sector in a Changing Climate: Meeting Malabo Declaration Goals through Climate-Smart Agriculture-ReSAKSS Annual Trends and Outlook Report 2016 (Washington, DC: IFPRI, 2017).

Note: Data refer to Africa as a whole. GDP = gross domestic product.

Seven African countries have already begun the process of developing investment compactsCôte d'Ivoire, Ethiopia, Ghana, Morocco, Rwanda, Senegal, and Tunisia.

During its presidency of the G20 in 2017, Germany proposed the establishment of a "Marshall Plan for Africa," in part to address causes of migration and create job opportunities for Africa's growing youth population. The plan represents a broad partnership between Europe and Africa under three pillars: economic activity, trade, and employment; peace, security, and stability; and democracy, rule of law, and human rights. ${ }^{6}$ As of January 2018, the final form of the plan was still taking shape.

\section{MALABO DECLARATION COMMITMENTS AND CAADP}

The year 2017 was pivotal in advancing the implementation of CAADP and the 2014 Malabo Declaration, which upheld key CAADP goals and committed to ambitious targets, including halving poverty, ending hunger, and reducing stunting to 10 percent and underweight to 5 percent by 2025. Under the Malabo Declaration commitment to "Mutual Accountability to Actions and Results," African leaders pledged to conduct a continentwide review every two years to track and report on progress. The inaugural biennial review report, including an innovative African Agricultural Transformation Scorecard, was launched during the January 2018 African Union Summit. According to the report, out of 47 reporting countries, 20 obtained an overall agricultural transformation score of at least 3.9 out of 10 , indicating that they are on track to achieve the Malabo commitments by 2025. ${ }^{7}$ During 2016 and 2017, countries, regions, continental institutions, and technical partners made concerted efforts to establish guidelines and collect, analyze, and report on data. The International Food Policy Research Institute (IFPRI), through the Regional Strategic Analysis and Knowledge Support System (ReSAKSS), assisted throughout, helping to design guidelines, develop indicators, and establish a roadmap for the biennial review process. ReSAKSS also provided training and technical assistance to countries and regional economic communities for data collection, analysis, and reporting, and assisted in drafting the continental report. A total of 47 of 55 African countries submitted their country reports in 2017. The draft continental report was presented to the African Union Commission Specialized Technical Committee in October 2017 in preparation for its submission to the African Union Assembly. 
Countries and regions also made significant progress in 2017 in formulating new national agriculture and food security investment plans. Many plans that had been implemented under the Maputo Declaration of 2003 came to a close in 2015, and countries began to develop next-generation plans under the 2014 Malabo Declaration, with coordination and assistance from the African Union Commission, the Planning and Coordinating Agency of the New Partnership for Africa's Development, regional economic communities, and technical partners including IFPRI and ReSAKSS. In 2016 and 2017, eight countries held events to launch the design process for the plans, and the Economic Community of West African States (ECOWAS) led an effort to support all 15 of its member states in completing their plans by the end of 2017. As of October, most ECOWAS countries had a draft document. IFPRI and ReSAKSS provided technical assistance to help guide the design of next-generation plans, including modeling expected growth and poverty outcomes of the draft plans.

\section{THREATS TO FOOD SECURITY}

Climate shocks and conflict severely threatened food security in a number of countries, with famine or near-famine conditions experienced in South Sudan, Nigeria, and Somalia in 2017. Continued poor rains in parts of Ethiopia, Kenya, and Somalia in late 2016 and early 2017 caused a major food security crisis, particularly in Somalia and Ethiopia. ${ }^{8}$ As of December 2017, emergency conditions were expected to continue in parts of the region into $2018 .^{9}$ The drought has significantly impacted agricultural and pastoral livelihoods in the Horn of Africa, and sustained humanitarian assistance will likely be needed.

In addition, civil unrest and conflict put millions at risk in Somalia and South Sudan. In Somalia, food crisis and emergency conditions are expected to continue through mid-2018..$^{10}$ In South Sudan, the government and the United Nations officially declared a famine in parts of the country in February 2017.11 Although the famine declaration was lifted in June, 6 million people-half the population of South Sudan-were estimated to be severely food insecure. ${ }^{12}$ With livelihoods as well as access to food aid still affected by conflict, food security crisis or emergency conditions were expected to persist in broad areas of the country well into $2018 .^{13}$
The Boko Haram insurgency continued in 2017 in northeastern Nigeria, where unrest, restrictions on trade, and displacement have resulted in crisis and emergency food security conditions and limited access to food aid. ${ }^{14}$ The Kamuina Nsapu insurgency in the Democratic Republic of the Congo displaced over a million people in 2016 and 2017. Although some refugees had been able to return as of October 2017, the country's food security crisis is projected to persist into $2018 .^{15}$

\section{AND BEYOND}

Moderately higher economic growth is expected for Africa in 2018, with GDP projected to grow at 3.2 percent. However, growth remains vulnerable to fiscal risks related to rising debt and debt-servicing costs, especially in natural resource-exporting countries. Growth also remains vulnerable in non-resource-intensive countries in the absence of a recovery in prices of commodities such as cocoa. ${ }^{16}$ To support stronger growth, African countries urgently need to reverse the decline in agricultural expenditure growth and raise investments to boost agricultural productivity. They need to continue the improvement of macroeconomic and sectoral policies that ended decades of economic decline and stagnation and ushered the continent into a prolonged period of growth and recovery. In particular, countries need to improve the management of debt, continue to pursue a more conducive business environment for the private sector, and attract FDI.

In addition, African countries need to promote more inclusive development programs and make agriculture programs more nutrition sensitive if the Malabo Declaration goals are to become a reality. In light of continued threats to food security from climate and conflict, building resilience of livelihoods and food systems is urgently needed. Efforts to enhance resilience should include strengthening social protection measures and building and enhancing early warning systems to trigger action as food security crises emerge. Sahelian countries have proven institutional arrangements for monitoring and responding to crises that can be replicated in other regions. ${ }^{17}$ Resilience to droughts and other climate shocks can be built through wider adoption of climate-smart agriculture, which supports climate change adaptation and mitigation while sustaining or raising agricultural productivity. ${ }^{18}$ 


\section{Middle East and North Africa}

\section{A Tale of Two MENAs}

\section{CLEMENS BREISINGER, FATMA ABDELAZIZ, AND NADIM KHOURI}

Clemens Breisinger is a senior research fellow and leader of the Egypt Strategy Support Program and Fatma Abdelaziz is a senior research assistant, Development Strategy and Governance Division, International Food Policy Research Institute, Cairo, Egypt. Nadim Khouri is an independent researcher supporting the Global Agriculture and Food Security Program and the Egypt Strategy Support Program.

As the most food import-dependent and the most important oil-exporting region in the world, the Middle East and North Africa (MENA) clearly benefits from functioning global commodity markets. ${ }^{1}$ However, as in other parts of the world, people in the region do not always perceive globalization as a positive driver of development. Discontent with the inequities sometimes exacerbated by globalization, especially with respect to income and food security, probably contributed to the revolutions that started in $2010 .^{2}$ In several countries, the uprisings turned into armed conflicts, making MENA the region with the greatest number of conflicts and refugees in the world. ${ }^{3}$

\section{CONFLICT AND COMMODITY PRICES}

In Iraq, Libya, Somalia, Sudan, Syria, Yemen, and in certain areas of neighboring countries, manmade disasters continue practically unabated. In addition to the harrowing toll in deaths and casualties, incomes (measured as per capita gross domestic product [GDP]) declined in most of the countries in conflict, and food security (measured as food affordability) continued to deteriorate in all countries over the last year (Table 1). In Syria, an estimated 6.9 million people were food insecure as of July 2017, even with the significant ongoing injection of food assistance that is sustaining about the same number of people. ${ }^{4}$ In Yemen, roughly 65 percent of Yemeni households, representing 17 million people, are now food insecure, and a quarter of a million people are affected by cholera, 60 percent of whom are under the age of $18 .^{5}$ More than 3.5 million people are facing severe levels of food insecurity in Sudan, where relatively good harvests in 2017 were not enough to compensate for the difficulty in accessing food resulting from poverty, internal conflict, and the influx of more than a quarter of a million refugees fleeing violence in South Sudan. ${ }^{6}$

Some MENA countries not in conflict are strongly affected by conflict in neighboring countries. The constant threat of spillover effects and concerns related to insecurity and instability continue to limit confidence and economic activity in the region as a whole. The shadow of conflict depresses businesses and investment inflows and hampers the tourism sector, which had been a vital source of revenue, especially for the oil-importing countries. ${ }^{7}$ All this contributes to low growth rates that are failing to address high unemployment and improve living standards. ${ }^{8}$ And while evidence on the impact of hosting refugees highlights both opportunities and challenges, it is clear that host countries with large refugee populations need significant support from the global community. ${ }^{9}$ An estimated 25 percent of Lebanon's population now constitutes refugees, principally from Syria and Palestine, and over 660,000 Syrian refugees are registered within Jordan's borders, causing huge strains on public finances in both Lebanon and Jordan. ${ }^{10}$ In Yemen, more than 3 million people are reported to be internally displaced, risking a major refugee outflow into neighboring countries. ${ }^{11}$

Global commodity prices also strongly influenced developments in MENA countries in 2017. While global food prices remained relatively stable, changes in international oil prices put a spotlight on the dichotomy between oil importers and oil exporters that has shaped MENA economies for decades. In 2017, oil production cuts led by the Organization of the Petroleum Exporting Countries (OPEC) caused a rise in oil prices, but not enough to completely erase the exporting countries' losses of the last two yearsincluding low or even negative GDP per capita growth 
TABLE 1 GDP, food affordability, and policy changes

\begin{tabular}{|c|c|c|c|c|c|c|}
\hline & \multirow[b]{3}{*}{$\begin{array}{l}\text { GDP per capita } \\
\text { annual } \% \text { change } \\
2015-2016, \text { or } \\
\text { latest two years }\end{array}$} & \multirow[b]{3}{*}{$\begin{array}{l}\text { Affordability of } \\
\text { food (index) }\end{array}$} & \multicolumn{4}{|c|}{ Policy changes ${ }^{c}(2016 / 2017)$} \\
\hline & & & \multicolumn{2}{|c|}{ - Policy reform in 2016} & \multicolumn{2}{|c|}{ - Policy reform in 2017} \\
\hline & & & $\begin{array}{l}\text { Macro/ } \\
\text { fiscal/ } \\
\text { trade }\end{array}$ & $\begin{array}{l}\text { Investment/ } \\
\text { investment } \\
\text { climate }\end{array}$ & $\begin{array}{c}\text { Social } \\
\text { protection }\end{array}$ & Agriculture \\
\hline \multicolumn{7}{|l|}{ Oil exporters } \\
\hline Algeria & 1.8 & -1.5 & $\bullet \bullet \bullet \bullet$ & $\bullet$ & & $\bullet$ \\
\hline Bahrain & 0.2 & -1.0 & $\bullet \bullet \bullet \bullet \bullet$ & & & \\
\hline Kuwait & -2.1 & -1.1 & $\bullet$ & & & \\
\hline Oman & -0.4 & -1.9 & $\bullet \bullet \bullet$ & & & \\
\hline Qatar & -1.3 & -0.3 & $\bullet \bullet$ & $\bullet$ & & \\
\hline Saudi Arabia & -0.5 & -0.7 & $\bullet \bullet \bullet \bullet \bullet \bullet$ & $\bullet$ & & $\bullet \bullet$ \\
\hline United Arab Emirates & 1.8 & -0.1 & $\bullet$ & $\bullet \bullet \bullet$ & & \\
\hline \multicolumn{7}{|c|}{ Oil exporters affected by conflict } \\
\hline Iraq & 7.8 & - & $\bullet \bullet$ & & $\bullet$ & \\
\hline Libya & - & - & & & $\bullet$ & \\
\hline Sudan & 2.2 & -1.9 & $\bullet \bullet$ & & & \\
\hline Yemen & -12.0 & -4.3 & & & & \\
\hline \multicolumn{7}{|l|}{ Oil importers } \\
\hline Comoros & -0.1 & - & $\bullet$ & & & \\
\hline Djibouti & 4.7 & - & $\bullet \bullet$ & & & $\bullet$ \\
\hline Egypt & 2.2 & -4.1 & $\bullet \bullet \bullet \bullet \bullet \bullet$ & $\bullet \bullet$ & $\bullet \bullet$ & \\
\hline Jordan & -1.2 & -1.1 & $\bullet \bullet \bullet$ & $\bullet \bullet$ & & $\bullet$ \\
\hline Lebanon & -0.9 & - & $\bullet$ & & $\bullet$ & \\
\hline Mauritania & -0.8 & - & & $\bullet$ & & \\
\hline Morocco & -0.3 & -1.5 & & $\bullet \bullet$ & $\bullet$ & \\
\hline Tunisia & 0.0 & -2.3 & $\bullet$ & $\bullet$ & $\bullet$ & \\
\hline West Bank and Gaza & 1.2 & - & & & & \\
\hline \multicolumn{7}{|c|}{ Oil importers affected by conflict } \\
\hline Syria & - & -4.2 & & & $\bullet$ & \\
\hline Somalia & - & & & & $\bullet$ & \\
\hline
\end{tabular}

Source: a World Bank, World Development Indicators Database, accessed September 2017; ${ }^{\mathrm{b}}$ Based on Economist Intelligence Unit Food Security Index; ' Policy changes in 2016 and 2017 based on authors' compilation from Economist Intelligence Unit, Country Reports (2016 and 2017).

Note: - indicates no data available. GDP = gross domestic product. Affordability includes the following indicators: Food consumption as a share of household expenditure, proportion of population under global poverty line, GDP per capita (US\$ PPP), agricultural import tariffs, presence of food safety net programs, access to financing for farmers.

and reduced food affordability-that were caused by a slippage in oil prices (Table 1). For oil-importing countries, the rise in oil prices in 2017 put more strain on private and public budgets, and inflation pressures increased substantially. ${ }^{12}$ The Comoros, Jordan, Lebanon, and Mauritania all experienced shrinking GDP per capita over recent years and a deterioration of access to food. GDP per capita growth in most other oil-importing countries that are not directly affected by large-scale conflict was too slow to lead to significant livelihood improvements for people and failed to improve access to food. In some cases, this may be explained by the short-term (often negative) impact of economic reforms initiated in recent years, and in other cases, by a reluctance to start critical reform processes or by the indirect impact of conflicts in neighboring countries or parts of their own territory-such as in Tunisia and Egypt, respectively. 


\section{ECONOMIC REFORMS}

Substantial reforms were undertaken in several oil-exporting countries as well as Egypt and Jordan in the area of macroeconomic policies and to a lesser extent in terms of investment climate, social protection, and agricultural policies. In response to low oil prices over the past years, the adjustment measures taken by oil-exporting countries include public-spending cuts; cuts in fuel and utilities subsidies in Kuwait (2016), Algeria and Bahrain (2017), and Saudi Arabia (planned 2018); and increases in excise taxes in Algeria and the Gulf Cooperation Council (GCC) states as well as a GCC-wide value-added tax scheduled for January $2018 .^{13}$ In the face of economic pressures, policy makers in other countries also pushed forward with reforms. These include the pass-through of recent exchange rate depreciations (Egypt, Sudan), implementation of a value-added tax (Egypt), and the removal of tax exemptions (Jordan). ${ }^{14}$ Despite persisting challenges, some countries kept up the momentum and continued the reform process in implementing energy subsidy reforms (Egypt, Sudan); undertaking structural reforms that improve the business climate and promote private sector activity; and easing key infrastructure bottlenecks (Egypt, Jordan, Mauritania).

While these policy reforms are expected to accelerate economic growth, create new jobs, and improve food security in the medium to long run, short-term negative impacts such as high inflation were observed in several countries. To protect the poor from the negative effects of reforms, several countries continued to expand existing social protection schemes addressing their nationwide social needs, including continuing to subsidize basic food items (Egypt, Lebanon, Morocco, Tunisia) and broadening cash transfer programs (Egypt). ${ }^{15}$

In addition, a few countries undertook some agricultural reforms, including expanding irrigated areas and improving the distribution of fertilizers and certified seeds (Algeria); enhancing water access to address severe food insecurity (Djibouti); and establishing a national strategy to facilitate the export of local agricultural products, especially fruits and vegetables, to the international market, with emphasis on the Gulf countries (Jordan). ${ }^{16}$ The Saudi government started rolling back its expansionary agricultural policy by terminating local production of wheat and is planning to phase out green fodder production by 2019, while continuing to encourage agricultural investments and production abroad for export back to its local market to meet strong domestic demand. ${ }^{17}$

\section{GOING FORWARD}

The MENA economies are united by their strong connections with the world, including through trade in goods and services (Figure 1). MENA will likely continue to rely increasingly on international trade for large components of its food supply; in view of this, the $G 20$ and other initiatives are facilitating the forecasting and exchange of information on potential difficulties in the production or trade of major crops. ${ }^{18}$ In addition, Gulf and other Arab countries have invested more than US\$9.3 billion in agricultural projects in Africa south of the Sahara, a trend that may have been encouraged by better governance and institutional frameworks in Africa. ${ }^{19}$ Oil exports will likely continue to shape the region for several years to come, despite the efforts of oil-exporting countries to diversify their economies. These facts should reassure the voices still clamoring for various degrees of protectionism in MENA countries.

Yet in 2017, the tale of two MENAs continued. One MENA was in conflict, the other MENA was managing as best it could, perhaps growing inured to the conflicts next door. In the present state of Arab crisis and disunity, it is difficult-but essentialto create a path to a more integrated economic outlook within MENA. The path toward integration can build on some progress made to date with the initial, fledgling steps toward a Pan-Arab Free Trade Agreement (PAFTA) by expanding into additional measures for intraregional integration: continued elimination of tariff and nontariff obstacles to trade; expansion of intraregional agreements and standards for services and investments, including telecommunications, transport, and financial services; harmonized employment regulations; and facilitation of labor movement. ${ }^{20}$

A major breakthrough could be made if countries not affected by conflict demonstrated that, by pursuing some of these reforms, Arab countries can achieve increases in GDP of 50 to 100 percent (as compared to the GDP that would be realized if they persisted with pre-2011 economic policies). ${ }^{21}$ Demonstrating this potential could offer 
FIGURE 1 Food imports and fuel exports in MENA compared to the world

\section{Food imports (\% of total imports)}

Countries in red = Countries affected by conflict

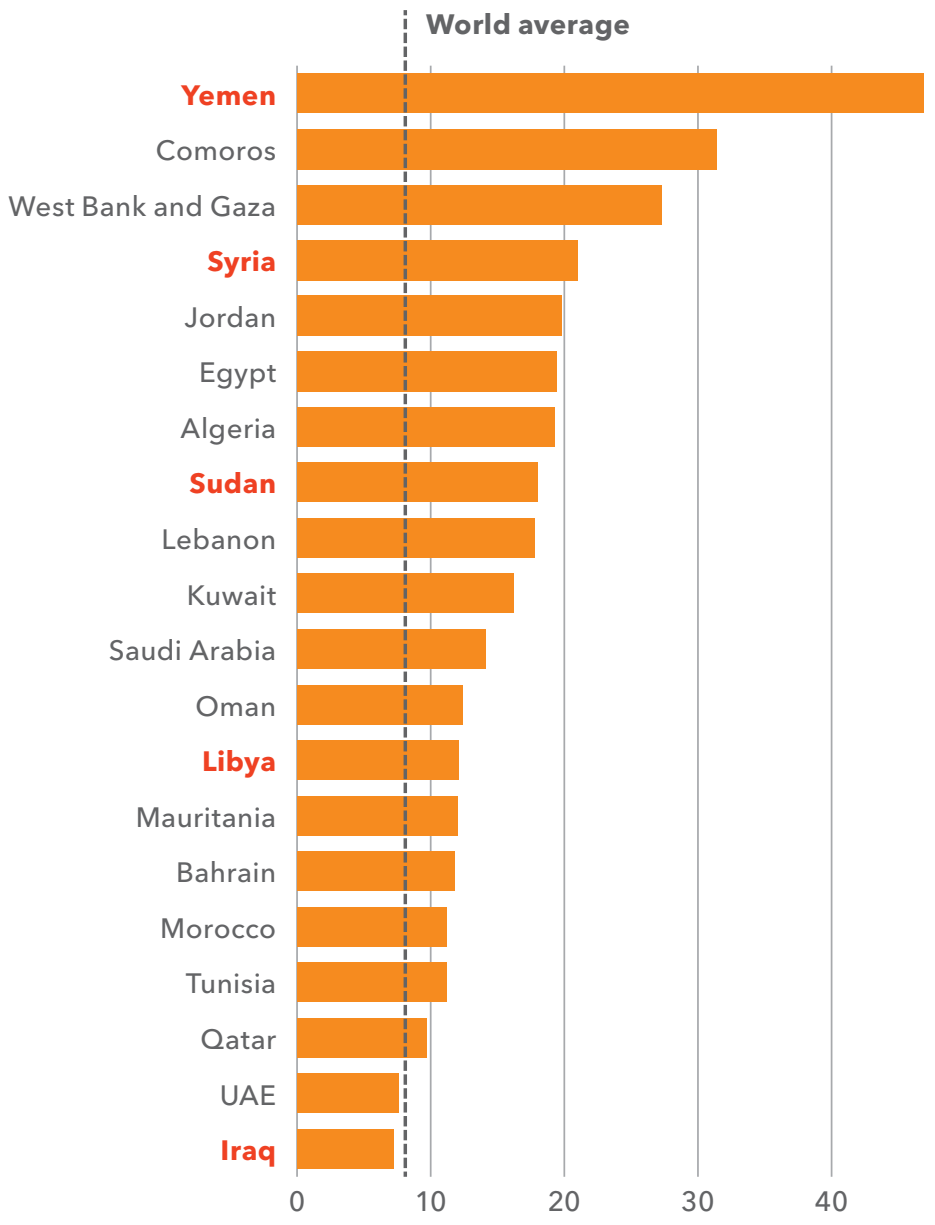

Fuel exports (\% of total exports)

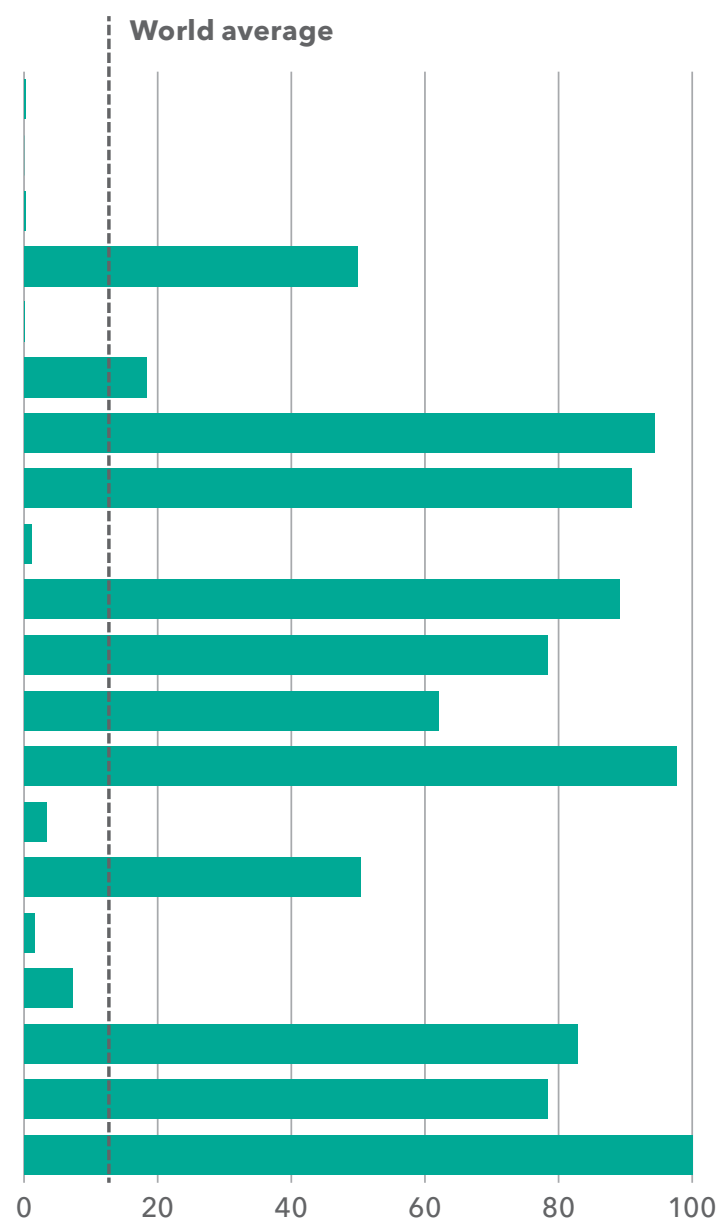

Source: Authors' compilation based on World Bank, World Development Indicators Database, accessed September 2017, https://data.worldbank.org.

Notes: Numbers reflect latest available data. "Fuel" includes mineral fuels, lubricants and related materials, including coal, coke and briquettes, petroleum, petroleum products and related materials, natural and manufactured gas, and electric current.

an alternative to the present state of conflict in the rest of the region and project a realistic hope for improvement. Achieving this change by 2025 will require immediate steps toward significant regional integration and country reforms toward more, not less, globalization. Globalization could become a positive driver of postconflict economic development and food security in MENA if the benefits of increased trade flows and investments are spread more widely and lead to greater prosperity for all.
While many MENA countries have missed opportunities for fundamental policy shifts in the past, now may be an opportune time for courageous, well-designed policy changes that go beyond macroeconomic reforms to allow all people to benefit from globalization. ${ }^{22}$ In view of the region's reliance on food imports, the food sector-and food security in particular-is an excellent place to start. 


\section{Central Asia}

\section{Steps toward Cooperation}

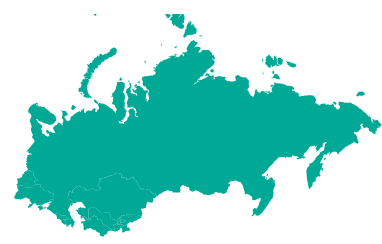

\section{KAMILJON AKRAMOV, JARILKASIN ILYASOV, AND ALLEN PARK}

Kamiljon Akramov is a research fellow, Jarilkasin Ilyasov is a research analyst, and Allen Park is a senior research analyst, Development Strategy and Governance Division, International Food Policy Research Institute, Washington, DC, USA.

After experiencing significant negative external shocks beginning in late 2014, the Central Asian countries-Kazakhstan, Kyrgyzstan, Tajikistan,

Turkmenistan, and Uzbekistan-began to enjoy more favorable external economic conditions in late 2016. Improvements include considerable increases in nonrenewable commodity prices and economic recovery in the region's key trading partners, including resumption of growth in Russia, a key driver of remittance flows and trade for Central Asian economies. 'These favorable external factors increase economic activity and food security in Central Asia through their impact on export earnings, remittance flows, and investments from the region's main economic partners.

The significant upturns in energy and metals prices supported economic recovery and appreciation of the Russian ruble in 2017, which in turn increased remittance flows to Kyrgyzstan, Tajikistan, and Uzbekistan (Figure 1). ${ }^{2}$ The combination of rebounding demand for migrant labor and a stronger ruble led to a 34 percent increase in remittance flows in nominal US dollar terms from Russia to Uzbekistan in the first half of 2017, compared to the same period in 2016. Remittance flows to Kyrgyzstan and Tajikistan increased by 28 percent and 22.4 percent, respectively, during the same period. Depreciation of the national currencies of Tajikistan and Uzbekistan led to even greater increases in remittances when accounted in the national currencies of these countries. For example, Tajikistan's somoni depreciated by almost 12 percent against the US dollar during the first three quarters of 2017.

Income from employment and remittances remain the primary drivers of poverty reduction and improved food security in the region. Increasing remittance inflows, while still well below 2012-2014 levels for Tajikistan and Uzbekistan, in combination with low inflation boosted the real purchasing power of households. Relatively stable food prices also contributed to the food security of poorer households. Thus poverty and undernourishment rates continued to decline. ${ }^{3}$ However, micronutrient deficienciesthat is, the lack of essential vitamins and minerals-remain common. In addition, overnourishment (overweight and obesity) is on the rise in all countries of the region. For instance, the overweight rate in Kyrgyzstan increased by more than 10 percentage points during the last decade and about 45 percent of adults were overweight in $2015 .^{4}$

\section{POLICY CHANGES IN THE REGION}

Since the change of political leadership in Uzbekistan following the death of its first president in 2016, the country has embarked on a set of important economic and governance reforms. To improve public administration, judicial systems, and social infrastructure, as well as to enhance economic growth and liberalize trade, the government adopted a Strategy of Actions on Further Development of Uzbekistan, including a five-point action plan for 2017-2021. ${ }^{5}$ Within the framework of this strategy to liberalize social and economic policy, the government adopted 15 laws and more than 700 normative legal and policy documents within the first nine months of 2017. The implementation of many of these policy changes will have important implications for food security and nutrition in the country.

Liberalization of the foreign exchange market could be considered the keystone of the new government's commitment to change. In September, President Shavkat Mirziyoyev signed a decree that allows citizens and businesses to freely exchange 
currency and supports an enabling environment for more sustainable and inclusive growth. ${ }^{6}$ Devaluation of the official exchange rate by almost 50 percent and unification of exchange rate markets are expected to stimulate exports and attract foreign investment. These reforms will also create a more favorable environment for Uzbekistan's agricultural producers, especially cotton and wheat producers, by eliminating the hidden tax on the sector created by exchange controls.

In the agriculture sector, the Uzbek government has continued to prioritize diversification and a shift from cotton production to horticultural products. Policy reforms aim to increase access to machinery, fertilizers, and credit, and simplify export requirements for local producers. ${ }^{7}$ However, it is not clear how this support will be provided, who will receive it, or whether such support will be fiscally sustainable. The government is also continuing its policy of increasing land allocation for horticultural crop production and allocating more land for forage and oil crops. ${ }^{8}$ Simultaneously, import tariffs and excise tax rates were substantially decreased or abolished for a number of important consumer goods and raw products. Increased availability of cheaper raw materials is expected to stimulate domestic production of final products and improve the country's competitiveness and export potential, as well as stabilize consumer prices in the domestic market. ${ }^{9}$

Infrastructure development is one of five areas prioritized by the new Uzbek strategy. In addition to ongoing development of roads and communications infrastructure, support for reconstruction of local bazaars and establishment of supermarkets and hypermarkets by the private sector is also being prioritized. Public support for the reconstruction of 301 major farm markets (dehkan bazaars) throughout the country between 2017 and 2019 aims to create jobs, modernize marketing infrastructure, and improve food safety standards.

Reforms for food safety and nutrition were also introduced, including fundamental changes in veterinary services. ${ }^{10}$ A new state Committee on Veterinary Services, formerly under the agriculture ministry, was established under the Cabinet of Ministers. The prime minister issued a resolution establishing a national Research Institute on Public Health and

\section{FIGURE 1 Total remittance inflows from Russia (2010-2017, quarters 1-3)}

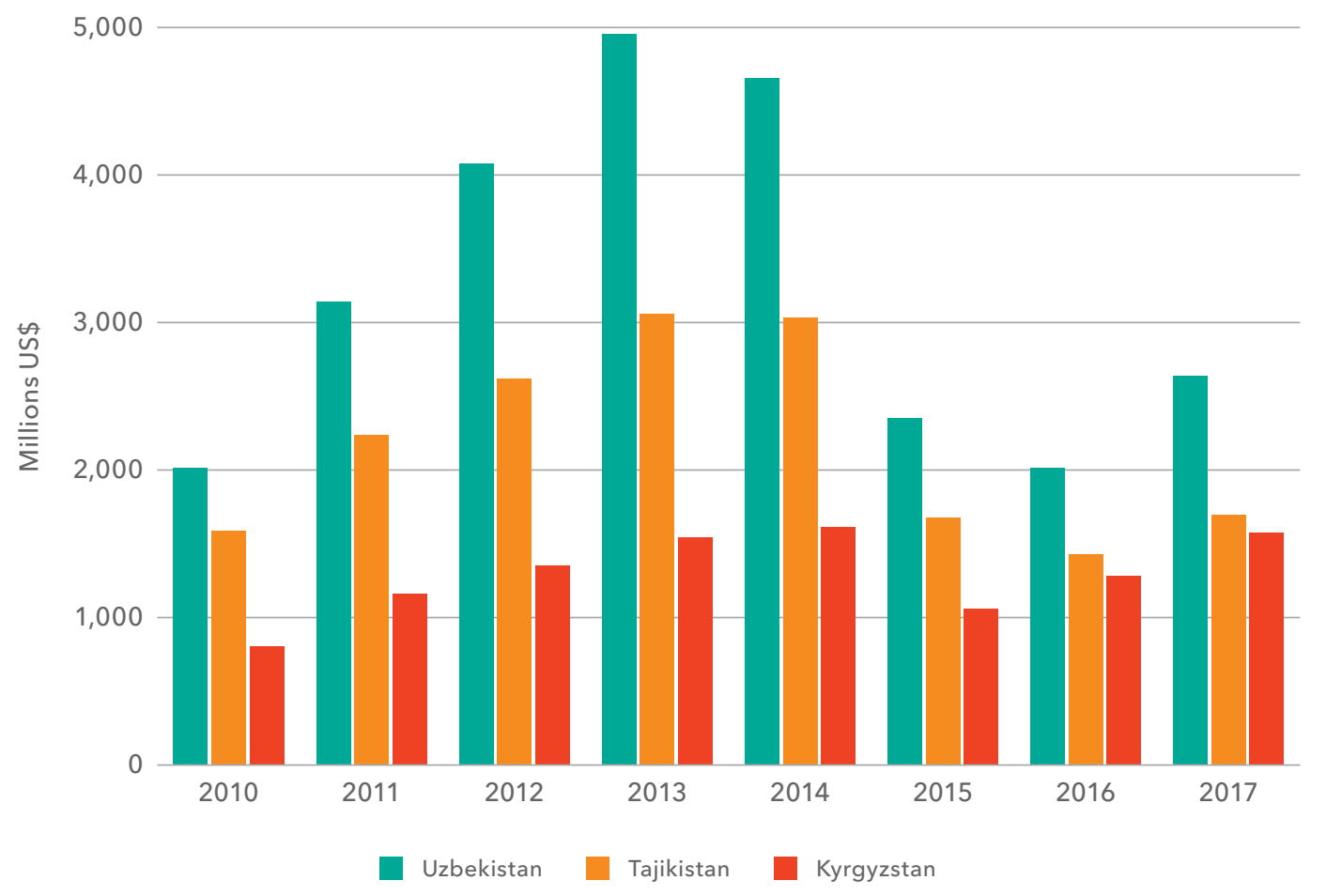

Source: Central Bank of Russia. 
Healthcare Administration, with responsibility for increasing public awareness regarding healthy lifestyles and nutrition, among other activities aimed at improving public health.

In 2017, Kazakhstan adopted an updated mid-term development strategy for 2050The Third Modernization of Kazakhstan: Global Competitiveness. ${ }^{11}$ It promotes the adoption of innovative and advanced technologies in the economy as well as sustainability and growth in prevailing major economic sectors, including agriculture, by investing in information and communications infrastructure, training, and education. The new strategy intends to promote labor productivity growth through technological modernization, creating an enabling business environment for entrepreneurship and market liberalization, and ensuring the rule of law and reducing corruption. ${ }^{12}$ The government approved a new State Program for Agro-Industrial Development (2017-2021) that prioritizes agricultural development through support for productivity growth, improved value chains, increased processing, and sustainable use of water and land resources. The program aims to shift public subsidies from grains to oil crops, expand state subsidies to smaller agricultural producers, and increase public funds for agricultural research and extension. The plan envisions stimulating agricultural exports by improving sanitary and phytosanitary compliance.

\section{REGIONAL INTEGRATION}

Poor regional integration and cooperation have been serious impediments to development and food security in Central Asia, but the recent political changes in Uzbekistan have created a more favorable environment for regional cooperation. ${ }^{13}$ The measures taken by the new Uzbek government have been welcomed by heads of state in the region and by major international development agencies. ${ }^{14}$

Relations are also thawing in the region more broadly. Diplomatic activity accelerated in 2017, following promising signs in 2016. This is a notable change for a region that has ranked poorly on almost all forms of regional integration, including trade, finance, infrastructure, migration, and institutional integration. ${ }^{15}$ It appears that Central Asian leaders are now beginning to pay serious attention to improving regional ties.
The recent initiatives were largely driven by the change in Uzbekistan. As the only country that borders all four other Central Asian countries, Uzbekistan has had running disputes with almost all of them over issues such as transport, energy, water, and trade. In 2017, the new Uzbek leadership initiated outreach to its neighbors and secured several commitments for further cooperation. For example, Turkmenistan and Uzbekistan, which had fraught ties for much of their post-independence histories, signed agreements to jointly develop energy deposits in the Caspian Sea and transmit electricity to other countries in the region.

Tajikistan and Uzbekistan resumed air flights after 25 years, reflecting a normalization of ties that had deteriorated largely due to disputes over water and energy resources. Uzbek president Mirziyoyev appeared to signal a softening of his country's opposition to hydropower projects in the region. Although no concrete agreement was signed between Tajikistan and Uzbekistan in this regard, the Uzbek government suggested that it was willing to compartmentalize the issue while pushing ahead with other areas of cooperation.

Furthermore, Uzbekistan and Kyrgyzstan achieved a breakthrough, agreeing to cooperate in the construction of the Kambarata Dam in Kyrgyzstan. As was the case with Tajikistan, Kyrgyzstan faced opposition over concerns about the dam's impact on the water supply to Uzbek farmers. Although specific terms for financial cooperation were not disclosed at a high-level meeting in September, the surprise agreement signaled a greater willingness among Central Asian countries to share resources. Uzbekistan and Kyrgyzstan also signed a landmark border demarcation treaty in 2017, settling a long-running dispute.

In addition, government representatives from Central Asia's two largest countries, Uzbekistan and Kazakhstan, met numerous times during the year, signing agreements for cooperation on agriculture, energy, industry, and transportation. Bilateral trade between Uzbekistan and Kazakhstan increased 35 percent through September as compared with the same period in 2016; Kazakh president Nursultan Nazarbayev spoke of setting a target of US $\$ 5$ billion in annual bilateral trade by 2020, a significant increase over the 2016 figure 
of US $\$ 2$ billion. Long-shuttered border crossings between the two countries were reopened, and a high-speed train link was launched between Almaty, Kazakhstan, and the Uzbek capital, Tashkent, in 2017.

While Uzbekistan's overtures to its neighbors drew the most attention, other countries in the region also continued to develop links. On the trade front, Kazakhstan and Kyrgyzstan agreed to increase railway cargo transport as part of their obligations under the Eurasian Economic Union. Moreover, Kazakhstan allocated US\$41 million in technical assistance to help Kyrgyzstan modernize its customs procedures and sanitary and phytosanitary testing facilities.

Regional integration was encouraged by initiatives from outside the region, such as China's continuing push to develop its Belt and Road Initiative. Several countries in the region, including Kazakhstan and Kyrgyzstan, already trade agricultural goods with China following a series of bilateral inspections and agreements. China and Kazakhstan agreed to further strengthen trade and cooperation in agriculture by signing a bilateral agreement in July 2017. The agreement includes the construction of a wheat terminal at the Kazakh-Chinese border and enhanced trade, investment, technology transfer, and innovation in agricultural production, wheat processing, and food safety infrastructure. Uzbekistan and China signed economic cooperation agreements worth US $\$ 20$ billion in May 2017 at the first meeting of the two countries' leaders. Chinese investment in logistics and infrastructure has increased in Central Asia in recent years, and several highway and railway projects crossing the region are being considered.

\section{LOOKING FORWARD}

Economic improvements in the region in 2017 primarily reflect recovery of commodity prices, macroeconomic stabilization, improved regional cooperation, and significant growth in remittance flows. Relatively positive price prospects for Central Asia's major commodity exports support a favorable economic outlook for the near future. Economic improvements in Russia and Kazakhstan will improve economic growth prospects, household welfare, and food security in other countries of the region through trade, investment, and remittances. In addition, greater regional cooperation and market integration in the context of ongoing reform efforts in Uzbekistan and other countries of the region may lead to a greater inflow of private investment. Also, China's Belt and Road Initiative may provide Central Asian countries new opportunities to address the region's infrastructure needs and strengthen regional economic connectivity.

On the downside, the Russian economy risks a slower recovery due to the expansion of Western sanctions in August 2017. ${ }^{16}$ Moreover, the benefits for economic growth and household welfare of higher export prices and remittance inflows will likely be partially offset by higher import prices, driven by higher energy prices and currency depreciation. Accelerating progress toward meeting Eurasian Economic Union standards for domestic production will remain a key challenge for Kyrgyzstan but will help Kyrgyz producers boost agricultural exports to the regional market. Continued challenges in the financial sector, especially in Tajikistan, may have negative impacts on the pace of poverty reduction and on food security as a result of reduced credit availability in pro-poor sectors of the economy and limited employment opportunities in low-skill sectors such as agriculture. ${ }^{17}$ 


\section{South Asia}

\section{Food Systems at a Crossroads}

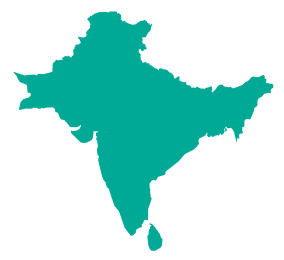

\section{ANJANI KUMAR, AKHTER AHMED, STEPHEN DAVIES, AND P. K. JOSHI}

Anjani Kumar is a research fellow, South Asia Office, International Food Policy Research Institute (IFPRI), New Delhi, India. Akhter Ahmed is a senior research fellow and chief of party, Bangladesh Policy Research and Strategy Support Program, IFPRI, Dhaka, Bangladesh. Stephen Davies is a senior research fellow, Development Strategy and Governance Division, IFPRI, Islamabad, Pakistan. P. K. Joshi is director for South Asia, South Asia Office, IFPRI, New Delhi.

Rising exports, low oil prices, higher infrastructure spending, and supportive macroeconomic policies helped to make South Asia the world's fastest growing region again in 2017, with economic growth projected to reach 7.1 percent in 2018. 'Growth across the region was not uniform, however, ranging from 0.6 percent in Nepal to 7.1 percent in both Bangladesh (a historical high) and India (Figure 1). ${ }^{2}$ Growth in agricultural gross domestic product (GDP) in South Asia also varied from country to country, shrinking by more than 4 percent in Sri Lanka in 2016, for example, and growing by 6 percent in Afghanistan. Agricultural GDP growth slowed in Bangladesh, but rose significantly in Bhutan and India.

\section{NATURAL CALAMITIES AND AGRICULTURAL GROWTH}

South Asia is highly vulnerable to the impacts of climate change. ${ }^{3}$ Climate variables such as temperature, rainfall, flooding, and drought increasingly affect agricultural activities in the region. Most South Asian countries weathered some form of natural calamity in 2017: by August, roughly a third of Nepal was flooded, affecting about 1.7 million people and damaging more than 34,000 homes ${ }^{4}$; heavy floods in Bangladesh damaged crops, including the country's main food staple, rice ${ }^{5}$; flooding and drought at turns plagued Sri Lanka as well as some 18 states in India,

FIGURE 1 Growth rates in GDP and agricultural GDP in South Asia, 2016

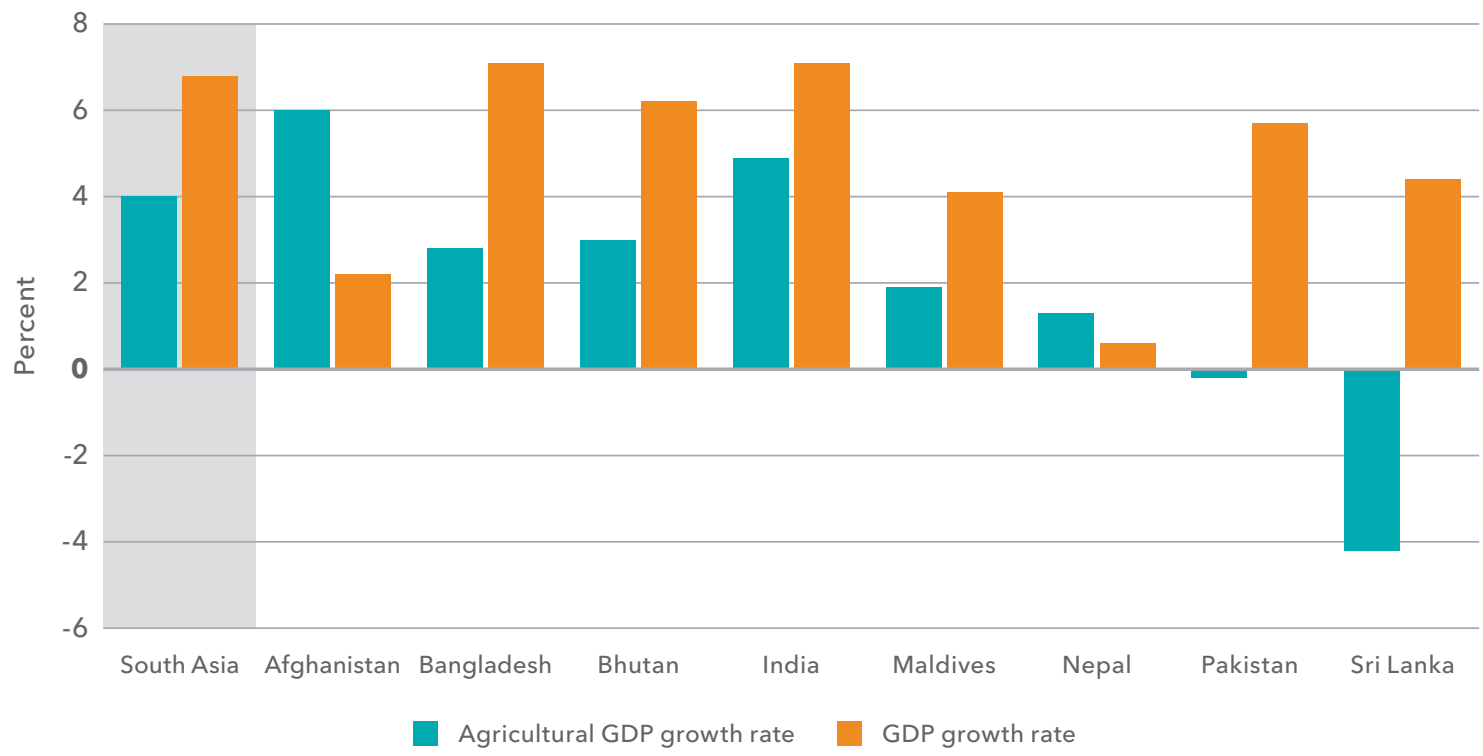

Source: World Bank, World Development Indicators, accessed November 15, 2017, https://data.worldbank.org/.

Note: GDP = gross domestic product. 
which saw a sizable drop in rainy-season food grain production as a result ${ }^{6}$; and below-average rains sharply reduced 2016 cereal production in Pakistan. ${ }^{7}$

\section{INFLATION}

Although consumer price inflation in South Asia slowed from 4.5 percent in 2016 to 4.2 percent in 2017 (Figure 2), ${ }^{8}$ this rate was the second highest among all regions. Moreover, inflation rates varied widely from country to country-from as little as 3.1 percent in the Maldives up to 7.0 percent in Sri Lanka-as did food inflation rates.

Food prices in Afghanistan-particularly of meat, spices, vegetables, and sugar-rose by 4.4 percent in 2016. Average annual inflation in Bangladesh dipped in 2016 and is expected to increase slightly in 2017, given rising nonfood inflation resulting from higher wages and natural gas and electricity prices. In Bhutan, average inflation halved in 2016, but is expected to rise in 2017. Inflation in India remained subdued for a second straight year, averaging 4.5 percent in 2016. In the Maldives, food prices skyrocketed by 70-100 percent when the government lifted subsidies for staple goods, and inflation rose, threatening to reach 3.1 percent in 2017. Inflation in Nepal is expected to drop to 4.5 percent after spiking to 9.9 percent in 2016 due to earthquakes, trade disruptions, and weak agricultural performance. In Pakistan, meanwhile, low global oil and commodities prices, a stable food supply, limited government borrowing, and exchange rate stability brought consumer inflation down to 2.9 percent in 2016, but this is expected to rise to 4.2 percent in 2017 as a result of rising fuel prices and domestic demand. Likewise, average annual inflation in Sri Lanka moderated to 4.0 percent in 2016, but is expected to reach 7.0 percent in 2017.

\section{GLOBAL FOOD VALUE CHAINS, INVESTMENTS, AND FOOD SYSTEMS}

The emergence of global food value chains has changed the nature of food systems across the world and offers new opportunities for South Asian countries to exploit their regional potential. As populations, incomes, and urbanization are all on the rise, consumers in the region are looking toward international markets to satisfy their food demand. South Asia's participation in the global food export market has also expanded. At the same time, the region is one of the least integrated internally: intraregional trade accounts for only 5 percent of South Asia's total trade, whereas it accounts for 25 percent in Southeast Asia. Similarly, intraregional investment makes up less than 1 percent of overall investment. ${ }^{9}$

While foreign direct investment (FDI) decreased globally in 2016, South Asia saw an increase of roughly US $\$ 13$ billion. $^{10}$ In 2017, India alone attracted

FIGURE 2 Year-on-year inflation in South Asia

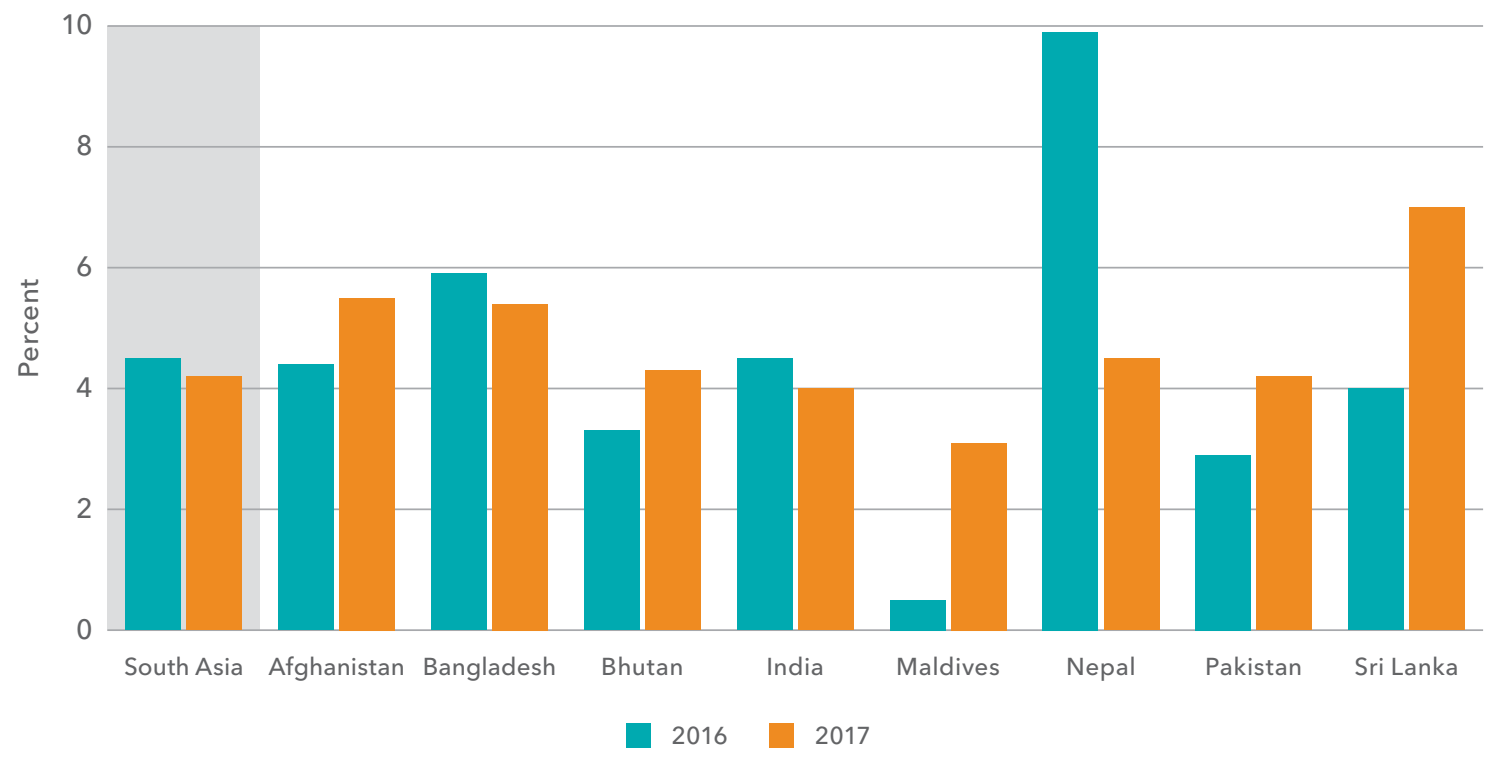

Source: Asian Development Bank, 2017, accessed on November 23, 2017, https://data.adb.org/. 
US $\$ 60$ billion in FDI, as investors gained confidence in India's recent efforts to improve the ease of doing business and reforms in FDI norms. The share of agriculture in total FDI inflow is low, however, accounting for just 3 percent in India and 1.8 percent in Bangladesh.

\section{IMPROVING FOOD AND NUTRITION SECURITY}

Poverty and malnutrition continue to vex South Asia. In 2016, two of every five stunted children in the world lived in the region, and more than 15 percent of children under five in South Asia were wasted. The region's stunting level (38 percent) is just above that of Africa south of the Sahara (37 percent) and more than three times higher than those of East Asia and the Pacific (12 percent) and Latin America (11 percent). ${ }^{11}$

Governments are working to address these challenges. Bangladesh has achieved one of the fastest and most prolonged reductions in child stunting in the world. The country belongs to the global Scaling Up Nutrition (SUN) Movement and participated in the Nutrition for Growth Summit and in Compact2025, enacted a National Nutrition Policy, and planned a nutrition-focused health program. As of 2016, social protection programs covered 28 percent of households and accounted for around 12 percent of public spending (2.2 percent of GDP). ${ }^{12}$ With its National Social Security Strategy, Bangladesh is widening the scope of social protection to include employment policies and social insurance. ${ }^{13}$ Through the Agriculture, Nutrition, and Gender Linkages (ANGeL) research project, the country aims to identify actions and investments in agriculture that will help improve nutrition and empower women. ${ }^{14}$

India, home to roughly 70 percent of South Asia's poor, is implementing numerous nutrition-specific and nutrition-sensitive programs to address the intermediate and underlying causes of undernutrition, including Integrated Child Development Services, the National Rural Health Mission, the Mid-Day Meals Scheme, the National Food Security Mission, and the Mahatma Gandhi National Rural Employment Guarantee Scheme. ${ }^{15}$ Still, high levels of maternal and child undernutrition persist. In September 2017, India unveiled its National Nutrition Strategy, which provides a framework for achieving an "India free from malnutrition," linked to a "clean India" and "healthy India." In December 2017, India launched the National Nutrition Mission with a three-year budget of about US $\$ 1.4$ billion to reduce the prevalence of stunting, undernutrition, anemia, and low-birthweight babies.

Nepal, whose 2015 Constitution enshrined the fundamental right to food, recorded the world's fastest reduction in child stunting in 2016 (from 56.0 percent in 2001 to 35.8 percent). ${ }^{16}$ Nepal belongs to the SUN Movement and is implementing an ambitious multisectoral nutrition program. Pakistan is also a member of the SUN Movement and various associated networks designed to improve nutrition. In May 2016, the Pakistan SUN Movement Secretariat launched a SUN Academia and Research Network. Pakistan's provinces have taken several steps to improve their food and nutrition status since the devolution of power in 2010 and, with support from UNICEF and other partners, developed a multisectoral strategy to help reduce malnutrition.

In Afghanistan, widespread internal displacement and an influx of returnees and refugees continued to hamper access to health and nutrition services in 2016 and $2017 .^{17}$ The government is aiming to reduce child stunting from 41 to 35 percent by 2020 . Afghanistan committed to joining the SUN Movement in 2017. Sri Lanka, in contrast, focused on poverty reduction in 2017 and launched a plan to achieve UN Sustainable Development Goal 2-"to end hunger, achieve food security and improved nutrition, and promote sustainable agriculture" by $2030 .^{18}$ Sri Lanka has been a SUN member since 2012.

\section{REFORMS IN PUBLIC FOOD DISTRIBUTION SYSTEMS}

Poor governance of food distribution is often cited as a barrier to food and nutrition security in South Asia, though most countries in the region have begun taking steps to address this problem. For instance, India is implementing ongoing reforms to its Public Distribution System, including end-to-end automation, digitization, linking identity (Aadhar) cards to ration cards, and installation of electronic points of sale. ${ }^{19}$ Bangladesh is revamping its Public Food Distribution System, instituting a nationwide electronic system for monitoring public food grain stocks, ${ }^{20}$ and implementing the World Bank-financed Modern Food Storage Facilities Project, which will construct eight modern steel grain-storage silos for 
rice and wheat and 500,000 silos for households in disaster-prone areas. Sri Lanka is emphasizing public-private partnership approaches to creating efficient and stable supply chains, developing a national strategic food reserve to guarantee buffer stocks of essential commodities to stabilize prices. Pakistan launched initiatives to improve quality and standards in its food distribution system.

\section{PROMOTING AGRICULTURAL GROWTH}

In 2016-2017, farming in South Asia received increased investments and renewed attention as a result of new programs and policies aimed at boosting productivity through promoting sustainable, diversified, and climate-smart agriculture. Nepal has increased its agricultural budget by about 42 percent over the last two years, and confirmed its commitment to modernize agriculture and achieve self-sufficiency in staple crops, fruits, and vegetables, although this can be a difficult policy to sustain fiscally. ${ }^{21}$ This effort entails facilitating smallholders' access to markets; ensuring that fertilizer, seed, irrigation, and technology are readily available to them; and improving their access to loans and insurance.

Bangladesh is working to increase production of diverse, nutritive, and high-value crops by promoting the use of agricultural technology through policy reforms, regulations, and incentives. Moreover, the country's efforts to liberalize input markets resulted in a greater supply of improved seeds and fertilizers as well as a burgeoning number of food markets and marketplaces where rural women can sell farm products. ${ }^{22}$ Given India's renewed pledge to double farmers' incomes by 2022, the government launched numerous agricultural initiatives in 2017, including increased credit limits for farmers, the creation of long-term and micro-irrigation funds, and a 60-day interest waiver on agricultural credit. The interest waiver may cause market distortions and may be financially unsustainable. India's government also began to remove structural barriers to agricultural development, in part through a series of legislative reforms, and introduced a new program to support start-ups. ${ }^{23}$ The government aims to facilitate a tripling of the capacity of the country's food processing sector and investment in "mega food parks"-networks of collection centers and primary processing centers designed to increase processing of perishable foods. Finally, a major 2017 tax reform will likely constrict the supply of agricultural inputs in the short term due to price adjustments, but should ultimately lower the price of inputs such as fertilizer and machinery. ${ }^{24}$

Pakistan focused on improving productivity of major crops, diverting scarce natural resources toward production of other high-value crops (such as olives and pistachios), and cultivating pulses and oilseeds for import substitution. In addition, several key pieces of seed legislation were passed in the last two years, and some regional-federal efforts are underway to facilitate farming via fertilizer subsidies and interest-free loans. Subsidies run the risk of promoting overuse of fertilizers, with potential negative environmental consequences, and may not be financially sustainable; interest-free loans run the risk of causing market distortions. The Maldives are developing the linkages between agriculture and tourism and raising agricultural productivity through the adoption of climate-smart agriculture. Sri Lanka continues to aim for self-sufficiency in five major food crops through its National Food Program, despite the potential downside of self-sufficiency strategies, and in 2017 the country strengthened its eco-certification program, improved degraded soil, granted income-tax concessions on backward integration activities in agriculture, introduced various subsidies for agribusinesses and fisheries as well as weather index insurance, and established dairy development zones.

\section{CHALLENGES AND OPPORTUNITIES}

Food systems in South Asia are at a crossroads. Climate change is the most pressing issue facing the region, given its implications for the food security of already vulnerable populations. Increasing climatic variability, extreme weather events, and rising temperatures pose new challenges to ensuring food and nutrition security in the region. Global food value chains and robust economic prospects offer untapped potential for prosperity in the region. Equally important are efforts to increase efficiencies, reduce postharvest losses, and develop the agroprocessing sector. Better intraregional linkages and increased intraregional trade will also help the region to grow. In 2018, South Asian countries are expected to reform their agriculture sectors, increase openness to trade, strengthen linkages with global food value chains, and take steps to adapt to climate change and weather uncertainties. 


\section{East and Southeast Asia}

\section{Progress Continues, Challenges Grow}

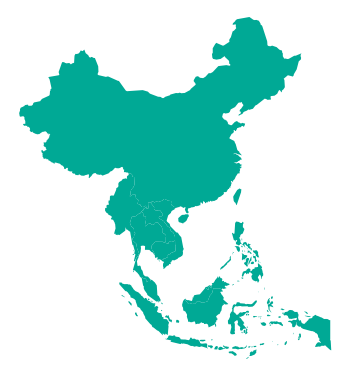

\section{KEVIN CHEN, PETER TIMMER, DAVID DAWE, AND ZIMEIYI WANG}

Kevin Chen is a senior research fellow and head of the East and Central Asia Office, International Food Policy Research Institute (IFPRI), Beijing, China. Peter Timmer is professor emeritus, Harvard University, Cambridge, and a nonresident fellow, Center for Global Development, Washington, DC, USA. David Dawe is a senior economist and regional strategy and policy advisor, Food and Agriculture Organization of the United Nations, Bangkok, Thailand. Zimeiyi Wang is a research assistant, East and Central Asia Office, IFPRI, Beijing, China.

The East and Southeast Asian economies saw strong growth in consumption and investment in 2017. Economic growth in China and the Association of Southeast Asian Nations (ASEAN) is expected to reach 6.8 percent and 5.1 percent for the year, respectively. ${ }^{1}$ Despite this favorable position, food insecurity and malnutrition remain a concern in a number of countries in the region. The 2017 Global Hunger Index reveals that six countries fall into the "serious" category, namely, Cambodia, Indonesia, Lao PDR, Myanmar, the Philippines, and Timor-Leste, while obesity is increasing rapidly throughout the region (albeit from a low base). ${ }^{2}$ To link the region's strong macroeconomic performance with continuing reductions in poverty and malnutrition, broad reforms are likely to be necessary to (1) improve productivity and sustainability in the agriculture and rural sectors, (2) promote and embrace regional integration, and (3) kick economic growth into higher gear.

\section{REGIONAL TRADE DYNAMICS}

China's imports of major agricultural products continued to increase rapidly, creating more opportunities for ASEAN's key agricultural exports. These opportunities are mainly driven by cost differentials and rising demand. China now has the world's largest middle class, with diversified and higher-quality diets. Strong growth in Chinese demand led to a surge in palm oil exports from Malaysia and Indonesia, and rice exports from
Cambodia, Thailand, and Viet Nam. Myanmar also has significant agricultural trade with China. ${ }^{3}$ Benefiting from China's growing appetite, Viet Nam, Thailand, and the Philippines are exporting more tropical fruits, and rising demand has the potential to drive an increase in the export price of some luxury fruits, such as durian, in international markets. ${ }^{4}$ Many regional exporters are seeking ways to penetrate global markets for higher-quality and higher-value products.

Demand for corn and soybean imports is growing in several countries as a result of the shift in domestic demand and trade policies. For example, in Viet Nam, higher incomes, a growing urban population, and a shift to more protein-rich diets combined to boost the country's meat and dairy production, with a corresponding need for animal feed. Viet Nam also needs to feed its rapidly expanding fish and shrimp export sectors. The fast-growing feed industrywhich relies heavily on imported feed ingredients due to inadequate domestic production and low quality-contributed to a surge in soybean and corn imports in $2017 .^{5}$

Facing the same problem, Indonesia imposed tighter rules on imported feed ingredients and is trying to promote domestic production. Indonesia's corn imports declined because of the government's push for corn self-sufficiency and the government may actually prohibit corn imports before the end of 2017 to increase corn prices and give Indonesian farmers an incentive to increase productivity. ${ }^{6}$ Given that feed is the major cost component in poultry 
production, these policies will raise the domestic price of chicken and make it more difficult for the poor to afford this high-quality protein.

\section{STRUCTURAL TRANSFORMATION}

Connecting rural areas to the economic growth process and helping the poor to enter pathways out of poverty requires a successful structural and agricultural transformation. Japan, the Republic of Korea, and Malaysia are well advanced in this transition, with agriculture playing a small role in their economies. Cambodia, Lao PDR, and Myanmar remain at the early stage, where agriculture dominates the economy. China, Indonesia, the Philippines, and Thailand are well into the transition.

Thailand is the largest food exporter in ASEAN, and farm policies will be a crucial element of Thailand's development strategy over the next two decades. Policies designed to upgrade productivity in the farm sector and make the country one of the world's "food super powers" are being prioritized."

China is focusing on reforming its domestic agricultural policies to address the coexistence of excess demand for some high-quality agricultural products and excess supply of key low-quality agricultural products. China also pledged to pursue a rural vitalization strategy, prioritizing the development of agriculture and rural areas in the coming years. ${ }^{8}$ In Viet Nam, the government's agricultural restructuring plan aims to reach 3 percent annual agricultural growth and increase both average labor productivity and the average income of farmers. The government is also implementing a national target program to build a "new countryside" through regional comparative advantage and local specialized products, especially in disaster-prone areas. ${ }^{9}$

Changing land tenure patterns are closely related to agricultural development and the broader process of structural transformation. In much of the region, the transition to larger farm sizes has been very slow, and land fragmentation remains a major obstacle to long-term agricultural investment. However, policy makers are designing land consolidation policies for larger-scale production and economies of scale. China has cleared the way for private investment in large-scale farming. This accelerates a trend toward agricultural capitalism by using "land management rights," which allow a village to collectively transfer its land to a corporation in return for a guaranteed revenue stream. Policies to encourage the lease of land-use rights are also in play in Viet Nam. The country is promoting the establishment of an agricultural land bank that will create a mechanism for mobilizing funds for agricultural development and high-tech production on a large scale. ${ }^{10}$ In Thailand, 800 farm cooperatives nationwide will be tasked by the Thai government with advancing large farms that benefit from economies of scale and greater bargaining power when dealing with middlemen. ${ }^{11}$

\section{BOOMING E-COMMERCE}

With Southeast Asia's skyrocketing internet connectivity and middle-class spending power, e-commerce giants are investing heavily in the region. These investments include the acquisition of Southeast Asian e-commerce platforms by leading companies from China and the United States. ${ }^{12}$ That said, the full potential of these innovations is still unknown. E-commerce could substantially improve the efficiency of agricultural supply chains and strengthen smallholders' access to critical inputs and urban markets. Already, Chinese e-grocery supply chains are using drones to deliver packages throughout rural areas and are setting up fully automated sorting centers. ${ }^{13}$ Online platforms can shorten the value chain by eliminating many middlemen, whose participation drives up prices for consumers and reduces farmers' profit margins.

E-commerce enjoys policy support across the region. China incorporates e-commerce development into its Internet Plus modern agriculture strategy. The Indonesian government is seeking to bring innovation and digital transformation to the largely undigitized agriculture sector. There is also a trend toward simplifying procedures for cross-border e-commerce. Malaysia launched the world's first Digital Free Trade Zone, while the Chinese government continues to provide preferential treatment to overseas goods purchased online and distributed through bonded warehouses. ${ }^{14}$

\section{BUILDING CLIMATE RESILIENCE}

As agricultural production in Southeast Asia is recovering from recent El Niño impacts, promoting resilience and adaptation to climate change remains at 
the top of the agenda. ${ }^{15}$ ASEAN is taking a common stance on this issue, and members are sharing experiences with climate adaptation through regional climate information systems and resilience networks. ${ }^{16}$

Smart farming is the movement of the moment. It represents the application of modern information and communication technologies in agriculture, leading to more precise and sustainable approaches. Countries across the region are designing national strategies to upgrade farming with technology and innovative farming methods that can boost farmers' profits and their ability to adapt to climate change. Thailand is formulating a 20-year national reform program to strengthen farmers' flexibility and diversify agricultural products, with the twin goals of helping farmers escape from poverty and farm sustainably. The Philippine government has tested the use of drones to identify where agricultural land is most vulnerable to natural disasters, and will use the information collected to adapt agricultural plans and better prepare for disasters. Myanmar began promoting climate-smart villages to support community-based adaptation programming. Indonesian farmers, with support from the Food and Agriculture Organization of the United Nations, are using conservation agriculture to make their production more secure. Conservation agriculture includes techniques that minimize soil disturbances and help farming systems weather climate change. ${ }^{17}$

Agricultural genetic resources can be victims of climate change, but they are also of fundamental importance for both climate change adaptation and mitigation. Lao PDR is planning to set up a gene bank for agro-biodiversity protection, primarily to protect its more than 15,000 varieties of rice. A multicountry seed policy agreement was signed by South and Southeast Asian countries to speed up the development and distribution of climate-resilient rice varieties and help vulnerable farmers achieve sustainable production. ${ }^{18}$

\section{REGIONAL INTEGRATION AND THE WAY FORWARD}

Despite rising protectionism around the world, Asian countries are pursuing deeper regional integration. Regional trade is being promoted through a set of plans and mechanisms that outline ASEAN's commitment to regional connectivity through (1) the enhancement of infrastructure, (2) seamless logistics, (3) an improved regulatory environment, (4) digital innovation, and (5) increased labor mobility. ${ }^{19} \mathrm{~A}$ wider bloc is being formed at the same time: the Regional Comprehensive Economic Partnership, a free trade agreement between ten ASEAN members and their six trade partners-Australia, China, India, Japan, New Zealand, and the Republic of Koreawill finalize an agreement at the end of 2018, offering a framework aimed at reducing trade barriers and ensuring improved market access for goods and services. China's Belt and Road Initiative is also welcomed, since it fits with the integration and infrastructure needs of ASEAN. ${ }^{20}$

In contrast to the trend toward integration, major rice importers, including China, Indonesia, Malaysia, and the Philippines, have historically placed great emphasis on self-sufficiency objectives, although such policies tend to cause supply shortages, drive up domestic rice prices, and exclude vulnerable households from the benefits of economic growth. ${ }^{21}$ High rice prices force the poor to spend a large share of their limited budget on rice, compromising their ability to purchase other, more nutritious foods, such as eggs and meat. ${ }^{22}$ Indeed, the Philippines and Indonesia have high child stunting rates for their levels of income (Figure 1), probably caused in part by high rice prices. Lao PDR and Timor-Leste also have high stunting rates and relatively high rice prices. Lowering domestic rice prices would promote more inclusive growth and improve nutrition outcomes.

Looking toward 2018, deeper regional and global market integration, as well as equitable distribution of gains from a broader market, remain a high priority in the region. The Regional Comprehensive Economic Partnership and the Belt and Road Initiative are highly compatible with ASEAN's development strategy and are viewed as important instruments to facilitate trade, economic integration, and market access.

For individual countries, broader trade facilitation measures are needed to take advantage of new market opportunities made possible by free trade agreements. Harmonization of standards and regulations, as well as inspection, certification, and accreditation procedures, are central to fostering market access.

While an integrated market shows great promise, it will be highly competitive. To benefit from opportunities associated with integration, all countries will need to enhance competitiveness by meeting the demands for higher quantity, quality, and safety of food products. Countries in the Greater Mekong 
FIGURE 1 Child stunting prevalence and GDP per capita, selected countries

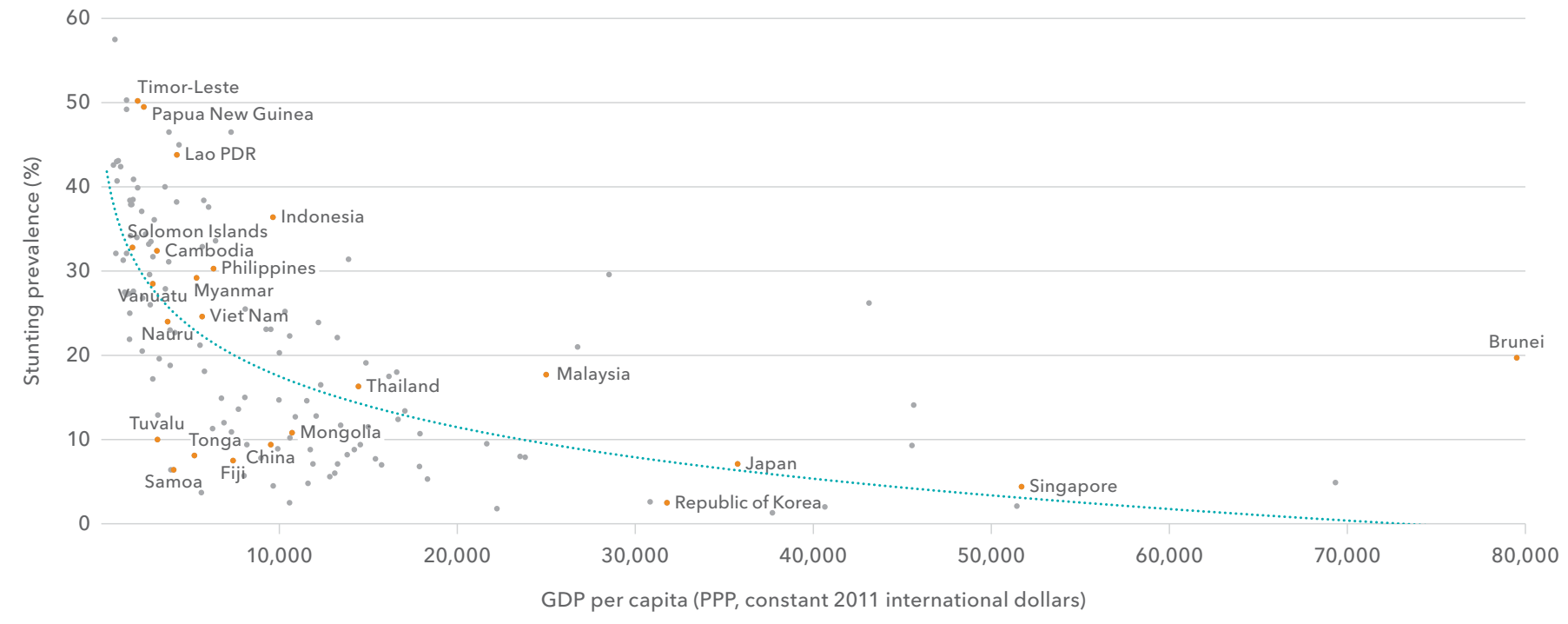

Source: Authors' calculations using data from Development Initiatives, Global Nutrition Report: Nourishing the SDGs (Bristol, UK: 2017).

Note: Data are the most recent available for each country. GDP = gross domestic product.

region (Cambodia, China, Lao PDR, Myanmar, Thailand, and Viet Nam) have already endorsed a five-year strategy and action plan to build a regionwide food safety system that features mutually recognized standards, product tracing, and information sharing. Enhanced food safety regulatory systems can improve competitiveness among food producers in both domestic and international markets, and benefit consumers with safer food and better health. ${ }^{23}$
Going forward, emphasis should be placed on enhancing infrastructure investments, upgrading agricultural value chains (and regulating them to ensure food safety), as well as enhancing farm management systems for higher productivity and reduced ecosystem damage. In the same vein, the region's governments should also incentivize the public and private sectors to promote agricultural research and development. 


\title{
Latin America and the Caribbean
}

\section{Integration and Growth Advance}

\author{
EUGENIO DÍAZ-BONILLA AND VALERIA PIÑEIRO
}

Eugenio Díaz-Bonilla is head of the Latin America and Caribbean program and Valeria Piñeiro is a senior research coordinator, Markets, Trade, and Institutions Division, International Food Policy Research Institute, Washington, DC, USA.

Agricultural production in Latin America and the Caribbean (LAC), along with other commodities, has always played a central role in the region's integration with the global economy. With an evolving range of export crops, the region's economic performance has been closely tied to trends and cycles in international commodity markets. Through different waves of globalization, the region moved toward greater integration into the global economy only to be followed by periods of de-linking. The last several decades saw increased globalization. ${ }^{1}$ For instance, the overall trade-to-gross domestic product (GDP) ratio-a key measure of openness-moved from about 0.20 in the 1960 s to 0.37 in the 2010s. Despite this strong shift, LAC is not the most open region in the world; East Asia and the Pacific's ratio is now at 0.52 . Foreign direct investment, which was about 0.7 percent of the LAC region's GDP in the 1980s, began to increase in the 1990 s (to about 1.7 percent) and reached 2.5 percent in the current decade. For comparison, the average for all developing and emerging markets is about 1.8 percent.

\section{GLOBAL INTEGRATION}

In terms of flows of people, while LAC was historically a significant recipient of immigrants, during recent decades several countries, particularly in the northern part of the region, became sources of migration, primarily to the United States and Europe. As shown by the levels of remittances from nationals living abroad, measured as a percentage of GDP (average 2010s), the countries benefiting most from remittances are Haiti (22.9 percent), Honduras (16.8 percent), El Salvador (16.4 percent), Jamaica (15.7 percent), Guyana (12.6 percent), Guatemala (10.1 percent), Nicaragua (9.5 percent), and the Dominican Republic (7.4 percent). And although the level of remittances is smaller in Mexico (about 2.0 percent), more than 10 percent of Mexico's domestically born population lives in the United States (including people of Mexican descent could more than double that percentage).

LAC's integration into the world economy was historically driven by ties to Europe and the United States, but is now also influenced by China's growing presence as a trade and investment actor in the region. China is currently the top destination for South American exports and the second destination, after the United States, for all LAC exports. However, the composition of LAC exports to China is heavily tilted toward primary commodities, much more so than the overall composition of LAC exports to the world. LAC is primarily buying manufactured goods from China and running a substantial deficit with that country as a result, which has led to increasing doubt about the benefits for LAC of this structure of trade. ${ }^{2}$

To characterize the increasing integration of the Latin American agriculture sector, we look at the export-orientation ratio and the import-penetration ratio-that is, the value of agricultural exports or imports over the value of agricultural production (Table 1).

The export-orientation ratio has increased consistently since the 1990s for the world as a whole, as well as for Mexico/Central America and South America, but has decreased for the Caribbean. The import-penetration ratio has increased for the world and all regions, with the exception of South America, which has remained stable. This suggests that the world as a whole and Mexico/Central America have become more globalized on both the export and import sides since the 1990s, while the Caribbean has increased its integration only on the 
import side, and South America has become more export-oriented as its import ratio remained steady. LAC's growing presence in world agricultural markets is also evidenced by the fact that net exports (exports minus imports) from the region are now the largest at the global level, surpassing the combined net exports of the United States, Canada, Australia, and New Zealand (Figure 1).

As noted in other sections of this report, a heated debate is taking place about whether globalization is a panacea for ending hunger and malnutrition and reducing poverty or whether it has a negative impact on those and other dimensions of welfare in developing countries. ${ }^{3}$ In the case of LAC, growing integration into the global economy developed in parallel with improvements in poverty and undernutrition indicators; the region as a whole attained several of the Millennium Development Goals in 2015 , including cutting by half both the percentage of underweight children under five and undernourishment in the total population between 1990 and 2015 and also reducing by half the percentage of people with incomes below US $\$ 1.25$ (PPP) per day. ${ }^{4}$ However, these changes have been accompanied by an increase in overnutrition and related noncommunicable diseases, problems that nonetheless coexist with undernutrition in some LAC countries. ${ }^{5}$
TABLE 1 Agricultural export and import ratios

\begin{tabular}{|l|c|c|c|}
\hline & \multicolumn{3}{|c|}{ Export-orientation ratios } \\
& $1990 \mathrm{~s}$ & $2000 \mathrm{~s}$ & $2010 \mathrm{~s}$ \\
\hline Caribbean & 0.63 & 0.56 & 0.56 \\
\hline Mexico/Central America & 0.43 & 0.62 & 0.81 \\
\hline South America & 0.48 & 0.65 & 0.64 \\
\hline World & $\mathbf{0 . 3 7}$ & $\mathbf{0 . 4 2}$ & $\mathbf{0 . 4 3}$ \\
\hline & Import-orientation & ratios \\
\hline Caribbean & 0.78 & 1.28 & 1.57 \\
\hline Mexico/Central America & 0.41 & 0.68 & 0.80 \\
\hline South America & 0.18 & 0.17 & 0.17 \\
\hline World & $\mathbf{0 . 3 9}$ & $\mathbf{0 . 4 4}$ & $\mathbf{0 . 4 4}$ \\
\hline
\end{tabular}

Source: $\mathrm{FAO}$ (Food and Agriculture Organization of the United Nations), FAOSTAT database, accessed December 28, 2017, http://faostat.fao.org/.

\section{RECENT DEVELOPMENTS}

After two difficult years in which $L A C$ economies barely grew (less than 0.1 percent regional GDP growth in 2015) or declined (-1.0 percent growth in 2016), the region was projected to grow at 1.1 percent in 2017 and 2.0 percent in 2018. ${ }^{6}$ Although an improvement, these projected rates remain below the more than 3.0 percent growth projected for the

FIGURE 1 Net trade in agricultural products (million current US\$)

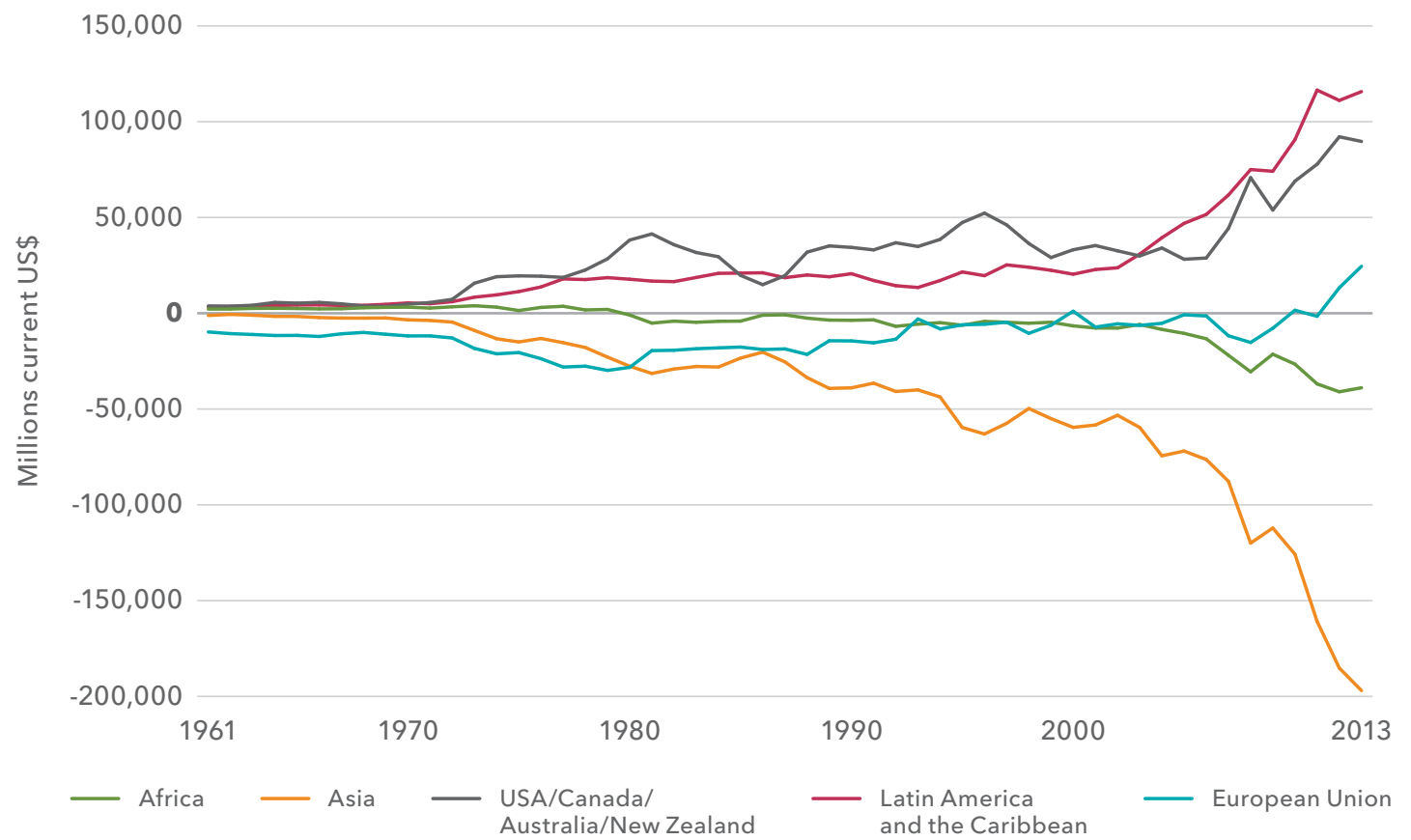

Source: FAO (Food and Agriculture Organization of the United Nations), FAOSTAT database, accessed December 28, 2017, http://faostat.fao.org/. 
world. The slowdown and sluggish recovery have taken a toll in terms of poverty and undernourishment. Recent estimates suggest that undernourishment rates in the region rose from 6.3 percent of the population in 2015 to 6.6 percent in 2016.7

The best economic performers for 2017 are expected to be Bolivia, Costa Rica, the Dominican Republic, Nicaragua, and Panama, all with GDP growth rates of 4.0 percent or higher. In the case of the region's three largest economies, Mexico is projected to have grown at 1.7 percent, Argentina at 2.2 percent, and Brazil at 0.2 percent. For Brazil, which suffered declines of more than 3.0 percent in 2015 and 2016, this represents the beginning of a turnaround. Venezuela continues to be the troubling exception, with per capita GDP projected to have continued shrinking for the fourth consecutive year in 2017 (-7.4 percent), contributing to a cumulative decline of more than 30 percent since 2014 , due to the fall in oil prices, serious macroeconomic imbalances, and political confrontations that have led to hundreds of civilian deaths. Conditions in Venezuela are increasingly worrisome, with acute shortages of food, medicine, and other basic products. International initiatives are starting a mediation process to try to solve the current political conflict-it is hoped that they will succeed in short order.

Policy changes in the United States related to trade and migration are also modifying the context of global integration for LAC countries. The renegotiation of the North American Free Trade Agreement (NAFTA), which has direct implications for Mexico (such as the disruption of the automobile value chain and the potential decline in agricultural imports from the United States), as well as the US decision to withdraw from the Trans-Pacific Partnership agreement that involves Chile, Mexico, and Peru, will have a variety of effects on the competitiveness of different countries and sectors, depending on how the trade talks evolve. The US government also stepped up countervailing and antidumping measures against imports, such as the case of biodiesel with Argentina, while the implementation of market-access measures that were at advanced stages of approval under the previous US administration were delayed (for example, for lemons from Argentina). Beef imports from Brazil were also restricted for a period of time due to concerns about sanitary issues.

Regarding immigration, the US administration announced changes in rules, procedures, and enforcement, potentially leading to higher rates of deportation. These changes are creating uncertainty, particularly for Mexico and several Central American countries, which could experience an increase in deportation of their nationals from the United States and a reduction in remittances, with potentially strong macroeconomic impacts for these countries. ${ }^{8}$ Also, the reinsertion of returned migrants in their own countries could force adjustments in labor markets, fiscal accounts, and business climate conditions.

Finally, the current US administration put on hold the diplomatic opening with Cuba initiated by the previous administration, which may have broad ramifications for hemispheric relations.

In Colombia, since the revised agreement with the largest guerrilla group (FARC, using the Spanish acronym) was approved by the Colombian congress in November 2016, the peace process seems to be moving forward steadily, which offers the prospect of expanded agricultural production in areas previously affected by conflict.

In terms of natural shocks, following the El Niño event in 2015 and 2016 that was associated with various extreme weather events (from droughts in Central America to floods in some Pacific areas), LAC is now coping with a period of heavy rains and hurricanes in the Caribbean. The 2017 hurricane season was particularly active, with eight storms formed and with strengths not seen since 2005. Hurricanes Harvey, Irma, and Maria severely affected several Caribbean islands, with loss of lives and devastation of agricultural and other production and infrastructure.

\section{GROWTH AND UNCERTAINTY}

The world economy improved in 2017, supporting higher commodity prices. Stronger global growth, along with stabilization of the political conditions in key countries such as Brazil, is allowing the region to recover from the difficult economic conditions of 2016, with the exception of Venezuela. Notwithstanding the current economic recovery, the previous downturn negatively affected social indicators, slowing or even reversing the decline in poverty and food insecurity experienced in prior years, while uncertainties about changes in trade, migration, and other policies in the United States act as a damper on prospects for 2018, especially for Mexico and Central America. Countries in LAC should continue to try to combine prudent macroeconomic policies with high-impact investments in human capital, infrastructure, and technology and innovation, ${ }^{9}$ while strengthening democratic governance. 
"At the global, regional, and national levels, data and evidence must remain at the heart of more open, transparent, and inclusive food systems." 


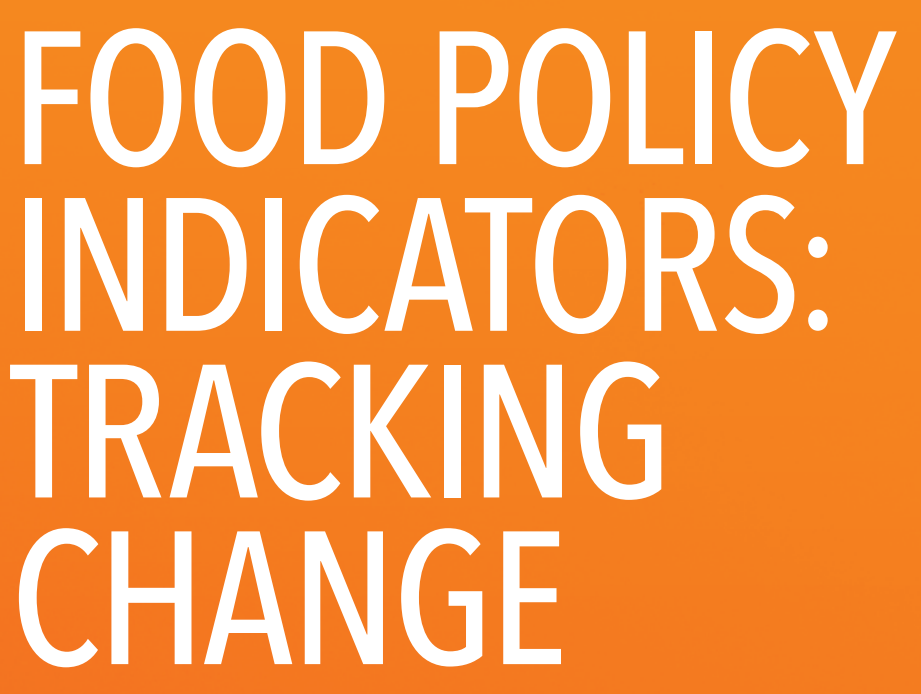

Decision makers and policy analysts need solid evidence and timely information to develop and implement effective food policies. The International Food Policy Research Institute (IFPRI) develops and shares global public goods-including datasets, indicators, and indexes-as part of its mission to provide research-based policy solutions that sustainably reduce poverty and end hunger and malnutrition. This information can be used to gauge the impact of policy changes and the progress made on specific aspects of development.

This section provides updates on data generated by IFPRI research and illustrations of key trends. Indicators include investments in agricultural research, public spending on agriculture, capacity for food policy research, agricultural total factor productivity, and a hunger index at the country level, as well as projections for agricultural production, food consumption, and risk of hunger to 2030 and 2050. All indicators are available online with an interactive display of the data. 
PROJECTIONS OF FOOD PRODUCTION, CONSUMPTION, AND HUNGER 


\section{Agricultural Science and Technology Indicators (ASTI)}

Policy makers recognize that increased investment in agricultural research is key to increasing agricultural productivity. Despite this, many low- and middle-income countries struggle with capacity and funding constraints in their agricultural research systems.

Agricultural Science and Technology Indicators (ASTI), led by the International Food Policy Research Institute (IFPRI), within the portfolio of the CGIAR Research Program on Policies, Institutions, and Markets, works with national, regional, and international partners to collect time series data on the funding, human resource capacity, and outputs of agricultural research in low- and middle-income countries. Based on this information, ASTI produces analysis, capacity-building tools, and outreach products to help facilitate policies for effective and efficient agricultural research.

\section{TRENDS IN CAPACITY AND INVESTMENT}

Global investment in agricultural research, once heavily weighted toward the developed world, shifted dramatically in recent years toward the developing world. Whereas spending growth in high-income countries as a group has stalled since the turn of the millennium, the developing world has accelerated its agricultural research investments at a rapid pace, driven by high growth rates in China and India (Table 1).

Agricultural research spending and capacity in Latin America and the Caribbean and in Asia have grown rapidly since 2000 , but considerable differences remain across countries. Brazil's world-class research infrastructure and outputs contrast sharply with the lagging infrastructure, investment levels, and capacity in many Central American and Caribbean island nations. China accounts for most of the agricultural research spending growth in Asia, with India and Indonesia close behind. But underinvestment in countries such as Cambodia, Lao PDR, and Pakistan impedes their ability to respond to the threats to food security associated with widespread poverty, rapid population growth, climate change, and environmental degradation.
Although agricultural research spending and human resource capacity in Africa south of the Sahara have grown considerably, this growth has been uneven and trends are driven by large countries such as Ethiopia, Nigeria, and South Africa. Furthermore, many countries are overly dependent on volatile and unsustainable donor funds. The region is dealing with serious challenges on the human capacity side: long-term recruitment restrictions have left many research agencies with aging pools of researchers.

Female scientists remain severely underrepresented in agricultural research, despite their unique position to address the pressing challenges of African farmers, the majority of whom are women. ASTI's Women in African Agricultural Research Data Portal-developed in partnership with African Women for Agricultural Research and Development (AWARD) and released in 2017-features detailed sex-disaggregated data on human resources in agricultural research, as well as graphic tools for country comparisons and analysis that allow researchers and policy makers to set priorities, establish benchmarks, and monitor progress over time. These data are currently for African countries, with plans to expand to other ASTI countries in the future. Such information is needed to understand the underlying obstacles faced by women agricultural researchers, and how to overcome them.

The West Asia and North Africa region has made valuable progress in agricultural research investment since the 2008 global food crisis, but inadequate systems, funding, and human resource capacity-coupled with a lack of political stability-hamper food security. Many national agricultural research institutes need to improve pay, working conditions, and incentives to compete with universities and attract, retain, and motivate well-qualified researchers.

In all regions, the imminent retirement of highly experienced agricultural researchers without adequate plans for their replacement creates concern about the quality of future research outputs. 


\section{INDICATORS}

"Agricultural research" includes government, higher education, and nonprofit agencies, but excludes the private for-profit sector. Total agricultural research spending includes salaries, operating and program costs, and capital investments for all agencies (excluding the private for-profit sector) involved in agricultural research in a country. Expenditures are adjusted for inflation and expressed in 2011 prices. Purchasing power parities (PPPs) measure the relative purchasing power of currencies across countries by eliminating national differences in pricing levels for a wide range of goods. PPPs are relatively stable over time, whereas exchange rates fluctuate considerably. In addition to looking at absolute levels of agricultural research investment and capacity, another way of comparing commitment to agricultural research is to measure research intensity-that is, total agricultural research spending as a percentage of agricultural output (AgGDP).

"Total agricultural researchers" (excluding the private for-profit sector) are reported in full-time equivalents (FTEs) to account for the proportion of time researchers actually spend on research activities. A critical mass of qualified agricultural researchers is crucial for implementing a viable research agenda, for effectively communicating with stakeholders, and in securing external funding. Therefore, it is important to look at the share of $\mathrm{PhD}$-qualified researchers. Gender balance in agricultural research is important, given that women researchers offer different insights and perspectives that can help research agencies more effectively address the unique and pressing challenges of female farmers. Age imbalances among research staff should be minimized. Having too many researchers approaching retirement age can jeopardize the continuity of future research.

Research involves unavoidable time lags from the point when investments are made until tangible benefits are attained; in the interim, long-term, stable funding is required. The volatility coefficient measures the volatility of agricultural research spending by applying the standard deviation formula to average one-year logarithmic growth of agricultural research spending over a certain period. A value of 0 indicates "no volatility"; countries with values between 0 and 0.1 are classified as having "low volatility"; countries with values between 0.1 and 0.2 are considered to have "moderate volatility"; and countries with values above 0.2 fall into the "high volatility" category.

\section{MORE INFORMATION}

Only a fraction of the available ASTI indicators is presented here. The ASTI website offers additional indicators, including national-level time series data on researcher capacity by qualification level, age bracket, discipline mix, and commodity, as well as a detailed breakdown of agricultural research investment. Interactive pages on the ASTI website allow users to access country-level time series data, make cross-country comparisons, create graphs, and download country datasets. The country pages also feature recent ASTI factsheets, other country-level publications, and detailed institutional information on agencies involved in agricultural research. The interactive benchmarking tool on the ASTI website is a convenient map-based instrument allowing users to make cross-country comparisons and rankings based on a wide set of financial and human resource indicators. The detailed ASTI datasets are available in an easy-to-use data download tool. Detailed information on definitions, methodology, and calculation procedures are available at www.asti.cgiar.org.

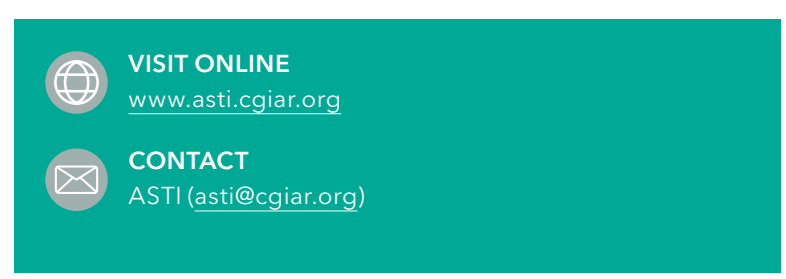


TABLE 1 Agricultural Science and Technology Indicators

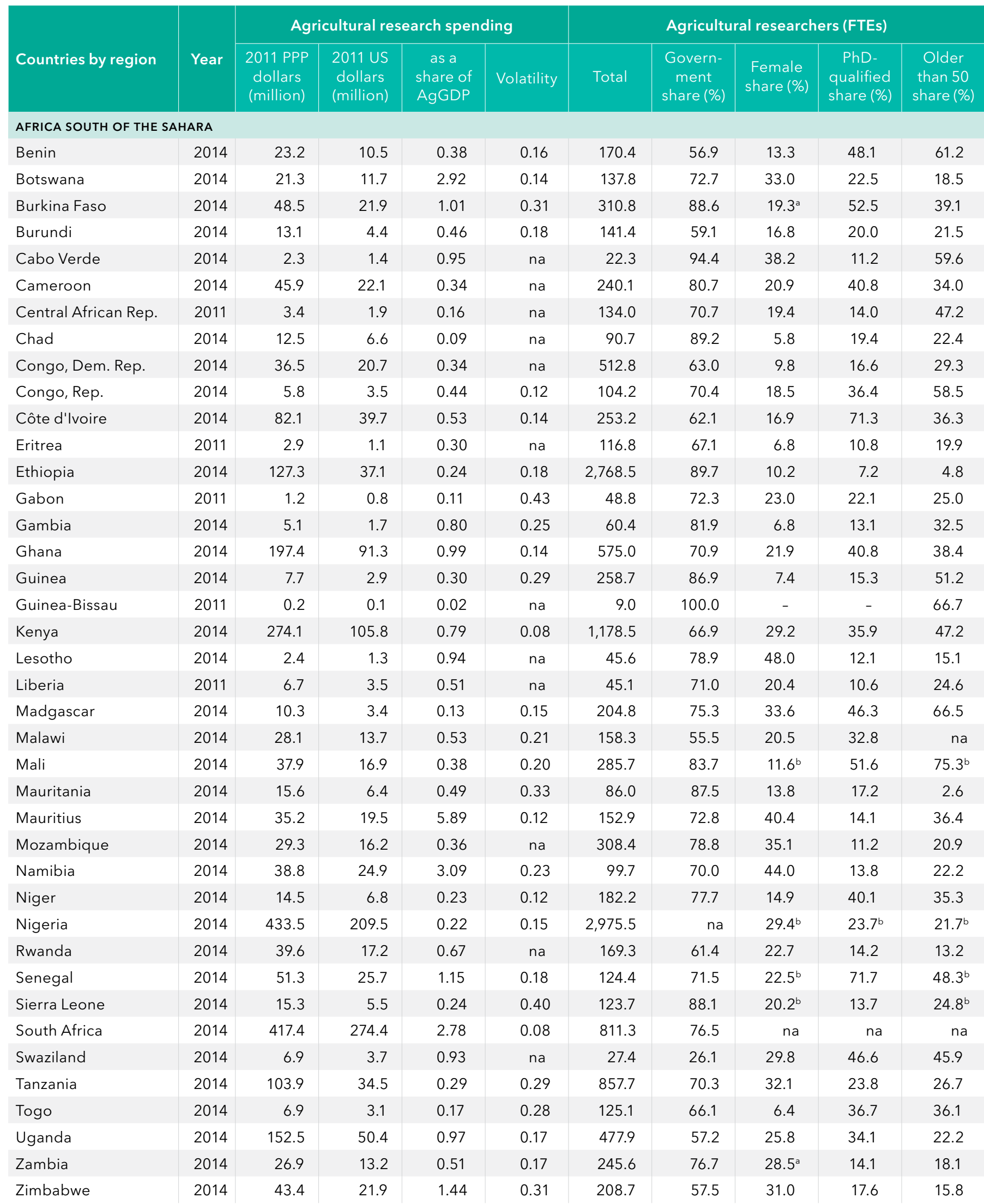


Table 1 continued

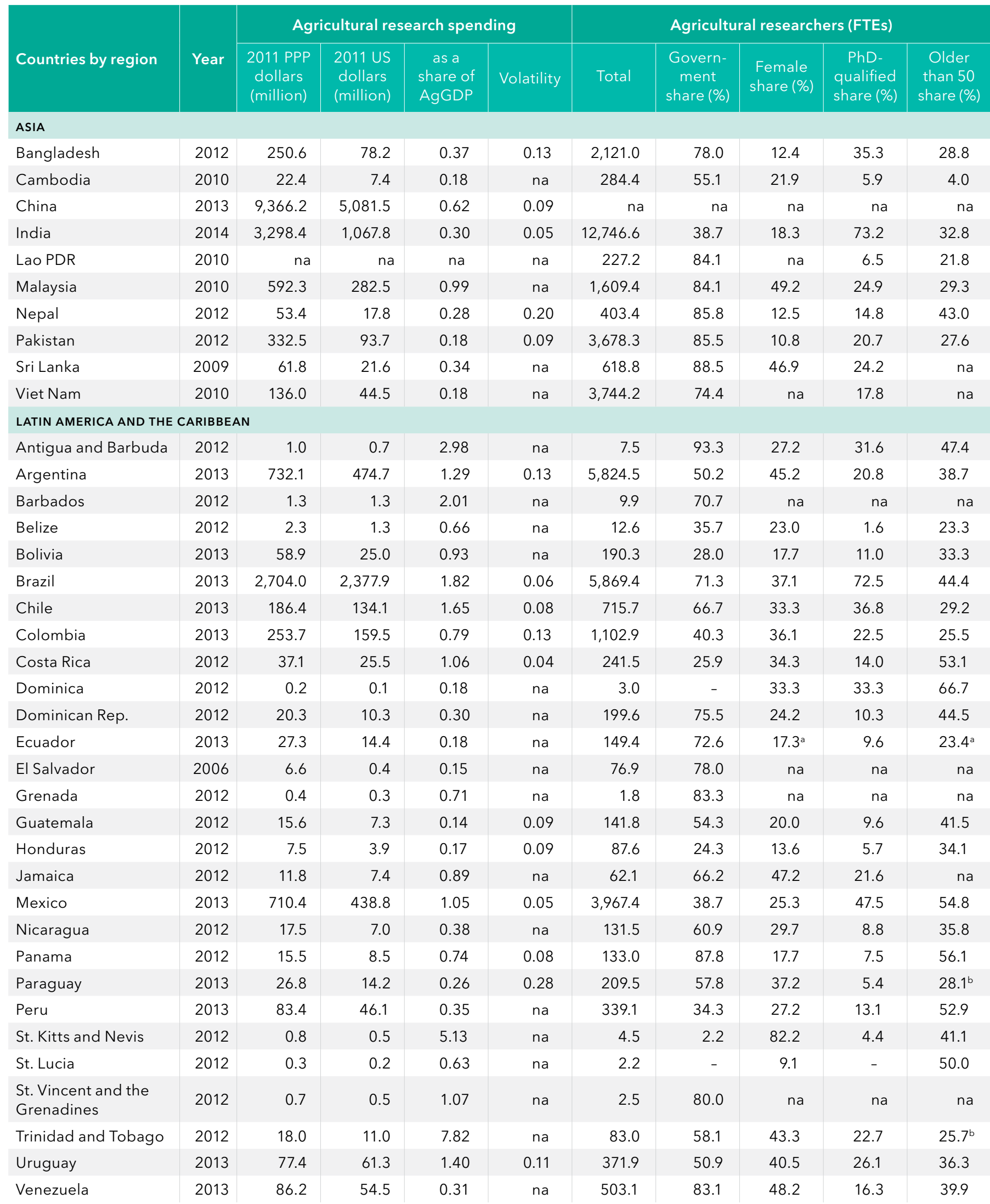


Table 1 continued

\begin{tabular}{|c|c|c|c|c|c|c|c|c|c|c|}
\hline Countries by region & Year & \multicolumn{4}{|c|}{ Agricultural research spending } & \multicolumn{5}{|c|}{ Agricultural researchers (FTEs) } \\
\hline \multicolumn{11}{|c|}{ WEST ASIA AND NORTH AFRICA } \\
\hline Algeria & 2012 & 91.6 & 38.3 & 0.21 & na & 593.4 & 69.8 & 51.3 & 23.0 & $37.5^{b}$ \\
\hline Lebanon & 2012 & 38.2 & 21.3 & 0.95 & na & 209.2 & 58.4 & 48.2 & 44.6 & 13.0 \\
\hline Morocco & 2012 & 147.3 & 442.3 & 0.49 & na & 556.3 & 72.4 & 23.3 & 40.0 & 39.0 \\
\hline Oman & 2012 & 110.0 & 2.6 & 6.51 & na & 243.6 & 91.5 & 31.1 & 25.5 & 10.1 \\
\hline Sudan & 2012 & 57.3 & 26.3 & 0.14 & 0.19 & 932.8 & 72.9 & na & 36.9 & $20.3^{b}$ \\
\hline
\end{tabular}

Notes: $n a=$ not available. PPP $=$ purchasing power parity. AgGDP = agricultural gross domestic product. $(-)=$ zero. FTE $=$ full-time equivalent.

Table only includes countries where ASTI has conducted survey rounds since 2002 with the exception of China, for which data were estimated based on statistical yearbook data published by the Chinese Ministry of Science and Technology. Agricultural research includes government, higher education, and nonprofit agencies, but excludes the private for-profit sector.

$a=$ data exclude the nonprofit sector. $b=$ data exclude the higher education sector. 


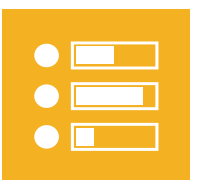

\section{Trend 1}

\section{WOMEN ARE PLAYING A GROWING ROLE IN AGRICULTURAL SCIENCES}

The number of women agricultural researchers rose in both absolute and relative terms between 2008 and 2014; however, the share varies widely across countries. Fewer women than men are trained, recruited, and employed in the agricultural sciences. Where they are employed, women researchers are often young and less likely to have postgraduate qualifications than their male colleagues.

SHARE OF WOMEN IN TOTAL NUMBER OF AGRICULTURAL RESEARCHERS

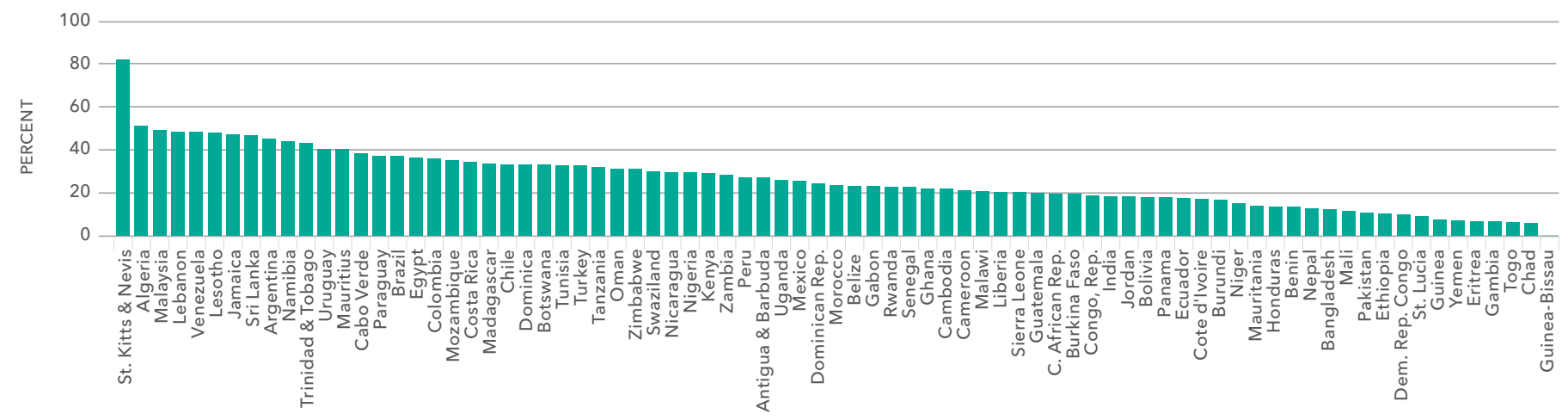

\section{Trend 2}

SPENDING ON RESEARCH IN AFRICA LAGS BEHIND AGRICULTURAL SPENDING INCREASES

Countries in Africa south of the Sahara have made progress in honoring regionwide commitments to support agriculture, as outlined in the Comprehensive Africa Agriculture Development Programme (CAADP). However, many African countries are overlooking research in favor of spending on other agricultural areas such as farm support, subsidies, and irrigation-slowing progress toward sustain-

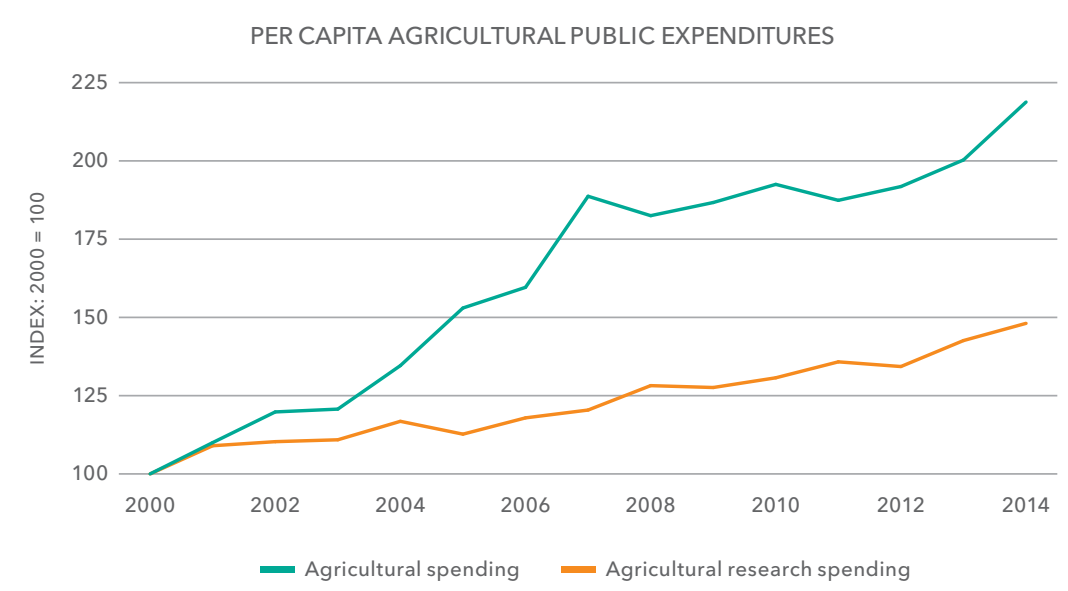
able development.

Source: Data on agricultural spending are from ReSAKSS (www.resakss.org); data on agricultural research spending are from ASTI and various secondary sources.

Note: Agricultural spending only includes funds derived from national governments; agricultural research spending includes funds derived from governments, donors, development banks, producer organizations, and revenues generated internally by research agencies. 


\section{Statistics on Public Expenditures for Economic Development (SPEED)}

The Statistics on Public Expenditures for Economic Development (SPEED) database is a resource of the International Food Policy Research Institute (IFPRI) that contains information on agricultural and other sectoral public expenditures in 147 countries from 1980 to 2014 (see Table 2).

Policy makers, researchers, and other stakeholders can use this robust database to examine both historical trends and the allocation of government resources across sectors. It also allows for comparisons with other countries within a region or at a similar level of development. Because the SPEED database covers many countries for a long time period, it allows analysts of government spending to examine national policy priorities, as reflected in the allocation of public expenditures, and track development goals and the cost-effectiveness of public spending both within and across countries. In addition to the dataset in the form of spreadsheets,
SPEED includes user-friendly tools that enable stakeholders to generate charts and geographic expenditure-maps using menu-driven options.

Indicators reported include total agricultural expenditure, agricultural spending per capita, and the ratio of agricultural spending to agricultural gross domestic product (GDP) for the period 1980 to 2014. IFPRI researchers have compiled data from multiple sources, including the International Monetary Fund, World Bank, United Nations, and national governments, and conducted extensive data checks and adjustments to ensure consistent spending measurements over time that are free of exchange-rate fluctuations and currency denomination changes.

\section{DOWNLOAD DATA}

https://doi.org/10.7910/DVN/INZ3OK

CONTACT

Ifpri-speed@cgiar.org

TABLE 2 Agricultural public expenditure for economic development, by country

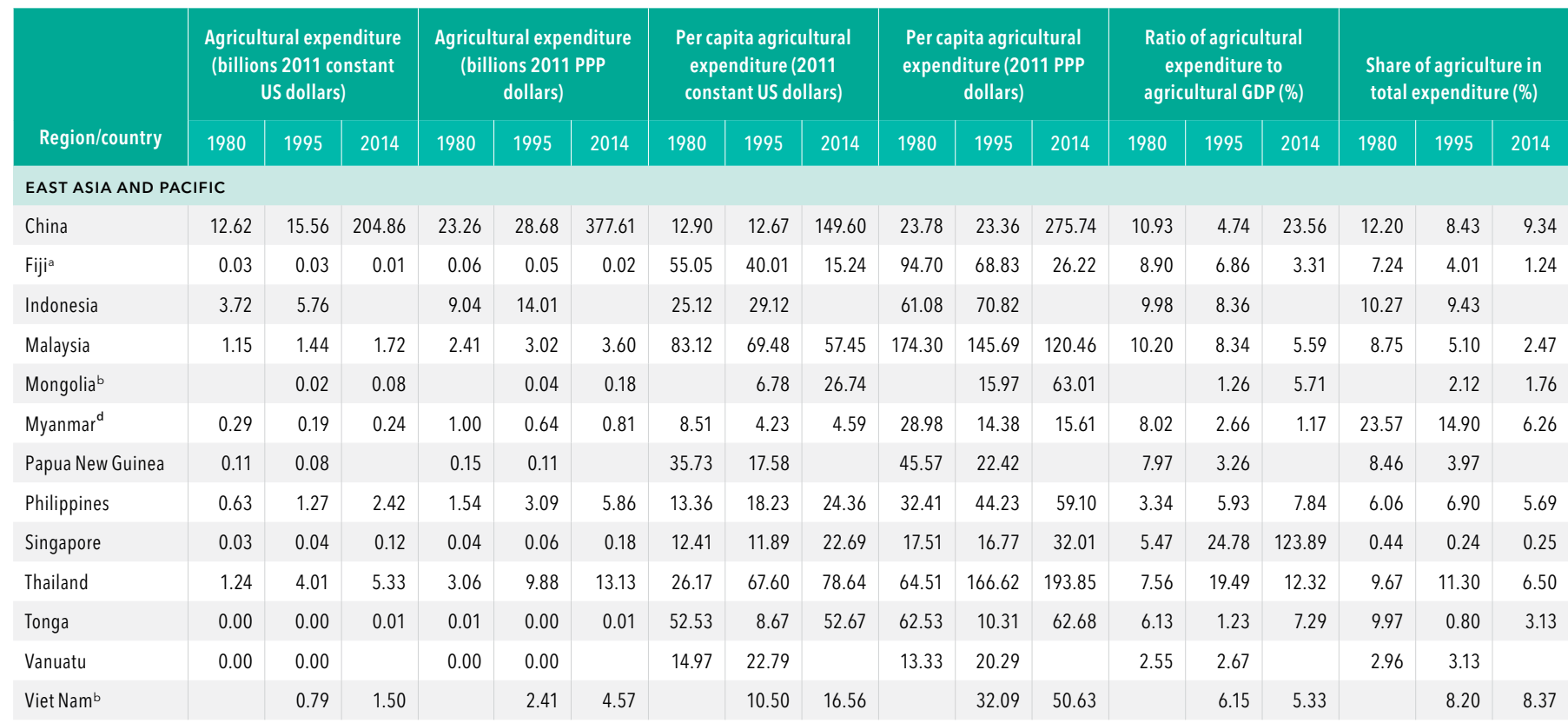


Table 2 continued

\begin{tabular}{|c|c|c|c|c|c|c|c|c|c|c|c|c|c|c|c|c|c|c|}
\hline \multirow[b]{2}{*}{ Region/country } & \multicolumn{3}{|c|}{$\begin{array}{c}\text { Agricultural expenditure } \\
\text { (billions } 2011 \text { constant } \\
\text { US dollars) }\end{array}$} & \multicolumn{3}{|c|}{$\begin{array}{c}\text { Agricultural expenditure } \\
\text { (billions } 2011 \text { PPP } \\
\text { dollars) }\end{array}$} & \multicolumn{3}{|c|}{$\begin{array}{l}\text { Per capita agricultural } \\
\text { expenditure (2011 } \\
\text { constant US dollars) }\end{array}$} & \multicolumn{3}{|c|}{$\begin{array}{l}\text { Per capita agricultural } \\
\text { expenditure (2011 PPP } \\
\text { dollars) }\end{array}$} & \multicolumn{3}{|c|}{$\begin{array}{l}\text { Ratio of agricultural } \\
\text { expenditure to } \\
\text { agricultural GDP (\%) }\end{array}$} & \multicolumn{3}{|c|}{$\begin{array}{l}\text { Share of agriculture in } \\
\text { total expenditure (\%) }\end{array}$} \\
\hline & 1980 & 1995 & 2014 & 1980 & 1995 & 2014 & 1980 & 1995 & 2014 & 1980 & 1995 & 2014 & 1980 & 1995 & 2014 & 1980 & 1995 & 2014 \\
\hline \multicolumn{19}{|l|}{ SOUTH ASIA } \\
\hline Afghanistan ${ }^{\mathrm{a}}$ & & & 0.25 & & & 0.69 & & & 8.30 & & & 22.36 & & & 4.56 & & & 1.81 \\
\hline Bangladesha & 0.29 & 0.36 & 1.79 & 0.93 & 1.14 & 5.74 & 3.56 & 3.01 & 11.41 & 11.39 & 9.66 & 36.54 & 2.97 & 2.74 & 8.30 & 13.02 & 4.93 & 11.08 \\
\hline Bhutan & 0.01 & 0.04 & 0.07 & 0.04 & 0.11 & 0.20 & 34.88 & 78.80 & 96.09 & 96.56 & 218.17 & 266.06 & 19.53 & 23.98 & 21.91 & 31.86 & 19.69 & 13.18 \\
\hline India & 2.57 & 5.07 & 20.95 & 7.93 & 15.65 & 64.71 & 3.68 & 5.27 & 16.37 & 11.37 & 16.29 & 50.58 & 2.63 & 3.14 & 5.94 & 7.18 & 5.26 & 5.97 \\
\hline Maldives ${ }^{c}$ & 0.00 & 0.02 & 0.01 & 0.00 & 0.04 & 0.01 & 14.76 & 91.06 & 18.88 & 25.28 & 155.94 & 32.33 & 6.99 & 46.24 & 7.17 & 8.84 & 12.07 & 0.74 \\
\hline Nepal & 0.10 & 0.14 & 0.44 & 0.31 & 0.43 & 1.31 & 6.84 & 6.62 & 15.51 & 20.56 & 19.89 & 46.62 & 3.93 & 3.96 & 6.83 & 16.39 & 9.64 & 10.98 \\
\hline Pakistan & 0.15 & 0.09 & 0.95 & 0.52 & 0.33 & 3.38 & 1.86 & 0.76 & 5.15 & 6.61 & 2.68 & 18.25 & 0.98 & 0.31 & 1.66 & 2.13 & 0.46 & 1.90 \\
\hline Sri Lanka & 0.29 & 0.39 & 0.77 & 0.84 & 1.11 & 2.20 & 19.50 & 21.35 & 37.31 & 55.78 & 61.07 & 106.73 & 9.44 & 8.69 & 10.77 & 5.77 & 5.28 & 5.74 \\
\hline \multicolumn{19}{|c|}{ EUROPE AND CENTRAL ASIA } \\
\hline Albania & & 0.07 & 0.07 & & 0.15 & 0.15 & & 21.81 & 23.60 & & 47.37 & 51.26 & & 2.15 & 2.56 & & 3.95 & 1.74 \\
\hline Azerbaijan & & 0.20 & 0.64 & & 0.45 & 1.40 & & 26.27 & 66.30 & & 57.56 & 145.27 & & 6.68 & 16.54 & & 8.01 & 2.45 \\
\hline Belarus & & 0.41 & 1.54 & & 1.07 & 4.04 & & 39.88 & 161.63 & & 105.00 & 425.57 & & 12.56 & 31.59 & & 5.96 & 6.04 \\
\hline Bulgaria $^{a}$ & & 0.03 & 0.51 & & 0.05 & 1.03 & & 3.16 & 70.84 & & 6.36 & 142.61 & & 0.55 & 19.28 & & 0.25 & 2.37 \\
\hline Georgia & & & 0.12 & & & 0.24 & & & 30.72 & & & 60.32 & & & 9.41 & & & 2.50 \\
\hline Kazakhstan & & & 1.52 & & & 2.77 & & & 87.34 & & & 159.72 & & & 16.43 & & & 3.43 \\
\hline Kyrgyzstan & & 0.03 & & & 0.08 & & & 6.36 & & & 16.54 & & & 2.41 & & & 3.54 & \\
\hline Latvia $^{a}$ & & 0.14 & 0.15 & & 0.20 & 0.21 & & 58.16 & 74.97 & & 82.09 & 105.82 & & 12.76 & 16.41 & & 2.83 & 1.35 \\
\hline Lithuania & & 1.45 & 0.43 & & 2.27 & 0.67 & & 398.62 & 147.31 & & 625.40 & 231.11 & & 68.61 & 28.68 & & 29.69 & 2.56 \\
\hline Moldova & & 0.02 & 0.11 & & 0.05 & 0.22 & & 5.14 & 25.93 & & 10.89 & 54.98 & & 1.69 & 10.34 & & 1.38 & 3.33 \\
\hline Russian Federation & & 0.43 & 14.29 & & 0.73 & 24.21 & & 2.92 & 99.64 & & 4.95 & 168.79 & & 0.62 & 20.26 & & 0.15 & 1.08 \\
\hline Serbiab & & & 0.50 & & & 0.97 & & & 68.97 & & & 134.98 & & & 14.33 & & & 2.30 \\
\hline Ukraine & & & 0.59 & & & 1.37 & & & 13.16 & & & 30.52 & & & 4.57 & & & 0.76 \\
\hline \multicolumn{19}{|c|}{ MIDDLE EAST AND NORTH AFRICA } \\
\hline Algeria $^{c}$ & & 0.85 & 3.00 & & 2.03 & 7.17 & & 29.41 & 81.64 & & 70.34 & 195.22 & & 7.62 & 18.48 & & 2.42 & 3.68 \\
\hline Bahrainc & 0.02 & 0.02 & 0.02 & 0.03 & 0.03 & 0.04 & 41.71 & 29.88 & 18.18 & 74.41 & 53.31 & 32.43 & 18.58 & 17.04 & 28.36 & 0.63 & 0.54 & 0.31 \\
\hline Egypt & 1.10 & 1.47 & & 4.02 & 5.36 & & 25.37 & 23.52 & & 92.63 & 85.89 & & 12.78 & 8.43 & & 5.14 & 4.39 & \\
\hline Iran & 2.27 & 2.43 & & 5.17 & 5.55 & & 58.61 & 40.37 & & 133.61 & 92.02 & & 10.17 & 6.67 & & 3.36 & 4.22 & \\
\hline Jordan & 0.03 & 0.18 & 0.07 & 0.08 & 0.44 & 0.16 & 13.85 & 41.99 & 9.07 & 33.52 & 101.62 & 21.94 & 8.08 & 37.73 & 6.45 & 0.98 & 4.46 & 0.69 \\
\hline Kuwaita & 0.02 & 0.24 & 0.38 & 0.03 & 0.39 & 0.62 & 12.27 & 147.66 & 106.70 & 19.68 & 236.93 & 171.22 & 13.33 & 70.59 & 64.98 & 0.10 & 0.59 & 0.61 \\
\hline Lebanon $^{b}$ & & 0.03 & 0.03 & & 0.05 & 0.05 & & 9.36 & 5.68 & & 16.82 & 10.21 & & 2.58 & 1.83 & & 0.40 & 0.24 \\
\hline Morocco & 0.59 & 0.58 & & 1.29 & 1.28 & & 29.29 & 21.41 & & 64.43 & 47.11 & & 10.61 & 8.67 & & 6.80 & 4.21 & \\
\hline Palestine, State of ${ }^{\mathrm{b}}$ & & & 0.02 & & & 0.01 & & & 5.49 & & & 2.51 & & & 4.56 & & & 0.73 \\
\hline Oman ${ }^{a}$ & 0.10 & 0.25 & 0.19 & 0.19 & 0.49 & 0.39 & 84.01 & 112.43 & 49.75 & 168.63 & 225.65 & 99.86 & 24.24 & 20.17 & 20.83 & 1.85 & 1.56 & 0.57 \\
\hline $\begin{array}{l}\text { Syrian Arab } \\
\text { Republic }\end{array}$ & 0.45 & 0.77 & & 1.01 & 1.71 & & 50.54 & 53.82 & & 112.32 & 119.61 & & 12.00 & 9.02 & & 5.04 & 10.24 & \\
\hline Tunisiab & 0.56 & 0.56 & 0.74 & 1.33 & 1.34 & 1.76 & 88.03 & 61.69 & 67.92 & 209.29 & 146.67 & 161.47 & 34.71 & 25.19 & 17.08 & 15.63 & 8.17 & 4.16 \\
\hline Turkey & 0.58 & 0.68 & 10.25 & 0.98 & 1.15 & 17.31 & 13.25 & 11.63 & 132.26 & 22.38 & 19.63 & 223.35 & 1.52 & 1.52 & 16.95 & 2.08 & 1.03 & 3.22 \\
\hline $\begin{array}{l}\text { United Arab } \\
\text { Emirates }^{a}\end{array}$ & 0.09 & 0.08 & 0.09 & 0.13 & 0.12 & 0.13 & 87.88 & 35.01 & 9.98 & 126.85 & 50.53 & 14.41 & 14.01 & 2.78 & 3.40 & 0.83 & 0.67 & 0.09 \\
\hline Yemen & & 0.05 & & & 0.13 & & & 3.10 & & & 8.74 & & & 1.86 & & & 1.68 & \\
\hline \multicolumn{19}{|c|}{ LATIN AMERICA AND THE CARIBBEAN } \\
\hline Argentina & 0.30 & 0.26 & & 0.47 & 0.40 & & 10.73 & 7.37 & & 16.55 & 11.37 & & 2.19 & 1.87 & & 0.65 & 0.58 & \\
\hline Bahamas $^{d}$ & 0.01 & 0.02 & 0.01 & 0.01 & 0.02 & 0.02 & 45.81 & 55.87 & 41.49 & 48.25 & 58.86 & 43.71 & 11.45 & 7.47 & 8.88 & 1.45 & 1.67 & 0.97 \\
\hline Barbados & 0.03 & 0.03 & & 0.03 & 0.03 & & 106.40 & 113.90 & & 105.52 & 112.95 & & 12.77 & 28.30 & & 3.20 & 2.80 & \\
\hline
\end{tabular}


Table 2 continued

\begin{tabular}{|c|c|c|c|c|c|c|c|c|c|c|c|c|c|c|c|c|c|c|}
\hline \multirow[b]{2}{*}{ Region/country } & \multicolumn{3}{|c|}{$\begin{array}{c}\text { Agricultural expenditure } \\
\text { (billions } 2011 \text { constant } \\
\text { US dollars) }\end{array}$} & \multicolumn{3}{|c|}{$\begin{array}{c}\text { Agricultural expenditure } \\
\text { (billions } 2011 \text { PPP } \\
\text { dollars) }\end{array}$} & \multicolumn{3}{|c|}{$\begin{array}{l}\text { Per capita agricultural } \\
\text { expenditure (2011 } \\
\text { constant US dollars) }\end{array}$} & \multicolumn{3}{|c|}{$\begin{array}{l}\text { Per capita agricultural } \\
\text { expenditure (2011 PPP } \\
\text { dollars) }\end{array}$} & \multicolumn{3}{|c|}{$\begin{array}{l}\text { Ratio of agricultural } \\
\text { expenditure to } \\
\text { agricultural GDP (\%) }\end{array}$} & \multicolumn{3}{|c|}{$\begin{array}{l}\text { Share of agriculture in } \\
\text { total expenditure (\%) }\end{array}$} \\
\hline & 1980 & 1995 & 2014 & 1980 & 1995 & 2014 & 1980 & 1995 & 2014 & 1980 & 1995 & 2014 & 1980 & 1995 & 2014 & 1980 & 1995 & 2014 \\
\hline Belize & 0.01 & 0.01 & & 0.02 & 0.02 & & 79.20 & 42.87 & & 137.75 & 74.58 & & 12.96 & 6.96 & & & 4.61 & \\
\hline Bolivia & 0.05 & 0.01 & & 0.12 & 0.01 & & 9.28 & 0.83 & & 21.84 & 1.95 & & 2.61 & 0.32 & & 3.33 & 0.35 & \\
\hline Brazil & & 16.41 & 11.30 & & 18.66 & 12.85 & & 100.81 & 54.82 & & 114.63 & 62.34 & & 21.12 & 8.68 & & 5.70 & 1.71 \\
\hline Chile & 0.29 & 0.27 & 1.08 & 0.40 & 0.37 & 1.50 & 25.62 & 18.71 & 60.95 & 35.61 & 26.00 & 84.70 & 9.16 & 4.26 & 12.65 & 1.77 & 1.18 & 1.65 \\
\hline Colombia $^{a}$ & 0.22 & 0.40 & 0.00 & 0.35 & 0.64 & 0.00 & 7.93 & 10.70 & 0.03 & 12.62 & 17.02 & 0.04 & 1.40 & 2.21 & 0.01 & 2.00 & 1.77 & 2.10 \\
\hline Costa Rica & 0.08 & 0.14 & 0.20 & 0.12 & 0.21 & 0.29 & 34.06 & 40.80 & 42.50 & 49.68 & 59.51 & 61.97 & 5.24 & 5.65 & 8.75 & 3.38 & 3.15 & 1.42 \\
\hline Dominican Rep. & 0.28 & 0.22 & & 0.55 & 0.43 & & 48.50 & 27.65 & & 95.34 & 54.35 & & 11.93 & 8.66 & & 16.71 & 7.83 & \\
\hline Ecuador ${ }^{a}$ & & & 0.32 & & & 0.61 & & & 20.44 & & & 38.85 & & & 4.23 & & & 1.40 \\
\hline El Salvador ${ }^{a}$ & 0.01 & 0.04 & 0.06 & 0.02 & 0.07 & 0.12 & 2.59 & 6.68 & 9.57 & 5.15 & 13.28 & 19.02 & 0.36 & 1.73 & 2.41 & 5.80 & 1.69 & 0.98 \\
\hline Grenada & & 0.01 & & & 0.02 & & & 126.82 & & & 192.04 & & & 31.37 & & & 9.65 & \\
\hline Guatemala & 0.22 & 0.07 & 2.16 & 0.46 & 0.16 & 4.64 & 30.24 & 7.11 & 134.86 & 64.94 & 15.26 & 289.55 & 6.95 & 1.82 & 37.51 & 7.88 & 2.72 & 29.32 \\
\hline Jamaica & & 0.09 & 0.10 & & 0.14 & 0.15 & & 35.55 & 34.83 & & 56.42 & 55.28 & & 7.89 & 11.28 & & 2.13 & 2.06 \\
\hline Mexico $^{d}$ & 8.53 & 3.42 & 5.67 & 13.81 & 5.54 & 9.18 & 123.03 & 36.26 & 47.81 & 199.20 & 58.72 & 77.41 & 20.68 & 9.77 & 15.71 & 14.56 & 3.36 & 2.32 \\
\hline Panama ${ }^{a}$ & 0.13 & 0.05 & 0.12 & 0.23 & 0.09 & 0.21 & 64.62 & 18.07 & 30.49 & 118.07 & 33.02 & 55.71 & 17.62 & 5.04 & 9.62 & 5.29 & 1.64 & 1.35 \\
\hline Paraguay & 0.04 & & & 0.07 & & & 11.46 & & & 21.56 & & & 1.56 & & & 3.47 & & \\
\hline Peru & & & 0.34 & & & 0.62 & & & 11.09 & & & 20.08 & & & 2.62 & & & 1.25 \\
\hline $\begin{array}{l}\text { St. Vincent and } \\
\text { Grenadines }\end{array}$ & 0.00 & 0.00 & & 0.00 & 0.01 & & 22.05 & 35.42 & & 35.20 & 56.54 & & 9.38 & 8.74 & & 3.81 & 3.46 & \\
\hline $\begin{array}{l}\text { Trinidad and } \\
\text { Tobago } 0^{b}\end{array}$ & 0.18 & 0.12 & 0.19 & 0.29 & 0.20 & 0.30 & 166.27 & 98.70 & 138.46 & 270.62 & 160.64 & 225.36 & 68.72 & 66.01 & 181.53 & 5.10 & 4.49 & 2.18 \\
\hline Uruguay & 0.07 & 0.08 & & 0.08 & 0.10 & & 22.78 & 25.66 & & 28.79 & 32.43 & & 2.25 & 3.63 & & 2.08 & 1.04 & \\
\hline \multicolumn{19}{|c|}{ AFRICA SOUTH OF THE SAHARA } \\
\hline Angola & & 0.14 & 0.46 & & 0.19 & 0.63 & & 10.37 & 18.93 & & 14.26 & 26.03 & & 5.34 & 6.70 & & 1.74 & 0.86 \\
\hline Benin & & 0.06 & 0.15 & & 0.12 & 0.32 & & 9.21 & 13.80 & & 20.30 & 30.42 & & 6.33 & 7.57 & & 7.26 & 7.97 \\
\hline Botswana & 0.08 & 0.17 & 0.28 & 0.14 & 0.30 & 0.50 & 75.64 & 105.58 & 125.02 & 137.41 & 191.80 & 227.13 & 29.17 & 46.66 & 68.93 & 9.71 & 5.96 & 4.15 \\
\hline Burkina Faso & 0.20 & 0.39 & 0.29 & 0.45 & 0.86 & 0.64 & 29.81 & 38.67 & 16.43 & 65.83 & 85.41 & 36.28 & 19.10 & 30.21 & 7.06 & 31.37 & 45.68 & 9.39 \\
\hline Burundia & & 0.02 & 0.02 & & 0.05 & 0.06 & & 2.53 & 1.95 & & 7.49 & 5.78 & & 3.71 & 2.14 & & 5.10 & 2.79 \\
\hline Cameroon & 0.04 & 0.07 & & 0.07 & 0.15 & & 4.02 & 5.17 & & 8.34 & 10.74 & & 1.19 & 2.21 & & 2.22 & 4.16 & \\
\hline CaboVerde ${ }^{b}$ & & 0.00 & 0.03 & & 0.00 & 0.05 & & 5.50 & 66.95 & & 8.98 & 109.29 & & 1.84 & 21.06 & & & 4.93 \\
\hline $\begin{array}{l}\text { Central African } \\
\text { Republic }^{b}\end{array}$ & 0.04 & 0.03 & 0.01 & 0.07 & 0.05 & 0.01 & 16.06 & 7.60 & 1.45 & 29.61 & 14.01 & 2.67 & 5.41 & 3.99 & 0.73 & & 9.94 & 1.69 \\
\hline Congo, Rep. & & 0.01 & & & 0.01 & & & 3.31 & & & 5.40 & & & 1.07 & & & 0.34 & \\
\hline Côte d'Ivoire & 0.17 & 0.17 & 0.35 & 0.35 & 0.35 & 0.73 & 20.69 & 11.79 & 15.89 & 42.78 & 24.38 & 32.86 & 3.76 & 3.46 & 4.64 & 2.60 & 3.56 & 4.79 \\
\hline $\begin{array}{l}\text { Democratic Rep. of } \\
\text { Congo }\end{array}$ & & 0.00 & & & 0.00 & & & 0.04 & & & 0.07 & & & 0.02 & & & 0.18 & \\
\hline Equatorial Guinea & & 0.01 & & & 0.01 & & & 16.16 & & & 25.89 & & & 2.31 & & & & \\
\hline Ethiopiac & & 0.16 & 0.30 & & 0.54 & 1.04 & & 2.76 & 3.37 & & 9.48 & 11.57 & & 3.23 & 2.41 & & 9.72 & 3.90 \\
\hline Gambia & 0.01 & & & 0.02 & & & 12.94 & & & 38.36 & & & 9.25 & & & 17.13 & & \\
\hline Ghana & 0.09 & 0.03 & 0.06 & 0.19 & 0.06 & 0.13 & 8.11 & 1.53 & 2.24 & 17.52 & 3.32 & 4.84 & 1.76 & 0.51 & 0.59 & 12.21 & 0.73 & 2.08 \\
\hline Guinea-Bissaua & & 0.00 & 0.00 & & 0.00 & 0.00 & & 0.11 & 0.70 & & 0.23 & 1.51 & & 0.03 & 0.26 & & 1.19 & 0.88 \\
\hline Kenya ${ }^{a}$ & 0.20 & 0.31 & 0.43 & 0.53 & 0.79 & 1.10 & 12.55 & 11.16 & 9.76 & 32.50 & 28.90 & 25.27 & 5.41 & 5.15 & 3.48 & 8.28 & 7.00 & 4.11 \\
\hline Lesothob & 0.02 & 0.09 & 0.05 & 0.04 & 0.17 & 0.10 & 17.39 & 51.25 & 25.93 & 32.18 & 94.86 & 47.99 & 12.29 & 54.22 & 30.30 & 8.02 & 12.41 & 3.15 \\
\hline Liberiab & 0.02 & 0.00 & 0.01 & 0.04 & 0.01 & 0.02 & 11.25 & 1.91 & 2.20 & 21.77 & 3.69 & 4.26 & 10.62 & 3.35 & 0.85 & 5.02 & 2.76 & 1.97 \\
\hline Madagascar ${ }^{c}$ & & 0.07 & 0.02 & & 0.20 & 0.05 & & 4.95 & 0.70 & & 14.89 & 2.11 & & 3.48 & 0.59 & & 6.10 & 1.59 \\
\hline Malawi & 0.06 & 0.06 & 0.00 & 0.13 & 0.12 & 0.01 & 10.27 & 5.98 & 0.19 & 21.08 & 12.28 & 0.39 & 3.75 & 4.94 & 0.13 & 10.15 & 8.85 & 15.66 \\
\hline
\end{tabular}


Table 2 continued

\begin{tabular}{|c|c|c|c|c|c|c|c|c|c|c|c|c|c|c|c|c|c|c|}
\hline \multirow[b]{2}{*}{ Region/country } & \multicolumn{3}{|c|}{$\begin{array}{c}\text { Agricultural expenditure } \\
\text { (billions } 2011 \text { constant } \\
\text { US dollars) }\end{array}$} & \multicolumn{3}{|c|}{$\begin{array}{l}\text { Agricultural expenditure } \\
\text { (billions } 2011 \text { PPP } \\
\text { dollars) }\end{array}$} & \multicolumn{3}{|c|}{$\begin{array}{l}\text { Per capita agricultural } \\
\text { expenditure (2011 } \\
\text { constant US dollars) }\end{array}$} & \multicolumn{3}{|c|}{$\begin{array}{l}\text { Per capita agricultural } \\
\text { expenditure (2011 PPP } \\
\text { dollars) }\end{array}$} & \multicolumn{3}{|c|}{$\begin{array}{l}\text { Ratio of agricultural } \\
\text { expenditure to } \\
\text { agricultural GDP (\%) }\end{array}$} & \multicolumn{3}{|c|}{$\begin{array}{l}\text { Share of agriculture in } \\
\text { total expenditure (\%) }\end{array}$} \\
\hline & 1980 & 1995 & 2014 & 1980 & 1995 & 2014 & 1980 & 1995 & 2014 & 1980 & 1995 & 2014 & 1980 & 1995 & 2014 & 1980 & 1995 & 2014 \\
\hline Malia & 0.03 & 0.20 & 0.24 & 0.07 & 0.46 & 0.55 & 4.49 & 21.12 & 14.73 & 10.08 & 47.40 & 33.07 & 1.85 & 11.75 & 6.54 & 7.05 & 17.28 & 9.71 \\
\hline Mauritius & 0.04 & 0.07 & 0.08 & 0.08 & 0.13 & 0.14 & 45.89 & 63.04 & 63.10 & 82.64 & 113.53 & 113.63 & 17.02 & 14.87 & 24.16 & 6.87 & 5.86 & 2.48 \\
\hline Mozambique $^{a}$ & & & 0.37 & & & 0.67 & & & 13.99 & & & 25.37 & & & 10.20 & & & 6.85 \\
\hline Niger & 0.08 & 0.07 & 0.36 & 0.17 & 0.16 & 0.76 & 13.42 & 7.92 & 18.70 & 28.64 & 16.90 & 39.90 & 5.46 & 6.35 & 12.15 & 14.17 & 13.17 & 12.30 \\
\hline Nigeria & 0.44 & 0.28 & 0.20 & 0.92 & 0.58 & 0.41 & 6.02 & 2.56 & 1.10 & 12.53 & 5.34 & 2.30 & 2.66 & 0.79 & 0.20 & 2.92 & 3.60 & 0.80 \\
\hline Rwandab & & & 0.13 & & & 0.29 & & & 11.76 & & & 27.08 & & & 5.46 & & & 7.09 \\
\hline Senegal & 0.05 & 0.07 & 0.41 & 0.11 & 0.14 & 0.82 & 9.52 & 8.03 & 28.12 & 19.02 & 16.04 & 56.16 & 6.31 & 5.34 & 18.98 & 4.04 & 5.23 & 8.52 \\
\hline Seychelles & & 0.01 & 0.01 & & 0.01 & 0.01 & & 68.69 & 65.97 & & 127.12 & 122.08 & & 17.50 & 23.03 & & 1.99 & 1.62 \\
\hline Swaziland ${ }^{b}$ & 0.04 & 0.03 & 0.06 & 0.07 & 0.06 & 0.10 & 66.73 & 36.08 & 45.33 & 124.22 & 67.17 & 84.39 & 15.11 & 10.66 & 18.24 & 12.98 & 5.68 & 4.23 \\
\hline Togo & 0.06 & 0.03 & 0.07 & 0.14 & 0.07 & 0.16 & 23.18 & 7.46 & 10.05 & 50.85 & 16.37 & 22.05 & 10.50 & 3.66 & 4.03 & 6.99 & 6.13 & 5.84 \\
\hline Uganda & 0.01 & 0.01 & 0.18 & 0.03 & 0.03 & 0.54 & 0.73 & 0.52 & 4.73 & 2.21 & 1.56 & 14.31 & 0.64 & 0.40 & 2.95 & 6.71 & 1.87 & 4.50 \\
\hline $\begin{array}{l}\text { United Rep. of } \\
\text { Tanzania }\end{array}$ & 0.15 & 0.14 & & 0.45 & 0.41 & & 7.96 & 4.65 & & 23.95 & 13.99 & & 8.38 & 2.99 & & 10.90 & 8.55 & \\
\hline$Z a_{b i a}{ }^{c}$ & 0.63 & 0.06 & 0.29 & 1.29 & 0.12 & 0.59 & 106.70 & 6.11 & 20.15 & 218.07 & 12.48 & 41.18 & 73.83 & 4.40 & 12.65 & 22.81 & 2.80 & 7.27 \\
\hline \multicolumn{19}{|c|}{ HIGH-INCOME EUROPEAN COUNTRIES } \\
\hline Austria & 4.90 & 3.94 & 1.79 & 4.22 & 3.39 & 1.54 & 645.19 & 494.19 & 210.50 & 555.54 & 425.52 & 181.25 & 50.86 & 58.78 & 32.98 & 2.51 & 2.32 & 0.78 \\
\hline Belgium & 1.09 & 0.65 & 0.24 & 0.94 & 0.56 & 0.21 & 111.07 & 64.27 & 21.34 & 95.14 & 55.05 & 18.28 & 16.74 & 13.11 & 7.12 & 0.88 & 0.33 & 0.08 \\
\hline Croatiac $^{c}$ & & 0.23 & 0.91 & & 0.32 & 1.29 & & 49.73 & 211.78 & & 70.36 & 299.64 & & 9.26 & 36.50 & & 2.50 & 3.99 \\
\hline Germany & 3.53 & 17.93 & 7.30 & 3.24 & 16.45 & 6.70 & 45.22 & 219.74 & 90.55 & 41.48 & 201.58 & 83.07 & 8.79 & 62.86 & 30.93 & 0.49 & 1.09 & 0.43 \\
\hline Greece & 3.71 & 3.05 & 0.44 & 3.81 & 3.13 & 0.45 & 385.55 & 286.29 & 39.92 & 396.11 & 294.13 & 41.02 & 18.49 & 18.56 & 4.98 & 5.30 & 3.11 & 0.34 \\
\hline Hungary & & 1.89 & 0.89 & & 3.04 & 1.43 & & 182.43 & 90.02 & & 293.84 & 144.99 & & 27.31 & 16.31 & & 3.51 & 1.23 \\
\hline Iceland & 0.27 & 0.21 & 0.14 & 0.23 & 0.18 & 0.12 & $1,179.75$ & 774.04 & 434.90 & $1,015.17$ & 666.06 & 374.23 & 40.70 & 25.19 & 17.14 & 12.44 & 7.22 & 1.99 \\
\hline Ireland & & 1.20 & 1.03 & & 1.04 & 0.89 & & 330.13 & 219.43 & & 285.40 & 189.70 & & 19.17 & 27.99 & & 2.71 & 1.04 \\
\hline Italy & 10.26 & 9.17 & 6.65 & 9.60 & 8.58 & 6.23 & 182.13 & 160.46 & 111.30 & 170.43 & 150.15 & 104.15 & 12.38 & 15.57 & 15.72 & 1.10 & 0.89 & 0.60 \\
\hline Luxembourg & 0.15 & 0.18 & 0.21 & 0.12 & 0.15 & 0.17 & 402.60 & 447.66 & 379.95 & 323.78 & 360.01 & 305.56 & 49.06 & 59.54 & 125.85 & 2.16 & 1.44 & 0.79 \\
\hline Malta & 0.01 & 0.01 & 0.04 & 0.02 & 0.02 & 0.05 & 45.92 & 33.30 & 103.55 & 57.90 & 41.99 & 130.57 & 13.66 & 8.35 & 35.84 & 3.77 & 0.53 & 0.94 \\
\hline Netherlands & 2.80 & 2.02 & 1.41 & 2.43 & 1.75 & 1.22 & 198.51 & 130.46 & 83.48 & 171.99 & 113.04 & 72.33 & 18.39 & 10.52 & 9.60 & 1.05 & 0.60 & 0.34 \\
\hline Norway & 7.83 & 5.28 & 3.02 & 4.88 & 3.30 & 1.89 & $1,917.85$ & $1,211.61$ & 587.34 & $1,196.32$ & 755.78 & 366.37 & 94.68 & 57.67 & 38.18 & 7.16 & 2.99 & 1.25 \\
\hline Poland & & 2.69 & 2.19 & & 4.37 & 3.55 & & 69.79 & 56.63 & & 113.14 & 91.81 & & 21.02 & 14.94 & & 2.68 & 0.92 \\
\hline Portugal & & 1.73 & 0.90 & & 2.01 & 1.05 & & 171.65 & 86.81 & & 199.29 & 100.80 & & 19.03 & 18.93 & & 2.14 & 0.74 \\
\hline Romania & 3.89 & 2.81 & 1.61 & 7.45 & 5.38 & 3.08 & 172.00 & 122.22 & 81.69 & 329.50 & 234.13 & 156.49 & 24.63 & 12.78 & 17.07 & 7.42 & 6.77 & 2.32 \\
\hline Slovakia & & & 0.34 & & & 0.47 & & & 62.12 & & & 86.18 & & & 8.16 & & & 0.78 \\
\hline Slovenia & & 0.50 & 0.22 & & 0.57 & 0.25 & & 251.00 & 107.59 & & 286.45 & 122.79 & & 42.69 & 22.97 & & 3.61 & 0.88 \\
\hline Spain & 7.18 & 6.28 & 5.80 & 7.34 & 6.42 & 5.93 & 190.42 & 157.88 & 125.37 & 194.58 & 161.33 & 128.11 & 16.12 & 16.34 & 17.49 & 3.36 & 1.43 & 0.90 \\
\hline
\end{tabular}


Table 2 continued

\begin{tabular}{|c|c|c|c|c|c|c|c|c|c|c|c|c|c|c|c|c|c|c|}
\hline \multirow[b]{2}{*}{ Region/country } & \multicolumn{3}{|c|}{$\begin{array}{c}\text { Agricultural expenditure } \\
\text { (billions } 2011 \text { constant } \\
\text { US dollars) }\end{array}$} & \multicolumn{3}{|c|}{$\begin{array}{l}\text { Agricultural expenditure } \\
\text { (billions } 2011 \text { PPP } \\
\text { dollars) }\end{array}$} & \multicolumn{3}{|c|}{$\begin{array}{l}\text { Per capita agricultural } \\
\text { expenditure (2011 } \\
\text { constant US dollars) }\end{array}$} & \multicolumn{3}{|c|}{$\begin{array}{l}\text { Per capita agricultural } \\
\text { expenditure (2011 PPP } \\
\text { dollars) }\end{array}$} & \multicolumn{3}{|c|}{$\begin{array}{l}\text { Ratio of agricultural } \\
\text { expenditure to } \\
\text { agricultural GDP (\%) }\end{array}$} & \multicolumn{3}{|c|}{$\begin{array}{l}\text { Share of agriculture in } \\
\text { total expenditure (\%) }\end{array}$} \\
\hline & 1980 & 1995 & 2014 & 1980 & 1995 & 2014 & 1980 & 1995 & 2014 & 1980 & 1995 & 2014 & 1980 & 1995 & 2014 & 1980 & 1995 & 2014 \\
\hline Sweden & 4.74 & 2.51 & 0.93 & 3.48 & 1.84 & 0.68 & 570.68 & 284.08 & 96.20 & 418.57 & 208.36 & 70.56 & 41.83 & 27.39 & 13.15 & 2.87 & 1.06 & 0.31 \\
\hline Switzerland ${ }^{a}$ & 10.95 & 14.93 & 6.01 & 6.79 & 9.26 & 3.72 & $1,737.45$ & $2,128.37$ & 739.84 & $1,077.05$ & $1,319.39$ & 458.63 & 107.58 & 195.59 & 121.80 & 4.87 & 9.24 & 2.46 \\
\hline United Kingdom & 6.71 & 1.66 & 3.66 & 5.99 & 1.48 & 3.27 & 119.37 & 28.69 & 56.94 & 106.48 & 25.60 & 50.79 & 32.40 & 6.50 & 21.82 & 1.19 & 0.22 & 0.30 \\
\hline \multicolumn{19}{|c|}{ OTHER HIGH-INCOME COUNTRIES } \\
\hline Australia & 2.30 & 3.03 & 4.27 & 1.48 & 1.94 & 2.74 & 156.40 & 167.00 & 180.68 & 100.34 & 107.14 & 115.92 & 7.11 & 9.79 & 11.25 & 1.78 & 1.24 & 0.72 \\
\hline Canada & 3.15 & 4.77 & & 2.51 & 3.81 & & 128.39 & 162.91 & & 102.46 & 130.01 & & 9.77 & 14.98 & & 2.20 & 1.93 & \\
\hline Israel & 0.90 & 0.86 & & 0.81 & 0.78 & & 239.87 & 161.84 & & 217.57 & 146.80 & & 26.53 & 35.89 & & 1.97 & 1.49 & \\
\hline Japan & 19.22 & 13.47 & 7.17 & 14.27 & 10.00 & 5.33 & 165.78 & 108.17 & 56.55 & 123.13 & 80.34 & 42.00 & 18.18 & 14.78 & 9.91 & 3.49 & 1.69 & 0.60 \\
\hline New Zealand ${ }^{b}$ & 1.57 & 0.37 & 1.03 & 1.34 & 0.31 & 0.88 & 498.75 & 100.48 & 231.90 & 424.87 & 85.59 & 197.55 & 19.88 & 5.14 & 10.71 & 5.42 & 1.06 & 1.32 \\
\hline Rep. of Korea ${ }^{b}$ & 1.39 & 8.39 & 14.60 & 1.80 & 10.88 & 18.94 & 37.11 & 187.82 & 294.36 & 48.12 & 243.58 & 381.74 & 4.99 & 27.28 & 53.14 & 5.59 & 10.02 & 3.53 \\
\hline United States & 20.40 & 13.26 & 23.18 & 20.40 & 13.26 & 23.18 & 88.87 & 49.81 & 72.57 & 88.87 & 49.81 & 72.57 & 15.56 & 10.52 & 11.32 & 1.48 & 0.64 & 0.70 \\
\hline
\end{tabular}

Note: PPP (purchasing power parity) dollars measure the relative purchasing power of currencies across countries by eliminating national differences in pricing levels for a wide range of goods and services.

$a=$ last year of data available is $2013 ; b=$ last year of data available is $2012 ; c=$ last year of data available is $2014 ; d=$ last year of data available is 2010 . 


\section{Trend 1}

REGIONAL DIVERGENCE MARKS AGRICULTURAL SUPPORT

Per capita agricultural public spending has increased most rapidly in East Asia and the Pacific, especially following the 2008/09 food crisis. Spending in the Middle East and North Africa has also risen. But for the rest of the world, stagnation in agricultural spending has marked the last 35 years, leaving per capita levels in 2014 close to 1980 levels.

\section{Trend 2}

\section{DIVERGENCE IS NOT EXPLAINED BY AGRICULTURAL GROWTH}

Growth in agricultural gross domestic product (GDP) does not explain the divergence in public spending. East Asia and the Pacific and the Middle East and North Africa both increased spending relative to the size of their agricultural economies; the other regions have shown volatility in spending ratios, but no long-term increase in comparison with agricultural GDP.

\section{Trend 3}

A RISING TIDE LIFTS ALL BOATS, BUT NOT EQUALLY

Agricultural spending in the East Asia and Pacific region appears to be rising with overall public spending, though not as fast as aggregate spending. In fact, the ratio of agricultural to total expenditures fell for much of the period in all regions, with the largest drops in Africa south of the Sahara and Latin America and the Caribbean.
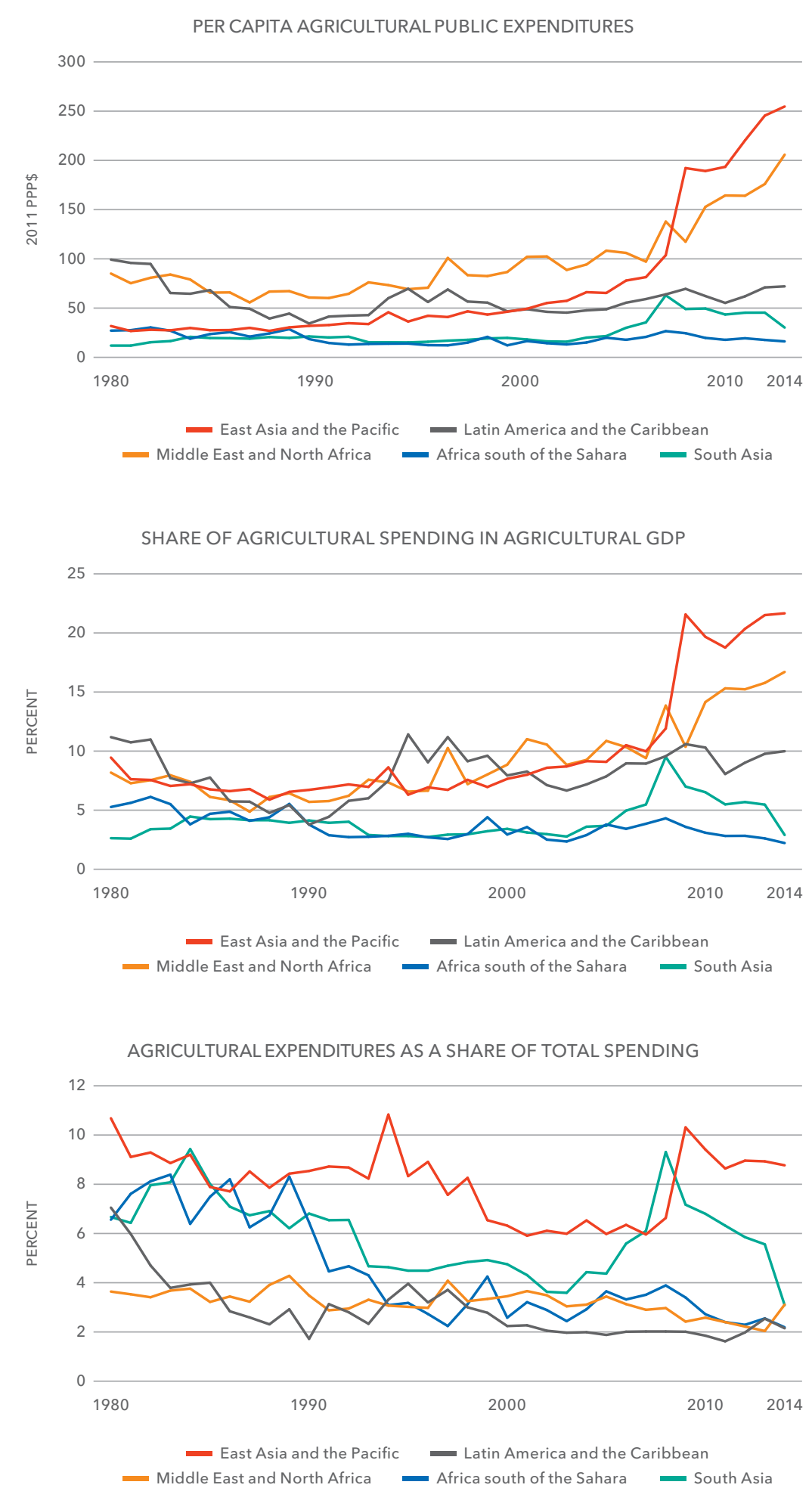


\section{Global Hunger Index (GHI)}

The Global Hunger Index (GHI) provides a comprehensive measure of hunger at the global level and by country. It allows for tracking progress and setbacks in addressing hunger and malnutrition over time and for assessing the drivers of these changes. The GHI is designed to raise awareness and understanding of regional and country differences in the struggle against hunger and to trigger action to reduce hunger around the world.

\section{UNDERSTANDING GHI SCORES}

$\mathrm{GHI}$ scores reflect the multidimensional nature of hunger by combining four standardized indicators into one index number that falls within the range 0-100:

1. Percentage of the population that is undernourished

2. Percentage of children under five who suffer from wasting (low weight-for-height)

3. Percentage of children under five who suffer from stunting (low height-for-age)

4. Percentage of children who die before the age of five (child mortality)

Higher scores indicate greater hunger-the lower the score, the better a country's situation (Figure 1). GHI scores above 20 are considered "serious"; scores greater than 35 are "alarming"; and scores exceeding 50 are "extremely alarming."

\section{TRENDS IN GLOBAL HUNGER}

The 2017 Global Hunger Index (GHI) indicates that worldwide levels of hunger and undernutrition have declined over the long term: At 21.8 on a scale of 100 , the average $\mathrm{GHI}$ score for 2017 is 27 percent lower than the 2000 score (29.9). This improvement reflects the reductions since 2000 in each of the four GHI indicators-the prevalence of undernourishment, child stunting (low height-for-age), child wasting (low weight-for-height), and child mortality.

Despite these improvements, a number of factors, including deep and persistent inequalities, undermine efforts to end hunger and undernutrition worldwide. As a result, even as the average global hunger level has declined, certain regions of the world still struggle with hunger more than others, disadvantaged populations experience hunger more acutely than their better-off neighbors, and isolated and war-torn areas are ravaged by famine.

At the regional level, South Asia and Africa south of the Sahara have the highest $2017 \mathrm{GHI}$ scores-30.9 and 29.4, respectively, indicating serious levels of hunger. The GHI scores, and therefore the hunger levels, for East and Southeast Asia, the Near East and North Africa, Latin America and the Caribbean, and Eastern Europe and the Commonwealth of Independent States are considered low or moderate, ranging from 7.8 to 12.8 points. Within each region in the low range, however, are also countries with serious or alarming GHI scores, including Tajikistan in Central Asia, which is part of the Commonwealth of Independent States; Guatemala and Haiti in Latin America and the Caribbean; and Iraq and Yemen in the Near East and North Africa region. Seven of 14 countries in East and Southeast Asia have serious scores, though the low score of highly populous China improves the regional average.

From the $2000 \mathrm{GHI}$ to the $2017 \mathrm{GHI}$, the scores of 14 countries improved by 50 percent or more; those of 72 countries dropped by between 25 and 49.9 percent; and those of 27 countries fell by less than 25 percent. Only the Central African Republic showed no progress; its 2017 and 2000 GHI scores are the same.

FIGURE 1 GHI severity scale according to GHI score

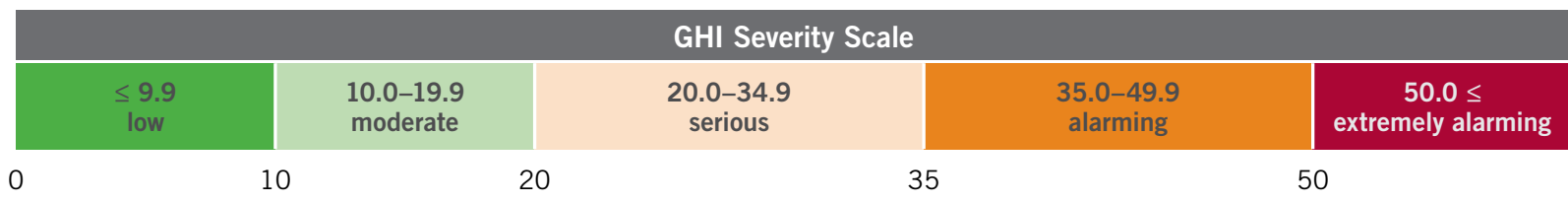


Eight countries suffer from extremely alarming or alarming levels of hunger. Except for Yemen, all are in Africa south of the Sahara: Central African Republic, Chad, Liberia, Madagascar, Sierra Leone, Sudan, and Zambia. Due to incomplete data, 2017 $\mathrm{GHI}$ scores could not be calculated for 13 countries. Nine of these-Burundi, Comoros, Democratic Republic of the Congo, Eritrea, Libya, Papua New Guinea, Somalia, South Sudan, and Syria-are classified in the $2017 \mathrm{GHI}$ report as "cause for significant concern" based on available data and reports from international organizations that specialize in hunger and malnutrition.

\section{DOWNLOAD DATA}

http://dx.doi.org/10.7910/DVN/ZTCWYO

CONTACT

Klaus von Grebmer (k.vongrebmer@cgiar.org), Nilam Prasai (n.prasai@cgiar.org), and Jill Bernstein (jtwbernstein@yahoo.com)

TABLE 3 Global Hunger Index scores (various years), ranked by 2017 country scores

\begin{tabular}{|c|c|c|c|c|c|}
\hline Rank $^{\mathrm{a}}$ & Country & 1992 & 2000 & 2008 & 2017 \\
\hline \multirow{14}{*}{ 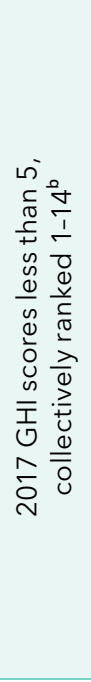 } & Belarus & -- & $<5$ & $<5$ & $<5$ \\
\hline & Bosnia and Herzegovina & -- & 9.8 & 7.0 & $<5$ \\
\hline & Chile & 5.9 & $<5$ & $<5$ & $<5$ \\
\hline & Croatia & -- & 6.2 & $<5$ & $<5$ \\
\hline & Cuba & 10.5 & 5.3 & $<5$ & $<5$ \\
\hline & Estonia & -- & 6.2 & $<5$ & $<5$ \\
\hline & Kuwait & 20.0 & $<5$ & $<5$ & $<5$ \\
\hline & Latvia & -- & 6.7 & $<5$ & $<5$ \\
\hline & Lithuania & -- & 5.9 & $<5$ & $<5$ \\
\hline & Montenegro & -- & -- & 5.2 & $<5$ \\
\hline & Slovak Republic & -- & 8.0 & 6.4 & $<5$ \\
\hline & Turkey & 14.3 & 10.4 & 5.6 & $<5$ \\
\hline & Ukraine & -- & 13.7 & $<5$ & $<5$ \\
\hline & Uruguay & 9.7 & 7.7 & 6.4 & $<5$ \\
\hline 15 & Romania & 9.3 & 8.7 & 6.0 & 5.2 \\
\hline 16 & Costa Rica & 7.5 & 6.2 & 5.0 & 5.3 \\
\hline 16 & Macedonia, FYR & -- & 7.7 & 6.4 & 5.3 \\
\hline 18 & Argentina & 7.0 & 6.6 & 5.8 & 5.4 \\
\hline 18 & Brazil & 15.9 & 11.7 & 5.4 & 5.4 \\
\hline 18 & Bulgaria & 7.9 & 8.2 & 7.6 & 5.4 \\
\hline 21 & Kazakhstan & -- & 11.3 & 10.9 & 5.8 \\
\hline 22 & Russian Federation & -- & 10.5 & 6.8 & 6.2 \\
\hline 23 & Mexico & 14.0 & 10.8 & 8.4 & 6.5 \\
\hline 24 & Serbia & -- & -- & 7.2 & 6.6 \\
\hline 25 & Jordan & 13.4 & 10.3 & 6.5 & 6.7 \\
\hline 26 & Trinidad and Tobago & 14.5 & 11.7 & 10.4 & 6.9 \\
\hline 27 & Saudi Arabia & 14.3 & 12.5 & 11.2 & 7.1 \\
\hline 28 & Tunisia & 15.4 & 10.7 & 8.0 & 7.4 \\
\hline 29 & China & 25.9 & 15.8 & 11.2 & 7.5 \\
\hline 30 & Iran & 17.5 & 13.6 & 8.7 & 7.6 \\
\hline 30 & Moldova & -- & 16.3 & 13.3 & 7.6 \\
\hline 32 & Armenia & -- & 18.4 & 11.4 & 7.7 \\
\hline
\end{tabular}

\begin{tabular}{|c|c|c|c|c|c|}
\hline Rank $^{a}$ & Country & 1992 & 2000 & 2008 & 2017 \\
\hline 32 & Georgia & -- & 14.7 & 8.3 & 7.7 \\
\hline 34 & Colombia & 14.6 & 11.3 & 9.4 & 8.0 \\
\hline 34 & Jamaica & 12.0 & 8.4 & 7.6 & 8.0 \\
\hline 36 & Fiji & 11.5 & 9.8 & 9.1 & 8.1 \\
\hline 36 & Lebanon & 11.4 & 9.0 & 8.2 & 8.1 \\
\hline 38 & Peru & 28.7 & 20.9 & 15.3 & 8.7 \\
\hline 39 & Panama & 19.9 & 20.0 & 14.1 & 9.2 \\
\hline 40 & Kyrgyzstan & -- & 19.7 & 13.4 & 9.3 \\
\hline 41 & Algeria & 17.5 & 15.6 & 11.3 & 9.5 \\
\hline 42 & Azerbaijan & -- & 27.5 & 15.3 & 9.6 \\
\hline 43 & Suriname & 17.0 & 16.0 & 11.4 & 9.9 \\
\hline 44 & Malaysia & 19.8 & 15.5 & 13.7 & 10.2 \\
\hline 44 & Morocco & 18.7 & 15.7 & 12.0 & 10.2 \\
\hline 46 & Thailand & 25.8 & 18.1 & 12.0 & 10.6 \\
\hline 47 & Paraguay & 16.7 & 14.1 & 12.1 & 11.0 \\
\hline 48 & Albania & 20.8 & 21.6 & 16.5 & 11.1 \\
\hline 48 & El Salvador & 19.5 & 16.2 & 12.7 & 11.1 \\
\hline 50 & Oman & 20.8 & 13.7 & 10.2 & 11.3 \\
\hline 51 & Dominican Republic & 23.8 & 18.4 & 15.4 & 11.6 \\
\hline 52 & Turkmenistan & -- & 21.9 & 16.5 & 12.2 \\
\hline 53 & Venezuela & 15.2 & 15.2 & 9.3 & 13.0 \\
\hline 54 & Uzbekistan & -- & 23.8 & 16.1 & 13.1 \\
\hline 55 & South Africa & 18.5 & 18.8 & 16.6 & 13.2 \\
\hline 56 & Mauritius & 17.4 & 15.9 & 14.3 & 13.3 \\
\hline 57 & Mongolia & 37.5 & 31.7 & 18.1 & 13.4 \\
\hline 58 & Nicaragua & 36.1 & 24.7 & 18.2 & 13.6 \\
\hline 59 & Guyana & 22.3 & 17.9 & 17.0 & 13.7 \\
\hline 60 & Gabon & 24.2 & 20.7 & 17.4 & 13.8 \\
\hline 61 & Honduras & 25.9 & 20.6 & 17.0 & 14.3 \\
\hline 62 & Ecuador & 22.3 & 20.5 & 16.4 & 14.4 \\
\hline 63 & Egypt & 20.1 & 16.4 & 16.6 & 14.7 \\
\hline 64 & Viet Nam & 40.2 & 28.6 & 21.6 & 16.0 \\
\hline
\end{tabular}


Table 3 continued

\begin{tabular}{|c|c|c|c|c|c|c|c|c|c|c|c|}
\hline Rank $^{a}$ & Country & 1992 & 2000 & 2008 & 2017 & Rank $^{a}$ & Country & 1992 & 2000 & 2008 & 2017 \\
\hline 66 & Bolivia & 36.7 & 30.3 & 23.9 & 17.2 & 94 & Guinea & 46.5 & 44.0 & 33.4 & 28.6 \\
\hline 67 & Senegal & 37.5 & 37.3 & 23.7 & 18.4 & 94 & Mali & 51.4 & 44.2 & 35.1 & 28.6 \\
\hline 68 & Philippines & 30.5 & 25.9 & 20.2 & 20.0 & 96 & Tajikistan & -- & 41.8 & 32.6 & 28.7 \\
\hline 69 & Guatemala & 28.5 & 27.4 & 22.2 & 20.7 & 97 & Tanzania & 42.9 & 42.4 & 33.0 & 28.8 \\
\hline 71 & Swaziland & 24.0 & 29.9 & 30.7 & 21.2 & 99 & Guinea-Bissau & 44.5 & 43.1 & 31.4 & 30.6 \\
\hline 72 & Indonesia & 35.0 & 25.5 & 28.3 & 22.0 & 100 & Djibouti & 60.3 & 46.7 & 35.1 & 31.4 \\
\hline 72 & Nepal & 42.5 & 36.8 & 28.9 & 22.0 & 100 & India & 46.2 & 38.2 & 35.6 & 31.4 \\
\hline 74 & Cameroon & 40.0 & 39.6 & 29.5 & 22.1 & 100 & Rwanda & 53.3 & 56.3 & 36.2 & 31.4 \\
\hline 75 & Cambodia & 45.8 & 43.6 & 27.1 & 22.2 & 103 & Uganda & 41.2 & 39.2 & 33.3 & 32.0 \\
\hline 79 & Gambia & 35.2 & 27.5 & 23.8 & 23.2 & 107 & Afghanistan & 50.2 & 52.7 & 37.9 & 33.3 \\
\hline 80 & Lesotho & 26.5 & 33.2 & 28.4 & 24.1 & 108 & Zimbabwe & 35.8 & 40.9 & 34.5 & 33.8 \\
\hline 81 & Benin & 44.5 & 37.5 & 31.7 & 24.4 & 109 & Haiti & 51.6 & 42.7 & 42.6 & 34.2 \\
\hline 81 & Botswana & 33.8 & 33.0 & 30.7 & 24.4 & 110 & Timor-Leste & -- & -- & 46.8 & 34.3 \\
\hline 83 & Mauritania & 39.4 & 33.6 & 23.7 & 25.2 & 111 & Niger & 66.2 & 52.6 & 37.0 & 34.5 \\
\hline 84 & Nigeria & 48.8 & 41.0 & 33.7 & 25.5 & 112 & Liberia & 51.2 & 48.2 & 38.9 & 35.3 \\
\hline 84 & Sri Lanka & 31.6 & 26.8 & 24.2 & 25.5 & 113 & Sudan & -- & -- & -- & 35.5 \\
\hline 86 & Congo, Rep. & 39.1 & 36.0 & 31.6 & 25.6 & 114 & Yemen & 43.5 & 43.4 & 36.2 & 36.1 \\
\hline
\end{tabular}

Notes: $(--)=$ data are not available or not presented. Some countries, such as the post-Soviet states prior to 1991 , did not exist in their present borders in the given year or reference period.

$\mathrm{a}=$ ranked according to $2017 \mathrm{GHI}$ scores. Countries that have identical 2017 scores are given the same ranking (for example, Argentina, Brazil, and Bulgaria are each ranked 18th). The following countries could not be included because of lack of data: Bahrain, Bhutan, Burundi, the Comoros, the Democratic Republic of the Congo, Equatorial Guinea, Eritrea, Libya, Papua New Guinea, Qatar, Somalia, South Sudan, and the Syrian Arab Republic. The rankings in this table cannot be compared with the rankings from previous $\mathrm{GHI}$ reports because different countries are included in the ranking each year based on data availability, data used to calculate the scores are continuously revised, and the methodology is subject to change between reports.

$b=$ the 14 countries with $2017 \mathrm{GHI}$ scores of less than 5 are not assigned individual ranks, but rather are collectively ranked 1-14. Differences between their scores are minimal. 


\section{$\square$ \\ $\square \square$ \\ $\square$}

\section{Trend 1}

\section{VAST INEQUALITY IS} FOUND WITHIN REGIONS

Inequality in hunger and undernutrition exists at all levels: between the major regions of the world, within these regions, and within the countries themselves. There are sizable gaps between the countries with the highest and lowest $\mathrm{GHI}$ scores in each region of the world. The greatest ranges of $\mathrm{GHI}$ scores are found in Africa south of the Sahara, the Near East and North Africa, and Latin America and the Caribbean.

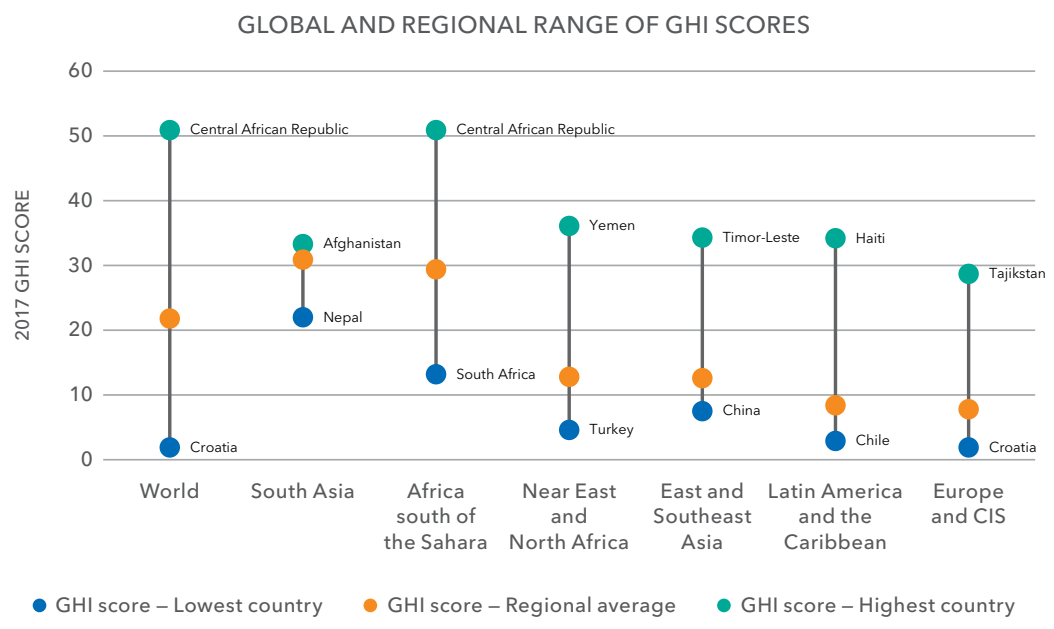

\section{Trend 2}

\section{CHILDREN'S UNDERNUTRITION VARIES WIDELY WITHIN COUNTRIES}

An examination of subnational-level data on child stunting (an indicator of chronic undernutrition) reveals wide disparities within countries. These differences in hunger and nutrition profiles mean that, in most countries, a one-size-fits-all approach to tackling hunger and undernutrition is unlikely to yield the best results.

SUBNATIONAL INEQUALITY OF CHILD STUNTING

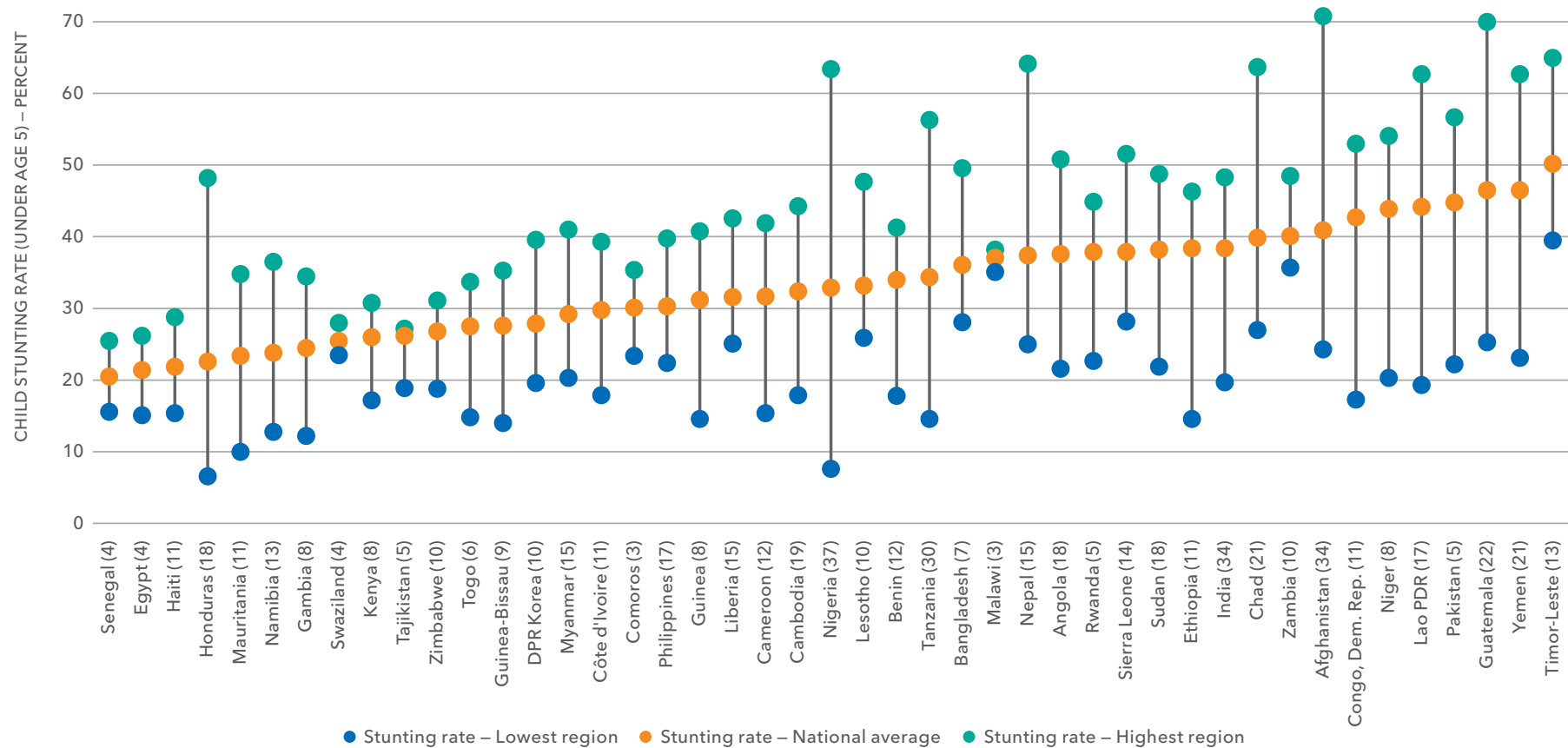

Note: (\#) indicates the number of regions in each country. Countries included are those with subnational data available for 2012-2016, with average stunting levels over 20 percent. 


\section{Food Policy Research Capacity Indicators (FPRCI)}

Food policy research plays a crucial role in guiding the agricultural development of countries. To achieve food security goals, countries need to strengthen their capacity to conduct food policy research. Strong local policy research institutions help in shaping an evidence-based policy-making process. Measuring national capacity for food policy research is important for identifying capacity gaps in food policy research and guiding allocation of resources to fill those gaps.

Food policy research capacity is defined as any socioeconomic or policy-related research capacity in the area of food, agriculture, or natural resources. To measure this capacity, the International Food Policy Research Institute (IFPRI) developed a set of indicators of the quantity and quality of policy research at the country level.

\section{INDICATORS}

IFPRI created a database for food policy research capacity in 2010, and has continued to expand and refine it. The data presented in Table 4 are currently collected for 33 countries; data for Myanmar were added in 2017. A consistent methodology is followed to enable comparison of values across time and countries. The database was most recently updated with numbers for 2017.

"Analysts/researchers" is a head count of professionals employed at local organizations whose work involves food policy research or analysis. To introduce some uniformity, IFPRI also presents a modified quantification of the head count: "full-time equivalent analysts/researchers with PhD equivalent." To obtain an indicator of per capita food policy research capacity, this research capacity is then divided by the country's rural population ("full-time equivalent researchers per million rural residents"). This helps to illustrate the impact of local food policy research in a country. This indicator was last updated in 2015.

The quality of a country's food policy research capacity is estimated by tallying the number of relevant international publications in peer-reviewed journals over a five-year period. IFPRI views this as a reflection of the local enabling environment for food policy research. This indicator allows for comparison across countries, as it ensures an internationally accepted standard of quality for publications. The final indicator ("publications per full-time equivalent researcher") is derived by dividing the number of international publications by the number of full-time equivalent researchers with a $\mathrm{PhD}$, providing a measure of productivity.

\section{TRENDS IN FOOD POLICY RESEARCH}

Overall food policy research capacity across all countries did not change from last year's level, but countries and regions had different experiences. For instance, Colombia has seen a steady decline in the number of food policy research publications since 2011, while other countries like Bangladesh, Ghana, and Nepal saw an increase.

All countries in Africa except Swaziland saw a slight increase in food policy research capacity as measured by the number of publications. Most Asian countries did not show a dramatic change in publications except for Bangladesh and Nepal which achieved steady increases. In Latin America, apart from Colombia and Guatemala, all countries experienced either a slight increase or no change in the number of publications.

IFPRI will continue to update and expand this database to include additional countries to better facilitate cross-country comparisons. This will also facilitate identification of the minimum food policy research capacity threshold for a country. It is hoped that such data will aid in informing national policy makers of the importance of investing in local food policy research capacity. Lastly, this data will provide donors with a framework for prioritizing investments to strengthen food policy research capacity across as well as within countries.

DOWNLOAD DATA

http://dx.doi.org/10.7910/DVN/LR6CQC

CONTACT

Suresh Babu (s.babu@cgiar.org) and Paul Dorosh (p.dorosh@cgiar.org) 
TABLE 4 Food policy research capacity indicators, 2011-2017

\begin{tabular}{|c|c|c|c|c|c|}
\hline Country & $\begin{array}{l}\text { Analysts/researchers } \\
\text { (head count) in } 2015\end{array}$ & $\begin{array}{l}\text { Full-time equivalent } \\
\text { analysts/researchers } \\
\text { with PhD in } 2015\end{array}$ & $\begin{array}{l}\text { International } \\
\text { publications } \\
\text { produced from } \\
2011-2017\end{array}$ & $\begin{array}{l}\text { Full-time equivalent } \\
\text { analysts/researchers } \\
\text { with PhD per million } \\
\text { rural population } \\
\text { in } 2015\end{array}$ & $\begin{array}{l}\text { Publications per } \\
\text { full-time equivalent } \\
\text { researchers with } \\
\text { PhD }\end{array}$ \\
\hline Afghanistan & 43 & 3.0 & 5 & 0.131 & 1.681 \\
\hline Bangladesh & 66 & 22.9 & 101 & 0.217 & 4.410 \\
\hline Burundi & 39 & 5.1 & 3 & 0.570 & 0.585 \\
\hline China* & 2,000 & $1,332.5$ & 1,564 & 2.096 & 1.174 \\
\hline Colombia & 85 & 6.5 & 29 & 0.553 & 4.496 \\
\hline Ethiopia & 141 & 30.4 & 28 & 0.397 & 0.921 \\
\hline Ghana & 153 & 23.3 & 77 & 1.903 & 3.305 \\
\hline Kenya & 155 & 31.6 & 77 & 0.947 & 2.437 \\
\hline Laos & 9 & 1.8 & 8 & 0.407 & 4.571 \\
\hline Liberia & 34 & 3.1 & 2 & 1.402 & 0.650 \\
\hline Madagascar & 187 & 11.5 & 11 & 0.760 & 0.954 \\
\hline Malawi & 68 & 18.2 & 28 & 1.321 & 1.541 \\
\hline Mali & 60 & 10.1 & 5 & 1.066 & 0.498 \\
\hline Mozambique & 37 & 3.3 & 13 & 0.188 & 3.910 \\
\hline Myanmar & 97 & 46.5 & 7 & 1.309 & 0.151 \\
\hline South Africa & 198 & 50.3 & 257 & 2.623 & 5.107 \\
\hline Swaziland & 32 & 2.9 & 1 & 2.900 & 0.351 \\
\hline Tanzania & 91 & 20.8 & 36 & 0.604 & 1.735 \\
\hline Togo & 81 & 6.8 & 5 & 1.641 & 0.733 \\
\hline Uganda & 34 & 10.9 & 28 & 0.344 & 2.563 \\
\hline Viet Nam & 175 & 32.5 & 13 & 0.536 & 0.400 \\
\hline Zambia & 29 & 5.3 & 18 & 0.608 & 3.396 \\
\hline Zimbabwe & 42 & 8.9 & 16 & 0.931 & 1.803 \\
\hline
\end{tabular}

Notes: * = "International publications produced" for China are from 2009-2017. 


\section{FPRCI}

\section{FOOD POLICY RESEARCH CAPACITY INDICATORS}

\section{Trend 1}

\section{RESEARCH CAPACITY IS UNEVEN WITHIN DEVELOPING REGIONS}

Food policy research capacity-measured in terms of full-time equivalent researchers with a PhD per million rural people-varies greatly across and within developing regions. Economic development levels explain capacity differences only in part. In Asia, China and Myanmar have a relatively high ratio of food policy researchers to rural people compared to Afghanistan, Bangladesh, Indonesia, Lao PDR, Nepal, and Viet Nam, which have less than 1 researcher per million rural people. Despite consistent decreases in rural population, Bangladesh, Lao PDR, and Indonesia show relatively low capacity compared to Myanmar, where the rural population is increasing.

\section{Trend 2}

\section{NUMBER OF PUBLICATIONS PER} RESEARCHER IS RISING IN AFRICA, BUT WITH WIDE VARIATION

The number of international publications produced per researcher has increased for all African countries, excepting Swaziland. But across the continent, the number of publications per researcher varies widely. For some countries-including Ghana, Malawi, and South Africa-this measure correlates with the number of researchers per million rural people. Other countries produce relatively more publications, despite low researcher-to-population ratios.

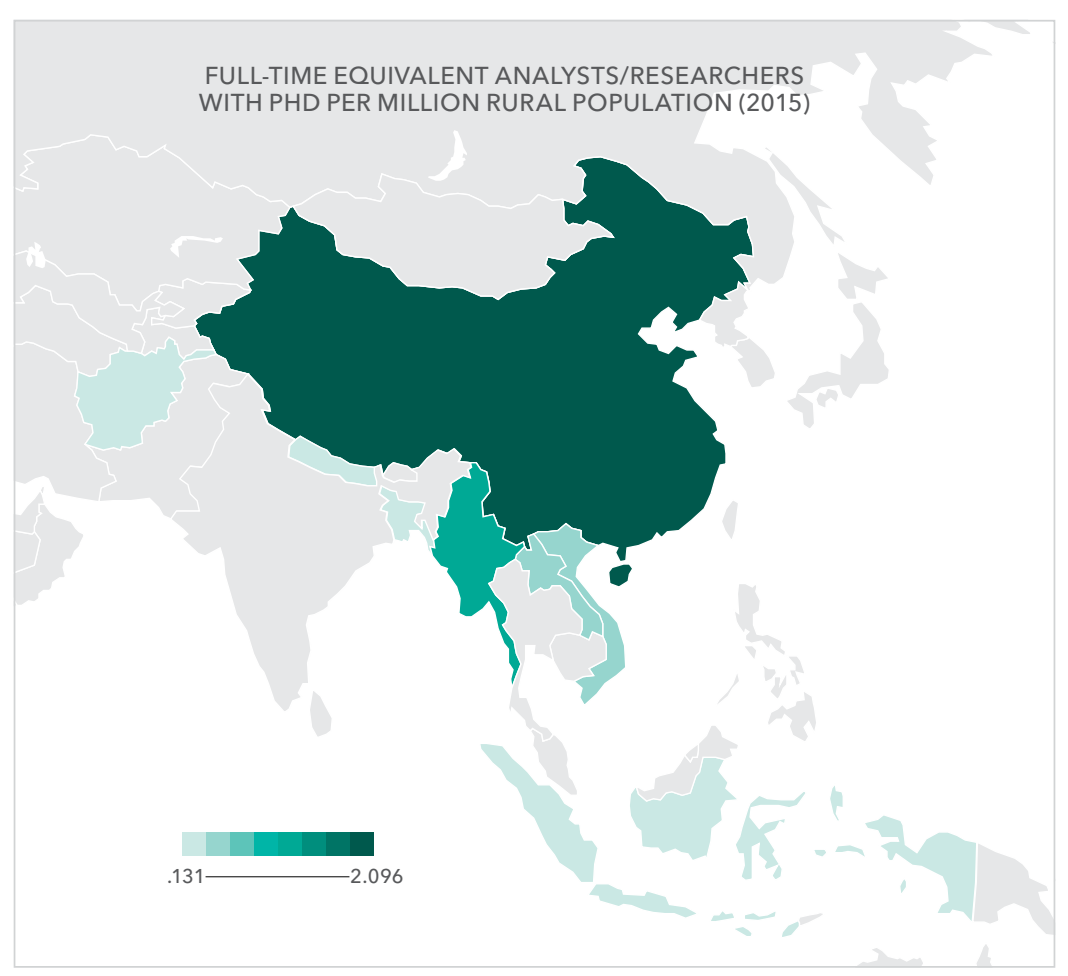

PUBLICATIONS PER FULL-TIME EQUIVALENT RESEARCHERS WITH PHD

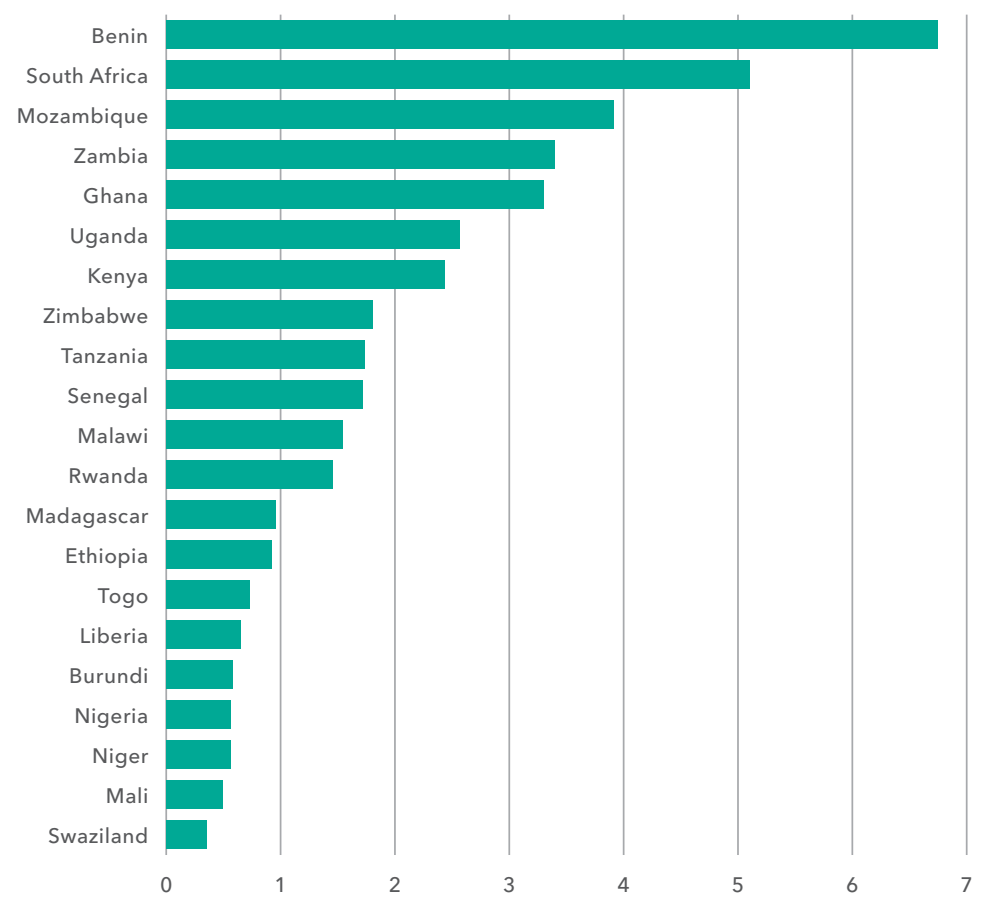




\section{Agricultural Total Factor Productivity (TFP)}

Increasing the efficiency of agricultural production-getting more output from the same amount of resources-is critical for improving food security. To measure the efficiency of agricultural systems, we use total factor productivity (TFP). TFP is an indicator of how efficiently agricultural land, labor, capital, and materials (agricultural inputs) are used to produce a country's crops and livestock (agricultural output)-it is calculated as the ratio of total agricultural output to total production inputs. When more output is produced from a constant amount of resources, meaning that resources are being used more efficiently, TFP increases. Measures of land and labor productivity-partial factor productivity (PFP) measures-are calculated as the ratio of total output to total agricultural area (land productivity) and to the number of economically active persons in agriculture (labor productivity). Because PFP measures are easy to estimate, they are often used to measure agricultural production performance. These measures normally show higher rates of growth than TFP, because growth in land and labor productivity can result not only from increases in TFP but also from a more intensive use of other inputs (such as fertilizer or machinery). Indicators of both TFP and PFP contribute to the understanding of agricultural systems needed for policy and investment decisions by allowing for comparisons across time and across countries and regions.

\section{TRENDS IN PRODUCTIVITY}

Table 5 presents estimates of TFP and land and labor productivity measures for developing countries and regions for three periods between 1991 and 2014 using the most recent data on outputs and inputs from the Economic Research Service of the United States Department of Agriculture (ERS-USDA), an internationally consistent and comparable dataset on production and input quantities built using data from the FAOSTAT database of the Food and Agriculture Organization of the United Nations (FAO), supplemented with data from national statistical sources.'

Data on TFP for 2001-2010 show a strong performance of Latin America and the Caribbean, despite the global crisis of 2008-2009, which explains the slowdown observed in TFP growth in other regions.
Asia and the Pacific and the Middle East and North Africa show signs of recovery in recent years (20112014), while Africa south of the Sahara continues to show sluggish growth, and TFP growth rates in Latin America and the Caribbean in recent years drop to only half of the values observed in 2001-2010, a result largely explained by poor performance of Brazil's agriculture sector in the last four years.

\section{DATA AND METHODOLOGY}

The output values from the ERS-USDA dataset used to estimate TFP are gross agricultural outputs. Inputs are agricultural land, in hectares of "rainfed cropland equivalents," measured as the sum of rainfed cropland (weight equals 1.00), irrigated cropland (weight varies from 1.00 to 3.00 depending on region), and permanent pasture (weight varies from 0.02 to 0.09 depending on region); a measure of labor is approximated using the number of economically active persons in agriculture; fertilizer is expressed in tons of fertilizer nutrients used; total stock of farm machinery is measured as the number of " $40-C V$ tractor equivalents"; total livestock capital on farms is in "cattle equivalents," calculated using FAO estimates of animal stocks on farms, with species weighted by their respective size (nondairy cattle taking a weight of 1.00). Finally, total animal feed from crops and crop processing residues is measured in dry-matter equivalents.

Land and labor productivity measures for the regions (such as Africa south of the Sahara) reflect a weighted average of individual country productivity measures using average outputs (1991-2014) of each country as weights. TFP is calculated using a growth accounting approach. This approach defines TFP as the ratio of an output index and an input index. As input prices are not available, input shadow prices were obtained for each country and year by estimating the parameters of distance functions through linear programming.

\section{DOWNLOAD DATA}

http://dx.doi.org/10.7910/DVN/IDOCML

CONTACT

Alejandro Nin-Pratt (a.ninpratt@cgiar.org) 
TABLE 5 Average annual growth of agricultural output and total factor productivity (TFP), and levels of land and labor productivity, various years

\begin{tabular}{|c|c|c|c|c|c|c|c|c|c|c|c|c|c|c|}
\hline \multirow[b]{2}{*}{ Country/region } & \multicolumn{4}{|c|}{$\begin{array}{l}\text { Land productivity } \\
\text { (in constant 2004-2006 US dollars) }\end{array}$} & \multicolumn{4}{|c|}{$\begin{array}{l}\text { Labor productivity } \\
\text { (in constant 2004-2006 US dollars) }\end{array}$} & \multicolumn{3}{|c|}{ Output growth (\%) } & \multicolumn{3}{|c|}{ TFP growth (\%) } \\
\hline & 1990 & 2000 & 2010 & 2014 & 1990 & 2000 & 2010 & 2014 & $\begin{array}{l}1991- \\
2000\end{array}$ & $\begin{array}{c}2001- \\
2010\end{array}$ & $\begin{array}{l}2010- \\
2014\end{array}$ & $\begin{array}{l}1991- \\
2000\end{array}$ & $\begin{array}{l}2001- \\
2010\end{array}$ & $\begin{array}{c}2010- \\
2014\end{array}$ \\
\hline $\begin{array}{l}\text { AFRICA } \\
\text { SOUTH OF THE SAHARA }\end{array}$ & 198 & 255 & 321 & 332 & 1,326 & 1,597 & 1,885 & 2,105 & 3.3 & 3.8 & 2.9 & 2.1 & 0.8 & 0.2 \\
\hline Botswana & 9 & 8 & 11 & 12 & 1,071 & 724 & 906 & 924 & -0.8 & 3.3 & 1.6 & -1.0 & 2.1 & 2.2 \\
\hline Burkina Faso & 111 & 146 & 196 & 222 & 297 & 296 & 388 & 378 & 2.8 & 6.0 & 2.6 & -0.5 & 1.4 & 0.4 \\
\hline Burundi & 528 & 602 & 673 & 701 & 406 & 342 & 299 & 274 & -0.5 & 2.2 & 0.2 & -0.4 & -0.5 & -1.0 \\
\hline Cameroon & 434 & 533 & 659 & 722 & 713 & 841 & 1,398 & 1,562 & 3.1 & 5.7 & 3.2 & 0.8 & 3.8 & 1.8 \\
\hline Comoros & 593 & 578 & 557 & 528 & 409 & 384 & 332 & 300 & 1.7 & 1.0 & 0.0 & -2.4 & -0.8 & -1.3 \\
\hline Congo & 20 & 27 & 40 & 43 & 466 & 546 & 776 & 810 & 2.7 & 4.2 & 1.7 & 0.7 & 0.4 & 0.4 \\
\hline Congo, Dem. Rep & 180 & 159 & 163 & 169 & 493 & 347 & 296 & 289 & -1.5 & 0.3 & 1.2 & -0.1 & -1.2 & -1.6 \\
\hline Côte d'Ivoire & 208 & 291 & 295 & 314 & 1,520 & 1,946 & 2,262 & 2,692 & 3.5 & 0.9 & 4.4 & 0.9 & 0.0 & 0.0 \\
\hline Equatorial Guinea & 161 & 182 & 237 & 255 & 363 & 278 & 265 & 258 & 0.1 & 1.6 & 1.6 & -1.4 & 0.8 & 0.9 \\
\hline Ethiopia, former & 99 & 145 & 250 & 286 & 255 & 218 & 300 & 315 & 1.8 & 6.4 & 3.9 & 2.1 & 3.0 & -1.1 \\
\hline Gabon & 41 & 52 & 59 & 62 & 949 & 1,227 & 1,522 & 1,540 & 2.3 & 1.3 & 1.5 & 0.7 & 1.1 & 0.4 \\
\hline Gambia & 129 & 228 & 267 & 214 & 233 & 288 & 295 & 160 & 4.8 & 3.2 & -12.0 & 1.4 & -0.3 & -10.6 \\
\hline Ghana & 178 & 313 & 450 & 524 & 567 & 905 & 1,114 & 1,194 & 7.5 & 4.6 & 4.1 & 4.5 & 0.5 & 2.4 \\
\hline Malawi & 243 & 404 & 536 & 514 & 302 & 491 & 620 & 531 & 6.3 & 4.6 & -1.1 & 3.7 & 0.5 & -3.8 \\
\hline Mali & 44 & 51 & 95 & 101 & 822 & 885 & 1,345 & 1,347 & 2.6 & 6.7 & 2.5 & 1.3 & 3.5 & 0.5 \\
\hline Mauritania & 9 & 10 & 12 & 14 & 767 & 676 & 631 & 639 & 1.5 & 2.2 & 2.9 & -1.0 & -0.7 & 1.9 \\
\hline Mauritius & 2,528 & 2,749 & 3,369 & 3,642 & 3,174 & 3,952 & 5,554 & 6,227 & 0.3 & 0.4 & -0.6 & -1.3 & 1.0 & 0.9 \\
\hline Mozambique & 24 & 34 & 60 & 55 & 221 & 230 & 343 & 281 & 3.5 & 6.2 & -2.5 & -0.3 & 2.0 & -5.4 \\
\hline Namibia & 10 & 10 & 11 & 11 & 1,689 & 1,529 & 1,614 & 1,599 & 0.4 & 0.6 & 0.5 & -1.9 & 1.5 & 0.6 \\
\hline Niger & 35 & 51 & 74 & 77 & 500 & 545 & 793 & 711 & 4.2 & 7.1 & 0.9 & 1.6 & 2.9 & -1.9 \\
\hline Nigeria & 291 & 388 & 505 & 494 & 1,244 & 1,607 & 1,709 & 1,762 & 5.0 & 2.6 & 2.7 & 3.0 & -0.6 & 1.1 \\
\hline Rwanda & 599 & 669 & 1,037 & 947 & 459 & 420 & 535 & 481 & 0.7 & 5.2 & 0.0 & 0.7 & 1.7 & -2.9 \\
\hline Réunion (France) & 2,085 & 3,191 & 3,212 & 3,207 & 8,487 & 16,644 & 30,233 & 45,042 & 2.0 & 0.9 & -0.2 & 1.6 & 0.6 & 3.3 \\
\hline Sao Tome and Principe & 268 & 513 & 595 & 686 & 512 & 932 & 802 & 798 & 7.2 & 1.1 & 2.6 & 5.0 & -0.9 & 0.5 \\
\hline Senegal & 111 & 147 & 198 & 178 & 374 & 397 & 428 & 314 & 3.0 & 3.4 & -4.6 & 0.3 & 0.3 & -4.5 \\
\hline Sierra Leone & 147 & 121 & 287 & 331 & 400 & 316 & 829 & 921 & -2.9 & 11.9 & 3.7 & 0.1 & 4.9 & 2.1 \\
\hline Somalia & 33 & 33 & 38 & 40 & 816 & 707 & 654 & 630 & -0.1 & 1.3 & 1.6 & 2.1 & -1.0 & 4.0 \\
\hline South Africa & 96 & 111 & 136 & 146 & 5,713 & 7,315 & 10,927 & 13,005 & 1.6 & 2.0 & 1.7 & 5.2 & 1.8 & 1.1 \\
\hline Sudan, former & 32 & 55 & 95 & 120 & 732 & 1,107 & 1,168 & 1,417 & 6.4 & 2.3 & 6.4 & 3.7 & -1.0 & -0.3 \\
\hline
\end{tabular}




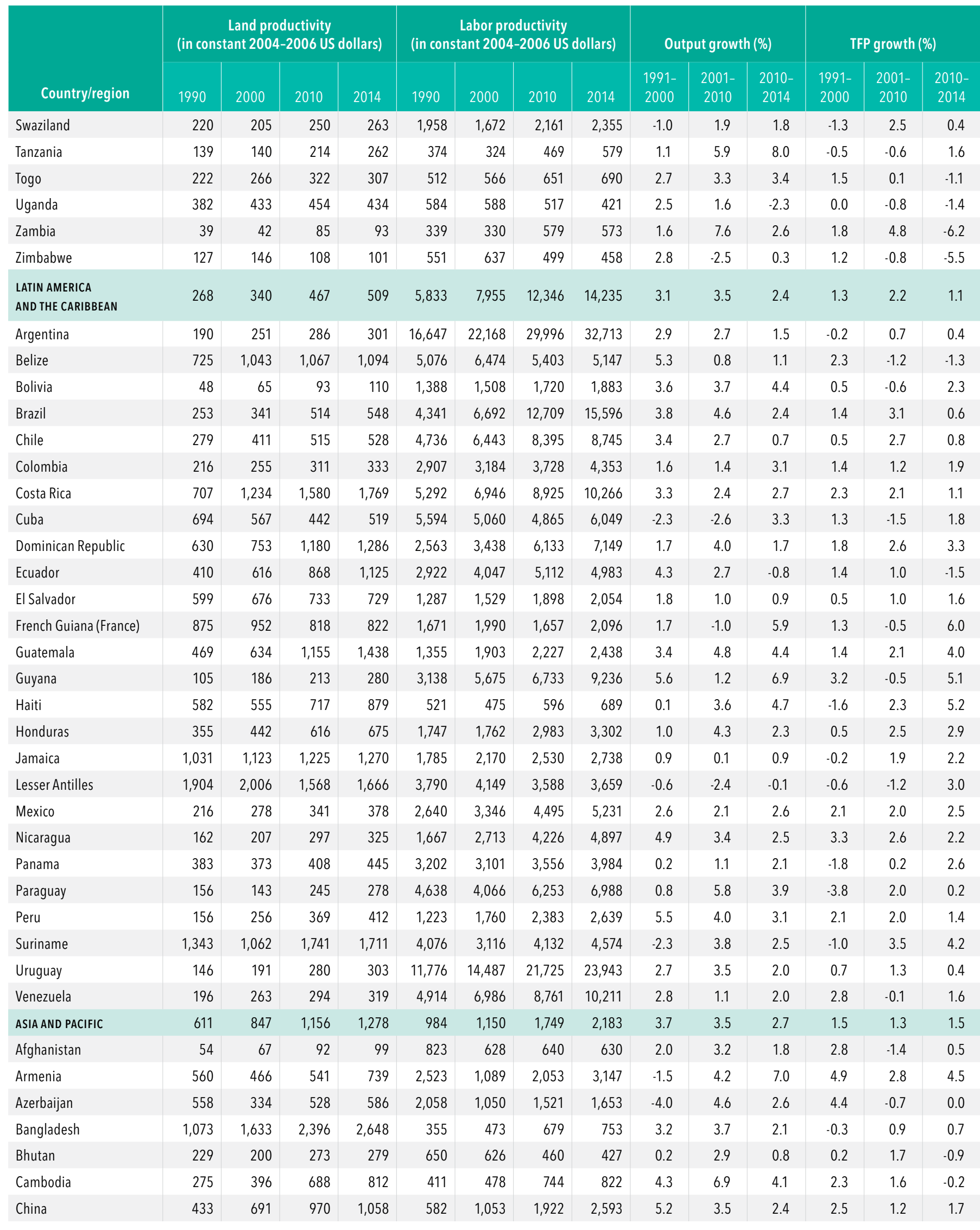




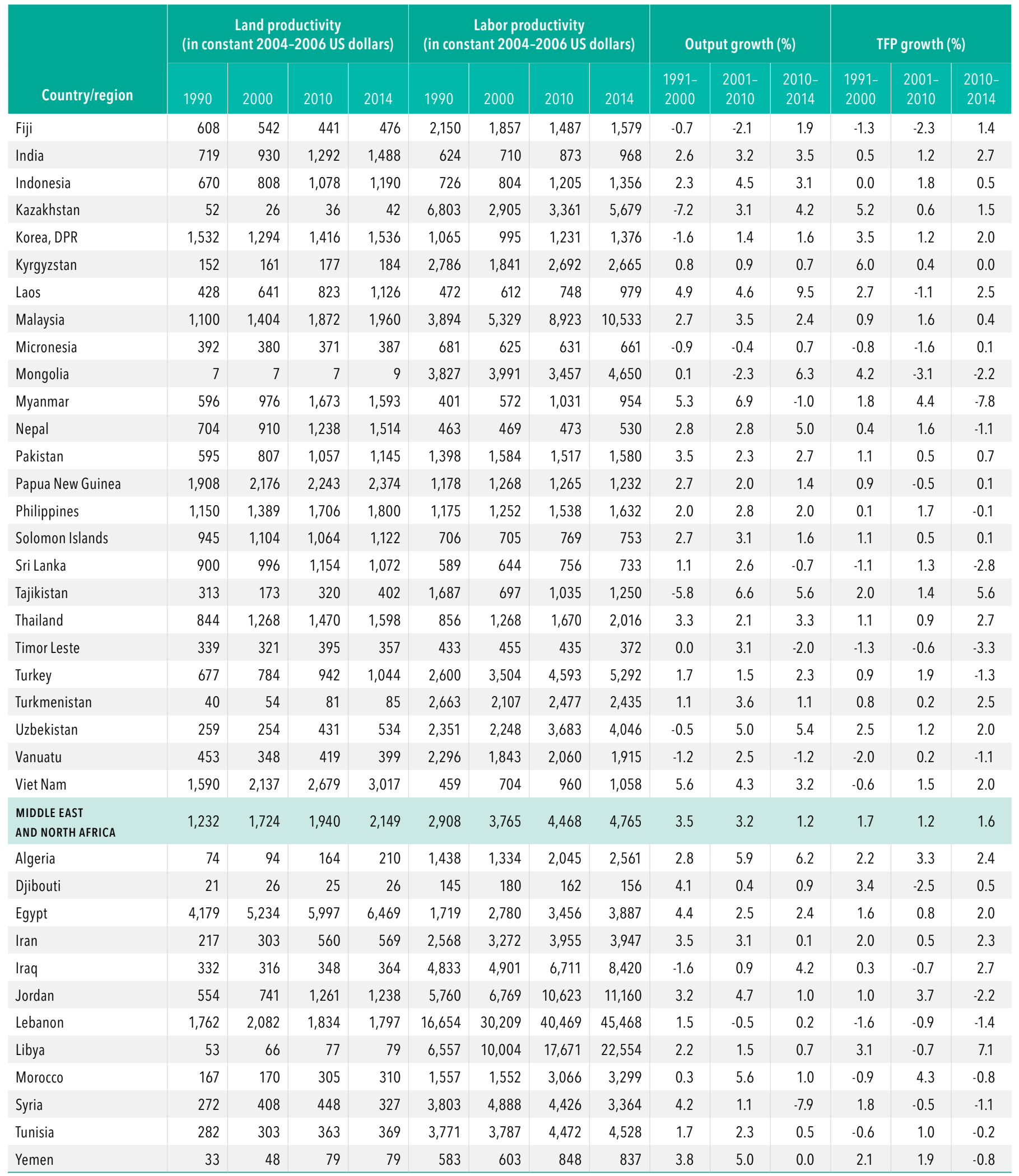

Note: Land productivity is agricultural gross production per hectare of agricultural land; labor productivity is agricultural gross production per economically active person in agriculture. 


\section{Trend 1}

\section{SUSTAINED TFP GROWTH IN DEVELOPING COUNTRIES}

Between 1990 and 2014, total factor productivity (TFP) in developing countries increased by 45 percent, representing an average annual growth rate of 1.6 percent. The fastest growth was observed in 1991-2000, when the growth rate averaged 1.7 percent. Between 2001 and 2008, growth in TFP accelerated from 1.2 percent to almost 3.0 percent (average growth of 1.85 percent), but the negative impact of the global economic crisis of 20082009 slowed TFP growth to 1.5 percent on average between 2011 and 2014.

\section{Trend 2}

\section{CHINA, BRAZIL, AND INDIA ARE} THE DRIVERS OF TFP GROWTH

TFP growth in developing countries has been driven by growth in Brazil, China, and India. Together, these countries produced on average about 50 percent of all agricultural output in developing countries in 1991-2014, but contributed 70 percent of total TFP growth. China has been the major driver of global agricultural TFP (55 and 42 percent of TFP growth in 1991-2000 and 2011-2014, respectively). The contribution of Brazil and India to global TFP growth increased after policy reforms in the 1990s and early 2000s. Brazil was a major driver of TFP growth in the 2000s (20 percent), while 31 percent of TFP growth in 2011-2014 is explained by TFP growth in India.
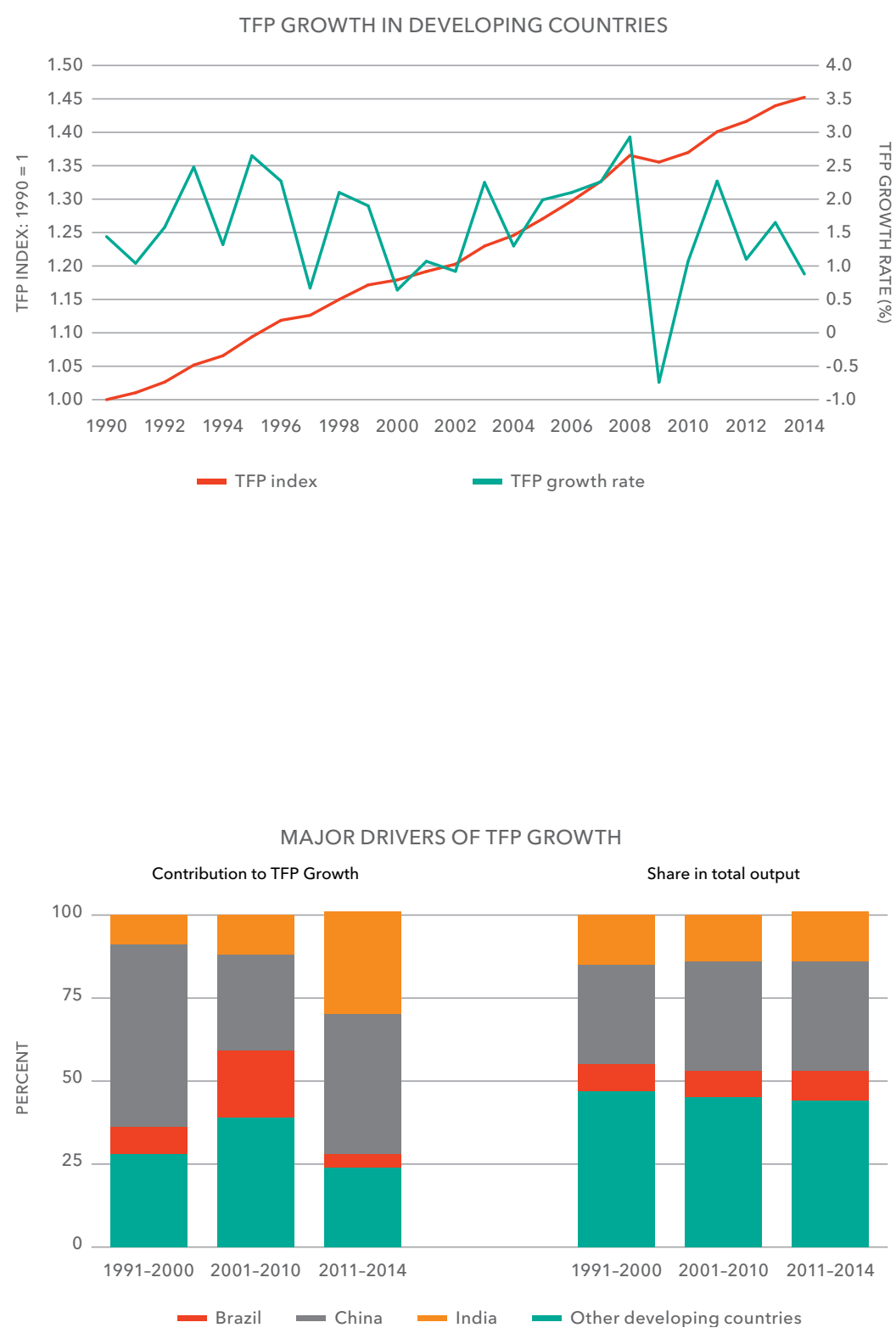


\title{
Projections of Food Production, Consumption, and Hunger
}

\author{
INTERNATIONAL MODEL FOR POLICY ANALYSIS OF AGRICULTURAL \\ COMMODITIES AND TRADE (IMPACT)
}

Policy makers, analysts, and civil society face increasing challenges to reducing hunger and improving food security in a sustainable way. Modeling alternative future scenarios and assessing their outcomes can help inform their choices. The International Food Policy Research Institute's IMPACT model is an integrated system of linked economic, climate, water, and crop models that allows for exploration of such scenarios.

\section{METHODOLOGY}

At IMPACT's core is a partial equilibrium, multimarket economic model that simulates national and international agricultural markets. Links to climate, water, and crop models support the integrated study of changing environmental, biophysical, and socioeconomic trends, allowing for in-depth analysis of a variety of critical issues of interest to policy makers at national, regional, and global levels. IMPACT benefits from close interactions with scientists at all 15 CGIAR research centers through the Global Futures and Strategic Foresight (GFSF) program, and with other leading global economic modeling efforts around the world through the Agricultural Model Intercomparison and Improvement Project (AgMIP).

The tables on the following pages summarize results from the latest IMPACT projections to 2030 and 2050. Results are shown for production, consumption, and trade of major food commodity groups, as well as for the population at risk of hunger, by region and for selected countries. Results are shown for two "baseline" scenarios-one considers the impacts of climate change, while the other assumes no climate change (for comparison). Results for additional countries can be found at the IMPACT website.

\section{KEY FINDINGS FROM THE LATEST IMPACT PROJECTIONS}

The baseline projections from IMPACT indicate that global food production will grow by about 60 percent over 2010 levels by 2050 in the context of climate change-10 percentage points less than would be the case without climate change (Table 6). Production will grow more rapidly in developing countries, particularly in Africa. Even with population growth and climate change, per capita consumption (assumed equivalent to per capita availability) is projected to increase by 9 percent globally to more than 3,000 kilocalories per day. But differences in access to food within and between countries mean that nearly 500 million people will remain at risk of hunger. In Africa south of the Sahara, an additional 38 million people are projected to be at risk of hunger in 2050 as a result of climate change-25 percent more than would be at risk in the absence of climate change.

Despite the impacts of climate change, meat production is projected to grow by 66 percent globally by 2050 , and by 78 percent in developing countries. Per capita consumption levels in developing countries, however, will remain under half of those in developed countries (Table 7). Production of fruits and vegetables, pulses, and oilseeds will grow even more rapidly, by more than 80 percent globally and more than doubling in some regions. Per capita consumption of fruits and vegetables in developing countries is projected to surpass that of developed countries by 2050, with important benefits for nutrition and health. Production of cereals and roots and tubers will grow more slowly, by around 40 percent globally but roughly doubling in Africa south of the Sahara. Developing countries as a group will become larger net importers of food from developed countries.

In addition to the indicators presented here, IMPACT also explores changes in prices, land and water use, greenhouse gas emissions, and other socioeconomic and environmental indicators. For example, prices are projected to rise by about 50 percent for most food commodity groups by 2050 when the impacts of climate change are consideredabout double the increase projected in the absence of climate change. Selected results from alternative strategies are presented following Table 7. 


\section{MORE INFORMATION}

More information on these results, and on the results of alternative scenarios exploring different population, income, policy, investment, and technology pathways, can be found online (see box). Results for all 158 countries and regions modeled are available as well as information on IMPACT, the GFSF program, and recent publications. Tables 6 and 7 present baseline data that will be updated in the coming year.
VISIT ONLINE

IFPRI IMPACT: https://www.ifpri.org/program/

impact-model

Global Futures and Strategic Foresight:

http://globalfutures.cgiar.org/

IMPACT documentation: http://www.ifpri.org/

publication/international-model-policy-analysis-a

$\underline{\text { gricultural-commodities-and-trade-impact-model-0 }}$

CONTACT

IMPACT (IFPRI-Impact-Model@cgiar.org)

TABLE 6 IMPACT projections of food production, consumption, and hunger to 2050, with and without climate change

\begin{tabular}{|c|c|c|c|c|c|c|c|c|c|c|c|c|c|c|c|}
\hline & \multicolumn{5}{|c|}{$\begin{array}{l}\text { Aggregate food production } \\
\quad \text { (index, 2010 = 1.00) }\end{array}$} & \multicolumn{5}{|c|}{$\begin{array}{l}\text { Per capita food consumption } \\
\text { (KCAL per capita per day) }\end{array}$} & \multicolumn{5}{|c|}{$\begin{array}{c}\text { Hunger } \\
\text { (millions of people at risk) }\end{array}$} \\
\hline & \multirow[b]{2}{*}{2010} & \multicolumn{2}{|c|}{$\begin{array}{l}\text { Without } \\
\text { climate change }\end{array}$} & \multicolumn{2}{|c|}{$\begin{array}{c}\text { With } \\
\text { climate change }\end{array}$} & \multirow[b]{2}{*}{2010} & \multicolumn{2}{|c|}{$\begin{array}{l}\text { Without } \\
\text { climate change }\end{array}$} & \multicolumn{2}{|c|}{$\begin{array}{l}\text { With } \\
\text { climate change }\end{array}$} & \multirow[b]{2}{*}{2010} & \multicolumn{2}{|c|}{$\begin{array}{l}\text { Without } \\
\text { climate change }\end{array}$} & \multicolumn{2}{|c|}{$\begin{array}{c}\text { With } \\
\text { climate change }\end{array}$} \\
\hline & & 2030 & 2050 & 2030 & 2050 & & 2030 & 2050 & 2030 & 2050 & & 2030 & 2050 & 2030 & 2050 \\
\hline WORLD & 1.00 & 1.37 & 1.69 & 1.33 & 1.60 & 2795 & 3032 & 3191 & 2982 & 3079 & 838.1 & 528.2 & 405.8 & 592.3 & 476.9 \\
\hline ASIA AND PACIFIC & 1.00 & 1.37 & 1.64 & 1.36 & 1.63 & 2656 & 3003 & 3185 & 2954 & 3072 & 539.8 & 249.8 & 181.8 & 280.9 & 204.6 \\
\hline East Asia & 1.00 & 1.23 & 1.35 & 1.26 & 1.41 & 3009 & 3509 & 3628 & 3459 & 3516 & 187.2 & 59.2 & 54.7 & 60.3 & 56.8 \\
\hline China & 1.00 & 1.23 & 1.34 & 1.26 & 1.40 & 3044 & 3604 & 3733 & 3552 & 3616 & 173.4 & 44.8 & 41.0 & 44.7 & 41.0 \\
\hline Japan & 1.00 & 1.24 & 1.52 & 1.31 & 1.69 & 2770 & 2787 & 2842 & 2757 & 2773 & 2.3 & 2.0 & 1.2 & 2.3 & 1.9 \\
\hline Bangladesh & 1.00 & 1.41 & 1.63 & 1.33 & 1.46 & 2426 & 2714 & 2911 & 2653 & 2781 & 26.0 & 11.3 & 6.9 & 14.8 & 8.7 \\
\hline India & 1.00 & 1.63 & 2.16 & 1.56 & 2.01 & 2354 & 2697 & 2998 & 2651 & 2883 & 189.7 & 73.9 & 45.0 & 90.5 & 44.9 \\
\hline Nepal & 1.00 & 1.33 & 1.60 & 1.37 & 1.71 & 2425 & 2695 & 3186 & 2625 & 3028 & 2.7 & 2.0 & 0.8 & 2.4 & 1.5 \\
\hline Pakistan & 1.00 & 1.33 & 1.63 & 1.27 & 1.50 & 2379 & 2540 & 2862 & 2514 & 2787 & 37.6 & 38.0 & 24.4 & 39.9 & 28.0 \\
\hline $\begin{array}{l}\text { Southeast Asia and } \\
\text { Pacific }\end{array}$ & 1.00 & 1.48 & 1.89 & 1.46 & 1.84 & 2551 & 2852 & 3051 & 2796 & 2931 & 84.1 & 52.3 & 39.4 & 58.9 & 50.8 \\
\hline Indonesia & 1.00 & 1.62 & 2.02 & 1.63 & 2.05 & 2540 & 2990 & 3281 & 2910 & 3110 & 32.4 & 12.9 & 7.2 & 15.3 & 11.1 \\
\hline Malaysia & 1.00 & 1.83 & 2.95 & 1.79 & 2.84 & 2838 & 3173 & 3462 & 3143 & 3384 & 0.9 & 0.8 & 0.9 & 0.8 & 0.9 \\
\hline Myanmar & 1.00 & 1.35 & 1.55 & 1.34 & 1.53 & 2169 & 2473 & 2592 & 2420 & 2487 & 10.5 & 6.5 & 4.8 & 7.2 & 6.0 \\
\hline Philippines & 1.00 & 1.33 & 1.68 & 1.31 & 1.65 & 2503 & 2641 & 2777 & 2602 & 2691 & 12.1 & 12.2 & 11.0 & 13.2 & 13.1 \\
\hline Ethiopia & 1.00 & 1.65 & 2.45 & 1.66 & 2.48 & 2066 & 2307 & 2614 & 2266 & 2533 & 32.7 & 32.3 & 22.5 & 34.7 & 26.5 \\
\hline Kenya & 1.00 & 1.76 & 3.12 & 1.79 & 3.14 & 2133 & 2395 & 2708 & 2300 & 2524 & 10.2 & 8.9 & 5.0 & 10.8 & 8.2 \\
\hline Nigeria & 1.00 & 1.62 & 2.31 & 1.56 & 2.16 & 2751 & 2943 & 3136 & 2866 & 2984 & 9.7 & 8.5 & 11.6 & 10.6 & 11.6 \\
\hline
\end{tabular}


Table 6 continued

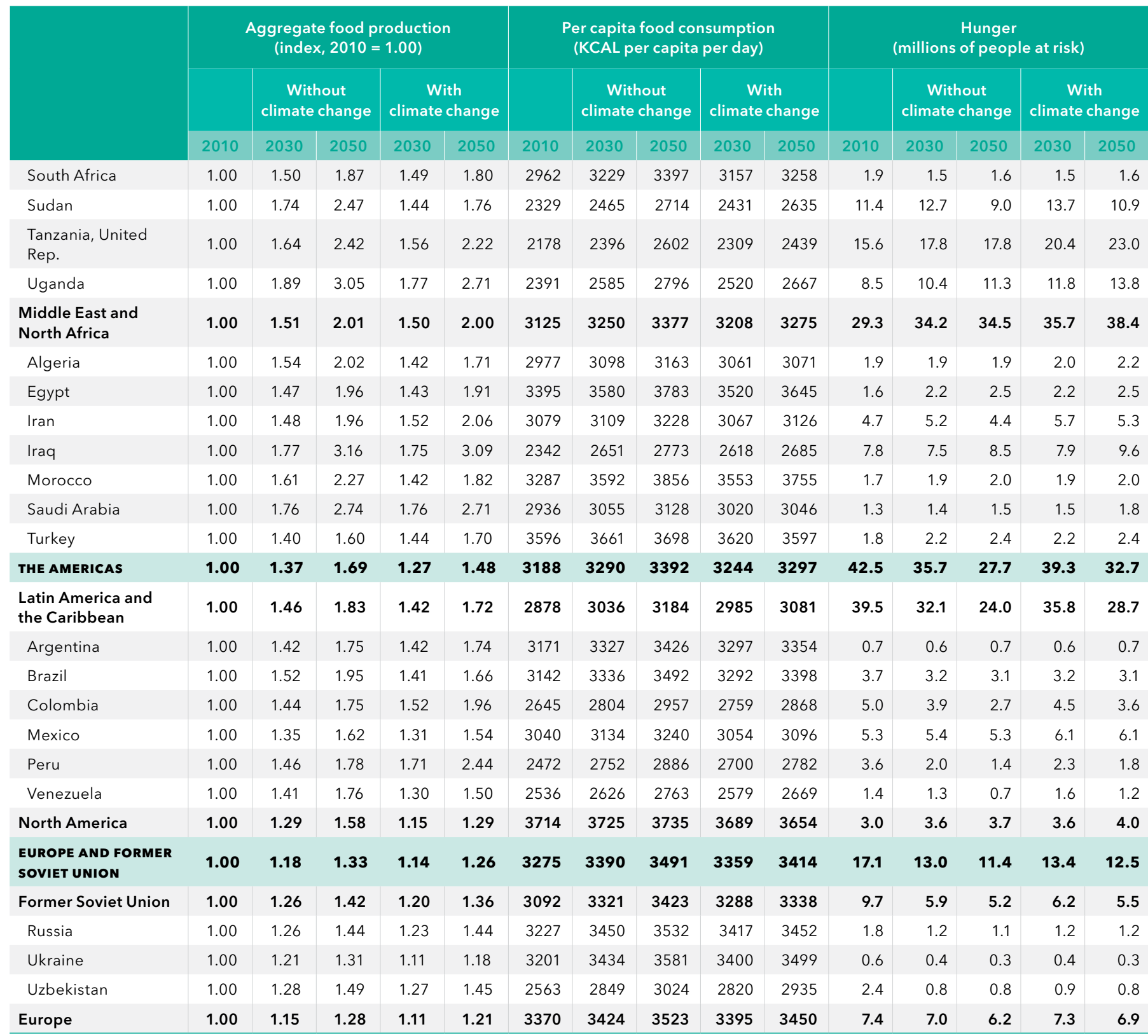

Notes: World and regional figures include other regions and countries not reported separately. Aggregate food production is an index, by weight, of cereals, meats, fruits and vegetables, oilseeds, pulses, and roots and tubers (which are reported separately in Table 7). Per capita food consumption is a projection of daily dietary energy supply. Estimates of the number of people at risk of hunger are based on a quadratic specification of the relationship between national-level calorie supply and the share of population that is undernourished as defined by the FAO. Values reported for 2010 are calibrated model results. Projections for 2030 and 2050 assume changes in population and income as reflected in the Intergovernmental Panel on Climate Change's (IPCC) Shared Socioeconomic Pathway 2. Climate change impacts are simulated using the IPCC's Representative Concentration Pathway 8.5 and the HadGEM general circulation model. Further documentation is available at www.ifpri.org/program/impact-model.

Source: IFPRI (International Food Policy Research Institute), IMPACT Model version 3.3, October 2016. 
TABLE 7 IMPACT projections of production, consumption, and net trade to 2050 by commodity group with and without climate change

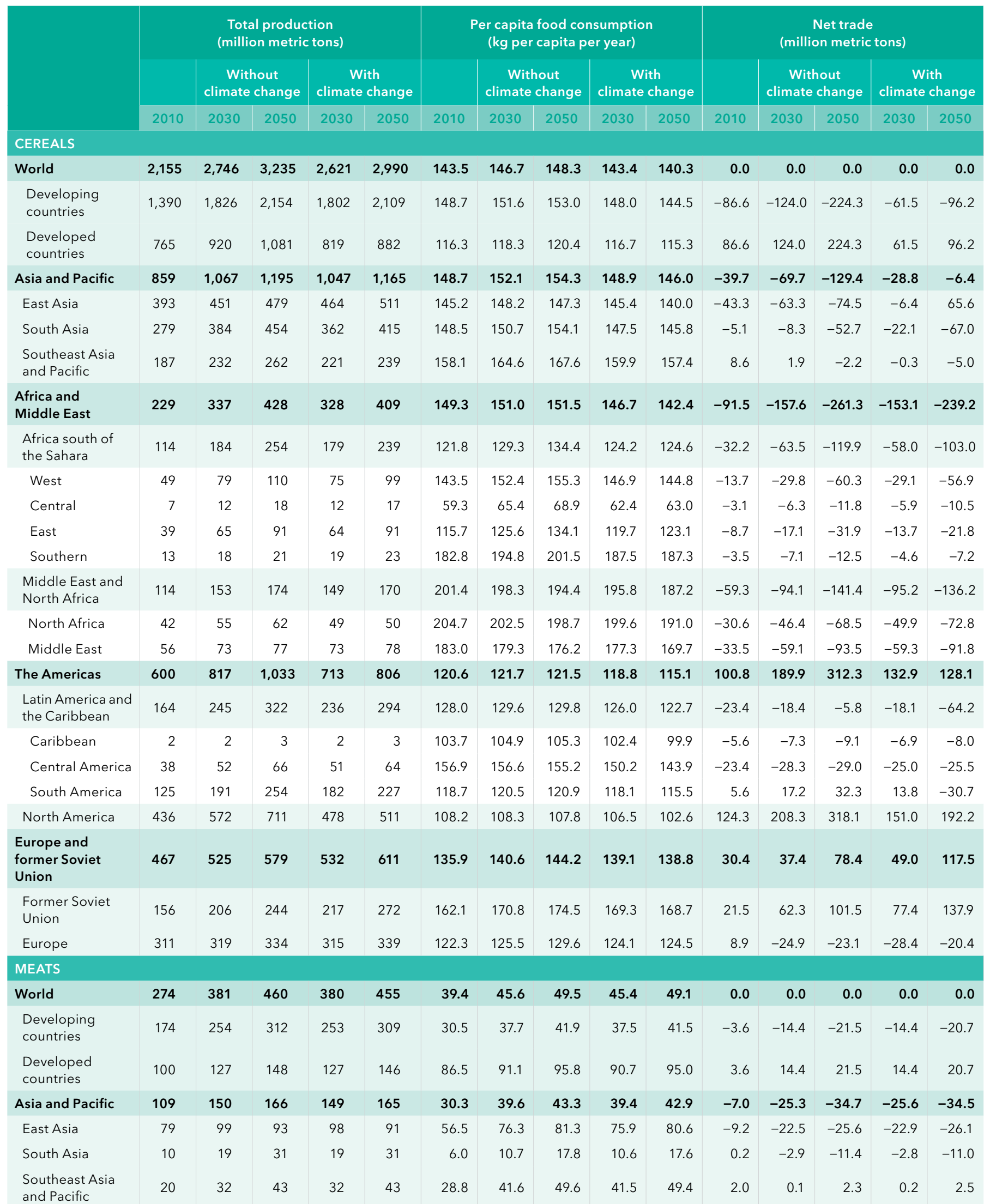


Table 7 continued

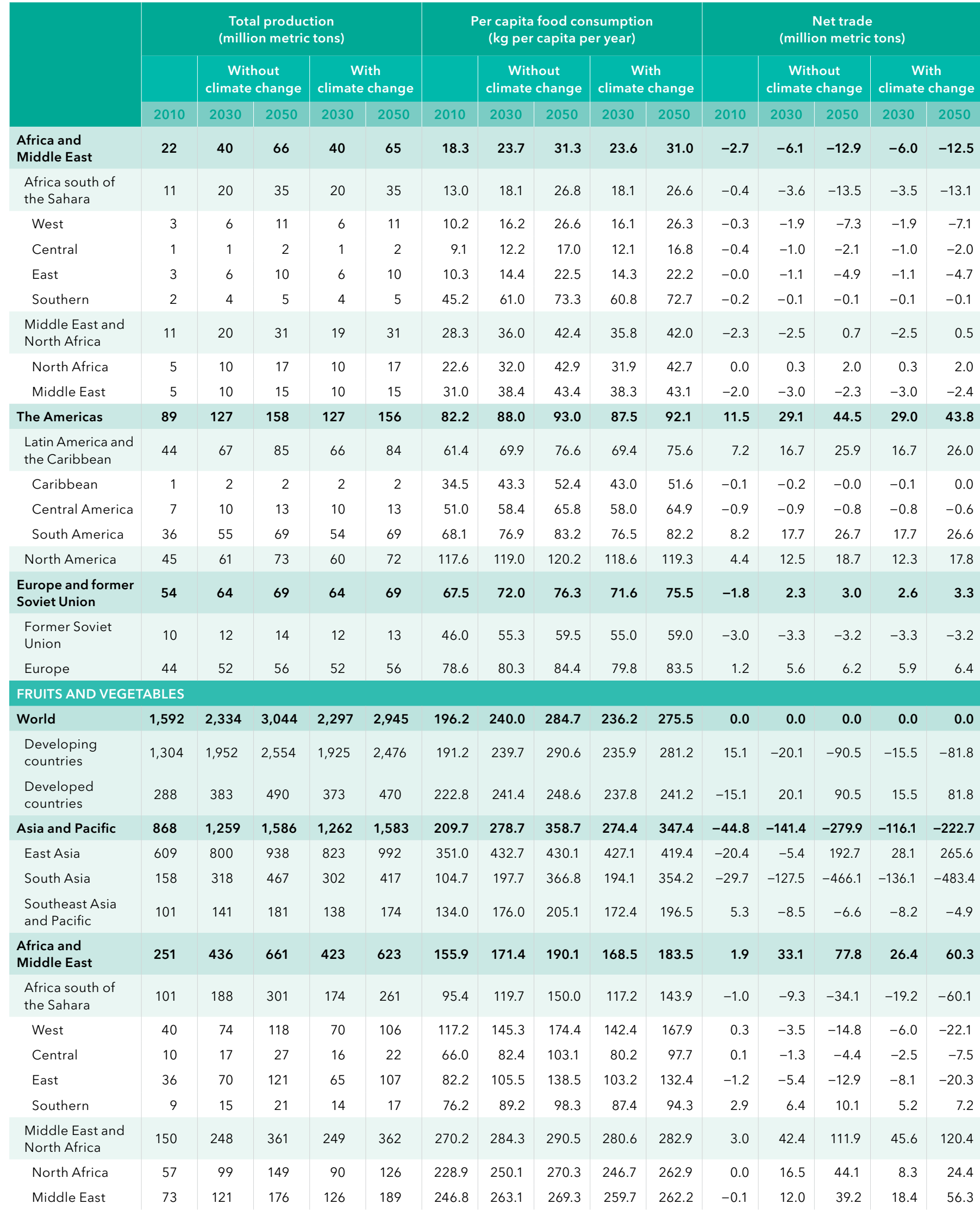


Table 7 continued

\begin{tabular}{|c|c|c|c|c|c|c|c|c|c|c|c|c|c|c|c|}
\hline & \multicolumn{5}{|c|}{$\begin{array}{l}\text { Total production } \\
\text { (million metric tons) }\end{array}$} & \multicolumn{5}{|c|}{$\begin{array}{l}\text { Per capita food consumption } \\
\text { (kg per capita per year) }\end{array}$} & \multicolumn{5}{|c|}{$\begin{array}{l}\text { Net trade } \\
\text { (million metric tons) }\end{array}$} \\
\hline & \multirow[b]{2}{*}{2010} & \multicolumn{2}{|c|}{$\begin{array}{l}\text { Without } \\
\text { climate change }\end{array}$} & \multicolumn{2}{|c|}{$\begin{array}{l}\text { With } \\
\text { climate change }\end{array}$} & \multirow[b]{2}{*}{2010} & \multicolumn{2}{|c|}{$\begin{array}{l}\text { Without } \\
\text { climate change }\end{array}$} & \multicolumn{2}{|c|}{$\begin{array}{l}\text { With } \\
\text { climate change }\end{array}$} & \multirow[b]{2}{*}{2010} & \multicolumn{2}{|c|}{$\begin{array}{l}\text { Without } \\
\text { climate change }\end{array}$} & \multicolumn{2}{|c|}{$\begin{array}{c}\text { With } \\
\text { climate change }\end{array}$} \\
\hline & & 2030 & 2050 & 2030 & 2050 & & 2030 & 2050 & 2030 & 2050 & & 2030 & 2050 & 2030 & 2050 \\
\hline The Americas & 255 & 351 & 447 & 338 & 422 & 187.0 & 212.1 & 226.7 & 208.4 & 218.7 & 49.2 & 74.6 & 123.8 & 67.4 & 110.9 \\
\hline $\begin{array}{l}\text { Latin America and } \\
\text { the Caribbean }\end{array}$ & 164 & 236 & 299 & 225 & 273 & 159.6 & 182.9 & 202.9 & 179.7 & 195.7 & 46.3 & 76.3 & 108.3 & 67.4 & 88.7 \\
\hline Caribbean & 12 & 15 & 18 & 14 & 15 & 192.6 & 218.7 & 245.0 & 216.2 & 239.1 & 2.3 & 3.4 & 4.6 & 2.0 & 1.9 \\
\hline Central America & 46 & 59 & 67 & 55 & 59 & 165.5 & 180.0 & 196.8 & 176.7 & 189.5 & 15.4 & 18.6 & 18.1 & 15.2 & 11.5 \\
\hline South America & 107 & 162 & 214 & 156 & 199 & 154.2 & 181.0 & 202.0 & 177.8 & 194.8 & 28.7 & 54.3 & 85.7 & 50.2 & 75.3 \\
\hline North America & 91 & 114 & 147 & 114 & 149 & 233.6 & 262.4 & 265.9 & 257.7 & 256.7 & 2.9 & -1.7 & 15.4 & 0.0 & 22.2 \\
\hline $\begin{array}{l}\text { Europe and former } \\
\text { Soviet Union }\end{array}$ & 218 & 289 & 351 & 274 & 317 & 209.2 & 230.9 & 241.8 & 227.8 & 235.3 & -6.3 & 33.7 & 78.4 & 22.3 & 51.5 \\
\hline \multicolumn{16}{|l|}{ OILSEEDS } \\
\hline World & 673 & 1,033 & 1,293 & 1,017 & 1,257 & 6.8 & 8.2 & 7.8 & 7.9 & 7.3 & 0.0 & 0.0 & 0.0 & 0.0 & 0.0 \\
\hline $\begin{array}{l}\text { Developing } \\
\text { countries }\end{array}$ & 525 & 842 & 1,079 & 833 & 1,057 & 7.0 & 8.6 & 8.2 & 8.3 & 7.6 & -3.0 & -8.5 & -11.5 & -7.4 & -9.6 \\
\hline $\begin{array}{l}\text { Developed } \\
\text { countries }\end{array}$ & 148 & 191 & 214 & 184 & 200 & 5.6 & 5.9 & 5.9 & 5.6 & 5.5 & 3.0 & 8.5 & 11.5 & 7.4 & 9.6 \\
\hline Asia and Pacific & 322 & 536 & 713 & 534 & 707 & 8.1 & 10.4 & 9.5 & 10.0 & 9.0 & -35.4 & -59.6 & -69.9 & -56.0 & -62.1 \\
\hline East Asia & 49 & 63 & 68 & 64 & 70 & 10.9 & 15.9 & 15.1 & 15.4 & 14.4 & -44.3 & -62.8 & -66.7 & -59.2 & -59.5 \\
\hline South Asia & 41 & 52 & 57 & 51 & 52 & 3.6 & 4.5 & 4.3 & 4.4 & 4.0 & 0.5 & -4.5 & -9.7 & -4.7 & -9.9 \\
\hline $\begin{array}{l}\text { Southeast Asia } \\
\text { and Pacific }\end{array}$ & 231 & 421 & 589 & 420 & 586 & 13.1 & 14.7 & 14.6 & 14.3 & 13.9 & 8.4 & 7.7 & 6.4 & 8.0 & 7.2 \\
\hline East & 4 & 6 & 7 & 6 & 7 & 3.7 & 4.4 & 5.3 & 4.2 & 4.8 & 0.1 & -0.3 & -1.3 & -0.2 & -0.9 \\
\hline Southern & 1 & 1 & 2 & 1 & 1 & 1.9 & 2.1 & 2.1 & 2.0 & 2.0 & -0.2 & -0.3 & -0.3 & -0.2 & -0.2 \\
\hline $\begin{array}{l}\text { Middle East and } \\
\text { North Africa }\end{array}$ & 9 & 12 & 14 & 12 & 14 & 4.7 & 5.5 & 6.0 & 5.3 & 5.5 & -6.3 & -7.6 & -8.8 & -7.0 & -7.6 \\
\hline North Africa & 4 & 6 & 7 & 5 & 6 & 4.6 & 5.3 & 5.7 & 5.1 & 5.3 & -1.5 & -1.8 & -2.2 & -1.7 & -2.1 \\
\hline Middle East & 5 & 7 & 8 & 7 & 8 & 5.4 & 6.1 & 6.4 & 5.9 & 5.9 & -3.9 & -5.0 & -6.0 & -4.6 & -5.1 \\
\hline The Americas & 235 & 323 & 371 & 314 & 350 & 6.8 & 6.7 & 6.5 & 6.4 & 6.0 & 58.7 & 83.7 & 97.5 & 78.1 & 85.2 \\
\hline $\begin{array}{l}\text { Latin America and } \\
\text { the Caribbean }\end{array}$ & 126 & 184 & 215 & 180 & 206 & 6.6 & 6.4 & 6.0 & 6.1 & 5.5 & 27.2 & 46.3 & 56.6 & 43.5 & 49.6 \\
\hline Caribbean & 1 & 1 & 1 & 1 & 1 & 7.8 & 8.0 & 7.8 & 7.7 & 7.3 & -0.3 & -0.3 & -0.4 & -0.3 & -0.4 \\
\hline Central America & 6 & 9 & 10 & 8 & 9 & 3.2 & 3.1 & 3.1 & 3.0 & 2.9 & -5.5 & -6.0 & -6.5 & -5.7 & -5.9 \\
\hline South America & 119 & 174 & 204 & 170 & 196 & 7.9 & 7.7 & 7.1 & 7.3 & 6.4 & 33.0 & 52.6 & 63.5 & 49.5 & 55.8 \\
\hline North America & 110 & 139 & 155 & 134 & 144 & 7.1 & 7.2 & 7.2 & 7.0 & 6.7 & 31.5 & 37.3 & 40.8 & 34.6 & 35.6 \\
\hline $\begin{array}{l}\text { Europe and former } \\
\text { Soviet Union }\end{array}$ & 55 & 72 & 83 & 71 & 81 & 2.6 & 2.7 & 2.9 & 2.6 & 2.7 & -17.2 & -15.3 & -14.1 & -14.0 & -11.6 \\
\hline $\begin{array}{l}\text { Former Soviet } \\
\text { Union }\end{array}$ & 14 & 19 & 22 & 19 & 23 & 1.1 & 1.2 & 1.2 & 1.2 & 1.2 & -0.4 & 0.5 & 1.4 & 0.7 & 1.8 \\
\hline Europe & 40 & 53 & 60 & 52 & 58 & 3.3 & 3.5 & 3.6 & 3.3 & 3.4 & -16.8 & -15.8 & -15.4 & -14.7 & -13.4 \\
\hline
\end{tabular}


Table 7 continued

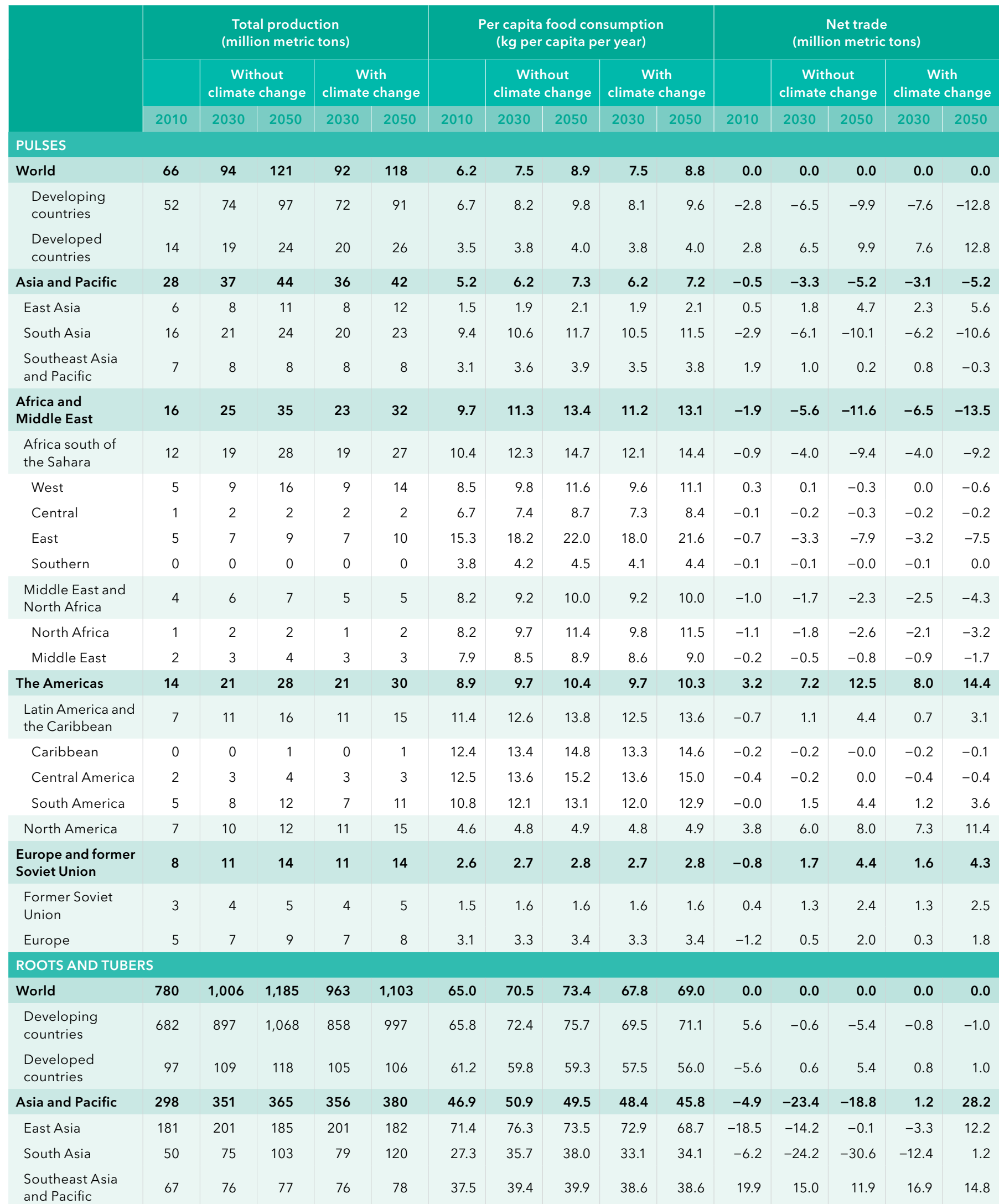


Table 7 continued

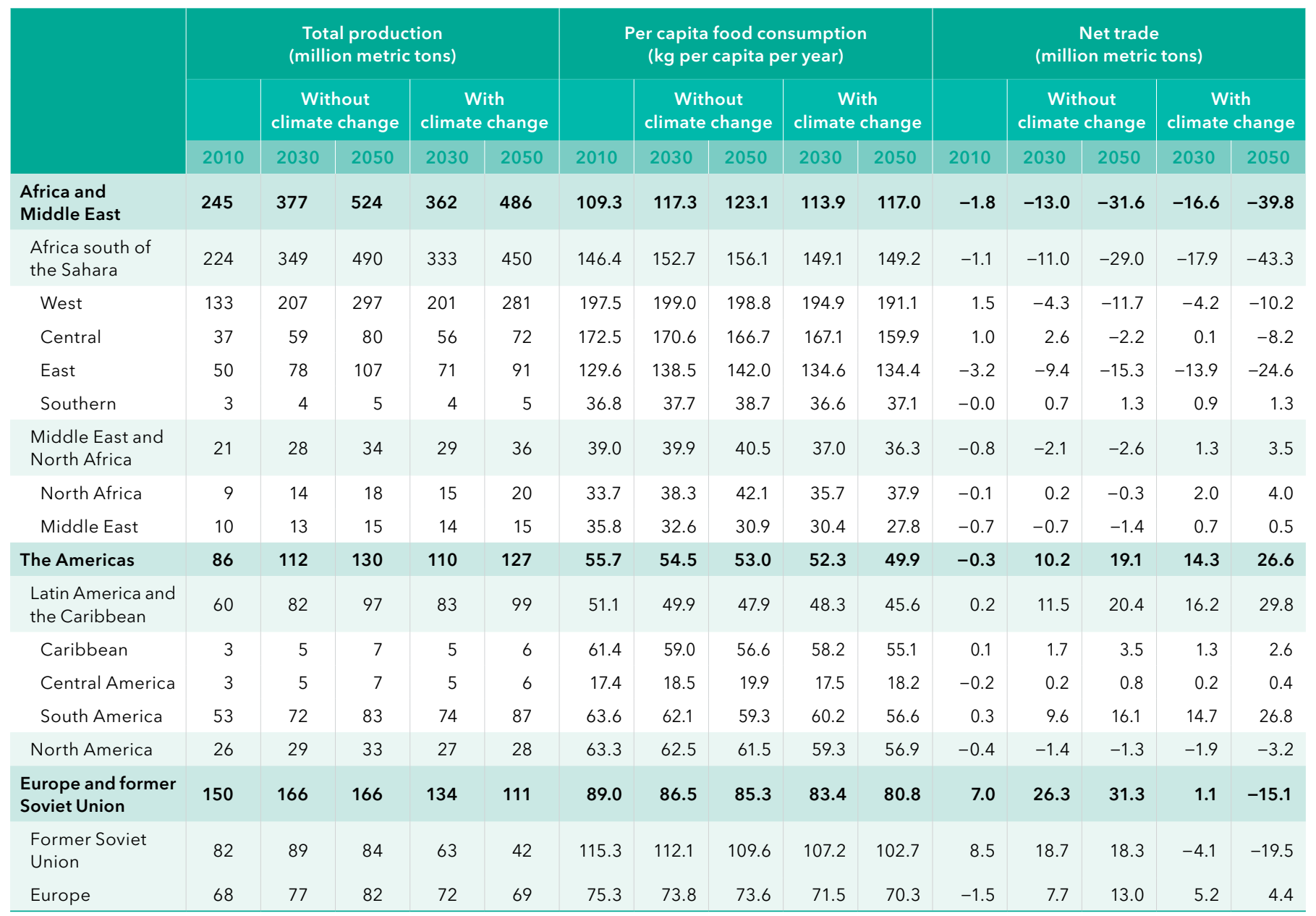

Notes: World and regional figures include other regions and countries not reported separately. Total production is aggregated across irrigated and rainfed systems at the national level and aligned with years as reported in FAOSTAT. Per capita food consumption is based on food availability at the national level. Net trade includes negative and positive numbers indicating that a region is a net importer or exporter, respectively, and balances to zero at the global level. Cereals include barley, millet, rice, sorghum, wheat, and aggregated other cereals. Meats include beef, pork, poultry, and sheep and goats. Fruits and vegetables include banana, plantain, aggregated temperate fruits, aggregated tropical fruits, and aggregated vegetables. Oilseeds include groundnuts, rapeseed, soybean, sunflower, and aggregated other oilseeds. Pulses include beans, chickpeas, cowpeas, lentils, pigeonpeas, and aggregated other pulses. Roots and tubers include cassava, potato, sweet potato, yams, and aggregated other roots and tubers. Values reported for 2010 are calibrated model results. Projections for 2030 and 2050 assume changes in population and income as reflected in the Intergovernmental Panel on Climate Change's (IPCC) Shared Socioeconomic Pathway 2. Climate change impacts are simulated using the IPCC's Representative Concentration Pathway 8.5 and the HadGEM general circulation model. Further documentation is available at www.ifpri.org/program/impact-model.

Source: IFPRI (International Food Policy Research Institute), IMPACT Model version 3.3, October 2016. 


\section{Trend 1}

\section{SOURCES OF GROWTH ARE PROJECTED} TO VARY FOR FOOD AND FEED CROPS

Demand and supply for major crops are projected to continue increasing through midcentury, but sources of growth will vary. For crops consumed directly as food, such as rice and wheat, rising demand will be met primarily through yield increases ranging from 30 to 60 percent by 2050, while area devoted to those crops will remain roughly constant at the global level. By contrast, demand for feed crops, such as maize and soybean, will require expansion of harvested area by about 40 percent. Total global supply of these four major crops is projected to expand by over 1.3 trillion metric tons, dominated by maize and wheat.

Note: Graphic shows indexed values for changes in yield and area harvested from 2010 to 2050 . The circle sizes are scaled to show the relative increase in total global supply for each crop from 2010 to 2050, in million metric tons. The center of each circle is aligned with the indexed values for growth in area harvested and yield for each crop from 2010 to 2050. Projections are from the "Comprehensive" investment scenario modeled in Rosegrant et al. (2017), which posits a relatively optimistic but feasible expansion in R\&D investments in yield growth, irrigation and water use, and value-chain efficiency in developing countries.
SOURCES OF AGRICULTURAL PRODUCTION GROWTH, 2010-2050

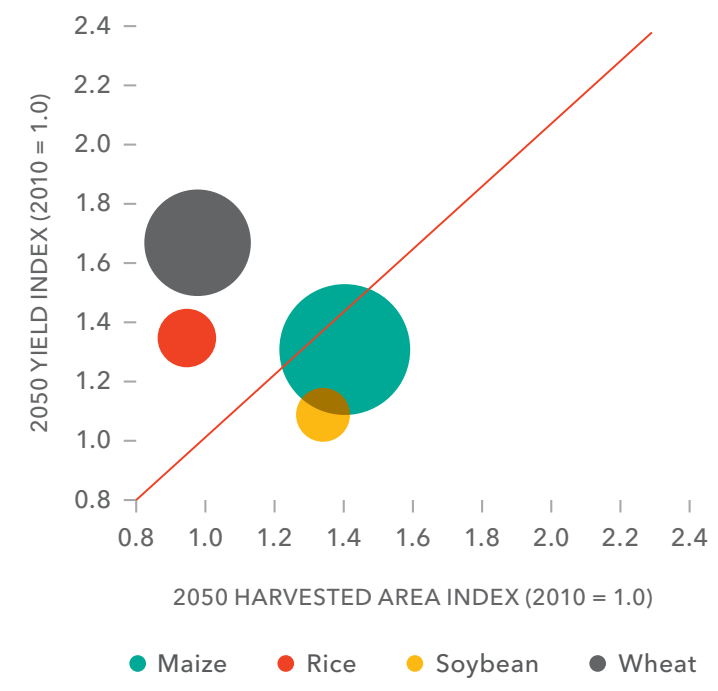

\section{Trend 2}

INCREASED INVESTMENT CAN REDUCE HUNGER, DESPITE SETBACKS DUE TO CLIMATE CHANGE

IMPACT model projections indicate that the Sustainable Development Goal of eliminating hunger will not be achieved by 2030 globally, but important progress is being made. Climate change hinders progress, but key investments in the agriculture sector can more than overcome the negative effects. With increased investments to enhance agricultural productivity, water use, and value-chain efficiency, most regions of the world can reduce the share of the population at risk of hunger in 2030 to below 5 percent. But persistent challenges will keep the hungry population in Africa south of the Sahara at about 12 percent.

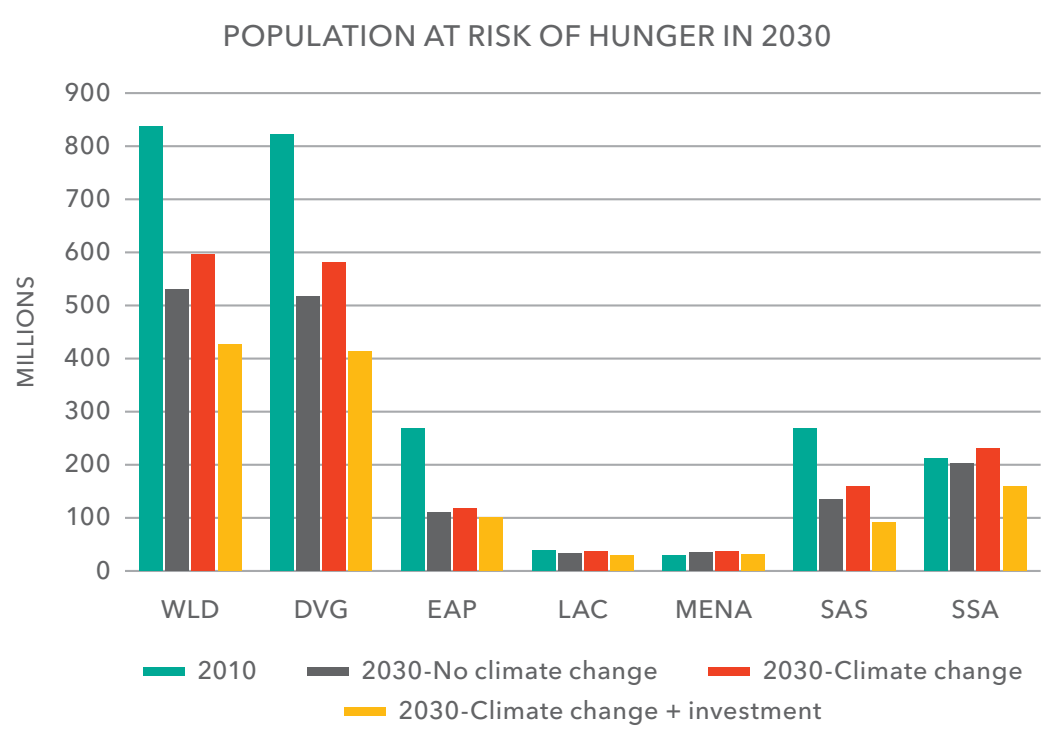

Note: WLD = World; DVG = Developing countries; EAP = East Asia and Pacific; $L A C=$ Latin America and Caribbean; MENA = Middle East and North Africa; SAS = South Asia; SSA = Africa south of the Sahara. "Climate Change" shows one realization of future climate change for the Representative Concentration Pathway 8.5 modeled by the HadGEM general circulation model. "Climate Change + Investment" is a scenario with increased investments in agriculture sector R\&D, as modeled in the "Comprehensive" scenario from Rosegrant et al. (2017).

Source: M. Rosegrant et al. "Quantitative Foresight Modeling to Inform the CGIAR Research Portfolio," project report for USAID, International Food Policy Research Institute, Washington DC, 2017. 


\section{Notes}

\section{CHAPTER 1}

1 IMF (International Monetary Fund), World Economic Outlook 2017: Seeking Sustainable Growth: Short-Term Recovery, Long-Term Challenges (Washington, DC: 2017).

2 F. Alvaredo et al., World Inequality Report 2018 (Paris: World Inequality Lab, 2018).

3 FAO (Food and Agriculture Organization of the United Nations), IFAD (International Fund for Agricultural Development), UNICEF, WFP (World Food Programme), and WHO (World Health Organization), The State of Food Security and Nutrition in the World 2017: Building Resilience for Peace and Food Security (Rome: FAO, 2017).

4 Development Initiatives, Global Nutrition Report 2017: Nourishing the SDGs (Bristol, UK: 2017).

5 FAO, IFAD, UNICEF, WFP, and WHO, The State of Food Security and Nutrition in the World 2017.

6 K. Akramov and A. Park, "Assessing Food Consumption Patterns and Nutrition Outcomes in Kyrgyzstan," paper presented at the Second Annual Eurasian Food Security Conference, Dushanbe, Tajikistan, October 2-4, 2017; European Bank for Reconstruction and Development, Life in Transition: A Decade of Measuring Transition (London: 2016).

7 FAO, Food Price Index, accessed December 15, 2017, www.fao.org/ worldfoodsituation/foodpricesindex/en/.

8 FAO, "Crop Prospects and Food Situation," Quarterly Global Report no. 4, December 2017.

9 OECD (Organisation for Economic Co-operation and Development) and FAO, OECD-FAO Agricultural Outlook 20172026 (Paris: OECD, 2017).

10 E. Díaz-Bonilla, "That Was Then, This Is Now: WTO and Agriculture," IFPRI Blog, December 15, 2017.

11 WTO (World Trade Organization), "Trade Statistics and Outlook: WTO Upgrades Forecast for 2017 as Trade Rebounds Strongly," press release, September 21, 2017.

12 UNCTAD (United Nations Conference on Trade and Development), World Investment Report 2017: Investment and the Digital Economy (Geneva: United Nations, 2017).

13 G20 (Group of 20), "Towards Food and Water Security: Fostering Sustainability, Advancing Innovation," G20 Agriculture Ministers' Action Plan 2017, January 22, 2017, www.g20.utoronto. ca/2017/170122-agriculture-action-en.html.

14 G7 (Group of 7), "2017 Agriculture Ministerial Meeting," accessed January 26, 2018, www.g7italy.it/en/meeting/agricolture.

15 Global Nutrition Summit 2017, "Global Nutrition Summit 2017: Milan," press release, November 2017, https://nutritionforgrowth. org/press-release-global-nutrition-summit-2017-milan/.

$16 \mathrm{WMO}$ (World Meteorological Organization), Statement on the State of the Global Climate in 2017 (Geneva: 2017).

17 FAO, Global Information and Early Warning System (GIEWS) Country Briefs: Algeria, Djibouti, and Jordan, June 2017.
18 World Bank Group, Global Economic Prospects, January 2018: Broad-based Upturn, but for How Long? (Washington, DC: 2018).

19 McKinsey Global Institute, Jobs Lost, Jobs Gained: Workforce Transitions in a Time of Automation (McKinsey, 2017).

20 IMF, Regional Economic Outlook-Sub-Saharan Africa: Fiscal Adjustment and Economic Diversification (Washington, DC: 2017).

21 US National Intelligence Council, "Global Trends: Paradox of Progress," accessed January 26, 2018, www.dni.gov/index.php/ global-trends-home.

\section{TIMELINE}

JANUARY: M. Hogan, "G20 Farm Ministers Seek to Protect Precious Water Supplies," Reuters, January 22, 2017; F. Mathuros, "\$400 Million Fund Launched in Davos to Stop Tropical Deforestation and Boost Farming," press release, Davos-Klosters, World Economic Forum, January 18, 2017.

MARCH: UN News Centre, "Tackling Hunger Crises in South Sudan, Somalia, Nigeria, and Yemen Requires \$4.4 Billion," news release, United Nations, New York, February 22, 2017.

MAY: UNICEF, WHO (World Health Organization), and World Bank, Levels and Trends in Child Malnutrition, Joint Child Malnutrition Estimates: Key Findings of the 2017 Edition (New York: UNICEF, 2017).

JUNE: "Paris Climate Deal: Trump Pulls US Out of 2015 Accord," BBC News, US-Canada Edition, June 1, 2017.

JULY: State Council Information Office of the People's Republic of China, "China Issues National Nutrition Plan (2017-2030)," press release, July 14, 2017.

AUGUST: "Bangladesh Rolls Out a New Action Plan to Combat Malnutrition," BDNews24.com, August 14, 2017.

SEPTEMBER: FAO et al., The State of Food Security and Nutrition in the World; NITI Aayog (National Institution for Transforming India), "Nourishing India, National Nutrition Strategy" (Government of India, 2017); Office for the Coordination of Humanitarian Affairs, "The Caribbean: Hurricane Season," Situation Report No. 12 (New York: United Nations, October 13, 2017).

OCTOBER: G7 Ministers of Agriculture, "Bergamo Agriculture Ministers' Meeting Communiqué: Empowering Farmers, Developing Rural Areas, and Enhancing Cooperation to Feed the Planet," prepared for the G7 Agriculture Ministerial Meeting, Bergamo, Italy, October 14-15, 2017.

NOVEMBER: C. Cheney, "Global Nutrition Summit Sees New Funding, Political Commitments," Devex, November 6, 2017; United Nations, "Climate Change Conference 2017 Aims for Further, Faster Ambition Together," UN Climate Change Press Release, November 5, 2017; CES IFO, "IFO World Economic Climate Indicator Reaches Highest Level since 2011," press release, November 13, 2017.

DECEMBER: L. Cohen and D. Lawder, "WTO Meeting Ends in Discord, Ministers Urge Smaller-Scale Trade Talks," Reuters, December 13, 2017; F. Alvaredo et al., World Inequality Report 2018, World Inequality Lab (Paris: Paris School of Economics, 2017). 


\section{CHAPTER 2}

1 E. Gakidou, "Global, Regional, and National Comparative Risk Assessment of 84 Behavioural, Environmental and Occupational, and Metabolic Risks or Clusters of Risks, 1990-2016: A Systematic Analysis for the Global Burden of Disease Study 2016," Lancet 390, no. 10100 (2016): 1345-1422; J. Rockström et al., "Planetary Boundaries: Exploring the Safe Operating Space for Humanity," Ecology and Society 14, no. 2 (2009): 32.

2 Overweight is defined as a body mass index (BMI) of 25 or more, thus it includes pre-obesity, defined as a BMI between 25 and 30, and obesity, defined as a BMl of 30 or more.

3 FAO (Food and Agriculture Organization of the United Nations), IFAD (International Fund for Agricultural Development), UNICEF, WFP (World Food Programme), and WHO (World Health Organization, The State of Food Security and Nutrition in the World 2017 (Rome: 2017); Development Initiatives, Global Nutrition Report 2017: Nourishing the SDGs (Bristol, UK: 2017).

4 C. Hawkes, J. Harris, and S. Gillespie, "Changing Diets: Urbanization and the Nutrition Transition," in 2017 Global Food Policy Report (Washington, DC: International Food Policy Research Institute, 2017): 34-41.

5 M. W. Rosegrant, C. Ringler, and T. Zhu, "Water for Agriculture: Maintaining Food Security under Growing Scarcity," Annual Reviews 34 (2009): 205-222.

6 IFPRI (International Food Policy Research Institute), 2011 Global Food Policy Report (Washington, DC: 2012)

7 C. Arndt, S. Msangi, and J. Thurlow, "Green Energy: Fueling the Path to Food Security," in 2016 Global Food Policy Report (Washington, DC: International Food Policy Research Institute, 2016): 56-65.

8 Rockström et al., "Planetary Boundaries: Exploring the Safe Operating Space for Humanity."

9 United Nations, World Economic Situation and Prospects 2017: Update as of mid-2017 (New York: 2017).

10 FAO et al., The State of Food Security and Nutrition in the World 2017; United Nations High Commissioner for Refugees, Global Trends: Forced Displacement in 2016 (Geneva: 2017).

11 J. G. da Silva and S. Fan, Conflict, Migration, and Food Security: The Role of Agriculture and Rural Development, FAO-IFPRI Joint Brief (Rome, Italy and Washington, DC: FAO and IFPRI, 2017).

12 C. Breisinger et al., How to Build Resilience to Conflict: The Role of Food Security, IFPRI Food Policy Report (Washington, DC: International Food Policy Research Institute, 2014).

13 See also, K. Anderson, W. Martin, and D. van der Mensbrugghe, "Distortions to World Trade: Impacts on Agricultural Markets and Farm Incomes," Applied Economic Perspectives and Policy 28, no. 2 (2006): 168-194.

14 S. Fan, L. Zhang, and X. Zhang, "Reforms, Investment, and Poverty in Rural China", Economic Development and Cultural Change 52, no. 2 (2004): 395-421.

15 K. J. Duffey et al., "Food Price and Diet and Health Outcomes: 20 Years of the CARDIA Study," Archives of Internal Medicine 170 (2010): 420-426; R. Sturm and A. Datar, "Body Mass Index in Elementary School Children, Metropolitan Area Food Prices and Food Outlet Density," Public Health 119 (2005):1059-1068J; J. Kearney, "Food Consumption Trends and Drivers," Philosophical Transactions of the Royal Society B: Biological Sciences 365 (2010): 2793-2807.
16 E. Díaz-Bonilla and J. Hepburn, Trade, Food Security, and the 2030 Agenda (Geneva: International Centre for Trade and Sustainable Development, 2016).

17 J. G. da Silva and S. Fan, 2017. "Smallholders and Urbanization: Strengthening Rural-Urban Linkages to End Hunger and Malnutrition," in 2017 Global Food Policy Report (Washington, DC: International Food Policy Research Institute, 2017): 14-23.

18 da Silva and Fan, Conflict, Migration, and Food Security: The Role of Agriculture and Rural Development.

19 Fan et al. "Reforms, Investment, and Poverty in Rural China."

20 IFPRI, "Agricultural Science and Technology Indicators," in 2017 Global Food Policy Report (Washington, DC: 2017).

$21 \mathrm{H}$. Bouis and Y. Islam, "Delivering Nutrients Widely through Biofortification: Building on Orange Sweet Potato" in Scaling Up in Agriculture, Rural Development, and Nutrition: Focus 19, ed. J. Linn (Washington, DC: International Food Policy Research Institute, 2012).

22 A. U. Ahmed, J. F. Hoddinott, and S. Roy, "Which Kinds of Social Safety Net Transfers Work Best for the Ultra Poor in Bangladesh? Operation and Impacts of the Transfer Modality Research Initiative" (Dhaka, Bangladesh: International Food Policy Research Institute and World Food Programme, 2016).

23 M. Springmann et al., "Global and Regional Health Effects of Future Food Production under Climate Change: A Modelling Study," Lancet 387, no. 10031 (2016): 1937-1946.

24 M. T. Ruel, J. L. Garrett, and S. Yosef, "Food Security and Nutrition: Growing Cities, New Challenges," in 2017 Global Food Policy Report (Washington, DC: International Food Policy Research Institute, 2017): 24-33.

25 D. Resnick, "Governance: Informal Food Markets in Africa's Cities," in 2017 Global Food Policy Report (Washington, DC: International Food Policy Research Institute, 2017): 50-57.

26 C40 Cities Initiative, accessed January 15, 2017, www.c40.org.

\section{CHAPTER 3}

1 L. Deason and D. Laborde, "Trade and Nutritional Contents," International Food Policy Research Institute (unpublished 2012).

2 D. Donaldson, "Railroads of the Raj: Estimating the Impact of Transportation Infrastructure," American Economic Review (forthcoming).

3 M. Martínez-Torres and P. Rosset, "Diálogo de Sabers in La Vía Campesina: Food Sovereignty and Agroecology," Journal of Peasant Studies 41, no. 6 (2014): 979-997.

4 D. Burgess and D. Donaldson, "Can Openness Mitigate the Effects of Weather Shocks? Evidence from India's Famine Era," American Economic Review: Papers \& Proceedings 100 (2010): 449-453.

5 A. Costinot and D. Donaldson, "How Large Are the Gains from Economic Integration? Theory and Evidence from U.S. Agriculture, 1880-1997," NBER Working Paper No. 22946, National Bureau of Economic Research, Cambridge, MA, 2016; J. Alston et al. "The Economic Returns to U.S. Public Agricultural Research," American Journal of Agricultural Economics 93, no. 5 (2011): 1257-1277.

6 O. Galor, "The Demographic Transition: Causes and Consequences," Cliometrica 6, no. 1 (2012): 1-28.

7 R. Evenson, J. P. Houck, Jr., and V. W. Ruttan, "Change and Agricultural Trade: Three Examples-Sugarcane, Bananas, and 
Rice," in The Technology Factor in International Trade, ed. R. Vernon (Cambridge, MA: National Bureau of Economic Research, 1970), 415-483.

8 A. Bouët and D. Laborde, introduction to Agriculture, Development, and the Global Trading System: 2000-2015 (Washington, DC: International Food Policy Research Institute, 2017).

9 D. Hathaway and M. Ingco, "Agricultural Liberalization and the Uruguay Round," in The Uruguay Round and the Developing Countries, eds. W. Martin and L. A. Winters (Cambridge: Cambridge University Press, 1997).

10 O. DeSchutter, "Food Democracy South and North: From Food Sovereignty to Transition Initiatives," Open Democracy/ISA RC-47: Open Movements, March 17, 2015,

11 Simulating the reduction of global agricultural trade by 95 percent using the MIRAGRODEP computable general equilibrium model leads to a net increase in average food prices of 12 percent, since a larger share of consumers are in net food importing countries, with increases of more than 20 percent for regions and countries with strong structural imbalances such as the Middle East and North Africa or Japan. This price change is much lower than the total cost to consumers since it is associated with a reduction in consumption, both in quantity and diversity.

12 Bouët and Laborde, introduction to Agriculture, Development, and the Global Trading System.

13 Ibid.; M. Bellemare, J. Fajardo-Gonzalez, and S. Gitter, "Foods and Fads: The Welfare Impacts of Rising Quinoa Prices in Peru," Department of Economics Working Paper 2016-06 (Towson, MD: Towson University, 2016).

14 See for example, M. Lenzen et al., "International Trade Drives Biodiversity Threats in Developing Nations," Nature 486 (June 2012): 109-113.

15 M. S. Taylor, "Buffalo Hunt: International Trade and the Virtual Extinction of the North American Bison," American Economic Review 101, no. 7 (2011): 3162-3195.

16 Ibid.

17 D. Laborde, "Assessing the Land Use Change Consequences of European Biofuel Policies," Research Report, Atlas Consortium, 2011.

18 M. Evans et al., "Globalization, Diet, and Health: An Example from Tonga," Bulletin of the World Health Organization 79 (2001): 856-862.

19 K. Cummings, "Programs and Policies to Discourage the Use of Tobacco Products," Oncogene 21 (2002): 7349-7364.

20 R. Mundell, "The Appropriate Use of Monetary and Fiscal Policy for Internal and External Stability," IMF Staff Papers 9, no. 1 (1962): 70-79.

21 A current account deficit is the gap between a country's income and its expenditure. It requires the country to either borrow or to run down its assets, just as a household must do when it spends more than its income. No amount of trade policy intervention will affect the deficit unless spending is reduced relative to income.

22 A. Bouët and D. Laborde, "Assessing the Potential Cost of a Failed Doha Round," World Trade Review 9, no. 2 (2010): 319-351; A. Bouët and D. Laborde, "US Trade Wars with Emerging Countries in the 21st Century: Make America and Its Partners Lose Again," IFPRI Discussion Paper no. 1669 (Washington, DC: International Food Policy Research Institute, 2017); A. Bouët and D. Laborde, "A Global Assessment of the Economic Effects of Export Taxes," World Economy 36, no.10 (2013): 1333-1354.
23 R. E. Baldwin, "The Case against Infant-Industry Protection," Journal of Political Economy 77, no. 3 (1969): 295-305.

24 P. Samuelson, "Summing Up on the Australian Case for Protection," Quarterly Journal of Economics 96, no. 1 (1981): 147-160.

25 G20, "Price Volatility in Food and Agricultural Markets: Policy Responses Policy Report" (June 2011).

26 A. Bouët and D. Laborde Debucquet, "Food Crisis and Export Taxation: The Cost of Non-Cooperative Trade Policies," Review of World Economics/Weltwirtschaftliches Archiv 148, no. 1 (2012): 209-233; K. Anderson, M. Ivanic, and W. Martin, "Food Price Spikes, Price Insulation and Poverty," in The Economics of Food Price Volatility, eds. J.-P. Chavas, J. D. Hummels, and B. Wright (Chicago: University of Chicago Press for National Bureau of Economic Research, 2014).

27 G. Grossman and E. Helpman, "Protection for Sale," American Economic Review 84, no. 4 (1994): 833-850.

28 K. Anderson, "Lobbying Incentives and the Pattern of Protection in Rich and Poor Countries," Economic Development and Cultural Change 43, no. 2 (1995): 401-423.

29 K. Anderson, G. Rausser, and J. Swinnen, "Political Economy of Public Policies: Insights from Distortions to Agricultural and Food Markets," Journal of Economic Literature 51, no. 2 (2013): 423-477.

30 R. Rogowski, Commerce and Coalitions: How Trade Affects Domestic Political Alignments (Princeton, NJ: Princeton University Press, 1989).

31 E. Barbier et al., "The Linkages between the Timber Trade and Tropical Deforestation-Indonesia," World Economy 18, no. 3 (1995): 411-42.

32 Bioversity International, Mainstreaming Agrobiodiversity in Sustainable Food Systems: Scientific Foundations for an Agrobiodiversity Index (Rome: 2017).

\section{CHAPTER 4}

1 FAO (Food and Agriculture Organization of the United Nations), How to Feed the World in 2050 (Rome: 2009).

2 UNCTAD (United Nations Conference on Trade and Development), World Investment Report 2014 (Geneva and New York: 2014).

3 D. Laborde et al., Ending Hunger: What Would It Cost? (Winnipeg: International Institute for Sustainable Development, 2016).

4 FAO, State of Food and Agriculture 2012 (Rome: 2012).

5 UNCTAD, World Investment Report 2012 (Geneva and New York: 2012).

6 FAO, An Introduction to the Basic Concepts of Food Security (Rome: EC-FAO Food Security Programme, 2008).

7 United Nations,Transforming Our World: The 2030 Agenda for Sustainable Development-A/RES/70/1 (New York: 2015).

8 W. Speller, "Reducing Food Waste: The Role of Foreign Investors in Promoting Efficiency, International Institute for Sustainable Development (IISD) blog, July 25, 2016.

9 W. Speller et al., "The Impact of Larger-Scale Agricultural Investments on Local Communities: Updated Voices from the Field," Food and Agriculture Global Practice Discussion Paper No. 12 (Washington, DC: World Bank Group, 2017).

10 IFC (International Finance Corporation), IFC Performance Standards on Environmental and Social Sustainability (Washington, DC: 2012). 
11 UNCTAD, Investment Policy Frameworks for Sustainable Development (Geneva and New York: 2015).

12 IISD (International Institute for Sustainable Development), The Rise of Agricultural Growth Poles in Africa (Geneva and Winnepeg: 2015).

13 For example, Hello Tractor is a phone application that allows users to hire tractors when needed. See www.hellotractor.com/.

14 UNCTAD, World Investment Report 2017 (Geneva and New York: 2017).

15 For full details of notes, see https://responsibleagroinvestment.org/.

16 UN DESA (United Nations Department of Economic and Social Affairs) and UNDP (United Nations Development Programme), TST Issues Brief 3 "Food Security and Nutrition," May 10, 2013.

\section{CHAPTER 5}

1 A. M. Mayda and G. Peri, "The Economic Impact of US Immigration Policies in the Age of Trump," in Economics and Policy in the Age of Trump, ed. C. P. Bown (London: Center for Economics and Policy Research, 2017).

2 K. Warner et al., In Search of Shelter: Mapping the Effects of Climate Change on Human Migration and Displacement (Bonn: United Nations University, CARE, and Center for International Earth Science Information Nation Columbia University, 2009).

3 C. Cattaneo and G. Peri, "The Migration Response to Increasing Temperatures," Journal of Development Economics 122 (September 2016): 127-146.

4 For example, D. McKenzie, J. Gibson, and S. Stillman, "How Important Is Selection? Experimental versus Non-experimental Measures of the Income Gains from Migration," Journal of the European Economic Association 8, no. 4 (2010): 913-945.

5 J. Crush, "Linking Food Security, Migration, and Development," International Migration 51, no. 5 (2013): 61-75.

6 A. Zezza et al., "Assessing the Impact of Migration on Food and Nutrition Security," Food Policy 36 (2011): 1-6.

7 A. de Brauw and C. Carletto, "Improving the Measurement and Policy Relevance of Migration Information in Multi-Topic Household Surveys, Living Standards Measurement Study," May 2012, http://siteresources.worldbank.org/INTLSMS/ Resources/3358986-1199367264546/Migration_Data_v14.pdf.

8 D. Card, "The Impact of the Mariel Boatlift on the Miami Labor Market," Industrial and Labor Relations Review 43, no. 2 (1990): 245-257.

9 A. İçduygu, Syrian Refugees in Turkey: The Long Road Ahead (Washington, DC: Migration Policy Institute, 2015); X. Del Carpio and M. Wagner, "The Impact of Syrian Refugees on the Turkish Labor Market" (working paper, Department of Economics, Boston College, 2017).

10 V. Calderón-Mejía and A. M. Ibáñez, "Labour Market Effects of Migration-Related Supply Shocks: Evidence from Internal Refugees in Colombia," Journal of Economic Geography 16, no. 3 (2016): 695-713.

11 P. Cortes and J. Tessada, "Low-Skilled Immigration and the Labor Supply of Highly Skilled Women," American Economic Journal: Applied Economics 3, no. 3 (2011): 88-123.
12 C. P. Muste, "The Dynamics of Immigration Opinion in the United States, 1992-2012," Public Opinion Quarterly 77, no. 1 (2013): 398-416.

13 A. Chalfin and M. Deza, "New Evidence on Mexican Immigration and Crime in the United States: Evidence from a Natural Experiment in Immigration Enforcement" (working paper, Department of Criminology, University of Pennsylvania, 2016).

14 B. Bell, F. Fasani, and S. Machin, "Crime and Immigration: Evidence from Large Immigrant Waves," Review of Economics and Statistics 95, no. 4 (2013): 1278-1290.

15 C. Dustmann and T. Frattini, "The Fiscal Effects of Immigration to the UK," Economic Journal 124 (2014): F593-F643.

16 "Rejected Report Shows Revenue Brought in by Refugees," New York Times, September 19, 2017.

17 National Academies of Sciences, Engineering, and Medicine, The Economic and Fiscal Consequences of Immigration (Washington, DC: The National Academies Press, 2017).

18 L. C. Smith, M. Ruel, and A. Ndiaye, "Why Is Child Malnutrition Lower in Urban than in Rural Areas? Evidence from 36 Developing Countries," World Development 33, no. 8 (2005): 1285-1305.

19 See A. de Brauw, "Migration and Development: Implications for Rural Areas," presented at the JRC-IFPRI Conference on Food and Nutrition Security Measurement, Brussels, November 15-17, 2017.

20 R. E. B. Lucas and O. Stark, "The New Economics of Labor Migration," American Economic Review 75, no. 2 (1985): 173-178.

21 D. McKenzie, "Paper Walls Are Easier to Tear Down: Passport Costs and Legal Barriers to Emigration," World Development 35, no. 11 (2007): 2026-2039.

22 Zezza et al., "Assessing the Impact of Migration on Food and Nutrition Security."

23 A. de Brauw, "Migration and Child Development during the Food Price Crisis in El Salvador," Food Policy 36 (2011): 28-40; C. Carletto, K. Covarrubias, and J. A. Maluccio, "Migration and Child Growth in Guatemala," Food Policy 36 (2011): 16-27.

24 C. Azzarri and A. Zezza, "International Migration and Nutritional Outcomes in Tajikistan," Food Policy 36 (2011): 54-70.

25 R. H. Adams, Jr., "Evaluating the Economic Impact of International Remittances on Developing Countries Using Household Surveys: A Literature Review," Journal of Development Studies 47, no. 6 (2011): 809-828.

26 G. Bryan, S. Chowdhury, and A. M. Mobarak, "Under-investment in a Profitable Technology: The Case of Seasonal Migration in Bangladesh," Econometrica 82, no. 5 (2014): 1671-1748.

27 FAO (Food and Agriculture Organization of the United Nations), IFAD (International Fund for Agricultural Development), UNICEF, WFP (World Food Programme), and WHO (World Health Organization), The State of Food Security and Nutrition in the World 2017: Building Resilience for Peace and Food Security (Rome: FAO, 2017).

$28 \mathrm{lbid}$

29 C. Breisinger, O. Ecker, and J. F. Trinh Tan, "Conflict and Food Insecurity: How Do We Break the Links?" in 2014-2015 Global Food Policy Report (Washington, DC: International Food Policy Research Institute, 2015), 51-59. 
30 C. Barrett, "Food Aid's Intended and Unintended Consequences" (background paper for State of Food and Agriculture 2006, Food and Agriculture Organization of the United Nations, Rome, 2006).

31 J.-F. Maystadt and P. Verwimp, "Winners and Losers among a Refugee Hosting Population," Economic Development and Cultural Change 62, no. 4 (2014): 769-809.

32 J. Alix-Garcia et al., "Do Refugee Camps Help or Hurt Hosts? The Case of Kakuma, Kenya," Journal of Development Economics 130 (forthcoming, 2018): 66-83.

33 J. E. Taylor et al., "Economic Impact of Refugee Settlements in Uganda," World Food Programme Report, Kampala, 2016.

34 Bryan, Chowdhury, and Mobarak, "Under-investment in a Profitable Technology."

35 Evidence Action, "'No Lean Season' Announces Major Grant from Global Innovation Fund," March 23, 2017, www.evidenceaction. org/blog-full/no-lean-season-announces-major-grant-from-globalinnovation-fund.

36 E. Beam, D. McKenzie, and D. Yang, "Unilateral Facilitation Does Not Raise International Labor Migration from the Philippines," Economic Development and Cultural Change 64, no. 2 (2016): 323-368.

37 J. Graziano da Silva and S. Fan, Conflict, Migration, and Food Security: The Role of Agriculture and Rural Development, FAO and IFPRI Joint Brief (Rome and Washington, DC: FAO and IFPRI, 2017).

\section{CHAPTER 6}

1 L. James, "Defining Open Data," October 3, 2013, https://blog. okfn.org/2013/10/03/defining-open-data.

2 L. Carolan et al., "How Can We Improve Agriculture, Food and Nutrition with Open Data?" ODI-GODAN Working Paper (London: Open Data Institute and Global Open Data for Agriculture and Nutrition, 2015).

3 "Agriculture," American Institutes for Research, accessed October 10, 2017, www.air.org/topic/international/agriculture.

4 S. M. Capalbo, J. M. Antle, and C. Seavert, "Next Generation Data Systems and Knowledge Products to Support Agricultural Producers and Science-based Policy Decision Making," Agricultural Systems 155 (2017): 191-199.

5 S. Babu et al., "Assessment of the 2016/17 Food Insecurity Response Programme (FIRP) in Malawi" (unpublished report prepared for UNDP Malawi by the International Food Policy Research Institute, Lilongwe, 2018).

6 A. Kejriwal, "RTI: An Enormous Power with the People," interview by Vinita Deshmukh, Magsaysay, India Together, August 7, 2006.

7 I. Parihar, "How Is Open Data Changing India?" World Economic Forum, February 19, 2015.

8 L. C. Smith, O. Dupriez, and N. Troubat, "Assessment of the Reliability and Relevance of the Food Data Collected in National Household Consumption and Expenditure Surveys," International Household Survey Network Working Paper No. 008 (2014).

9 S. Bhalla, "Inclusion and Growth in India: Some Facts, Some Conclusions," LSE Working Paper 39 (London: Asia Research Centre, London School of Economics and Political Science, 2011).

10 Data.gov, accessed October 10, 2017, www.data.gov/open-gov.
11 Open Data Charter, "What Is the Vital Data Infrastructure for Agriculture?" July 15, 2016, https://opendatacharter.net/ vital-data-infrastructure-agriculture.

12 UNCTAD (United Nations Conference on Trade and Development), Information Economy Report 2012 (Geneva, 2012).

13 USAID (United States Agency for International Development), "Securing Water for Food: Annual Report," 2015.

14 E. Stuart et al., The Data Revolution: Finding the Missing Millions (London: Overseas Development Institute, 2015).

15 R. Parthipan and K. Sreenivas, "A Systematic Application for Public Distribution-Ration Shop," International Journal of Innovative Research in Computer and Communication Engineering 3, no. 6 (2015).

16 Ibid.

17 Open Knowledge International, https://okfn.org/about.

18 C. Niu and C. Ragasa, "Limited Attention and Information Loss in the Lab-to-Farm Knowledge Chain: The Case of Malawian Agricultural Extension Programs," IFPRI Discussion Paper 01654 (Washington, DC: International Food Policy Research Institute, 2017).

19 Digital Green, http://www.digitalgreen.org/videos.

20 Agriculture Situation in India, http://eands.dacnet.nic.in/ publications2017.htm.

21 AIMS (Agricultural Information Management Standards), "Big Data: Unlocking the Future for Agriculture," http://aims.fao.org/activity/ blog/big-data-unlocking-future-agriculture.

22 Global Open Data for Agriculture and Nutrition (GODAN), www.godan.info.

23 World Bank Open Data, https://data.worldbank.org.

\section{CHAPTER 7}

1 OECD (Organisation for Economic Co-operation and Development), Agricultural Policy Monitoring and Evaluation 2017 (Paris: 2017).

2 Ibid.

3 lbid.

4 N. Minot and L. Daniels, "Impact of Global Cotton Markets on Rural Poverty in Benin," Agricultural Economics 33, supplement (2005): 453-466.

5 J. Glauber and A. Effland, "U.S. Agricultural Policy" in Handbook of International Food and Agricultural Policies, volume 1-Policies for Agricultural Markets and Rural Economic Activity, eds. W. Meyers and T. Johnson (Singapore: World Scientific Publishing, 2017).

6 OECD, Agricultural Policy Monitoring and Evaluation 2017.

7 D. G. Johnson, World Agriculture in Disarray (New York: St. Martin's Press and New Viewpoints, 1973).

8 J. Anton and C. Le Mouël, "Do Counter-cyclical Payments in the 2002 US Farm Act Create Incentives to Produce?" Agricultural Economics 31, nos. 2-3 (2004): 277-284.

9 FAO (Food and Agricultural Organization of the United Nations), $A$ Compendium of Crop Insurance Programmes (Rome: 1991).

$10 \mathrm{~J}$. Glauber, "Agricultural Insurance and the WTO," in Agriculture, Development, and the Global Trading System: 2000-2015, eds. 
A. Bouët and D. Laborde (Washington: International Food Policy Research Institute, 2017).

11 European Commission, "EU Farm Policy Rules to Be Further Simplified," press release, December 13, 2017.

12 M. Miranda and K. Farrin, "Index Insurance for Developing Countries," Applied Economic Perspectives and Policy 34, no. 3 (2012): 391-427; D. Hatch et al., "Agricultural Insurance in the Americas: A Risk Management Tool," Inter-American Institute for Cooperation on Agriculture, San Jose, Costa Rica, 2012.

13 V. Smith, J. Glauber, and B. Goodwin, Time to Reform the US Federal Agricultural Insurance Program (Washington, DC: American Enterprise Institute, 2017).

14 lbid.

15 Under the AoA, domestic support levels were bound and subject to reduction commitments (20 percent reduction over 6 years for developed countries; 13 percent cuts over 10 years for developing countries). Significantly, countries were encouraged to adopt support policies that had minimal production- and trade-distorting effects and were exempt from reduction commitments (the so-called green box).

16 J. Glauber and P. Westhoff, "The 2014 Farm Bill and the WTO," American Journal of Agricultural Economics 97, no. 5 (2015): 1287-1297.

17 B. Goodwin and A. Mishra, "Are 'Decoupled' Farm Program Payments Really Decoupled?" American Journal of Agricultural Economics 88, no. 1 (2006): 73-89; N. P. Hendricks and D. A. Sumner, "The Effects of Policy Expectations on Crop Supply, with an Application to Base Updating," American Journal of Agricultural Economics 96, no. 3 (2014): 903-923.

18 B. K. Goodwin, M. Vandeveer, and J. L. Deal, "An Empirical Analysis of Acreage Effects of Participation in the Federal Crop Insurance Program," American Journal of Agricultural Economics 86, no. 4 (2004): 1058-1077; B. Goodwin and V. Smith, "What Harm Is Done by Subsidizing Crop Insurance?" American Journal of Agricultural Economics 95, no. 2 (2012): 489-497; J. Yu, A. Smith, and D. Sumner, "Effects of Crop Insurance Premium Subsidies on Crop Acreage," American Journal of Agricultural Economics 100, no. 1 (2018): 91-114.

19 Glauber, "Agricultural Insurance and the WTO."

20 OECD, Agricultural Policy Monitoring and Evaluation 2017.

21 R. Schnepf, Status of the WTO Brazil-US Cotton Case, Congressional Research Service Report R43336 (Washington, DC: Library of Congress, 2014).

\section{CHAPTER 8}

1 J. Candel, "Food Security Governance: A Systematic Literature Review," Food Security 6, no. 4 (2014): 585-601.

2 FAO (Food and Agriculture Organization of the United Nations), IFAD (International Fund for Agricultural Development), UNICEF, WFP (World Food Programme), and WHO (World Health Organization), The State of Food Security and Nutrition in the World 2017: Building Resilience for Peace and Food Security (Rome: FAO, 2017).
3 K. von Grebmer et al., 2017 Global Hunger Index: Inequalities of Hunger (Bonn, Washington, DC, and Dublin: Welthungerhilfe, IFPRI, and Concern Worldwide, 2017).

4 Malabo Montpellier Panel, Nourished: How Africa Can Build a Future Free from Hunger and Malnutrition (Dakar: IFPRI, 2017).

5 L. S. Finkelstein, "What Is Global Governance?" Global Governance 1 (1995): 367-372; K. Dingwerth and P. Pattberg, "Global Governance as a Perspective on World Politics," Global Governance 12 (2006): 185-203; D. C. North, "The New Institutional Economics and Third World Development," in The New Institutional Economics and Third World Development, eds. J. Harriss, J. Hunter, and C. M. Lewis (London: Routledge, 1995), 17-26.

6 P. A. Samuelson, "The Pure Theory of Public Expenditure," The Review of Economics and Statistics 36 (1954): 387-389.

7 O. Williamson, "The Economics of Organization-The Transactions Cost Approach," American Journal of Sociology 87 (1981): 548-577.

8 FAO, Voluntary Guidelines to Support the Progressive Realization of the Right to Adequate Food in the Context of National Food Security (Rome: 2005).

9 ATNF (Access to Nutrition Foundation), Access to Nutrition Index, accessed December 29, 2017, www.accesstonutrition.org/.

10 RSPO (Roundtable on Sustainable Palm Oil), RSPO Principles and Criteria for Sustainable Palm Oil Production-Including Indicators and Guidance, October 2007; The Grow Africa Partnership (www.growafrica.com) is working to increase private sector investment in agriculture.

11 A. M. Slaughter, A New World Order (Princeton, NJ: Princeton University Press, 2004).

12 UNECA (United Nations Economic Commission for Africa), Illicit Financial Flows: Report of the High Level Panel on Illicit Financial Flows from Africa (Addis Ababa: 2015).

13 R. Vos, Thought for Food: Strengthening Global Governance of Food Security, CDP Background Paper No. 29, November 2015, Committee for Development Policy.

14 Y. Balarajan and M. R. Reich, "Political Economy Challenges in Nutrition," Globalization and Health 12: 70 (2016); P. PinstrupAndersen, The Political Economy of Food and Nutrition Policies (Baltimore: Johns Hopkins University Press for the International Food Policy Research Institute, 1993).

15 B. Swinburn et al., "Strengthening of Accountability Systems to Create Healthy Food Environments and Reduce Global Obesity," Lancet 385, no. 9986 (2015): 2534-2545.

$16 \mathrm{~J}$. von Braun and M. Kalkuhl, International Science and Policy Interaction for Improved Food and Nutrition Security: Toward an International Panel on Food and Nutrition (IPFN), ZEF Working Paper 142 (Bonn: Center for Development Research [ZEF], University of Bonn, 2015).

17 L. Edwards, "Food Fight: The International Assessment of Agricultural Knowledge, Science, and Technology for Development," AgBioForum 15 (2012): 70-76. 


\section{REGIONAL DEVELOPMENTS}

\section{AFRICA}

1 IMF (International Monetary Fund), Regional Economic OutlookSub-Saharan Africa: Fiscal Adjustment and Economic Diversification (Washington, DC: 2017).

2 K. von Grebmer et al., 2017 Global Hunger Index: Inequalities of Hunger (Bonn, Washington, DC, and Dublin: Welthungerhilfe, IFPRI, and Concern Worldwide, 2017).

3 UNCTAD (United Nations Conference on Trade and Development), World Investment Report 2017 (Geneva: United Nations, 2017).

4 lbid.

5 WTO (World Trade Organization), World Trade Statistical Review 2017 (Geneva: 2017).

6 Germany, BMZ (Federal Ministry for Economic Cooperation and Development), Africa and Europe-A New Partnership for Development, Peace and a Better Future: Cornerstones of a Marshall Plan with Africa (Bonn: 2017).

7 African Union Commission, The Inaugural Biennial Review Report of the African Union Commission on the Implementation of the Malabo Declaration on Accelerated Agricultural Growth and Transformation for Shared Prosperity and Improved Livelihoods: The 2017 Progress Report to the Assembly, Highlights on IntraAfrican Trade for Agriculture Commodities and Services: Risks and Opportunities (Addis Ababa: 2018).

8 FEWS NET (Famine Early Warning Systems Network), "East Africa Special Report: Illustrating the Extent and Severity of the 2016/17 Horn of Africa Drought," July 13, 2017.

9 FEWS NET, "Key Message Update: Extreme Food Insecurity to Persist in East Africa, Yemen through at Least Mid-2018," December 2017.

10 FEWS NET, "Food Security Outlook: A Fifth Consecutive BelowAverage Season Likely; Famine (IPC Phase 5) Risk Continues," November 2017

11 WFP (World Food Programme), "Famine Hits Parts of South Sudan," February 20, 2017.

12 IPC (Integrated Food Security Phase Classification), "The Republic of South Sudan: May 2017-Communication Summary," May 2017.

13 FEWS NET, "Key Message Update: Crisis (IPC Phase 3) and Emergency (IPC Phase 4) Persist as the Lean Season Starts Early," January 2018.

14 FEWS NET, "Key Message Update: Persisting Conflict in the Northeast Continues to Drive Severe Food Insecurity," November 2017.

15 FEWS NET, "Food Security Outlook: Les Conflits Continuent à Perturber les Moyens d'Existence des Ménages dans les Zones Affectées," October 2017.

16 IMF, Regional Economic Outlook-Sub-Saharan Africa.

17 See FAO (Food and Agriculture Organization of the United Nations), "Sahelian and West African Governments Avoid Surprises Thanks to Seasonal Monitoring," accessed December 13, 2017, www.fao.org/in-action/sahelian-and-west-african-governmentsavoid-surprises-thanks-to-seasonal-monitoring/en/.

18 A. De Pinto and J. M. Ulimwengu, eds., A Thriving Agricultural Sector in a Changing Climate: Meeting Malabo Declaration Goals through ClimateSmart Agriculture-ReSAKSS Annual Trends and Outlook Report 2016 (Washington, DC: International Food Policy Research Institute, 2017).

\section{MIDDLE EAST AND NORTH AFRICA}

1 C. Breisinger et al., Beyond the Arab Awakening: Policies and Investments for Poverty Reduction and Food Security, IFPRI Food Policy Report (Washington, DC: International Food Policy Research Institute, 2012); World Bank, Global Economic Prospects: Weak Investment in Uncertain Times (Washington, DC: 2017).

2 C. Breisinger et al., How to Build Resilience to Conflict? The Role of Food Security, IFPRI Food Policy Report 28 (Washington, DC: International Food Policy Research Institute, 2014).

3 UNHCR (United Nations High Commissioner for Refugees, Operational Data Portal: Refugee Situations, accessed October 14, 2017, http://data2.unhcr.org/en/situations\#_ ga=2.101302209.1339062458.1507068181-938018684.1507068181.

4 FAO (Food and Agriculture Organization of the United Nations) and WFP (World Food Programme), "FAO/WFP Crop and Food Security Assessment Mission to the Syrian Arab Republic," July 18, 2017, www.wfp.org/content/syria-fao-wfp-crop-and-food-securityassessment-mission-july-2017.

5 WFP, UNICEF, and FAO, "Yemen Emergency Food Security and Nutrition Assessment (EFSNA) 2016-Preliminary Results," January 26, 2017, https://reliefweb.int/report/yemen/yemenemergency-food-security-and-nutrition-assessment-efsna-2016preliminary-results.

6 FAO and WFP, "Monitoring Food Security in Countries with Conflict Situations," June 2017.

7 World Bank, Global Economic Prospects.

8 FAO, Global Information and Early Warning System (GIEWS) Country Briefs: Tunisia, Syria, Libya, Egypt, and Oman, June 2017.

9 J.-F. Maystadt and C. Breisinger, The EU Refugee Crisis: The Tip of a Global lceberg, IFPRI Policy Brief 23 (Washington, DC: International Food Policy Research Institute, 2015).

10 FAO, GIEWS Country Briefs: Jordan, June 2017.

11 FAO, GIEWS Country Briefs: Yemen, April 2017.

12 World Bank, "Middle East and North Africa Economic Outlook," April 2017, www.worldbank.org/en/region/mena/overview.

13 EIU (Economist Intelligence Unit), EIU Country Reports for Kuwait, Algeria, Bahrain, Saudi Arabia, and Oman, August 2017, http://country.eiu.com/AllCountries.aspx.

14 IMF (International Monetary Fund), "Middle East and Central Asia: Regional Outlook Reflecting Global Developments: Oil Importers: A Fragile Recovery," April 2017.

15 EIU, EIU Country Reports for Egypt, Lebanon, Tunisia, Morocco, Mauritania, and Jordan, August 2017, http://country.eiu.com/ AllCountries.aspx.

16 FAO, GIEWS Country Briefs: Algeria, Djibouti, and Jordan, June 2017.

17 S. Fiaz, M. A. Noor, and F. O. Aldosri, "Achieving Food Security in the Kingdom of Saudi Arabia through Innovation: Potential Role of Agricultural Extension," Journal of the Saudi Society of Agricultural Sciences (September 23, 2016).

18 AMIS (Agricultural Market Information Systems), AMIS: Market Monitor, accessed December 15, 2017, www.amis-outlook.org/.

19 A. Anjarwalla, "Gulf Investments in Africa Beginning to Spread Far and Wide," The National, October 2, 2016.

20 UNESCWA (United Nations Economic and Social Commission for Western Asia), Assessing Arab Economic Integration: Towards the Arab Customs Union (Beirut: 2015). 
21 UNESCWA, An Economic Outlook for the Arab Region by 2025, June 13, 2017.

22 M. Noland, H. Pack, and M. El-Erian, The Arab Economies in a Changing World (Washington, DC: Peterson Institute for International Economics, 2007).

\section{CENTRAL ASIA}

1 In 2017, nominal price indexes for energy and metals increased by 23.7 percent and 22.4 percent, respectively. World Bank, Commodity Markets Outlook, October 2017, Washington, DC; World Bank, "From Recession to Recovery," Russia Economic Report 37, May 2017; IMF (International Monetary Fund), "Regional Economic Outlook Update, Middle East and Central Asia," April 2017.

2 According to data from the Central Bank of Russia, the real effective exchange rate of the Russian ruble appreciated by 20.5 percent during first nine months of 2017 compared to the same period of 2016. Russian Federation, Central Bank, External Sector Statistics, accessed October 27, 2017, www.cbr.ru/statistics/?Prtld=svs.

3 World Bank, "Macro Poverty Outlook: Europe and Central Asia," October 2017.

4 European Bank for Reconstruction and Development, Life in Transition: A Decade of Measuring Transition (London: 2016); K. Akramov and A. Park, "Assessing Food Consumption Patterns and Nutrition Outcomes in Kyrgyzstan," paper presented at the Second Annual Eurasian Food Security Conference, Dushanbe, Tajikistan, October 2-4, 2017

5 Uzbekistan, Presidential Decree No. 4947 (February 7, 2017).

6 Uzbekistan, Presidential Decree No. 5177 (September 2, 2017).

7 Uzbekistan, Presidential Decrees No. 5057 (May 25, 2017)and No. 3077 (June 21, 2017); Uzbekistan, Resolutions of the Cabinet of Ministers No. 384 (June 16, 2017), No. 477 (July 7, 2017), and No. 609 (August 10, 2017); Uzbekistan, Central Bank Resolution No. 21/3 (August 26, 2017), and No. 7/4 (April 8, 2017).

8 Uzbekistan, Presidential Decree No. 3281 (September 15, 2017).

9 Uzbekistan, Presidential Decrees No. 3213 (August 15, 2017), No. 3254, and No. 3269 (September 12, 2017).

10 Uzbekistan, Presidential Decree No. 5067 (June 1, 2017).

11 Kazakhstan, Strategy 2050, President's Address to the Nation, January 31, 2017, https://strategy2050.kz/en/page/ message_text20171/.

12 Kazakhstan, Prime Minister, "Bakytzhan Sagintayev: The Strategic Plan Reflects the Main Directions of Development until 2025," June 15, 2017, https://primeminister.kz/en/news/all/bakitzhansagintaev-v-strategicheskom-plane-otrazheni-osnovnienapravleniya-razvitiya-do-2025-goda.

13 World Bank, Doing Business: Economy Rankings, 2016, www.doingbusiness.org/rankings; K. Akramov, A. Park, and J. llyasov, "Central Asia," 2017 Global Food Policy Report (Washington, DC: International Food Policy Research Institute, 2017).

14 Kazakhstan, President, "Negotiations with Shavkat Mirziyoyev, President of the Republic of Uzbekistan," September 16, 2017, www.akorda.kz/en/events/international_community/foreign_visits/ negotiations-with-shavkat-mirziyoyev-president-of-the-republicof-uzbekistan; IMF, "Statement by IMF Managing Director Christine
Lagarde on Uzbekistan," September 19, 2017; World Bank, "World Bank Group President Jim Yong Kim Discusses Reforms with President of Uzbekistan Shavkat Mirziyoyev," September 20, 2017; UNDP (United Nations Development Programme), "Helena Fraser: Statement on the Concept of Administrative Reform in the Republic of Uzbekistan," September 14, 2017.

15 H.-S. Huh and C.-Y. Park, Asia-Pacific Regional Integration Index: Construction, Interpretation, and Comparison, ADB Economics Working Paper 511 (Manila: Asian Development Bank, 2017).

16 World Bank, "Macro Poverty Outlook: Europe and Central Asia." 17 Ibid.

\section{SOUTH ASIA}

1 World Bank, Globalization Backlash: South Asia Economic Focus Spring 2017 (Washington, DC: 2017).

2 World Bank, World Development Indicators, accessed November 15, 2017, https://data.worldbank.org/.

3 United Nations Environment Programme (UNEP), Global Environment Outlook 2003 (Nairobi: 2003).

4 UNICEF, "Nepal Humanitarian Situation Report" no. 6, August 26, 2017.

5 UNICEF, "Bangladesh Humanitarian Situation Report Monsoon Floods," September 1, 2017.

6 FAO (Food and Agriculture Organization of the United Nations) and WFP (World Food Programme), "Special Report, FAO/WFP Crop and Food Security Assessment Mission to Sri Lanka" (FAO/WFP: Rome, 2017); "Fall in Food Production Likely as Floods, Drought Hit 18 States This Monsoon," Hindustan Times, September 4, 2017; Ministry of Finance, "Monthly Economic Report" (August 2017), Department of Economic Affairs, Economic Division.

7 FAO, Global Information and Early Warning System on Food and Agriculture (GIEWS) Country Brief, Pakistan (Rome: 2017).

8 Asian Development Bank, "Asian Development Outlook 2017, Inflation Rate in Asia and the Pacific," accessed November 23, 2017, https://data.adb.org/dataset/ inflation-rate-asia-and-pacific-asian-development-outlook.

9 World Bank, "South Asia Regional Integration," accessed November 23, 2017, www.worldbank.org/en/programs/ south-asia-regional-integration.

10 UNCTAD (United Nations Conference on Trade and Development), World Investment Report, 2017 (Geneva: United Nations, 2017).

11 World Bank, World Development Indicators, accessed November 15, 2017.

12 Bangladesh Bureau of Statistics, "Preliminary Report on Household Income and Expenditure Survey 2016," Statistics and Information Division, Ministry of Planning, (Government of Bangladesh, Dhaka, 2017).

13 Food Planning and Monitoring Unit (FPMU), National Food Policy Plan of Action and Country Investment Plan: Monitoring Report 2016, Ministry of Food (Dhaka: Government of Bangladesh, 2016).

14 A. U. Ahmed et al., Agriculture, Nutrition, and Gender Linkages (ANGeL) Baseline Study (Dhaka: International Food Policy Research Institute-Bangladesh, 2017).

15 National Institution for Transforming India (NITI Aayog), Nourishing India, National Nutrition Strategy, Government of India, accessed 
November 15, 2017, http://niti.gov.in/writereaddata/files/ document_publication/Nutrition_Strategy_Booklet.pdf.

16 Ministry of Health, Nepal, Nepal Demographic and Health Survey 2016, New Era and ICF International (Kathmandu: 2016).

17 European Commission, "Country Profile on Nutrition, Afghanistan, 2017," https://ec.europa.eu/europeaid/sites/devco/files/2017 country_profile_on_nutrition_-_afghanistan.pdf.

18 WFP, National Strategic Review of Food Security and Nutrition, Towards Zero Hunger (Colombo: 2017).

19 Press Information Bureau, "Special Service and Features" (Government of India, June 7, 2016), http://pib.nic.in/newsite/ mbErel.aspx? relid=146019.

20 FPMU, National Food Policy Plan of Action.

21 Ministry of Finance, Budget Speech of Fiscal Year 2017/18, (Government of Nepal, 2017).

22 FPMU, National Food Policy Plan of Action and Country Investment Plan.

23 Government of India, Union Budget 2017-1, http://indiabudget.nic. in/bspeecha.asp.

24 N. P. Singh and J. P. Bisen, "Goods and Services Tax: What It Holds for Agricultural Sector?" ICAR-NIAP Policy Brief no. 42, (New Delhi: National Institute of Agricultural Economics and Policy Research, 2017).

\section{EAST AND SOUTHEAST ASIA}

1 P. Lopez Murphy, Regional Economic Outlook: Asia and Pacific (Washington, DC: International Monetary Fund, 2017).

2 K. von Grebmer et al., 2017 Global Hunger Index: The Inequalities of Hunger (Bonn, Washington, DC, and Dublin: Welthungerhilfe, IFPRI, and Concern Worldwide, 2017); M. Senthilingam, "Ten Times More Children and Teens Obese Today than 40 Years Ago," CNN, October 10, 2017.

3 "Malaysian Plantation Minister Expects More Palm Oil Export to China," China Daily, May 18, 2017; M. Verdin, "Morning Markets: Chinese Import Surge Lifts Palm Oil Prices. Stocks Slump Boosts Rubber," Agrimoney, November 24, 2017; X.Wang, "Agricultural Imports in 2017 Rise Rapidly," China Daily, July 18, 2017; V. Chea, "Cambodia's Milled Rice Exports Increase," Khmer Times, July 12, 2017; S. Cheng, "Millers Push for China Access," Phnom Penh Post, April 5, 2017; "Malaysia, Indonesia in Talks with China to Expand Palm Oil Use in Biodiesel," Free Malaysia Today, August 23, 2017; "Malaysian Plantation Minister Expects More Palm Oil Export to China,"China Daily, May 17, 2017; "Vietnam to Reform Rice Production, Improve Exports," VietnamNet, August 29, 2017; "Thailand's Economy and Market Profile," Thailand Business News, September 11, 2017; "Myanmar-China Border Trade Rises in FY 2016-17," Xinhua News Agency, April 20, 2017.

4 "China Becomes the Largest Export Market of Vietnam's Fruits [in Chinese]," China Fruit Portal, January 23, 2017, www.chinafruitportal.com; "Global Durian Prices Rise as Demand Surges in China," Produce Report, June 19, 2017, producereport. com; M. R. Bondoc, "Export of Philippine Fruits to China Increased by 50\%," GMA News Online, July 26, 2017.

5 UkrAgroConsult, "Vietnam's Corn Imports Rising," August 30, 2017; Ho Binh Minh, "Vietnam's Soybean Imports to Rebound in 2017USDA," VN Express International, April 17, 2017.
6 "Indonesia Targets to Stop Corn Import This Year," Jakarta Post, May 8, 2017; "Agricultural Commodities: Indonesia Highly Dependent on Soybean Imports," Indonesia Investments, December 9, 2015.

7 "Thailand Food Production Superpower," LovePattayaThailand, June 8, 2017.

8 "China Focus: China to Deepen Reform in Agricultural Sector," Xinhua News Agency, Feburary 6, 2017; J. Xi, "Secure a Decisive Victory in Building a Moderately Prosperous Society in All Respects and Strive for the Great Success of Socialism with Chinese Characteristics for a New Era," speech at the 19th National Congress of the Communist Party of China, October 18, 2017.

9 "A Push for Building New Countryside," Vietnam Law \& Legal Forum, August 22, 2014; "VN Aims for 3\% Agriculture Growth," Viet Nam News, November 23, 2017; "Vietnam Eyes 25\% of Communes with New Countryside Title," Vietnam Breaking News, April 4, 2016.

10 "Land Bank Needed for Agricultural Development," VietnamNet, August 16, 2017.

11 L. Hornby, "China Land Reform Opens Door to Corporate Farming," Financial Times, November 3, 2016; "Land Bank Needed for Agricultural Development," VietnamNet; "PM Unveils New Plan with Focus on 'Smart Farmers,'" Nation, November 17, 2016.

12 J. Russell, "Alibaba Ups Its Stake in Southeast Asia's Lazada with $\$ 1$ Billion Investment," Tech Crunch, July 28, 2017; L. Lee, "Alibaba to Set Up Regional Logistics Hub in Malaysia," Reuters, March 22, 2017; J. Zhu and J. Pomfret, "Chinese E-commerce Giant JD.com Plans Expansion into Southeast Asia," VN Express International, June 12, 2017.

13 S. Hodge, "Is This the Future? JD.com Launches Unmanned Sorting Centre and Develops Drone Delivery Program," Supply Chain Digital, August 4, 2017.

14 China, State Council, "Role of 'Internet Plus' in Modern Agriculture Emphasized," September 13, 2016, http://english.gov.cn/state_ council/ministries/2016/09/13/content_281475441194339.htm; "Digital Free Trade Zone Goes Live on Nov 3," New Straits Times, November 2, 2017; N. Freischlad, "Indonesia Wants Farmers and Fishermen to Join the Ecommerce Revolution," Tech in Asia, April 28, 2016; T. Brennan, "China Signals Support for Cross-Border E-commerce," Alizila, April 11, 2017.

15 USDA-FAS (US Department of Agriculture-Foreign Agricultural Service), "Thailand: Rice Production Rebounds Following El Nino," Commodity Intelligence Report, February 15, 2017.

16 K. J. S. Villagracia and S. P. Sarie, "ASEAN Strengthens Climate Resiliency of the Agriculture Sector," ASEAN Climate Resilience Network, August 10, 2016; J. Dallinger, "ASEAN Member States Confirm Their Commitment to Take a Common Stance on Agriculture and Climate Change," ASEAN Climate Resilience Network, March 9, 2017; K. J. Villagracia, "ASEAN Collaborates on Climate Information Services for Agriculture," ASEAN Climate Resilience Network, April 5, 2017.

17 "BAAC Push for 1m Smart Farmers," Bangkok Post, July 17, 2017; The Nation, "PM Unveils New Plan with Focus on 'Smart Farmers'"; C. Chin, "Why is Smart Farming Asia's Big New Trend?", GovInsider, August 31, 2016; K. Dursin, "Indonesian Farmers Weather Climate Change with Conservation Agriculture," Inter Press Service News Agency, March 31, 2017; W. J. Barbon, R. Vidallo, and J. Gonsalves, "The Promotion of Climate-Smart Villages to Support 
Community-Based Adaptation Programming in Myanmar: Results of a Rapid Scoping Study," Working Paper No. 213, ReliefWeb.

18 F. Arkin, "Lao to Protect Crop Biodiversity with Gene Banks," SciDev.Net, June 6, 2017; "Asian Countries Sign Agreement on Seed-Sharing," Far Eastern Agriculture, July 13, 2017.

19 "ASEAN Leaders Adopt Master Plan on Connectivity 2025," ASEAN (Association of Southeast Asian Nations) Secretariat News, September 6, 2016; C. Ortega, "The Asean Economic Community: A Work in Progress," Manila Times, July 29, 2017.

20 Y. Le and L. Bui, "News Analysis: RCEP Opens up Myriad Opportunities for Many Economies," Xinhua News Agency, July 20, 2017; "RCEP Likely to Be Signed in November 2018: PM," Sun Daily, November 15, 2017; B. Yeung, "One Belt One Road: A Golden Opportunity for ASEAN," Think Business, May 17, 2017.

21 S. Ribka, "Indonesia's Rice Self-Sufficiency to Be Achieved by 2020," Jakarta Post, March 31, 2017; L. M. Simeon, "Rice Self-Sufficiency Goal Set Back to 2020," PhilStar Global, March 16, 2017; "Malaysia Targets to Achieve 100\% Self-Sufficiency Level in Paddy Production by 2020: Datuk Seri Ismail Sabri Yaakob," Rice Outlook, May 16, 2015; "China Vows Self-Sufficiency in Rice, Aims to Cut Corn Glut," Bloomberg, March 7, 2017.

22 D. Placido, "Philippines Extends Rice Import Quota for 3 Years," ABS-CBN News, May 22, 2017; J. Y. Arcalas, "Government Wants High Tariff to Replace Rice QR," Business Mirror, September 19, 2017; J. M. N. dela Cruz and J. E. Y. Arcalas, "Bill Setting High Rice Tariffs Vice QR Advances in House," Business Mirror, October 12, 2017.

23 ADB (Asian Development Bank), "Ministers Agree to Step Up Cooperation on Boosting Food Safety in Mekong," September 8, 2017.

\section{LATIN AMERICA AND THE CARIBBEAN}

1 J. von Braun and E. Díaz-Bonilla, eds., Globalization of Food and Agriculture and the Poor (Washington, DC: International Food Policy Research Institute, 2008).

2 R. Ray and K. Gallagher, China-Latin America Economic Bulletin, Boston University Discussion Paper 2017-1, Global Economic Governance Initiative (2017).

3 von Braun and Díaz-Bonilla, eds., Globalization of Food and Agriculture and the Poor; E. Díaz-Bonilla, "Macroeconomic Policies and Food Security," Working Paper (Washington, DC: International Food Policy Research Institute, 2015).
4 E. Díaz-Bonilla and M. Torero, "Regional Developments: Latin America and the Caribbean," in 2016 Global Food Policy Report (Washington, DC: International Food Policy Research Institute, 2016).

5 IFPRI (International Food Policy Research Institute), Global Nutrition Report 2015: Actions and Accountability to Advance Nutrition and Sustainable Development (Washington, DC: 2015). This has led some governments in the region to adopt stricter labeling regulations (Chile and Ecuador) and to impose taxes on unhealthy food (Mexico). See Díaz-Bonilla and Torero, "Regional Developments: Latin America and the Caribbean." Preliminary evaluations find a positive impact in reduction of sugar consumption. See, for example, M. A. Colchero et al., "Beverage Purchases from Stores in Mexico under the Excise Tax on Sugar Sweetened Beverages: Observational Study," BMJ 352, h6704 (2016): 1-9.

6 IMF (International Monetary Fund), World Economic Outlook Database, accessed December 28, 2017, www.imf.org/external/ pubs/ft/weo/2017/02/weodata/index.aspx.

7 FAO (Food and Agriculture Organization of the United Nations), IFAD (International Fund for Agricultural Development), UNICEF, WFP (World Food Programme), and WHO (World Health Organization), The State of Food Security and Nutrition in the World 2017: Building Resilience for Peace and Food Security (Rome: FAO, 2017).

8 E. Díaz-Bonilla, V. Piñeiro, and P. Elverdin, "External Shocks, Food Security, and Development: Exploring Scenarios for Central America," IFPRI Discussion Paper 1592 (Washington, DC: IFPRI, 2016)

9 The average investment in agricultural research and development for LAC countries during the 2010 s is about 0.9 percent of agricultural GDP, while developed countries spend around 4.0 percent of their agricultural GDP.

\section{FOOD POLICY INDICATORS: TRACKING CHANGE}

\section{AGRICULTURAL TOTAL FACTOR PRODUCTIVITY (TFP)}

1 The data and the methodology used to build the database are available at: https://www.ers.usda.gov/data-products/ international-agricultural-productivity/. 




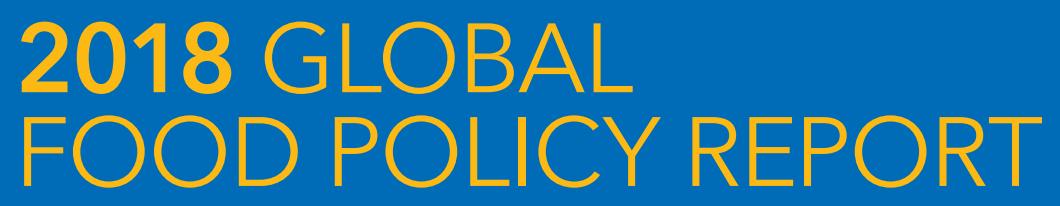

IFPRI's flagship report reviews the major food policy issues, developments, and decisions of 2017, and highlights challenges and opportunities for 2018 at the global and regional levels. This year's report looks at the impacts of greater global integration-including the movement of goods, investment, people, and knowledge-and the threat of current antiglobalization pressures. Drawing on recent research, IFPRI researchers and other distinguished food policy experts consider a range of timely topics:

- How can the global food system deliver food security for all in the face of the radical changes taking place today?

- What is the role of trade in improving food security, nutrition, and sustainability?

- How can international investment best contribute to local food security and better food systems in developing countries?

- Do voluntary and involuntary migration increase or decrease food security in source countries and host countries?

- What opportunities does greater data availability open up for improving agriculture and food security?

- How does reform of developed-country farm support policies affect global food security?

- How can global governance structures better address problems of food security and nutrition?

- What major trends and events affected food security and nutrition across the globe in 2017 ?

The 2018 Global Food Policy Report also presents data tables and visualizations for several key food policy indicators, including countrylevel data on hunger, agricultural spending and research investment, and projections for future agricultural production and consumption. In addition to illustrative figures, tables, and a timeline of food policy events in 2017, the report includes the results of a global opinion poll on globalization and the current state of food policy.

For more information about the 2018 Global Food Policy Report:

\section{gfpr.ifpri.info}

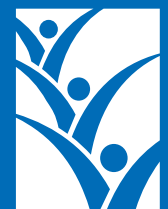

INTERNATIONAL FOOD POLICY RESEARCH INSTITUTE A world free of hunger and malnutrition

1201 Eye Street, NW | Washington, DC 20005 USA

T. +1-202-862-5600 | F. +1-202-862-5606 | ifpri@cgiar.org

IFPR www.ifpri.org

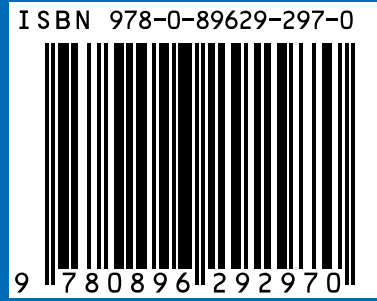

